\title{
Projeto estrutural DE PAVIMENTOS RODOVIÁRIOS E DE PISOS INDUSTRIAIS DE CONCRETO
}

\author{
PATRÍCIA LIZI DE OLIVEIRA
}

\begin{abstract}
Dissertação apresentada à Escola de Engenharia de São Carlos, da Universidade de São Paulo, como parte dos requisitos para obtenção do Título de Mestre em Engenharia de Estruturas
\end{abstract}

Orientador: Prof. Dr. Libânio Miranda Pinheiro

São Carlos 
Ao meu pai, Otávio 


\section{AGRADECIMENTOS}

Ao orientador, professor Libânio Miranda Pinheiro, pelo cuidado e atenção com que me apontou caminhos e me ajudou a encontrar soluções.

À CAPES, pela bolsa de estudos.

Aos professores Glauco Tulio Pessa Fabbri e Manoel Henrique Alba Soria, do Departamento de Transportes da EESC-USP, que forneceram bibliografia e ajudaram no desenvolvimento do trabalho.

Ao professor José Tadeu Balbo, do Laboratório de Transportes da Escola Politécnica da USP, pela atenção e pela gentileza de ter enviado sua Tese de Livre Docência.

Aos professores da Escola de Engenharia de São Carlos, especialmente aos do Departamento de Estruturas, responsáveis pela minha formação profissional.

Às bibliotecárias Nadir e Eliana, pela colaboração na pesquisa bibliográfica e pela revisão das referências bibliográficas indicadas neste trabalho.

Aos funcionários do Departamento de Engenharia de Estruturas que, cada um em sua função, tornaram possível a conclusão do mestrado.

Aos profissionais da $\mathrm{ABCP}$, que contribuíram na pesquisa bibliográfica e viabilizaram a participação em cursos e seminários. 
À Eng. Manuela Marqueño, da Prefeitura Municipal de Curitiba, pelas informações.

Ao Eng. Wagner Gasparetto, pela atenção e pelo fornecimento de bibliografia.

Ao amigo Yuri, que com carinho e paciência, ouviu, apoiou, opinou e fez companhia durante todo o tempo, nesses dois últimos anos.

Aos amigos de turma: Alio, Ana Cláudia, Edna, Eduardo, George, Gerson, Marcelo, Palmira, Patrícia, Rejane, Roberto, Rodrigo, Valentim, e agregados, pelos momentos que passamos juntos.

Aos amigos que fiz em São Carlos, pelo convívio.

A todos aqueles que, embora não citados nominalmente, contribuíram direta ou indiretamente para a execução deste trabalho.

À minha sobrinha Dayane, que apesar da pouca idade, me mostrou a importância de aprender, descobrir e vencer desafios.

Finalmente, aos meus pais que me incentivaram a prosseguir nos estudos, mesmo sabendo que isso me levaria a morar longe deles. Em especial à minha mãe, que com sua energia e vibração torna cada vitória mais importante. 


\section{SUMÁRIO}

Sumário i

Lista de figuras_ vi

Lista de tabelas xiv

Lista de siglas $\mathrm{xvi}$

Lista de símbolos xvii

Resumo xxiv

Abstract Xxv

Introdução 1

1.1 Objetivos ____________ 2

1.2 Etapas do trabalho ___ 3

Pavimentos rígidos ___ 5

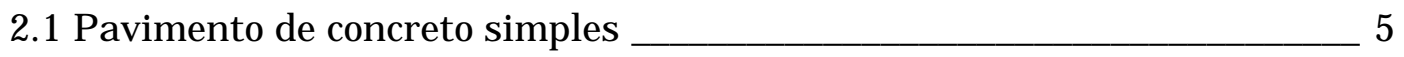

2.2 Pavimento de concreto com armadura distribuída descontínua ___ 9

2.3 Pavimento de concreto continuamente armado____ 11

2.4 Pavimento de concreto estruturalmente armado ___ 12

2.5 Pavimento de concreto rolado ___ 14

2.6 Pavimento de concreto com fibras____ 15

2.7 Pavimento de concreto protendido ___ 17

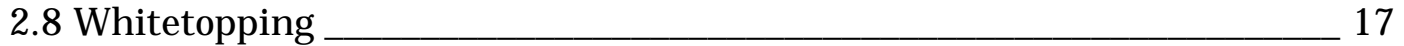

2.9 Considerações gerais ___ 19

Ações ___ 20

3.1 Ações diretas ___ 20

3.1.1 Ações móveis ___ 21

3.1.2 Carregamento distribuído ___ 29 
3.1.3 Forças concentradas ____ 29

3.2 Ações indiretas ___ 30

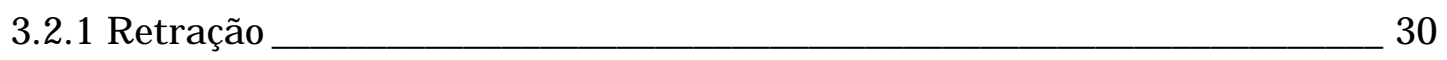

3.2.2 Dilatação térmica_____________________________ 32

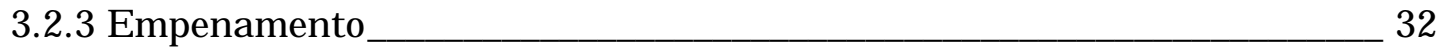

3.3 Considerações gerais _______ 34

Modelos e teorias ___ 35

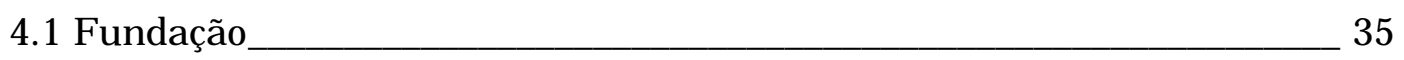

4.1.1 Modelo líquido denso_____________ 37

4.1.2 Modelo sólido elástico ___ 37

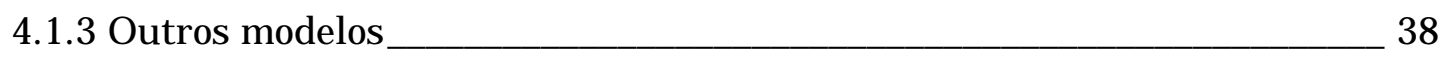

4.1.4 Determinação do Coeficiente de Recalque ______ 39

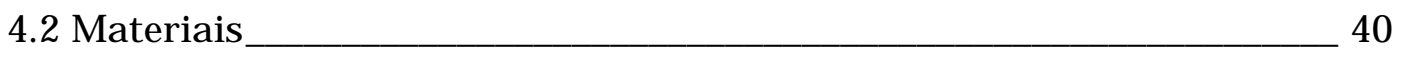

4.2.1 Concreto ____ 40

4.2.2 Aço___ 43

4.3 Teoria de Westergaard ___ 44

4.4 Teoria de Bradbury para determinação de tensões de empenamento __ 50

4.5 Análise numérica ___ 52

4.6 Considerações gerais ___ 57

Fadiga em pavimentos de concreto ___________ 58

5.1 Tipos de ações cíclicas ______________ 58

5.2 Comportamento do concreto à fadiga____ 59

5.3 Comportamento à fadiga do aço para concreto armado___ 62

5.4 Regra de palmgren-miner ___ 63

5.5 Modelos de fadiga aplicados a pavimentos de concreto ___ 66

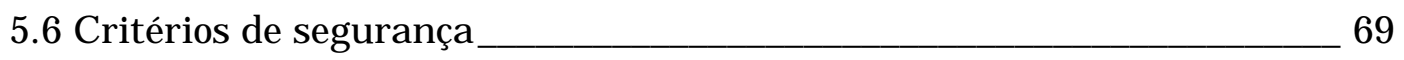

5.7 Considerações gerais ___ 70

Métodos de dimensionamento da espessura ___ 71

6.1 Método da aashto ___ 72

6.1.1 Número de eixos equivalentes _________ 72

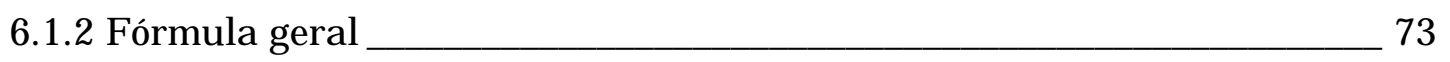

6.1.3 Determinação do coeficiente de recalque da fundação ___ 75

6.2 Método da pca / 66 
6.2.1 Critério de fadiga ___ 78

6.2.2 Determinação das tensões ___ 79

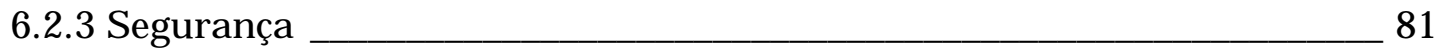

6.2.4 Procedimento de cálculo___ 81

6.3 Método da pca / 84

6.3.1 Critério de fadiga____ 83

6.3.2 Critério de erosão e escalonamento ___ 84

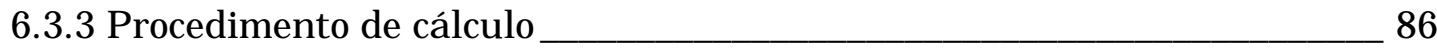

6.4 Método de packard (1976)____ 87

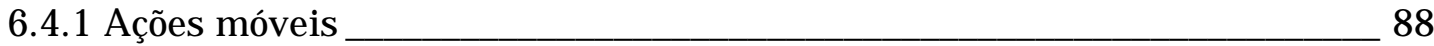

6.4.2 Carregamento de montantes____________ 91

6.4.3 Carregamento distribuído ___

6.5 Considerações gerais ___ 96

Dimensionamento da armadura_________________ 98

7.1 Armadura de retração ___ 98

7.2 Armadura positiva ___ 102

7.2.1 Determinação da área de aço, para o estado limite último de esgotamento da capacidade resistente da estrutura ___ 102

7.2.2 Estado limite último de fadiga do aço ___ 103

7.3 Detalhamento da armadura_____ 104

7.3.1 Cobrimento ___ 104

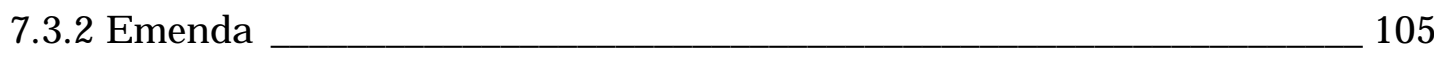

7.4 Considerações gerais ___ 107

Juntas___ 108

8.1 Mecanismo de aparecimento de fissuras ___ 108

8.2 Juntas transversais ___ 109

8.3 Juntas longitudinais ___ 111

8.4 Barras de transferência____ 111

8.5 Barras de ligação____ 117

8.6 Juntas de encontro ___________ 118

8.7 Eficiência de uma junta____________ 119

8.8 Considerações gerais _________________ 122

Exemplos ___ 123 
9.1 Pavimento rodoviário de concreto simples 123

9.1.1 Dados do problema 124

9.1.2 Método da AASHTO 125

9.1.3. Método da PCA/66 133

9.1.4. Método da PCA/84 136

9.1.5 Considerações sobre os resultados 140

9.2 Piso industrial de concreto simples 141

9.2.1 Dados do problema 142

9.2.2 Dimensionamento pelo método de PACKARD 143

9.2.3 Verificação da punção, segundo Revisão da NB-1 (1999) 147

9.2.4 Verificação da punção, segundo ACI 147

9.3 Piso industrial de concreto com armadura distribuída descontínua 148

9.3.1 Segundo PACKARD (1973) 148

9.3.2 Segundo RODRIGUES e CASSARO (1998) 149

9.3.3 Segundo Revisão da NB-1 (1999) 149

9.3.4 Segundo Corps of Engineers 150

9.3.5 Considerações sobre os resultados 150

9.4 Piso industrial de concreto estruturalmente armado 151 9.4.1 Determinação da altura útil 151

9.4.2 Dimensionamento da armadura de flexão para estado limite último de esgotamento da capacidade resistente 151

9.4.3 Verificação da armadura de flexão para estado limite último de fadiga do aço 152

9.4.4 Verificação da punção, segundo Revisão da NB-1 153

9.4.5 Determinação do comprimento de transpasse 154

9.4.6 Determinação da armadura de retração 155

9.4.7 Detalhamento 156

9.5 Dimensionamento das barras de ligação 158

9.6 Dimensionamento das barras de transferência 159 Considerações finais 161

10.1 Conclusões 161

10.1.1 Capacidade de suporte da fundação 161

10.1.2 Área de contato entre pneu e pavimento 162 
10.1.3 Empenamento 162

10.1.4 Influência entre as rodas dos eixos 163

10.1.5 Distribuição de esforços em placas isoladas 163

10.1.6 Eficiência das juntas 164

10.1.7 Fadiga em pavimentos de concreto 164

10.1.8 Métodos de dimensionamento 165

10.1.9 Análise numérica 166

10.1.10 Punção em pavimentos de concreto 166

10.2 Sugestões para novas pesquisas 166

10.2.1 Efeitos climáticos 167

10.2.2 Pavimento de concreto estruturalmente armado 167

10.2.3 Juntas 167

Tabelas e ábacos 168

Análises numéricas 196

B.1 Análise de placas isoladas sob carregamento de eixos rodoviários com carga máxima permitida pelo dner 196

B.1.1 Eixo simples de rodagem simples 196

B.1.2 Eixo tandem duplo 198

B.1.3 Eixo tandem triplo 199

B.2 Análise da variação dos esforços máximos de acordo com a posição do carregamento em placas isoladas 201

B.3 Análise da influência entre as rodas de eixos rodoviários 203

B.3.1 Eixo simples de rodagem simples 203

B.3.2 Eixo simples de rodagem dupla 204

B.3.3 Eixo tandem duplo 206

B.3.4 Eixo tandem triplo 207

B.4 Análise da influência entre as rodas de eixo de empilhadeira 209

Referências bibliográficas 212 Bibliografia complementar 216 


\section{LISTA DE FIGURAS}

Figura 2.1 - Perfil de um pavimento de concreto simples, sem barra de transferência 6

Figura 2.2 - Trecho da Rodovia dos Imigrantes, fonte: http://www.abcp.com.br $(08 / 11 / 1999)$ 9

Figura 2.3 - Trecho da Via Dutra, fonte: ABCP (1999) 9

Figura 2.4 - Perfil típico de pavimento de concreto com armadura distribuída descontínua 10

Figura 2.5 - Perfil de pavimento continuamente armado 11

Figura 2.6 - Perfil de um pavimento de concreto estruturalmente armado 13

Figura 2.7 - Seção de pavimento de concreto com fibras de aço 15

Figura 2.8 - Perfil de whitetopping 18

Figura 2.9 - Exemplo de whitetopping ultradelgado 19

Figura 3.1 - Dimensões da área de contato entre o pneu e a placa de concreto 23

Figura 3.2 - Momento fletor, na direção x, para força de 70,56 kN, aplicada no interior da placa de $10 \mathrm{~cm}$ de espessura. 24

Figura 3.3 - Veículo rodoviário com eixos simples e tandem triplo 25

Figura 3.4 - Veículo rodoviário com eixo tandem duplo 25

Figura 3.5 - Chassi de ônibus rodoviário 26

Figura 3.6 - Eixo simples de rodagem simples 26

Figura 3.7 - Eixo simples de rodagem dupla 26

Figura 3.8 - Eixo tandem duplo 26

Figura 3.9 - Eixo tandem triplo 26

Figura 3.10 - Chassi de ônibus urbano 27

Figura 3.11 - Chassi de ônibus urbano articulado 27 
Figura 3.12 - Biarticulado ___ 27

Figura 3.13 - Empilhadeira industrial de rodagem simples __ 28

Figura 3.14 - Empilhadeira industrial de rodagem dupla __ 28

Figura 3.15 - Eixo de empilhadeira de rodagem simples ___ 28

Figura 3.16 - Eixo de empilhadeira de rodagem dupla ___ 28

Figura 3.17 - Corredor de circulação entre forças uniformemente distribuídas, em planta____ 29

Figura 3.18 - Montantes de prateleiras industriais____ 29

Figura 3.19 - Reação à tendência de retração da placa de concreto ___ 31

Figura 3.20 - Tendência de empenamento das placas de concreto, durante o dia

Figura 3.21 - Tendência de empenamento das placas de concreto, durante a noite 33

Figura 4.1 - Comportamento real do solo ___ 36

Figura 4.2 - Comportamento de líquido denso_____ 37

Figura 4.3 - Comportamento de sólido elástico _____ 38

Figura 4.4 - Diagrama tensão-deformação do concreto, na tração, NB-1 (1999)42

Figura 4.5 - Diagrama tensão-deformação do concreto, na compressão, NB-1 (1999) 42

Figura 4.6 - Diagrama tensão-deformação do aço, NB-1 (1999)______ 43

Figura 4.7 - Posições de configurações de carregamentos analisadas por

Westergaard, em $1926 \_44$

Figura 4.8 - Representação de $\ell \_46$

Figura 4.9 - Coeficientes para as tensões de empenamento devidas ao gradiente de temperatura BRADBURY (1938) ___ 51

Figura 4.10 - Posições de carregamento __ 52

Figura 4.11 - Distribuição dos momentos fletores (MN.m), na direção x, para carregamento na borda da placa - eixo simples de rodagem dupla 54

Figura 4.12 - Distribuição dos momentos fletores (MN.m), na direção y, para carregamento na borda da placa - eixo simples de rodagem dupla 54

Figura 4.13 - Distribuição dos momentos fletores (MN.m), na direção x, para carregamento tangente à junta transversal - eixo simples de rodagem dupla 
Figura 4.14 - Distribuição dos momentos fletores (MN.m), na direção y, para carregamento tangente à junta transversal - eixo simples de rodagem dupla 55

Figura 4.15 - Variação do momento fletor máximo, em função da posição da força, borda - interior, semi-eixo simples de rodagem dupla 55

Figura 4.16 - Variação do momento fletor máximo positivo, em função da posição da força, canto - centro da junta transversal, semi-eixo simples de rodagem dupla 56

Figura 4.17 - Variação do momento fletor máximo negativo, em função da posição da força, canto - centro da junta transversal, semi-eixo simples de rodagem dupla 56

Figura 5.1 - Solicitações repetidas ____ 59

Figura 5.2 - Solicitações alternadas ___ 59

Figura 5.3 - Solicitações onduladas _ـ 59

Figura 5.4 - Solicitações por ondas quaisquer ___ 59

Figura 5.5 - Curva S-N para o concreto simples,______ 61

adaptado de LARANJEIRAS (1990) ___ 61

Figura 5.6 - Resistência do concreto à fadiga, adaptado de ACI 215R-81 (1992)

Figura 5.7 - Curvas S-N, do aço para concreto armado, traçadas a partir de valores fornecidos pelo CEB-FIP/90 (1991) ___ 63

Figura 5.8 - Regra linear para acúmulo de dano por fadiga___ 64

Figura 5.9 - Curvas S-N, para pavimentos de concreto ___ 66

Figura 6.1 - Critério de fadiga adotado pela PCA/66 ___ 79

Figura 6.2 - Distribuição percentual do carregamento nas posições em relação à placa 80

Figura 6.3 - Critério de fadiga adotado pela PCA/84 83

Figura 6.4 - Ruína por punção a 2d da área de aplicação da força 93

Figura 6.5 - Ruína por punção na face da área de aplicação da força 93

Figura 8.1 - Fissuras transversais de retração 109

Figura 8.2 - Fissuras devidas ao empenamento 109

Figura 8.3 - Pavimento de concreto com juntas transversais inclinadas 110

Figura 8.4 - Junta serrada, de contração 110 
Figura 8.5 - Junta de dilatação 110

Figura 8.6 - Junta longitudinal com encaixe tipo macho-fêmea 111

Figura 8.7 - Junta transversal com barra de transferência 112

Figura 8.8 - Distribuição da força nas barras de transferência 112

Figura 8.9 - Deformação de barra de aço mergulhada em concreto, sob carregamento perpendicular ao comprimento, fonte YODER \& WITCZAK (1975) 114

Figura 8.10 - Junta longitudinal serrada, com barra de ligação 117

Figura 8.11 - Distribuição dos momentos fletores (MN.m), na direção x, para carregamento tangente à junta transversal - eixo simples de rodagem dupla, eficiência da junta: $100 \%$ 120

Figura 8.12 - Distribuição dos momentos fletores (MN.m), na direção y, para carregamento tangente à junta transversal - eixo simples de rodagem dupla, eficiência da junta: $100 \%$ 120

Figura 8.13 - Distribuição dos momentos fletores (MN.m), na direção x, para carregamento tangente à junta transversal - eixo simples de rodagem dupla, eficiência da junta: $45 \%$ 121

Figura 8.14 - Distribuição dos momentos fletores (MN.m), na direção y, para carregamento tangente à junta transversal - eixo simples de rodagem dupla, eficiência da junta: $45 \%$ 121

Figura 9.1 - Geometria do pavimento 124

Figura 9.2 - Detalhamento da armadura de flexão 156

Figura 9.3 - Detalhamento da armadura de retração para placas de 16,29 metros 156

Figura 9.4 - Distribuição das placas 157

Figura 9.5 - Detalhamento da armadura de retração para placas de 19,60 metros 158

Figura A.1 - Relação entre índice de suporte Califórnia e coeficiente de recalque, adaptado de PITTA (1990) 168

Figura A.2 - Aumento de k devido à sub-base granular, adaptado de PCA (1984)

Figura A.3 - Aumento de k devido à sub-base de solo-cimento, adaptado de PCA (1984) 169 
Figura A.4 - Aumento de k devido à sub-base de solo melhorado com cimento, 170

adaptado de PITTA (1990) 170

Figura A.5 - Aumento de k devido à sub-base de concreto rolado, 170 adaptado de PITTA (1990) 170

Figura A.6 - Aumento de $\mathrm{k}$ devido à presença de sub-base, adaptado de AASHTO (1986) 171

Figura A.7 - Modificação de k devido à de extrato rígido, adaptado de AASHTO (1986) 171

Figura A.8 - Dano relativo, adaptado de AASHTO (1986) 172

Figura A.9 - Redução de k devido à perda de serventia, adaptado de AASHTO (1986) 172

Figura A.10 - Ábaco para dimensionamento da espessura de pavimentos rodoviários de concreto (caso de eixos simples), DNER (1989) 173

Figura A.11 - Ábaco para dimensionamento da espessura de pavimentos rodoviários de concreto (caso de eixos tandem duplos), DNER (1989) _ 173

Figura A.12 - Ábaco para dimensionamento da espessura de pavimentos rodoviários de concreto (caso de eixos tandem triplos), DNER (1989) _ 174

Figura A.13 - Número admissível de repetições de carga em função do fator de fadiga, DNER (1989) 174

Figura A.14 - Análise de erosão: número admissível de repetições de carga em função do fator de erosão (sem acostamento de concreto), DNER (1989)_ 175 Figura A.15 - Análise de erosão: número admissível de repetições de carga em função do fator de erosão (com acostamento de concreto), DNER (1989)_ 175

Figura A.16 - Área de contato efetiva____ 176

Figura A.17 - Ábaco para dimensionamento de pisos industriais, para empilhadeiras de rodagem simples, adaptado de PACKARD (1976) 176

Figura A.18 - Ábaco para determinação do fator de redução para empilhadeiras de rodagem dupla, adaptado de PACKARD (1976) 177

Figura A.19 - Ábaco para dimensionamento de pisos industriais, para cargas de montantes, $\mathrm{k}=13,8 \mathrm{MPa} / \mathrm{m}$, adaptado de PACKARD (1976) 177

Figura A.20 - Ábaco para dimensionamento de pisos industriais, para cargas de montantes, $\mathrm{k}=28 \mathrm{MPa} / \mathrm{m}$, adaptado de PACKARD (1976) 178 
Figura A.21 - Ábaco para dimensionamento de pisos industriais, para cargas de montantes, $\mathrm{k}=55,4 \mathrm{MPa} / \mathrm{m}$, adaptado de PACKARD (1976) 178

Figura A.22 - Ábaco para determinação da armadura de retração, segundo método da Corps of Engineers, fonte: RODRIGUES e CASSARO (1998)_ 179

Figura B.1 - Distribuição dos momentos fletores (MN.m), na direção x, para eixo tangente à borda da placa - eixo simples de rodagem simples 196

Figura B.2 - Distribuição dos momentos fletores (MN.m), na direção y, para eixo tangente à borda da placa - eixo simples de rodagem simples 197

Figura B.3 - Distribuição dos momentos fletores (MN.m), na direção x, para eixo no canto da placa - eixo simples de rodagem simples 197

Figura B.4 - Distribuição dos momentos fletores (MN.m), na direção y, para eixo no canto da placa - eixo simples de rodagem simples 197

Figura B.5 - Distribuição dos momentos fletores (MN.m), na direção x, para eixo tangente à borda da placa - eixo tandem duplo 198

Figura B.6 - Distribuição dos momentos fletores (MN.m), na direção y, para eixo tangente à borda da placa - eixo tandem duplo 198

Figura B.7 - Distribuição dos momentos fletores (MN.m), na direção x, para eixo no canto da placa - eixo tandem duplo 199

Figura B.8 - Distribuição dos momentos fletores (MN.m), na direção y, para eixo no canto da placa - eixo tandem duplo 199

Figura B.9 - Distribuição dos momentos fletores (MN.m), na direção x, para eixo tangente à borda da placa - eixo tandem triplo 199

Figura B.10 - Distribuição dos momentos fletores (MN.m), na direção y, para eixo tangente à borda da placa - eixo tandem triplo 200

Figura B.11 - Distribuição dos momentos fletores (MN.m), na direção x, para eixo no canto da placa - eixo tandem triplo 200

Figura B.12 - Distribuição dos momentos fletores (MN.m), na direção y, para eixo no canto da placa - eixo tandem triplo 200

Figura B.13 - Variação do momento fletor máximo, em função da posição da carga, borda - interior, semi-eixo simples de rodagem simples 201

Figura B.14 - Variação do momento fletor máximo positivo, em função da posição da carga, canto - centro da junta transversal, semi-eixo simples de rodagem simples 202 
Figura B.15 - Variação do momento fletor máximo negativo, em função da posição da carga, canto - centro da junta transversal, semi-eixo simples de rodagem simples 202

Figura B.16 - Distribuição dos momentos fletores (MN.m), na direção x, para semi-eixo tangente à borda da placa - eixo simples de rodagem simples 203

Figura B.17 - Distribuição dos momentos fletores (MN.m), na direção y, para semi-eixo no interior da placa - eixo simples de rodagem simples 203

Figura B.18 - Distribuição dos momentos fletores (MN.m), na direção x, para semi-eixo no canto da placa - eixo simples de rodagem simples 204

Figura B.19 - Distribuição dos momentos fletores (MN.m), na direção y, para semi-eixo tangente à junta transversal- eixo simples de rodagem simples 204

Figura B.20 - Distribuição dos momentos fletores (MN.m), na direção x, para semi-eixo tangente à borda da placa - eixo simples de rodagem dupla _ 205

Figura B.21 - Distribuição dos momentos fletores (MN.m), na direção x, para semi-eixo no interior da placa - eixo simples de rodagem dupla 205

Figura B.22 - Distribuição dos momentos fletores (MN.m), na direção x, para semi-eixo no canto da placa - eixo simples de rodagem dupla 205

Figura B.23 - Distribuição dos momentos fletores (MN.m), na direção y, para semi-eixo tangente à junta transversal- eixo simples de rodagem dupla 205

Figura B.24 - Distribuição dos momentos fletores (MN.m), na direção x, para semi-eixo tangente à borda da placa - eixo tandem duplo 206

Figura B.25 - Distribuição dos momentos fletores (MN.m), na direção y, para semi-eixo no interior da placa - eixo tandem duplo 206

Figura B.26 - Distribuição dos momentos fletores (MN.m), na direção y, para semi-eixo no canto da placa - eixo tandem duplo 207

Figura B.27 - Distribuição dos momentos fletores (MN.m), na direção y, para semi-eixo tangente à junta transversal- eixo tandem duplo 207

Figura B.28 - Distribuição dos momentos fletores (MN.m), na direção x, para semi-eixo tangente à borda da placa - eixo tandem duplo 208

Figura B.29 - Distribuição dos momentos fletores (MN.m), na direção y, para semi-eixo no interior da placa - eixo tandem duplo 208 
Figura B.30 - Distribuição dos momentos fletores (MN.m), na direção y, para semi-eixo no canto da placa - eixo tandem duplo 208

Figura B.31 - Distribuição dos momentos fletores (MN.m), na direção y, para semi-eixo tangente à junta transversal- eixo tandem duplo 208

Figura B.32 - Distribuição dos momentos fletores (MN.m), na direção x, para semi-eixo tangente à borda- empilhadeira de rodagem simples 210

Figura B.33 - Distribuição dos momentos fletores (MN.m), na direção x, para semi-eixo no interior da placa - empilhadeira de rodagem simples 210

Figura B.34 - Distribuição dos momentos fletores (MN.m), na direção y, para semi-eixo no interior da placa - empilhadeira de rodagem simples 210

Figura B.35 - Distribuição dos momentos fletores (MN.m), na direção x, para eixo de empilhadeira de rodagem simples, com uma das rodas tangente à borda 211

Figura B.36 - Distribuição dos momentos fletores (MN.m), na direção y, para eixo de empilhadeira de rodagem simples, com uma das rodas tangente à borda 211 


\section{LISTA DE TABELAS}

Tabela 4.1 - Dados do problema 53

Tabela 4.2 - Força e área de contato adotados no problema 53

Tabela 7.1 - Cobrimento nominal em função da classe de agressividade do meio

Tabela 9.1 - Tráfego da rodovia 104

Tabela 9.2 - Número de eixos equivalentes 125

Tabela 9.3 - Número de eixos equivalentes 126

Tabela 9.4 - Número de eixos equivalentes 130

Tabela A.1 - Coeficiente de atrito, fonte: MOURA (1999) 132

Tabela A.2 - Fatores de equivalência de carga por eixo simples, para índice de serventia final igual a 2,0 180

Tabela A.3 - Fatores de equivalência de carga por eixo tandem duplo, para índice de serventia final igual a 2,0 181

Tabela A.4 - Fatores de equivalência de carga por eixo tandem triplo, para índice de serventia final igual a 2,0 182

Tabela A.5 - Fatores de equivalência de carga por eixo simples, para índice de serventia final igual a 2,5 183

Tabela A.6 - Fatores de equivalência de carga por eixo tandem duplo, para índice de serventia final igual a 2,5 184

Tabela A.7 - Fatores de equivalência de carga por eixo tandem triplo, para índice de serventia final igual a 2,5 185

Tabela A.8 - Fatores de equivalência de carga por eixo simples, para índice de serventia final igual a 3,0 
Tabela A.9 - Fatores de equivalência de carga por eixo tandem duplo, para índice de serventia final igual a 3,0 187

Tabela A.10 - Fatores de equivalência de carga por eixo tandem triplo, para índice de serventia final igual a 3,0 188

Tabela A.11 - Nível de confiabilidade, R, DNER (1989) 189

Tabela A.12 - Coeficiente de Student e fator de segurança de carga, DNER (1989) 189

Tabela A.13 - Coeficiente de drenagem, Cd, DNER (1989) 189

Tabela A.14a - Faixa de valores da perda de suporte para diferentes tipos de sub-bases, DNER (1989) 189

Tabela A.14b - Faixa de valores da perda de suporte para diferentes tipos de sub-bases, adaptado de AASHTO (1986) 190

Tabela A.15 - Coeficiente de transferência de carga, J, DNER (1989) 190

Tabela A.16 - Coeficientes de segurança de carga, FsC, PCA (1966) 190

Tabela A.17 - $\mathrm{R}_{\mathrm{T}} \mathrm{x}$ N, PCA (1966) 191

Tabela A.18 - Tensão equivalente - Sem acostamento de concreto, PITTA (1996) 191

Tabela A.19 - Tensão equivalente - Com acostamento de concreto, , PITTA (1996) 192

Tabela A.20 - Fatores de erosão - juntas transversais com transferência de carga por entrosagem de agregados - sem acostamento de concreto, PITTA (1996) 192

Tabela A.21 - Fatores de erosão - juntas transversais com barras de transferência - sem acostamento de concreto, PITTA (1996) 193

Tabela A.22 - Fatores de erosão - juntas transversais com entrosagem de agregados - com acostamento de concreto, PITTA (1996) 193

Tabela A.23 - Fatores de erosão - juntas transversais com barras de tranferência - com acostamento de concreto, PITTA (1996) 194

Tabela A.24 - Coeficientes de segurança devido à fadiga, PACKARD (1976)_ 194

Tabela A.25 - Valores de $\mathrm{k}_{\mathrm{c}}$ e $\mathrm{k}_{\mathrm{s}}$, adaptado de PINHEIRO (1993)____ 195

Tabela A.26 - Barras de transferência, adaptado de: RODRIGUES e CASSARO (1998) e PITTA (1987) 195

Tabela B.1 - Dados do problema 209 


\section{LISTA DE SIGLAS}

$\begin{array}{ll}\text { AASHO } & \text { American Association of State Highway Officials } \\ \text { AASHTO } & \begin{array}{l}\text { American Association Of State Highway And Transportation } \\ \text { Officials }\end{array} \\ \text { ABCP } & \text { Associação Brasileira de Cimento Portland } \\ \text { ABNT } & \text { Associação Brasileira de Normas Técnicas } \\ \text { ACI } & \text { American Concrete Institute } \\ \text { CBR } & \text { California Bearing Test - Índice de Suporte Califórnia } \\ \text { CEB } & \text { Comite Euro-International du Beton } \\ \text { DNER } & \text { Departamento Nacional de Estradas de Rodagem } \\ \text { EESC } & \text { Escola de Engenharia de São Carlos } \\ \text { FAA } & \text { Forma Brasileira Registrada } \\ \text { NB } & \text { Norma Brasileira } \\ & \end{array}$




\section{LISTA DE SÍMBOLOS}

A área de aplicação da força; área de contato entre o pneu e o pavimento

A' área corrigida

a maior semi-eixo da elipse de contato; raio da área circular de contato entre pneu e pavimento

a 1 distância entre o centro de uma área de carregamento circular aplicada no canto de uma placa e o canto da placa

ad raio da área circular de contato de roda dupla

As área de aço

as,bl área de aço de barras de ligação por unidade de comprimento

as,bl,ef área de aço efetiva, de barras de ligação por unidade de comprimento

$\mathrm{A}_{\mathrm{s}, \mathrm{cal}} \quad$ área de aço calculada

$\mathrm{A}_{\mathrm{s}, \mathrm{ef}} \quad$ área de aço efetiva

$\mathrm{A}_{\mathrm{s}, \mathrm{ret}} \quad$ área de aço de retração

B largura da placa; largura da seção

b largura da área de contato entre pneu e pavimento; menor semi-eixo da elipse de contato; raio equivalente da área de distribuição de pressão

$b_{i} \quad$ coeficiente de cada barra de transferência

$b_{\text {o }} \quad$ perímetro crítico a d/2 da face do pilar

c comprimento da área de contato entre pneu e pavimento 


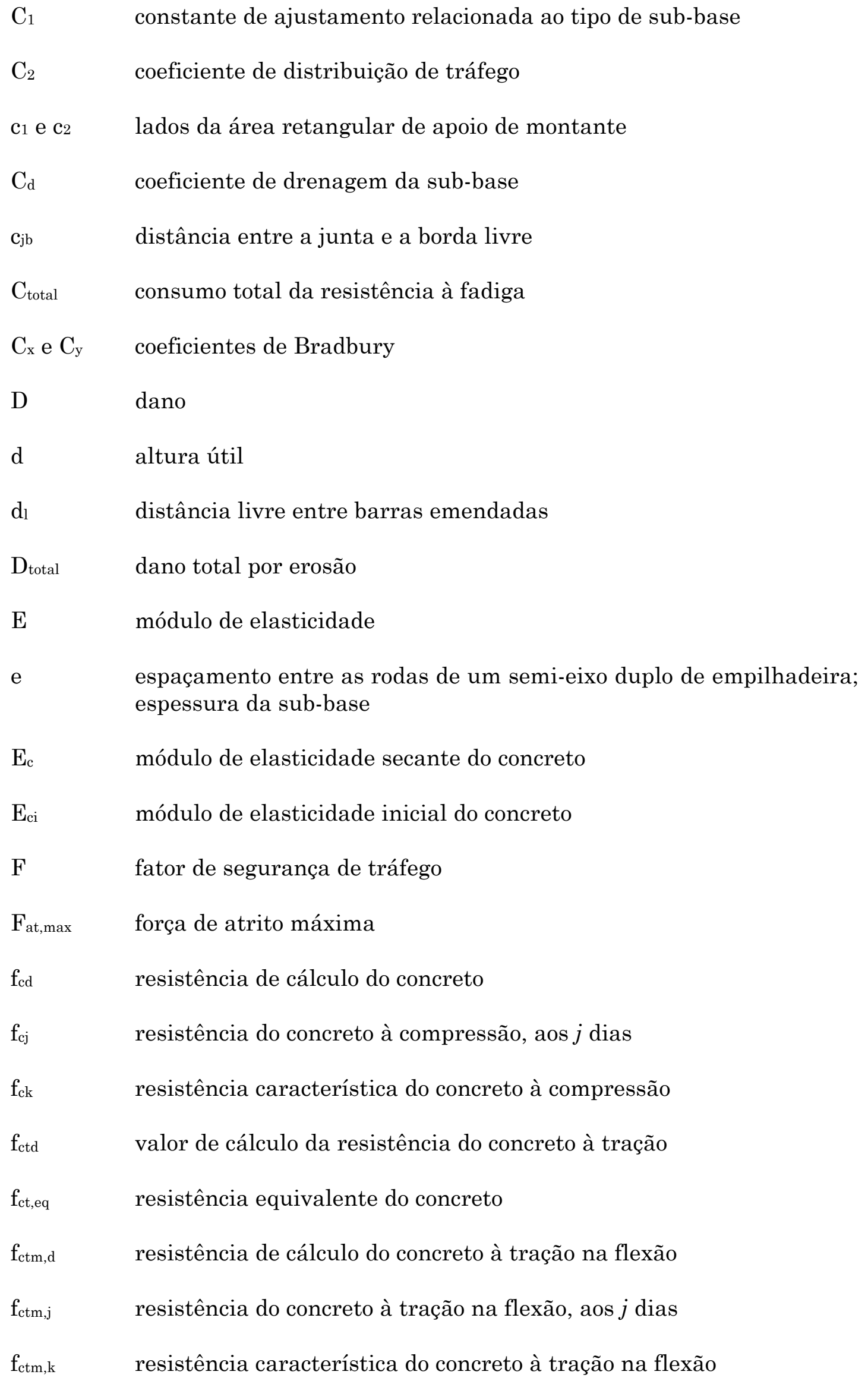




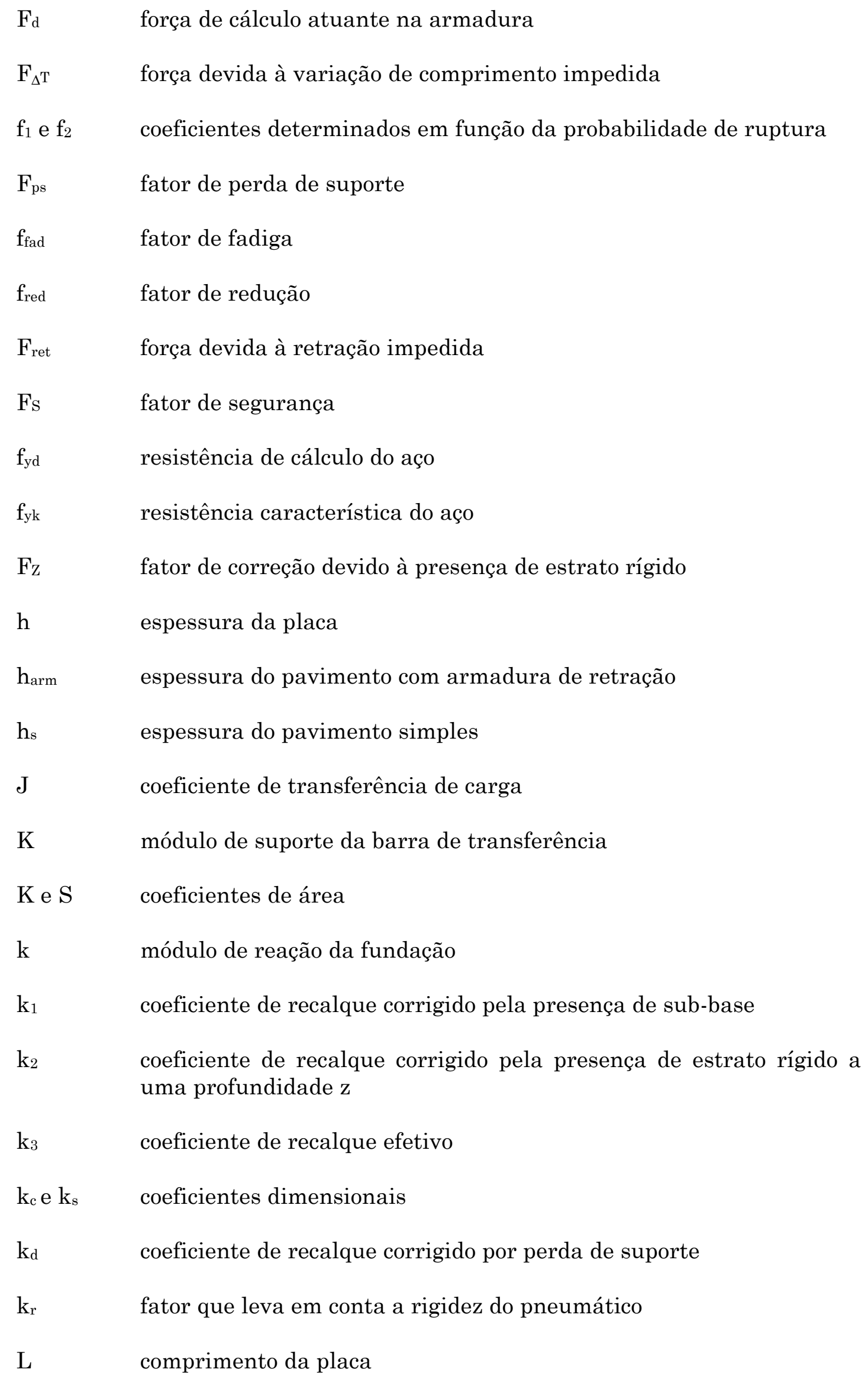




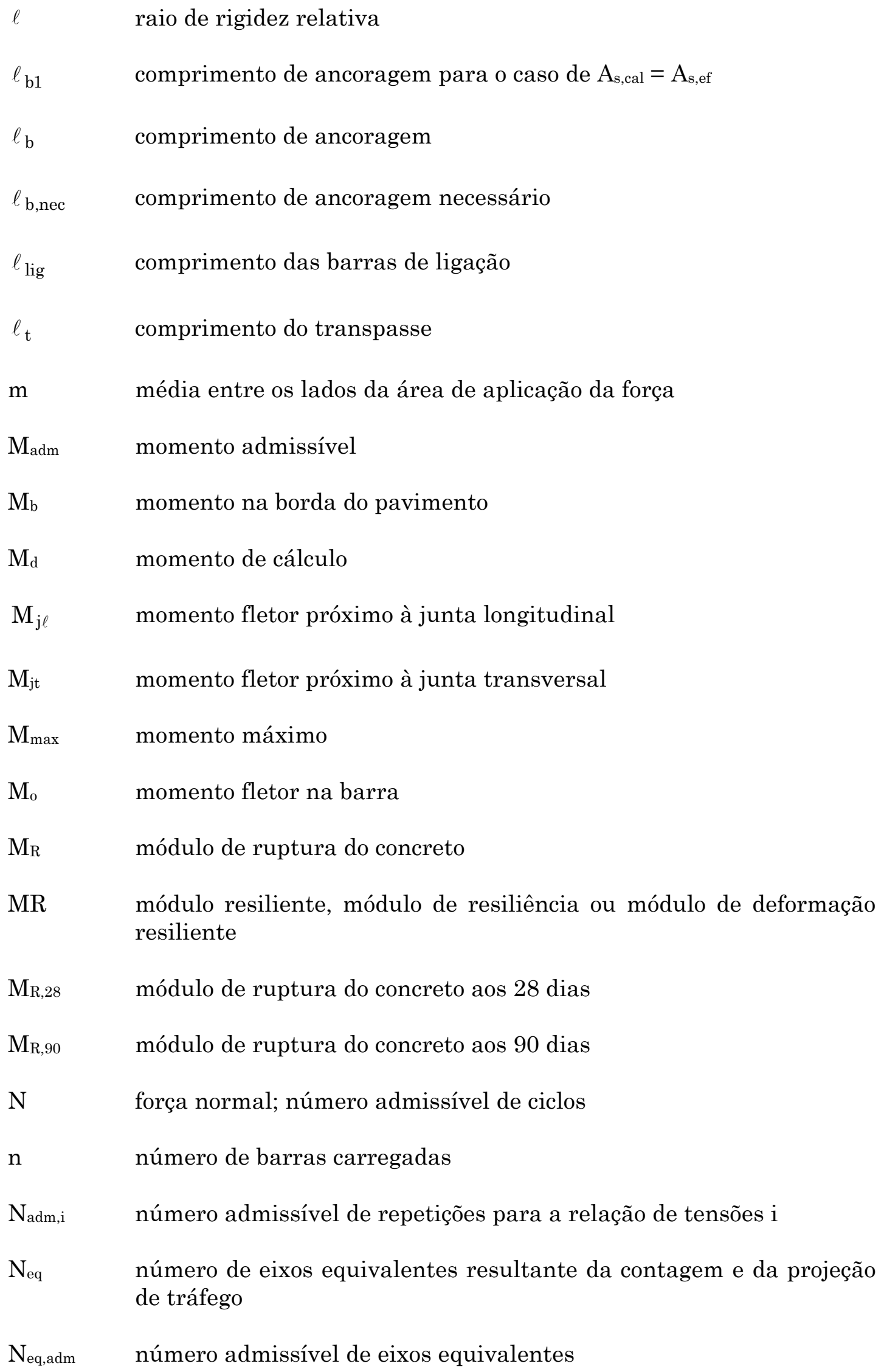


$\mathrm{N}_{\mathrm{i}} \quad$ número de ciclos que produz ruptura para uma variação de tenção

$\mathrm{n}_{\mathrm{i}} \quad$ número de ciclos com variação de tensão $\Delta \sigma_{\mathrm{i}}$

$\mathrm{N}_{\text {sol,i }} \quad$ número de repetições previstas para a relação de tensões $\mathrm{i}$

$\mathrm{N}_{\text {total }} \quad$ número total de eixos equivalentes de projeto

P força aplicada; fator de erosão; peso do eixo mais carregado

p pressão vertical exercida na fundação sob o canto da placa

$\mathrm{P}_{\mathrm{a}} \quad$ força na barra mais carregada

$\mathrm{P}_{\text {cor }} \quad$ peso do eixo, corrigido

$\mathrm{P}_{\text {mont }} \quad$ peso do montante

$\mathrm{P}_{\mathrm{r}} \quad$ peso atuante em uma roda

$\mathrm{p}_{\mathrm{s}} \quad$ perda de suporte, que depende do tipo de sub-base

Q tensão de trabalho

q pressão de enchimento dos pneus

qadm carregamento uniformemente distribuído admissível

Q $\quad$ tensão de trabalho corrigida

$\mathrm{r}$

coordenada polar

$\mathrm{R}$ relação entre tensão mínima e tensão máxima

$\mathrm{R}_{\mathrm{T}} \quad$ relação de tensões (solicitante e admissível)

s distância entre rodas de eixo de empilhadeira

$\mathrm{Si} \quad$ índice de serventia inicial

Sf índice de serventia final

So desvio padrão

$\mathrm{u} \quad$ perímetro crítico a $2 \mathrm{~d}$ da face do pilar; fator de dano

$\overline{\mathrm{u}} \quad$ fator de dano médio

x distância da junta até o ponto considerado; distância entre as barras de transferência; distância entre o ponto considerado e o canto da placa 
yo deslocamento da barra na face da junta

Z profundidade do estrato rígido em relação ao nível do subleito

Z

z'

$\mathrm{Z}_{\mathrm{j}}$

$\mathrm{Z}_{\mathrm{c}}$

$\mathrm{Z}_{\mathrm{R}}$

$\alpha$

$\alpha_{1}$

$\alpha_{2}$

$\alpha_{\mathrm{s}}$

$\beta$

$\beta_{\mathrm{c}}$

$\Delta \mathrm{f}_{\text {sd,fad }}$

$\Delta \mathrm{s}$

$\Delta \sigma_{\mathrm{s}}$

$\Delta \mathrm{t}$

$\delta \mathrm{T}$

$\varepsilon_{\text {junta }}$

$\varepsilon_{\mathrm{cc}}$

$\phi$

$\gamma_{c}$

$\gamma$

$\gamma_{\varepsilon}$

$\gamma_{\mathrm{fad}}$ deslocamento vertical do lado carregado da junta

deslocamento vertical do lado descarregado da junta

abertura da junta

deslocamento máximo para força no canto da placa

coeficiente de Student

coeficiente de dilatação térmica do concreto

coeficiente de redução devido a barras transversais soldadas

coeficiente de majoração devido à presença de várias barras emendadas na mesma seção

constante de posição de carregamento

rigidez relativa da barra mergulhada em concreto

razão entre os lados mais longo e mais curto do pilar

variação de tensão admissível, no aço

perda de serventia

variação de tensão no aço

variação de temperatura

gradiente de temperatura

eficiência da junta

coeficiente de retração

diâmetro da barra

coeficiente de segurança do concreto

peso específico do concreto armado

coeficiente de segurança da força devida à retração

coeficiente de segurança devido à fadiga 


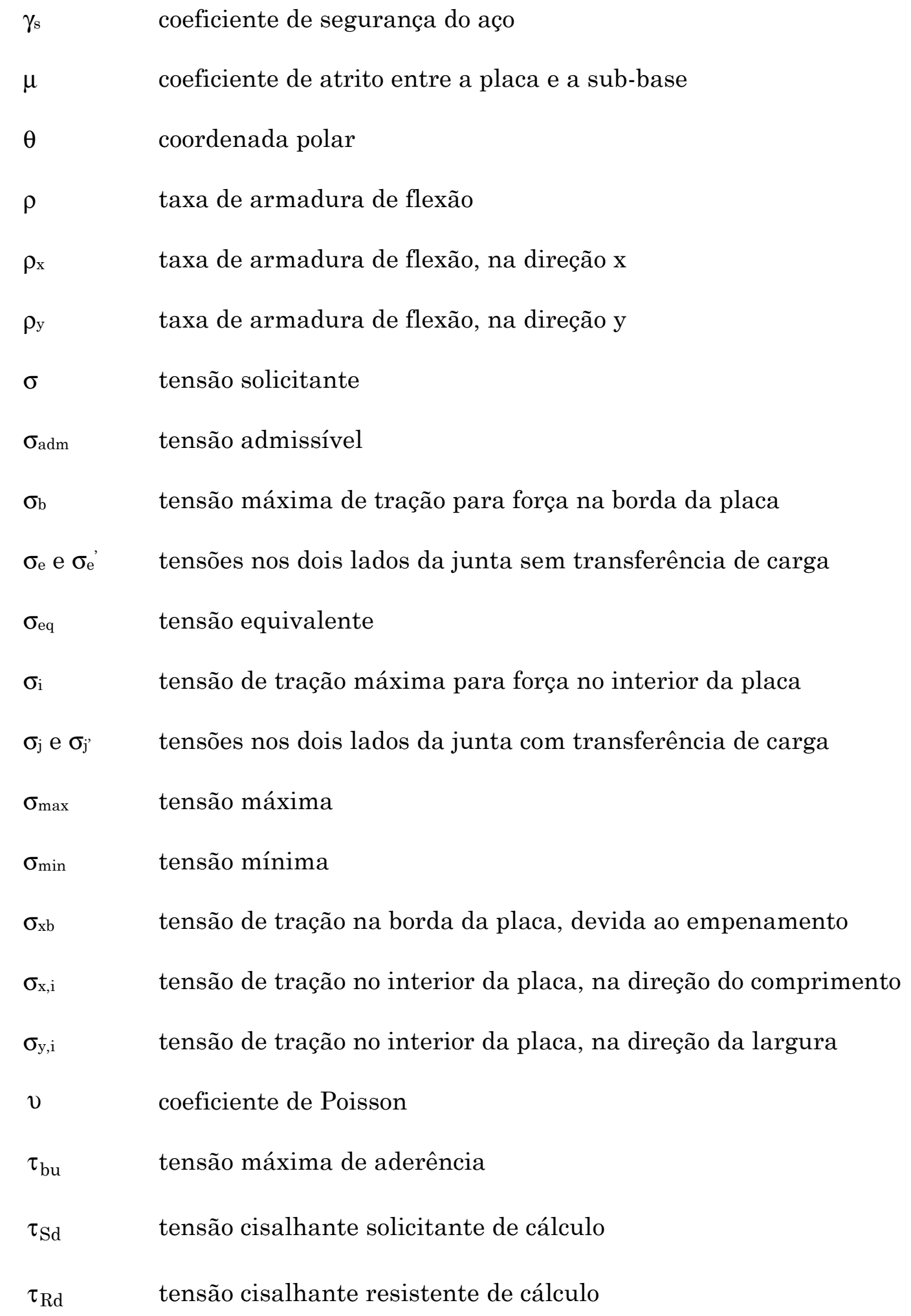




\section{RESUMO}

OLIVEIRA, P. L. (2000). Projeto estrutural de pavimentos rodoviários e de pisos industriais de concreto. São Carlos, 216 p. Dissertação (mestrado) - Escola de Engenharia de São Carlos, Universidade de São Paulo.

Neste trabalho são estudados os principais parâmetros do projeto estrutural de pavimentos rodoviários e de pisos industriais de concreto. Faz-se um levantamento bibliográfico, apresentando as características estruturais de diversos tipos de pavimentos rígidos. São discutidas as ações diretas e as indiretas em pavimentos de concreto e analisadas as formas de consideração das forças aplicadas. São apresentados modelos para representação da fundação, do pavimento e dos materiais. É feito um resumo da teoria de Westergaard, para determinação de tensões devidas ao tráfego, e da teoria de Bradbury, para determinação de tensões devidas ao empenamento. O comportamento dos pavimentos rígidos sob diversas configurações de carregamento são analisadas com auxílio de software com base no método dos elementos finitos. Apresentamse os métodos indicados pelo DNER para determinação da espessura de pavimentos de concreto simples. São discutidas equações para determinação da área de aço para combate à retração e desenvolvido um procedimento para dimensionamento da armadura de flexão, com base na Revisão da NB-1. São analisados os mecanismos de formação de fissuras e a importância das juntas. São apresentadas equações para dimensionamento das barras de transferência e das barras de ligação e analisada a influência da eficiência da junta nos esforços das placas. São desenvolvidos exemplos numéricos sobre dimensionamento de pavimentos de concreto simples e de concreto armado, e sobre detalhamento das juntas.

Palavras-chave: pavimento; pavimento de concreto; pavimento rígido; pavimentação 
OLIVEIRA, P. L. (2000). Structural design of highway and industrial floors concrete pavements. São Carlos, 216 p. Dissertação (mestrado) - Escola de Engenharia de São Carlos, Universidade de São Paulo.

In this work are studied the main parameters of the structural project of concrete highway and industrial pavements. A bibliographical rising is made presenting the structural characteristics of several types of rigid pavements. Direct and indirect actions in the concrete pavements are discussed and the procedures of load consideration are analyzed. Models for represent the foundation, the pavement and the materials are showed. A summary of Westergaard's theory for determination of stresses owed to the traffic and of Bradbury's theory for determination of stresses owed to the curling is presented. The behavior of rigid pavements under several loading configurations is analyzed, with a software based on finite elements method. The thickness design methods for concrete pavement indicated by DNER are presented and discussed. The equation for determination of shrinkage reinforcement is showed and a procedure for design of positive steel is developed, based on the Brazilian Code. The cracking mechanism and the importance of joints are analyzed. Design equations for dowels and tie bars are studied. Numeric design examples are developed for plain concrete pavements, for reinforced concrete pavement, and for design of the joints.

Keywords: pavement; concrete pavement; rigid pavement. 


\section{Capítulo}

\section{INTRODUÇÃO

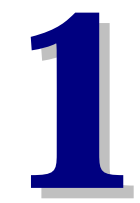

Durante a concepção de uma estrutura devem ser avaliadas diversas possibilidades, a fim de determinar a melhor solução para o projeto estudado. Os principais fatores que influenciam a decisão são: disponibilidade de materiais, de equipamentos e de mão de obra; segurança; durabilidade; economia e tempo. Para que seja possível escolher a melhor opção, é necessário o amplo conhecimento sobre as várias tecnologias existentes. Neste trabalho serão apresentados os pavimentos rígidos, que constituem alternativas viáveis na construção de rodovias, vias urbanas e pisos industriais, além das aplicações em pátios e pistas de aeroportos, entre outros.

A principal diferença estrutural entre pavimento rígido e pavimento flexível é a distribuição de tensões nas camadas subjacentes. O pavimento flexível, executado com concreto asfáltico, também conhecido como asfalto, funciona como camada de rolamento. Neste caso, quem absorve os esforços devidos ao tráfego é a fundação, normalmente composta por três camadas: base, sub-base e reforço do subleito. No pavimento de concreto de cimento, ou apenas pavimento de concreto, a camada de rolamento também funciona como estrutura, redistribuindo os esforços e diminuindo a tensão imposta à sub-base, que, normalmente, é a única camada executada entre as placas de concreto e o subleito.

Uma das principais vantagens do pavimento de concreto de cimento portland é a durabilidade. O concreto não deteriora com a ação da chuva, de óleos ou de combustíveis e não deforma a ponto de formar as trilhas de rodas. 
Dessa forma, o pavimento rígido pode funcionar mais de 20 anos sem sofrer intervenções para reparos ou manutenção.

Testes realizados pela Federal Highway Administration (EUA) mostram que um veículo de passeio a $95 \mathrm{~km} / \mathrm{h}$, em superfície seca e sem deformações, precisa de $16 \%$ menos distância de frenagem em pistas de concreto em relação às de pavimentos asfálticos. Em condições adversas essa diferença é de $40 \%$. A coloração cinza-claro do concreto de cimento melhora a visibilidade à noite, possibilitando uma diminuição de $30 \%$ na iluminação, conforme estudo da General Eletric (EUA).

Um projeto bem elaborado contribui para garantir as vantagens apresentadas pelos pavimentos de concreto. $\mathrm{O}$ dimensionamento conservador pode inviabilizar a construção por aumentar demasiadamente seu custo. O subdimensionamento pode causar problemas estruturais e diminuir a vida útil do pavimento, obrigando a execução de reparos e reforços que aumentam os custos e provocam transtornos aos usuários.

Atualmente os projetos de estruturas devem incorporar conceitos como vida útil e estados limites. Esses conceitos se aplicam também aos pavimentos. Um projeto deve ser realizado não apenas para garantir a segurança à ruptura, mas para atender às condições de serviço, por um determinado período de tempo.

Para dimensionar um pavimento, é necessário conhecer a categoria e o volume do tráfego que solicitará a estrutura. É importante estabelecer o período de projeto e realizar os cálculos, considerando não apenas o efeito do carregamento estático, mas também o fenômeno da fadiga.

\subsection{OBJETIVOS}

Este trabalho tem como objetivos principais: avaliar o comportamento estrutural das placas de concreto e das juntas de pavimentos rodoviários, de vias urbanas e de pisos industriais, e apresentar métodos de dimensionamento 
de pavimentos de concreto simples e de concreto armado, incorporando os conceitos preconizados pela norma brasileira de concreto.

Procura-se diferenciar os diversos tipos de pavimentos rígidos e estudar os principais fatores que influenciam o dimensionamento, como as ações, os modelos de cálculo e o comportamento sob carregamento cíclico.

\subsection{ETAPAS DO TRABALHO}

O trabalho será dividido em 10 capítulos.

No capítulo 1 são mostradas as vantagens dos pavimentos rígidos e a importância do estudo de seu comportamento estrutural, a fim de se obter um dimensionamento seguro e econômico.

No capítulo 2 são tratados os diversos tipos de pavimentos rígidos. São discutidas as principais características de cada um e citados exemplos de aplicação.

No capítulo 3 são apresentadas as ações que atuam nos pavimentos de concreto utilizados em rodovias, em vias urbanas e em pisos industriais. São analisadas as características do tráfego, das cargas permanentes e das variações volumétricas.

No capítulo 4 são apresentados modelos que representam a fundação e os materiais utilizados na construção de pavimentos rígidos. É realizada um revisão bibliográfica sobre as principais teorias que deram origem aos atuais métodos de dimensionamento. São apresentados resultados de análises de placas sobre apoio elástico, realizadas com auxílio de software com base no método dos elementos finitos.

No capítulo 5 é discutido o comportamento de estruturas submetidas a carregamento cíclico e apresentados métodos de consideração da fadiga no dimensionamento de pavimentos de concreto.

No capítulo 6 são apresentados métodos de dimensionamento da espessura de pavimentos rígidos rodoviários e de pisos industriais de concreto. 
No capítulo 7 trata-se da determinação da área de aço e do detalhamento da armadura dos pavimentos de concreto armado.

No capítulo 8 são estudados a formação de fissuras e o comportamento estrutural das juntas dos pavimentos de concreto. É avaliada a influência da eficiência das juntas nos esforços gerados nas placas.

No capítulo 9 são desenvolvidos exemplos numéricos que elucidam os assuntos tratados nos capítulos anteriores.

No capítulo 10 são apresentas as conclusões obtidas do trabalho e sugestões para novas pesquisas. 


\section{Capítulo}

\section{PaVimentos RÍGIDOS}

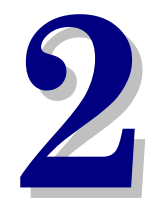

Os pavimentos rígidos podem ser construídos com concreto simples, armado, protendido, com adição de fibras, com concreto rolado ou com concreto de alta resistência. Podem ser apoiados sobre o solo, sobre a sub-base, ou sobre pavimentos antigos, de concreto ou de asfalto. Neste capítulo são discutidas as principais características dos pavimentos de concreto simples e de concreto armado. Faz-se ainda um breve comentário sobre o comportamento dos pavimentos de concreto protendido, de concreto rolado e de concreto com fibras.

\subsection{PAVIMENTO DE CONCRETO SIMPLES}

É o pavimento constituído de placas de concreto de cimento portland, apoiados sobre a fundação, nos quais os esforços, tanto os de compressão quanto os de tração, são resistidos apenas pelo concreto. As placas são separadas por juntas moldadas ou serradas, que controlam a fissuração devida à retração, ao empenamento e à dilatação térmica.

Os pavimentos de concreto simples podem ser divididos em:

- Sem barras de transferência;

- Com barras de transferência.

As barras de aço, que podem ser empregadas com a função de transferir esforços entre placas, não são consideradas armaduras, portanto não descaracterizam o pavimento de concreto simples. Um pavimento de concreto 
simples pode ainda apresentar armadura em poucas placas isoladas, eventualmente exigidas pelo projeto, para combater a fissuração por retração ou devido à geometria irregular da placa. A figura 2.1 mostra um perfil de pavimento de concreto simples, sem barra de transferência.

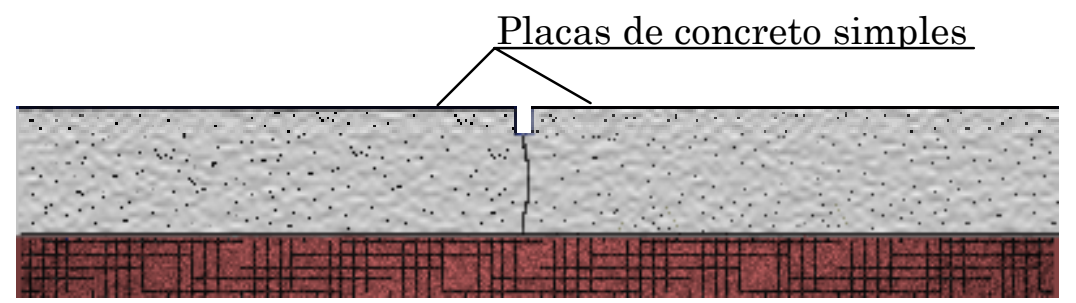

Figura 2.1 - Perfil de um pavimento de concreto simples, sem barra de transferência

Atualmente, no Brasil, os pavimentos rígidos com barras de transferência têm sido utilizados com maior frequência, ficando os pavimentos de concreto, sem barras de transferência, restritos a vias de baixo volume de tráfego e cargas de pequena intensidade. Quando não são utilizadas as barras de transferência, o pavimento têm entre 15 a $20 \mathrm{~cm}$ de espessura e as dimensões das placas são de 4 a 6 metros de comprimento e de 3 a 4 metros de largura. Neste caso deve ser executada sub-base tratada com cimento ou em concreto rolado, a fim de minimizar os efeitos de erosão na região de encontro entre duas placas. Os pavimentos de concreto simples com barras de transferência têm, em média, de 16 a $45 \mathrm{~cm}$ de espessura e suas dimensões em planta podem chegar a 7 metros.

Como possui uma grande área exposta ao ar, as placas de concreto estão sujeitas a grandes variações de umidade e de temperatura. Deve-se portanto procurar um concreto que sofra a menor retração possível, e que tenha resistência suficiente para absorver os esforços impostos por estas condições. No caso do pavimento de concreto simples, os esforços de tração devem ser resistidos apenas pelo concreto. Portanto ele deve apresentar elevada resistência à tração na flexão, a fim de suportar o momento fletor. Aumentar a resistência do concreto à tração, e, consequentemente, sua resistência à compressão, implica em maior consumo de cimento. Além de aumentar o custo do material, quanto maior a quantidade de cimento mais retrátil é o concreto. Dessa forma deve-se buscar um consumo que proporcione resistência adequada, 
sem acentuar demasiadamente o problema da retração. Assim sendo, o ideal é utilizar baixo fator água/cimento. As condições de concretagem normalmente exigem um concreto duro, de consistência seca, mas com uma certa trabalhabilidade que garanta homogeneidade, densidade e impermeabilidade adequadas. A realização de dosagem experimental é a melhor forma de garantir a qualidade do concreto, as características necessárias e a economia de materiais.

A NBR-7583 (1984) - "Execução de pavimentos de concreto simples por meio mecânico" estabelece as exigências para a construção dos pavimentos de concreto simples, por processo mecânico, aplicados em estradas, aeródromos, vias urbanas, pátios de estacionamento, pisos industriais e docas portuárias. Esta norma apresenta os materiais e os equipamentos utilizados e descreve o procedimento de execução. Os pavimentos executados com pavimentadora de formas deslizantes não estão incluídos na Norma Brasileira. PITTA (1989) apresenta uma prática recomendada para construção de pavimentos de concreto simples, que descreve os métodos de execução com três tipos de equipamentos diferentes:

- Equipamento reduzido;

- Equipamento sobre fôrmas-trilho;

- Equipamento de fôrmas deslizantes.

Segundo SENÇO (1997), os precursores dos pavimentos rígidos foram os ingleses, que iniciaram a sua construção em 1865 . O primeiro pavimento de concreto construído nos Estados Unidos data de 1891 e hoje funciona como calçadão para pedestres. Foi executado na cidade de Bellefontaine, no estado de Ohio. Em diversos países, principalmente Alemanha e Estados Unidos, o pavimento de concreto passou a ter preferência para auto-estradas, antes da Segunda Guerra Mundial. Nessa época a Alemanha tinha cerca de 92\% de suas auto-estradas em concreto. No fim dos anos 50 os Estados Unidos tinham cerca de $89 \%$ das grandes vias urbanas e $79 \%$ das vias rurais pavimentadas com concreto. No Brasil, o primeiro pavimento de concreto foi executado no Caminho do Mar - ligação de São Paulo a Cubatão -, em 1925. Em seguida foi realizada, 
em concreto, a pavimentação da travessia de São Miguel Paulista, da antiga estrada Rio-São Paulo, em 1932.

Diversos fatores podem conduzir à escolha de pavimento rígido. Um exemplo recente é a construção da canaleta de ônibus biarticulados, na cidade de Curitiba, na rua Presidente Faria. Inaugurada em agosto de 1995, os principais fatores que levaram a Secretaria de Obras da cidade a optar pelo pavimento de concreto foram: menor tempo de execução e menor espessura de escavação. Segundo MARQUEÑO (1999) asfalto, seria necessária uma escavação de 1,80 metros, o que poderia prejudicar as fundações dos edifícios da Universidade Federal do Paraná e do Correio Antigo, além de obrigar um remanejamento das redes de luz, água e telefone. Com o pavimento rígido, foi necessário escavar apenas 31 centímetros. A subbase foi executada com 10 centímetros de concreto rolado e o pavimento com 21 centímetros de concreto simples. Foram utilizadas placas de 3,5 por 5 metros e juntas com barras de transferência. $\mathrm{O}$ período de projeto é de 20 anos.

Os pavimentos de concreto simples foram os pavimentos rígidos mais utilizados no Brasil até hoje. A rodovia dos Imigrantes, que liga São Paulo à Baixada Santista (figura 2.2), inaugurada em junho de 1976, é um exemplo de sua aplicação e do bom desempenho desse tipo de pavimento. Segundo ABCP (1998), dos 32 quilômetros executados em pavimento rígido, apenas uma extensão de 35 metros necessitou de reparos, por problemas de drenagem.

A figura 2.3 mostra um trecho da marginal da Via Dutra, em Guarulhos, inaugurado em 1999, onde foi utilizado pavimento de concreto simples.

$\mathrm{Na}$ Alamanha, país com tradição na construção de estradas com pavimento rígido, o concreto de pavimentos antigos é triturado e reutilizado como agregado, na construção de novos pavimentos. Comumente se executa uma camada de aproximadamente 8 centímetros de concreto simples sobre uma camada de cerca de 20 centímetros de concreto reciclado.

${ }^{1}$ MARQUEÑO, Manuela do Amaral (1999). (Secretaria Municipal de Obras Públicas da Prefeitura Municipal de Curitiba). Informação pessoal. 


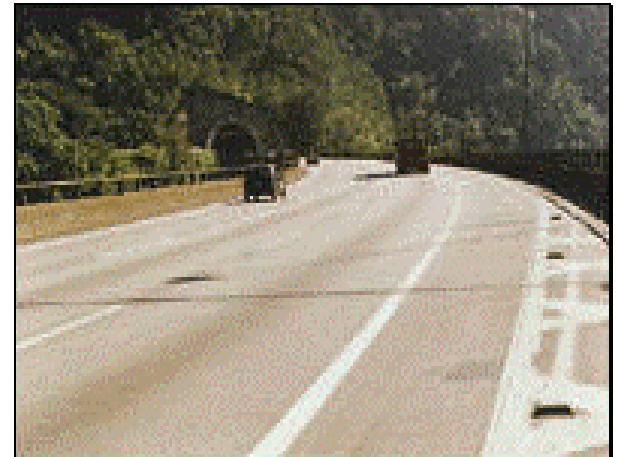

Figura 2.2 - Trecho da Rodovia dos Imigrantes, fonte: http://www.abcp.com.br $(08 / 11 / 1999)$

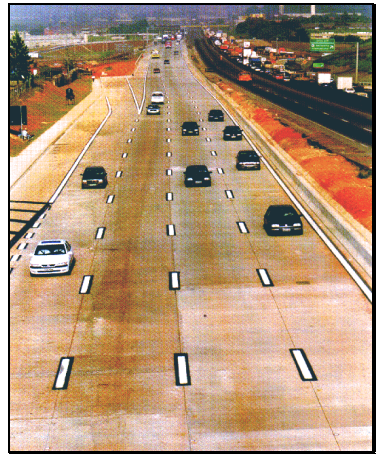

Figura 2.3 - Trecho da Via_Dutra, fonte: $\operatorname{ABCP}(1999)^{2}$

\subsection{PAVIMENTO DE CONCRETO COM ARMADURA DISTRIBUÍDA DESCONTÍNUA}

Este tipo de pavimento é constituído por um conjunto de placas de concreto armado apoiadas sobre a fundação. As placas são dotadas de malhas de aço posicionadas acima do plano médio da seção, mantendo-se ao menos $5 \mathrm{~cm}$ de cobrimento. A armadura tem a função de inibir a propagação de fissuras que ocorrem por efeito das variações de volume devidas à retração por secagem e às mudanças de temperatura. A malha funciona como dispositivo de controle das fissuras, mantendo as faces fortemente ligadas. Com esse tipo de aplicação é possível reduzir consideravelmente o número de juntas. O pavimento de concreto com armadura distribuída descontínua possibilita a execução de placas de até 30 metros de comprimento e mais de 6 metros de largura. É mais usual a construção de placas com cerca de 15 metros de comprimento.

A malha pode ser composta por barras de aço amarradas no local da obra, mas, hoje em dia, é mais comum a aplicação de telas soldadas. Essas telas são armaduras pré-fabricadas, constituídas por fios de aço longitudinais e transversais, sobrepostos e soldados por caldeamento em todos os pontos de cruzamento.

2 ASSOCIAÇÃO BRASILEIRA DE CIMENTO PORTLAND (1999). Via Dutra já está rodando. Cimento Hoje - Informativo da ABCP, v. 3, n. 22, junho de 1999. 
A figura 2.4 ilustra uma seção de pavimento de concreto com armadura distribuída descontínua.

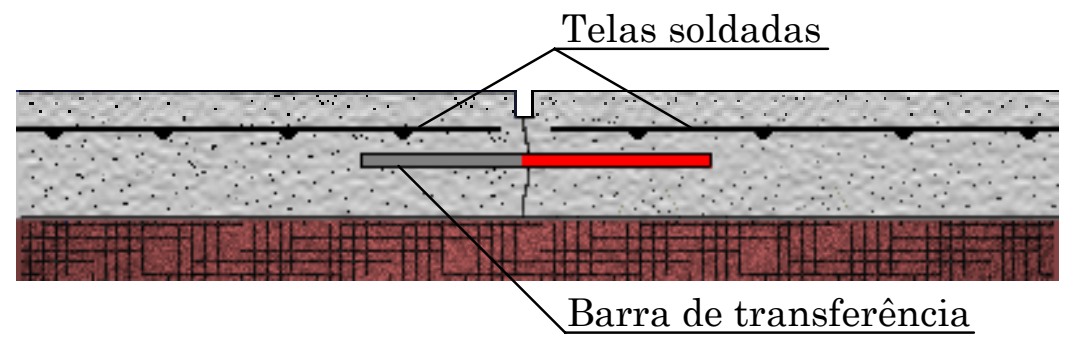

Figura 2.4 - Perfil típico de pavimento de concreto com armadura distribuída descontínua

No Brasil já existem diversas aplicações deste tipo de pavimento. Citam-se alguns exemplos de pisos industriais (GASPARETTO, 1999)

- Santa Marina, em São Paulo, 1985;

- Cofap, em Itajubá - MG, 1985, 1987 e 1992;

- Yakult, em São Bernardo do Campo, 1985;

- Coca-cola, em diversas cidades, desde 1989;

- Volkswagen do Brasil, em São Bernardo do Campo - SP, 1987;

- Kaiser, em várias cidades, a partir de 1990;

- Schincariol, em Itu - SP, 1990 e em Alagoinhas - BA, 1998;

- Cia Siderúrgica de Tubarão, em Tubarão - SP, 1991;

- Brahma, em Jacareí - SP, 1993, em Lajes - SC, 1995, em Estância - SE e em São Paulo, 1998;

- Sansung, em Manaus - AM, 1995;

- Monange, em Barueri - SP, 1997;

- Honda, em Sumaré - SP, 1997;

- Motorola, em São Paulo, 1997;

- Natura, em Cajamar - SP, 1999.

Além de pisos industriais, esse tipo de pavimento também foi utilizado em Hangar no Campo de Marte, em São Paulo, 1997/1998.

3 GASPARETTO, Wagner (1999). (Gerdau Aço para Construção Civil). Informação Pessoal 


\subsection{PAVIMENTO DE CONCRETO CONTINUAMENTE ARMADO}

O pavimento de concreto continuamente armado possui armadura distribuída em toda sua extensão, com o objetivo de ligar fortemente as faces das fissuras, que surgem pelo fato de não serem executadas juntas, a não ser as de construção. A distância entre a armadura e a face superior é de aproximadamente $1 / 3$ da espessura da placa. Assim como no caso dos pavimentos de concreto com armadura distribuída descontínua, o aço tem função de controlar a fissuração devida às variações volumétricas. Este tipo de pavimento apresenta a vantagem de não apresentar juntas transversais e, dependendo do método de execução, também não apresenta juntas longitudinais. São necessárias apenas as juntas de construção, executadas ao término de um ciclo de trabalho, ou quando as faixas de rolamento são construídas separadamente. A figura 2.5 ilustra um perfil de pavimento continuamente armado.

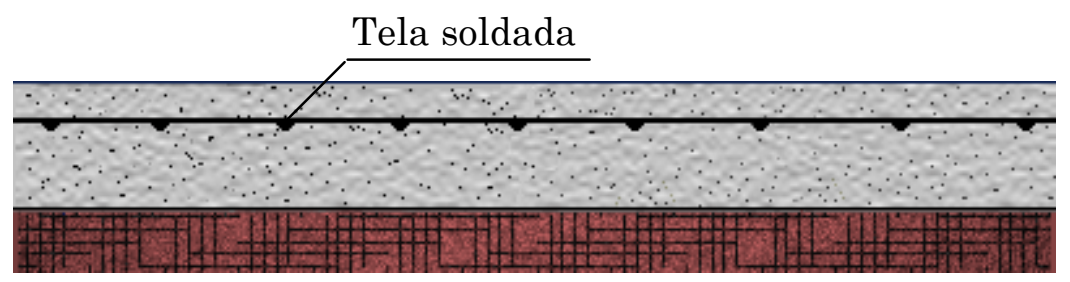

Figura 2.5 - Perfil de pavimento continuamente armado

O pavimento de concreto continuamente armado frequentemente apresenta fissuras de retração regularmente espaçadas. Estas fissuras são fortemente fechadas pela malha de aço.

Este tipo de pavimento nunca foi executado no Brasil, devido ao elevado custo de construção, mas é largamente empregado no Texas (EUA) e também já foi construído em Portugal, na França e na Inglaterra. 


\subsection{PAVIMENTO DE CONCRETO ESTRUTURALMENTE ARMADO}

Este tipo de pavimento de concreto é formado por placas armadas na parte inferior, onde se desenvolvem as maiores tensões de tração. $\mathrm{O}$ aço tem função de resistir a essas tensões, diminuindo, assim, a espessura de concreto. É importante frisar que os pavimentos com armadura distribuída, colocada apenas acima da linha média da seção, não devem ser considerados como sendo de concreto estruturalmente armado, pois a armadura absorve pouco esforço gerado pela ação do carregamento (RODRIGUES e PITTA, 1997). No projeto de um pavimento estruturalmente armado procura-se determinar as posições das diversas tensões atuantes, armando a placa nesses pontos específicos, obtendo assim maior eficiência da estrutura. Os pavimentos de concreto estruturalmente armados têm como principais vantagens, em relação aos pavimentos de concreto simples:

- Redução da espessura de concreto;

- Maior espaçamento entre juntas.

Embora esse tipo de pavimento seja composto por diversas placas, é comum a utilização de dispositivos eficazes de transferência de esforços nas juntas, como no caso das barras de transferência, de modo que se possa considerar, para fins estruturais, como sendo uma placa de grandes dimensões.

O pavimento de concreto estruturalmente armado possui duas malhas de armadura: uma abaixo do plano médio, para resistir à tração provocada pelo momento fletor, e outra acima, para controlar a fissuração por retração. A figura 2.6 ilustra uma seção de pavimento de concreto estruturalmente armado. As placas de concreto estruturalmente armado possuem, em média, 15 metros de comprimento e de 14 a 16 centímetros de espessura.

No Brasil, o primeiro trecho de estrada de concreto estruturalmente armado foi executado pela Cimento Itambé, em 1998, nos 3100 metros da rodovia de acesso à sua fábrica, na região metropolitana de Curitiba. Neste trecho foram empregadas placas de concreto estruturalmente armadas, e placas de concreto simples, executadas sobre camada de concreto compactado a rolo. 
Os pavimentos de concreto estruturalmente armados vêm sendo utilizados com maior frequência, no Brasil, a partir de 1998. Sua maior aplicação tem sido em parques industriais, podendo-se citar:

- Parque industrial da Armafer, no Rio de Janeiro;

- Piso industrial da Ferramentas Gerais, na região metropolitana de Porto Alegre;

- Piso do depósito da Madeireira Herval, em Dois Irmãos, RS.

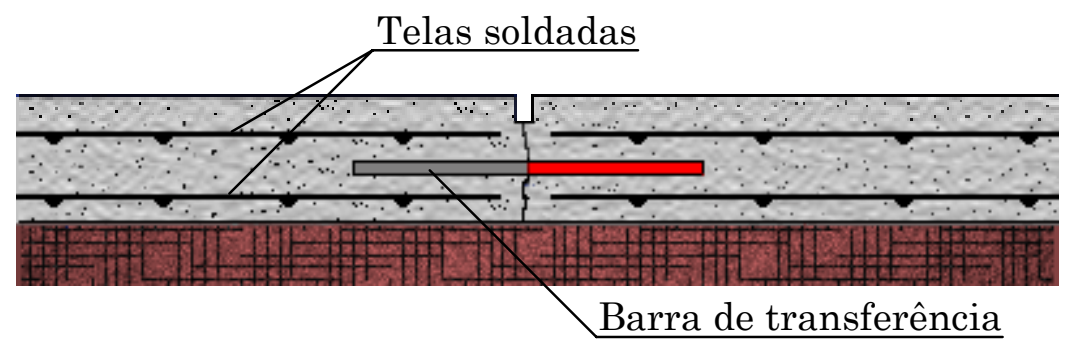

Figura 2.6 - Perfil de um pavimento de concreto estruturalmente armado

Recentemente foi utilizado este tipo de pavimento na construção do pavilhão de exposições Sierra Park, em Gramado, RS. A tecnologia do pavimento de concreto estruturalmente armado também está sendo empregada na construção do "Domo do Milênio", localizado no marco zero do relógio mundial, na península de Greenwich. O "Millenium Dome", construído pelos ingleses, em comemoração à entrada do terceiro milênio, será um centro de negócios e lazer, com $154.000 \mathrm{~m}^{2}$. Estão sendo utilizadas placas de concreto de 15 por 25 metros.

Outra aplicação dos pavimentos de concreto estruturalmente armado são as vias urbanas de grande tráfego. Em Curitiba, foi implantada essa tecnologia, em 1998, no corredor de ônibus da rua Luiz Gasparin. Nesta obra foi utilizada sub-base de 10 centímetros de concreto rolado. A espessura do pavimento é de 14 centímetros. A opção por este tipo de pavimento tem base em fatores como:

- Custo, que depende das condições da obra;

- Limitações de espessura, como por exemplo as devidas às instalações subterrâneas (água, esgoto, drenagem) e à necessidade de concordância com outras vias;

- Qualidade e durabilidade do pavimento;

- Disponibilidade dos materiais. 


\subsection{PAVIMENTO DE CONCRETO ROLADO}

O concreto rolado ou CCR - Concreto Compactado a Rolo constitui um material seco, de consistência dura, com baixo consumo de cimento, de trabalhabilidade tal que possa ser compactado com rolos compressores. O teor de cimento é muito menor que nos concretos tradicionais, portanto é mais econômico. Associando o baixo consumo de cimento à pouca quantidade de água, consegue-se reduzir consideravelmente a retração.

A resistência do CCR à tração na flexão é de 2 a 4 vezes maior que a do solo-cimento e, aproximadamente, 2 vezes menor que a do concreto simples.

As principais aplicações do concreto compactado a rolo, no Brasil, são a pavimentação e a construção de barragens. Na pavimentação, o CCR pode ser aplicado como camada de rolamento, base revestida com concreto asfáltico ou sub-base para pavimentos rígidos.

A maioria dos concretos rolados atuais tem teor de cimento entre 1:12 e 1:24. As misturas mais ricas podem apresentar fissuras e trincas e os teores mais baixos, normalmente, acarretam em heterogeneidade da mistura do cimento com o agregado, criando pontos de enfraquecimento.

Conforme o Manual de pavimentos de concreto rolado, do DNER (1992), a primeira notícia histórica do uso de um material semelhante ao atual CCR é datada de 1891. A camada inferior do pavimento da cidade de Bellefontaine foi executada com concreto de baixo consumo de cimento e compactado por compressão. Modernamente, a experiência com o CCR aplicado à pavimentação teve início na Grã-Bretanha, por volta de 1944. O Manual do DNER (1992) cita como exemplos de aplicação as estradas de Crawley, com $70 \mathrm{~km}$, e a Londres-Birmingham, com 100km, executadas entre 1940 e 1944. Em 1910, em Grand Forks, Dakota do Norte, EUA, foram construídas vias urbanas com tecnologia semelhante. Em 1950, a rodovia US 441 foi construída como pista experimental em concreto rolado, no estado da Flórida, EUA. Ainda na década de 50 foram construídas diversas rodovias com essa tecnologia, nos estados do Texas, Carolina do Sul e outros, nos Estados Unidos, conforme apresentado no manual do DNER (1992). Este manual cita ainda que, no Brasil, foram construídas ruas em Porto Alegre, com CCR como base para pavimentos 
asfálticos, desde 1972. Também foi utilizado o concreto rolado, em diversas aplicações para pavimentos, em Pelotas/RS e em Salvador/BA. Em Santa Catarina, a SC-438, estrada da Serra do Rio do Rastro, foi construída com subbase de concreto rolado e pavimento de concreto simples. Também como subbase de pavimento de concreto simples, foi utilizado o CCR na duplicação da SP55, trecho Cubatão-Pedro Taques, em São Paulo. Entre 1986 e 1990 foram construídos diversos trechos experimentais em concreto rolado, na Argentina, Chile, Uruguai, África do Sul e outros.

\subsection{PAVIMENTO DE CONCRETO COM FIBRAS}

Este tipo de pavimento é composto de placas de concreto com adição de fibras. O concreto reforçado com fibras é um material relativamente recente, que tem sido muito estudado nas duas últimas décadas. Já foi comprovado que, em diversos aspectos, apresenta características superiores às do concreto simples. O concreto com fibras de aço ou outro tipo de fibra apresenta maior resistência a fissuração, impacto e desgaste, além de possuir maior ductilidade. Por essas razões o concreto com fibras está sendo cada vez mais utilizado em estruturas como: pavimentos de aeroportos, pavimentos de auto-estradas, leito de pontes, pisos industriais, estruturas de suporte de máquinas, dormentes e tanques de estocagem. A figura 2.7 ilustra uma placa de concreto com fibras de aço.

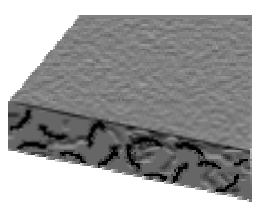

Figura 2.7 - Seção de pavimento de concreto com fibras de aço ${ }^{\square}$

Apesar da crescente utilização do concreto reforçado com fibras e sua aplicação em estruturas submetidas a carregamento cíclico e dinâmico, o comportamento desse material à fadiga ainda não foi vastamente estudado.

${ }^{4}$ DRAMIX (1999). Fibras de aço para pisos industriais. Hortolândia - SP. /folder/ 
ZHANG e STANG (1998) realizaram um estudo experimental com vigas de concreto com fibras de aço e de polipropileno, sujeitas a carregamento cíclico de amplitude constante, e concluíram que há uma melhora no comportamento à fadiga na flexão, para número de ciclos inferior a 1 milhão (limite do ensaio), nos concretos adicionados com 1 a $2 \%$ de fibras de aço. Verificou-se ainda que a utilização de fibras de polipropileno juntamente com as fibras de aço tem pouca influência no comportamento do concreto à fadiga. Utilizando emissão acústica, verificaram que o dano, na ruína, para concretos com fibras de aço, tanto para carregamento cíclico quanto para carregamento monotônico, é da ordem de duas vezes maior, se comparado com vigas de concreto simples. Verificou-se que o deslocamento por flexão, para vigas submetidas a fadiga, pode ser estimado através da curva obtida em ensaios estáticos, ou seja, o deslocamento máximo para carregamento cíclico é o mesmo que para carregamento estático. Apesar do deslocamento ser similar nesses dois estados, o dano acumulado é muito diferente.

CARNIO (1998) afirma que a adição das fibras de aço ao concreto tem por finalidade inibir a abertura das fissuras, bem como a sua propagação, e que, devido a esse controle de fissuração, o material apresenta capacidade de se deformar absorvendo esforço, característica esta de material com ductilidade. Portanto, nos elementos estruturais que apresentem possibilidade de redistribuição de esforços, como no caso de estruturas que têm interface com meio elástico (pisos, pavimentos, revestimentos de túneis e de taludes), é possível o uso das fibras em substituição às armaduras de flexão.

Quando se faz um dimensionamento considerando apenas o comportamento elástico do material, obtém-se um ganho qualitativo: o controle da fissuração; mas, de acordo com CARNIO (1998), estendendo a análise, considerando o comportamento plástico do concreto com fibras, é possível aproveitar sua ductilidade e obter também um ganho quantitativo: a redução da espessura. 


\subsection{PAVIMENTO DE CONCRETO PROTENDIDO}

O pavimento de concreto protendido é utilizado, principalmente, quando há tráfego pesado. Sua maior aplicação são as pistas e os pátios de aeroportos. Já foi utilizado em diversos aeródromos, tanto no Brasil quanto no exterior.

Segundo SCHIMD (1996), no pavimento rígido de concreto protendido, a resistência do concreto à tração é controlada pela protensão que comprime previamente o concreto, criando nele uma reserva de tensão que permite uma redução sensível na espessura da placa. A placa comprimida é praticamente impermeável e sem trincas. Os pavimentos de concreto protendido apresentam ainda a vantagem das juntas poderem ser espaçadas de até 150 metros, porém a execução é mais sofisticada.

Os primeiros pavimentos construídos com concreto protendido, na Europa e nos Estados Unidos, datam de 1945. Na década de 60, essa solução foi utilizada na construção de pisos industriais, na Austrália. Como exemplo brasileiro pode ser citada uma das pistas do Aeroporto Internacional do Galeão, no Rio de Janeiro, que foi construída com a tecnologia da pós-tensão. O pátio de estacionamento de aviões do aeroporto Afonso Pena, na região metropolitana de Curitiba, reinaugurado em julho de 1996, é um exemplo recente de aplicação deste tipo de pavimento. Nesta obra foram concretadas e protendidas placas de 20 centímetros de espessura.

\subsection{WHITETOPPING}

O whitetopping é uma solução para reabilitação de pavimentos asfálticos já existentes. Constitui na construção de pavimento de concreto apoiado sobre o asfalto antigo. Normalmente o whitetopping é construído em concreto simples, mas podem ser utilizadas qualquer uma das alternativas anteriores. A espessura usual de whitetopping varia entre 12 e 15 centímetros. 
O primeiro whitetopping foi construído em Terre Haute, Indiana, em 1918. Grande parte da tecnologia moderna do whitetopping foi desenvolvida no estado de Iowa, nos Estados Unidos, onde mais de $480 \mathrm{~km}$ de asfalto já foram sobrepostos com pavimento de concreto, desde 1960. A partir de 1977, esta tecnologia passou a ser utilizada com frequência, nesse país. Com o advento dos cimentos de cura acelerada e de alta resistência inicial, tornou-se ainda mais vantajoso, pois é possível a liberação do tráfego até 18 horas depois da concretagem. No Brasil, onde grande parte da malha viária é pavimentada com asfalto e apresenta sérios problemas de manutenção, o whitetopping pode vir a melhorar este panorama, aumentando a qualidade dos pavimentos e diminuindo os ciclos de manutenção. A figura 2.8 ilustra o perfil de um whitetopping.

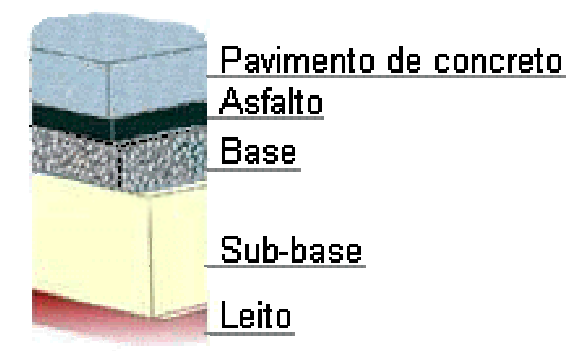

Figura 2.8 - Perfil de whitetopping

Perante o grande número de estradas asfaltadas, que necessitam de trabalhos de recuperação, o emprego do whitetopping, no Brasil, ainda é muito modesto. Um exemplo de utilização é um dos túneis da rodovia Carvalho Pinto, em São Paulo.

Em fase experimental, em todo mundo, mas com algumas obras já bem sucedidas, o "ultrathin whitetopping", ou whitetopping ultradelgado, é uma variação do whitetopping comum. Executado em concreto de alta resistência, permite a construção de placas de 5 a 10 centímetros de espessura. A fim de evitar a fissuração por retração, as juntas são menos espaçadas. Portanto, as placas possuem dimensões entre 60 e 180 centímetros. A abertura das juntas também é reduzida, e, normalmente, não é necessário o material selante. A figura 2.9 mostra um exemplo de whitetopping ultradelgado. 


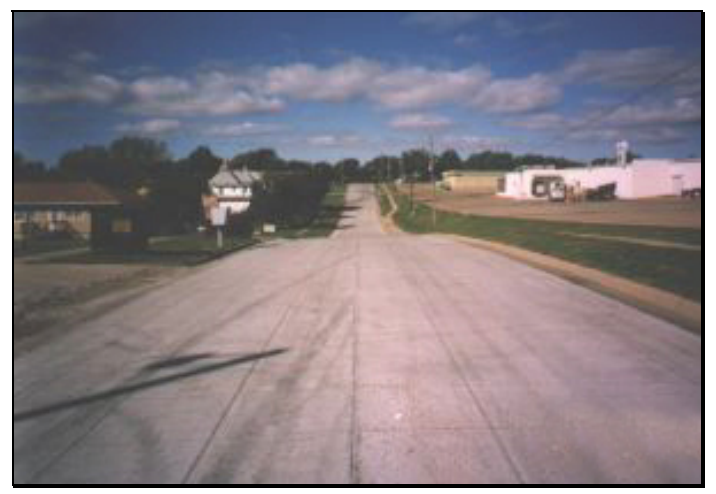

Figura 2.9 - Exemplo de whitetopping ultradelgado

O whitetopping ultradelgado é indicado para quando não houver deterioração da base do pavimento existente, pois, no dimensionamento, é considerada aderência entre as placas de concreto e o pavimento antigo. As placas devem estar submetidas apenas a esforços de compressão. É executado com os equipamentos tradicionais, e também pode ser liberado ao tráfego em menos de 24 horas.

\subsection{CONSIDERAÇÕES GERAIS}

Neste capítulo foram apresentadas características dos principais tipos de pavimentos rígidos. O conhecimento de cada um deles, quanto aos materiais empregados, aos equipamentos necessários, ao tempo e à tecnologia de execução, associado a um cálculo adequado, fornece subsídios para uma melhor decisão de projeto, alcançando a qualidade técnica, a durabilidade e a economia desejada, dentro da disponibilidade de equipamentos, de materiais e de mão-deobra na região, e respeitando os fatores limitantes, como por exemplo a espessura máxima.

\footnotetext{
5 http://www.moksacpa.com/concrete.html - (19/02/1999)
} 


\section{Capítulo}

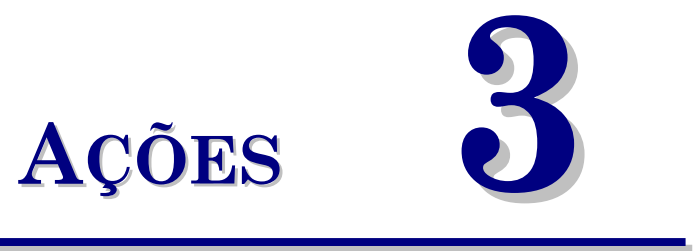

Os pavimentos de concreto são submetidos a ações diretas e indiretas. As ações diretas constituem-se de forças ou pressões aplicadas à estrutura. As ações indiretas são causadas por deformações impostas às placas. No caso dos pavimentos de concreto, as ações indiretas são:

- retração;

- dilatação térmica;

- empenamento.

As ações diretas são as forças impostas à estrutura pelo tráfego de veículos, ou pelo carregamento distribuído e concentrado aplicado em pisos, que variam conforme a finalidade do pavimento.

Neste capítulo são relacionadas as principais ações diretas e indiretas que solicitam os pavimentos. Procura-se dar uma visão geral sobre os tipos de ações em rodovias, vias urbanas e pisos industriais. São tratados os problemas da retração, da dilatação térmica, das variações volumétricas devidas a alterações de temperatura e do empenamento provocado pelo gradiente de temperatura na espessura das placas.

\subsection{AÇÕES DIRETAS}

Podem ser móveis, devidas aos veículos, distribuídas, como as decorrentes de material estocado, ou concentradas, como nos montantes de prateleiras. 


\subsubsection{Ações móveis}

Nos pavimentos, não só o valor das ações, mas também o número de repetições, a velocidade de circulação dos veículos e a posição na placa influenciam os esforços gerados na estrutura. As solicitações móveis que atuam em pavimentos rodoviários, urbanos e industriais, são, por natureza, transientes, ou seja, de curta duração. Embora o intervalo entre as forças seja um fator que melhore a resistência do material, o fato dessas forças atuarem repetidamente provoca o fenômeno da fadiga, que pode romper uma estrutura submetida a tensões abaixo da tensão limite. A fadiga é tratada com mais detalhes no capítulo 5, deste trabalho.

Verifica-se que as faixas de pavimentos correspondentes às rampas apresentam mais defeitos que as de contra-rampa, o que é atribuído à maior velocidade dos veículos na descida. Quanto maior a velocidade do veículo menores são as tensões geradas. Segundo SOUZA (1980), esse efeito começa a se estabilizar a partir de velocidades da ordem de $60 \mathrm{~km} / \mathrm{h}$. Outro efeito, assim como a velocidade dos veículos, que normalmente é desprezado no dimensionamento de pavimentos rodoviários é o abaulamento da pista de rolamento, que faz com que o eixo externo do veículo seja mais carregado que o eixo interno.

SOUZA (1980) indica um coeficiente de majoração das ações de 1,2, com a finalidade de levar em conta o impacto que as ações móveis exercem sobre um pavimento rígido. Hoje em dia esse efeito é desprezado devido à verificação de que as ações móveis provocam esforços inferiores às solicitações estáticas, o que chega a compensar o aumento das tensões provocado pelo impacto.

Um fator importante no dimensionamento de pavimentos é o número de solicitações em uma determinada área. Visto que nem todos os veículos trafegam na mesma posição, não é necessário considerar que o ponto mais crítico do pavimento será solicitado pelo número total de repetições de força. Trabalhos estatísticos têm determinado a porcentagem de veículos que trafegam em cada posição do pavimento. 
a. Área de contato do pneu

Para uma mesma força, áreas de aplicações diferentes geram esforços diferentes nas placas de concreto. Segundo SOUZA (1980), a área de contato entre um pneu carregado e um pavimento é aproximadamente elíptica, para pneumáticos novos com pressão de enchimento e peso máximo recomendado; para pneumáticos usados e com pesos além do máximo recomendado, a área de contato é aproximadamente retangular. A partir da força por roda e da pressão nos pneus é determinada a área de contato pneu-placa. A área é obtida, segundo SOUZA (1980), pela expressão:

$\mathrm{A}=\frac{\mathrm{P}_{\mathrm{r}}}{\mathrm{k}_{\mathrm{r}} \cdot \mathrm{q}}$

sendo:

- A: área de contato entre o pneu e o pavimento;

- Pr: peso atuante em uma roda;

- $\mathrm{k}_{\mathrm{r}}$ : fator que leva em conta a rigidez do pneumático, variando de 1 a 3 ;

- q: pressão de enchimento dos pneus.

A fim de simplificar o problema, podem ser adotadas áreas circulares. As dimensões do pneu, no caso de consideração de área circular, são dadas por (SOUZA, 1980):

$a=\sqrt{\frac{\mathrm{A}}{\pi}}$

sendo:

- a: raio de contato de um pneu;

- A: área circular de contato de um pneu.

Para consideração de área circular, no caso de roda dupla, o raio é determinado por (SOUZA, 1980): 
$\mathrm{a}_{\mathrm{d}}=2,5 \cdot \mathrm{a}$

sendo:

- ad: raio da área circular de contato de roda dupla;

- a: raio da área de contato de cada pneu.

As dimensões da área de contato do pneu, no caso de consideração de falsa elipse, composta por retângulo e semi-círculos, são dadas por (YODER \& WITCZAK, 1975):

$$
\begin{aligned}
& \mathrm{c}=\sqrt{\frac{\mathrm{A}}{0,5227}} \\
& \mathrm{~b}=0,6 \cdot \mathrm{c}
\end{aligned}
$$

As dimensões c e b estão indicadas na figura 3.1.

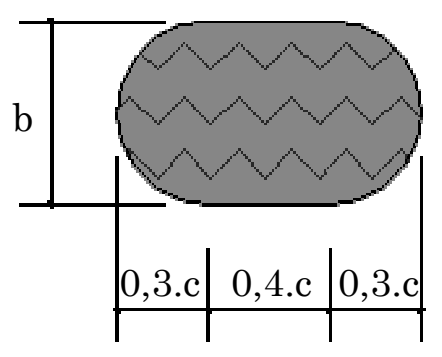

Figura 3.1 - Dimensões da área de contato entre o pneu e a placa de concreto

Neste trabalho serão realizadas análises com área retangular, adotando:

$$
\begin{aligned}
& \mathrm{c}=\sqrt{\frac{\mathrm{A}}{0,65}} \\
& \mathrm{~b}=\frac{\mathrm{A}}{\mathrm{c}}
\end{aligned}
$$

sendo: 
- c: comprimento da área de contato;

- b: largura da área de contato.

Através de análise numérica observou-se que a variação dos esforços, para força aplicada em área circular, retangular ou formada por retângulo e semi-círculos é inferior a 5\%. A análise foi realizada com auxílio do programa Ansys 5.5, versão universitária. Foram analisadas placas isoladas com espessuras de 10, 15, 20 e 25 centímetros, apoiadas sob base elástica, com $k$ igual a $50 \mathrm{MPa} / \mathrm{m}$. As forças foram posicionadas na borda, no interior, no canto e tangente à junta.

$\mathrm{Na}$ figura 3.2 é mostrada a distribuição dos esforços para força de $70,56 \mathrm{kN}$, no interior da placa de 10 centímetros de espessura.

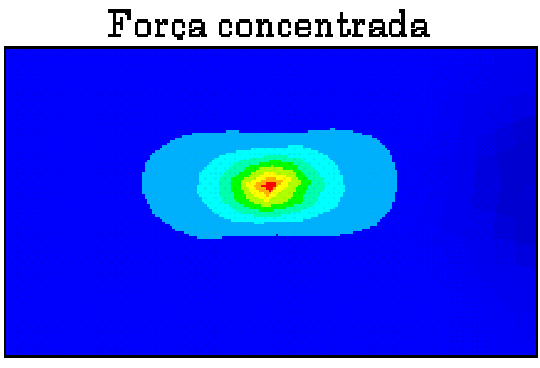

Area circular

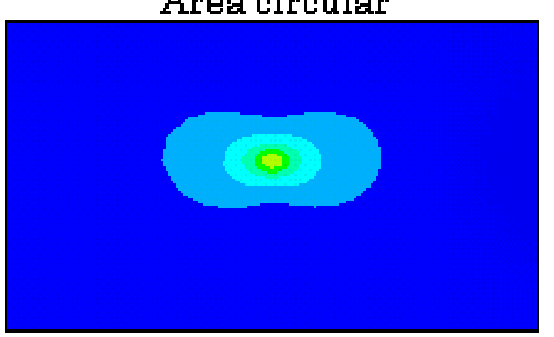

Area retangular

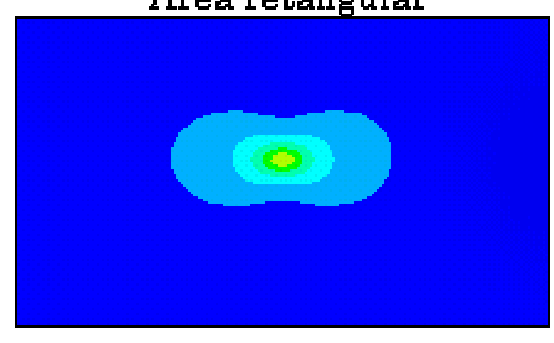

Retângulo e semi-círoulos

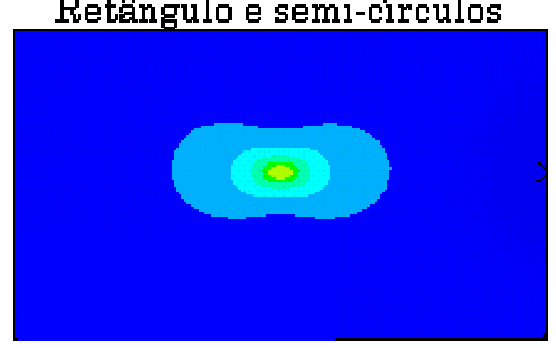

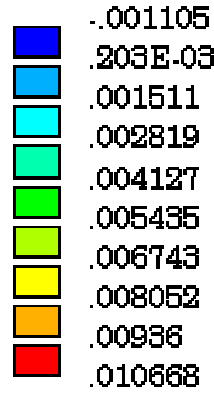

Figura 3.2 - Momento fletor, na direção x, para força de 70,56 kN, aplicada no interior da placa de $10 \mathrm{~cm}$ de espessura.

Verifica-se que a adoção de qualquer uma das configurações de área implica em pequena diferença nos esforços. A força concentrada provoca esforços cerca de 50\% maiores que as forças distribuídas, portanto essa hipótese seria muito conservadora e não é recomendada. 
b. Ações móveis em rodovias

Nas rodovias, circulam diversos tipos de veículos, desde motocicletas, com algumas dezenas de quilos, e carros de passeio com algumas centenas, até carretas que podem chegar a 50 toneladas. Para fins de dimensionamento estrutural, normalmente são desconsiderados os carros de passeio e as motocicletas, pois possuem peso muito inferior aos veículos de carga e de transporte coletivo. Verifica-se que, em rodovias de concreto dimensionadas para a passagem de veículos comerciais, é permitido um número infinito de repetições de veículos leves, com dano estrutural desprezível ao pavimento.

Dois veículos com o mesmo peso, mas com eixos de formas distintas, dão origem a diferentes esforços na placa de concreto. Os veículos rodoviários podem ter eixos de rodagem simples ou dupla, sendo os mais comuns:

- eixo simples de rodagem simples;

- eixo simples de rodagem dupla;

- eixo tandem duplo;

- eixo tandem triplo.

Na figura 3.3 é mostrado um veículo rodoviário com um eixo simples de rodagem simples (eixo de direção), um eixo simples de rodagem dupla e um eixo tandem triplo. $\mathrm{O}$ veículo da figura 3.4 possui, além do eixo de direção, eixo tandem duplo. A figura 3.5 mostra um tipo de chassi de ônibus rodoviário, com um eixo simples de rodagem simples e um eixo simples de rodagem dupla.

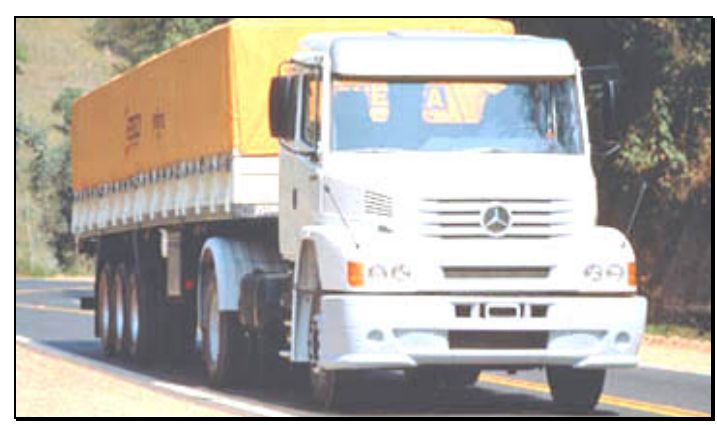

Figura 3.3 - Veículo rodoviário com eixos simples e tandem triplo

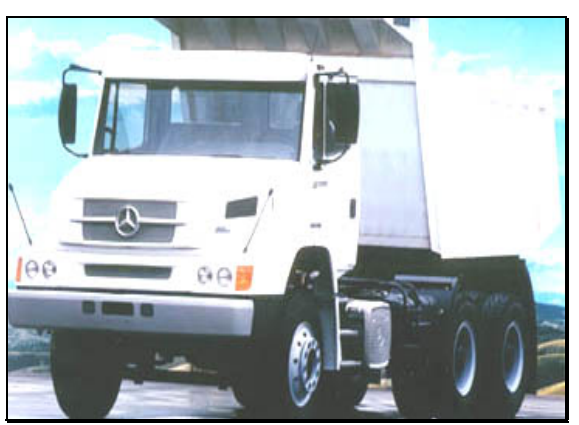

Figura 3.4 - Veículo rodovjário com eixo tandem duplo

\footnotetext{
1 fonte: http://www.mercedes-benz.com.br/veiculos_comerciais/caminhoes/extrapesados_ls1632.htm (31/05/99)
} 


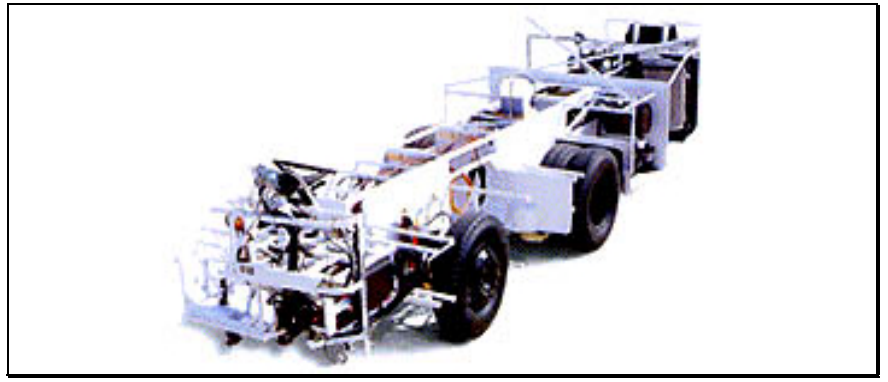

Figura 3.5 - Chassi de ônibus rodoviário

As dimensões dos eixos rodoviários estão esquematizadas nas figuras

3.6 a 3.9 .

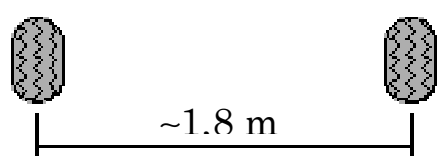

Figura 3.6 - Eixo simples de rodagem simples

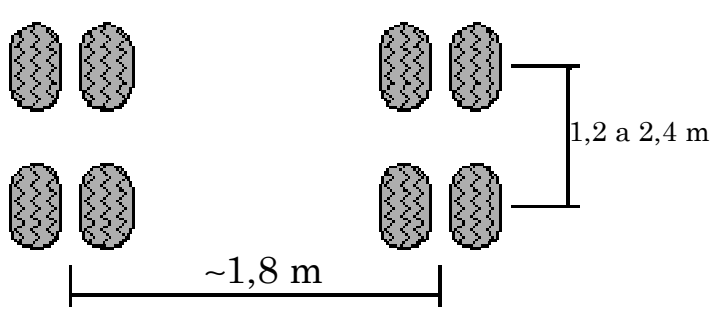

Figura 3.8 - Eixo tandem duplo

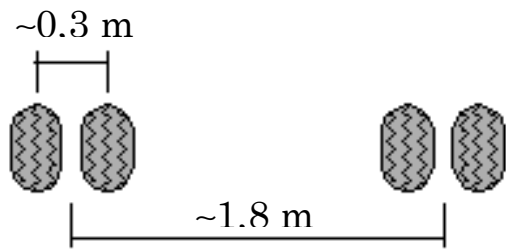

Figura 3.7 - Eixo simples de rodagem dupla

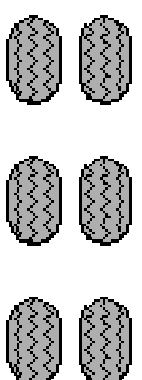

\section{$\sim 1,8 \mathrm{~m}$}

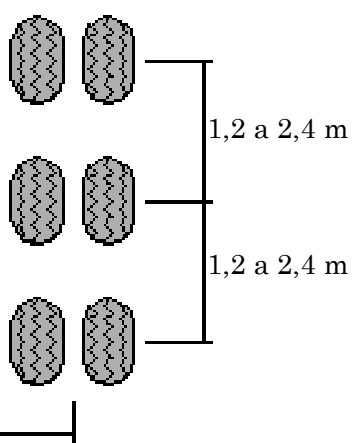

Figura 3.9 - Eixo tandem triplo

\section{c. Ações móveis em vias urbanas}

Em vias urbanas, a diversidade de veículos é menor que nas rodovias, sendo mais importantes os ônibus, destinados ao transporte coletivo. Algumas

\footnotetext{
2 fonte: http://www.mercedes-benz.com.br/veiculos_comerciais/caminhoes/extrapesados_ls2638.htm (31/05/99)

3 fonte: http://www.mercedes-benz.com.br/veiculos_comerciais/onibus/rodoviario_o400rse.htm (31/05/99)
} 
vias podem ser projetadas para veículos especiais. A figura 3.10 mostra um chassi de ônibus urbano, fabricado pela Mercedes Benz.

Algumas cidades como Curitiba e São Paulo desenvolveram projetos de vias exclusivas para ônibus articulados e biarticulados. Um exemplo de chassi de ônibus articulado está mostrado na figura 3.11. A figura 3.12 apresenta uma vista de ônibus biarticulados da cidade de Curitiba.

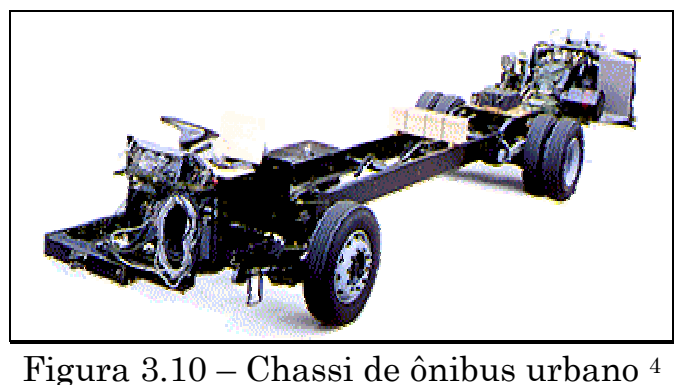

Figura 3.10 - Chassi de ônibus urbano

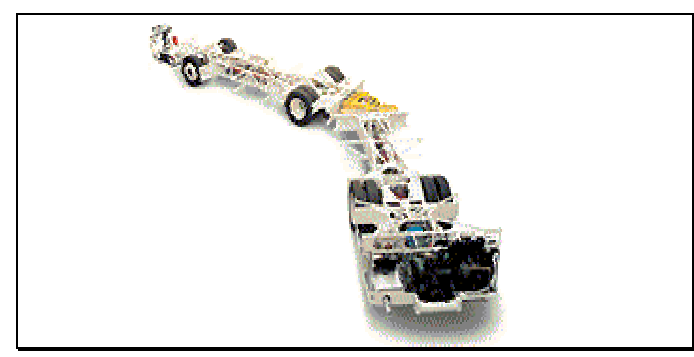

Figura 3.11 - Chassi de ônibus urbano articulado

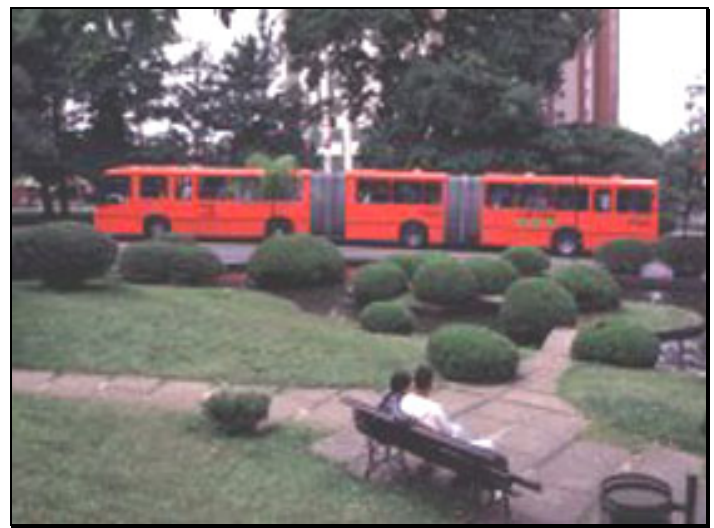

Figura 3.12 - Biarticulado

d. Ações móveis em pisos industriais

As ações móveis que solicitam os pisos industriais normalmente são as empilhadeiras, que, segundo RODRIGUES e CASSARO (1998), pela sua

\footnotetext{
4 fonte: http://www.mercedes-benz.com.br/veiculos_comerciais/onibus/urbano_oh16281.htm (31/05/99)

${ }^{5}$ fonte: http://www.mercedes-benz.com.br/veiculos_comerciais/onibus/urbano_o400upa.htm (31/05/99)

6 fonte: http://www.curitiba.pr.gov.br/solucoes/transporte/index.html (08/06/99)
} 
frequência de solicitação e pesos por eixo, acabam por superar as solicitações de eventual trânsito de caminhões. No instante de carga máxima, quase todo peso está concentrado no eixo dianteiro, sendo o eixo traseiro considerado apenas como direcional. Além dos pneumáticos, algumas empilhadeiras possuem rodas rígidas. Nesse caso pode-se utilizar a aproximação de elevada pressão de enchimento. RODRIGUES e CASSARO (1998) citam o valor de 1,75 MPa.

As empilhadeiras podem ser de rodagem simples ou dupla. As figuras 3.13 e 3.14 ilustram os dois tipos de eixos de empilhadeiras industriais.

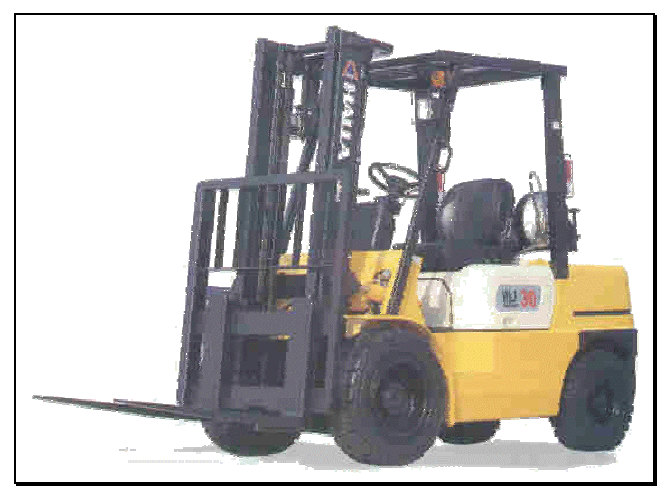

Figura 3.13 - Empilhadeira industrial de rodagem simples

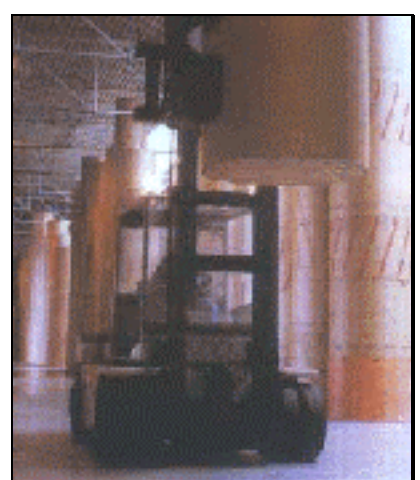

Figura 3.14 - Empilhadeiraindustrial de rodagem dupla

As figuras 3.15 e 3.16 indicam as dimensões dos eixos de empilhadeiras de rodagem simples e de rodagem dupla, respectivamente.

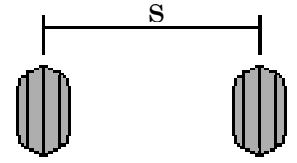

Figura 3.15 - Eixo de empilhadeira de rodagem simples

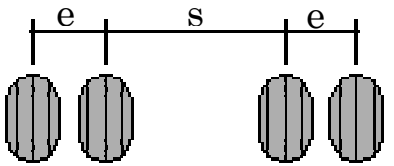

Figura 3.16 - Eixo de empilhadeira de rodagem dupla

O comprimento, $s$, varia em torno de 1 metro e o espaçamento, $e$, é de aproximadamente 40 centímetros.

\footnotetext{
7 fonte: http://www.nordeste distribuidora.he.com.br/hlfhgf/hlfhgf.htm (25/05/99)

8 fonte: http://www.nordeste distribuidora.he.com.br/hlfhgf/hlfhgf.htm (25/05/99)
} 


\subsubsection{Carregamento distribuído}

Em indústrias é bastante comum existirem forças distribuídas, devidas a material estocado, entre os quais existem corredores de circulação. Um exemplo de configuração desse tipo de carregamento está mostrado na figura 3.17. O esforço máximo gerado por esse tipo de carregamento é um momento fletor que traciona a face superior da placa na área do corredor.

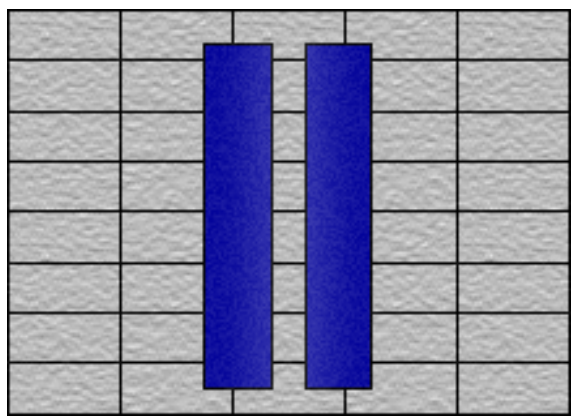

Figura 3.17 - Corredor de circulação entre forças uniformemente distribuídas, em planta

\subsubsection{Forças concentradas}

Os montantes de prateleiras aplicam forças distribuídas em pequenas áreas, que, por estarem próximas, produzem efeitos superpostos. Esse tipo de carregamento gera momento fletor, que traciona a face inferior do pavimento, e força cortante, que tende a puncionar a placa de concreto. Para o dimensionamento é importante conhecer a área dos apoios e as distâncias entre eles. A figura 3.18 ilustra uma configuração de prateleira industrial.

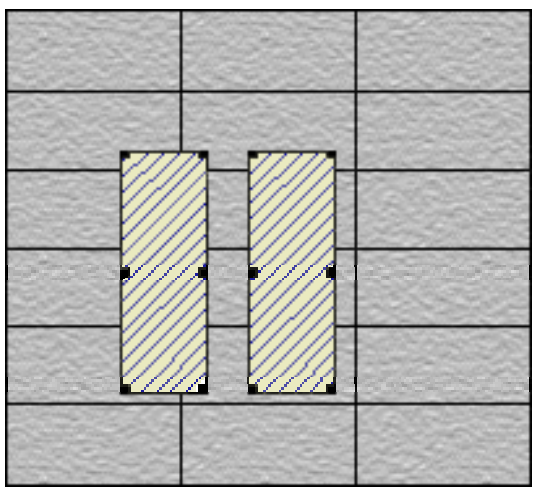

Figura 3.18 - Montantes de prateleiras industriais 


\subsection{AÇÕES INDIRETAS}

Como já foi visto, as ações indiretas são: retração, dilatação térmica e empenamento.

\subsubsection{Retração}

A retração é um fenômeno de redução de dimensões que ocorre em peças de concreto devido à perda de água - retração por secagem -, devido à redução de volume dos produtos de hidratação - retração autógena -, ou ainda por retração plástica, que ocorre antes da pega. No caso dos pavimentos, a retração por secagem é mais significativa, pois nesse tipo de estrutura existe uma grande área exposta ao ar, por onde ocorre a troca de umidade com o meio. A retração é um fenômeno atribuído à peça, pois depende, além das características físicas do material, da geometria da estrutura: volume e área. $\mathrm{O}$ clima também influencia na retração, que aumenta com a redução da umidade do ar, com o crescimento da temperatura e com uma maior incidência de ventos. A retração por secagem só ocorre quando a umidade relativa do ar é inferior a $100 \%$.

A importância da retração nas estruturas está associada à fissuração. O aparecimento de fissuras não depende apenas do valor da retração, mas também da deformabilidade do concreto, da sua resistência e do grau de restrição à deformação. A fim de se reduzir a fissuração por retração utilizam-se os procedimentos de cura, evitando a perda de água para o ar, nas primeiras idades do concreto. Se não for realizada uma cura adequada o material pode retrair antes de atingir a resistência mínima para resistir aos esforços introduzidos pelo fenômeno. Outra maneira de evitar a fissuração é restringir as dimensões da peça para que a deformação atinja, no máximo, um valor que introduza tensões inferiores à capacidade do material.

Se a retração fosse livre, não haveriam esforços, apenas redução de volume, porém, o atrito entre o pavimento e a sub-base impede a deformação, induzindo tensões de tração nas placas do pavimento. A peça de concreto tende 
a se deformar no sentido das bordas para o centro. $O$ atrito impede esse deslocamento, introduzindo um esforço na direção contrária. A figura 3.19, ilustra esse mecanismo.

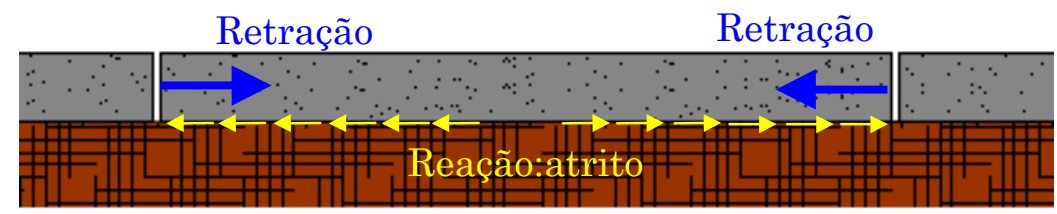

Figura 3.19 - Reação à tendência de retração da placa de concreto

O valor da força de reação à retração é dada por:

$\mathrm{F}_{\mathrm{ret}}=\mathrm{E} \cdot \mathrm{B} \cdot \mathrm{h} \cdot \varepsilon_{\mathrm{cc}}$

sendo:

- $\mathrm{F}_{\text {ret }}$ - força devida à retração impedida;

- E - módulo de elasticidade do concreto;

- B - largura da placa, normalmente adotada igual a 1 (um), determinando-se a força por unidade de largura;

- h-espessura da placa;

- $\varepsilon_{\mathrm{cc}}$ - valor da retração, determinado em função da umidade relativa do ar, da consistência do concreto e da geometria da peça, segundo Revisão da NB-1 (1999).

A máxima força de atrito que a sub-base pode introduzir na placa é dada por:

$\mathrm{F}_{\mathrm{at}, \max }=\mu \cdot \mathrm{N}$

sendo:

- $\mathrm{F}_{\mathrm{at}, \mathrm{max}}$ - força de atrito máxima;

- $\mu$ - coeficiente de atrito entre a placa e a sub-base (tabela A.1, anexo A);

- $\mathrm{N}$ - força normal - para estrutura descarregada equivale ao peso de metade da placa. 
A partir do valor de $\mathrm{F}_{\text {at,max }}$ há deslocamento de pontos da face inferior da placa, não havendo acréscimo na força resultante.

\subsubsection{Dilatação térmica}

A dilatação térmica é um fenômeno semelhante à retração, pois se caracteriza por variações de volume. Nesse caso, as mudanças nas dimensões da peça são causadas por variações de temperatura. Quando há um acréscimo na temperatura, a placa tende a aumentar de volume, sofrendo uma ação contrária de compressão devida ao atrito, ao passo que, quando há uma queda na temperatura, ela tende a se retrair, sendo tracionada pela força de atrito.

Caso a reação decorrente da dilatação ou da retração não exceda a força de atrito máximo, a força resultante é dada por:

$\mathrm{F}_{\Delta \mathrm{T}}=\mathrm{E} \cdot \mathrm{B} \cdot \mathrm{h} \cdot \alpha \cdot \Delta \mathrm{t}$

sendo:

- $\mathrm{F}_{\Delta \mathrm{T}}$ - força devida à variação de comprimento impedida;

- $\alpha$-coeficiente de dilatação térmica do concreto;

- $\Delta \mathrm{t}$ - variação de temperatura.

\subsubsection{Empenamento}

O empenamento é uma alteração que tende a ocorrer na forma das placas do pavimento, devida ao gradiente de temperatura na sua espessura. Durante o dia, o sol aquece a face superior do pavimento numa velocidade maior que as camadas inferiores, portanto a fibra externa tende a se dilatar mais que as internas, buscando a configuração da figura 3.20. Durante a noite a placa vai perdendo o calor absorvido. A fibra superior alcança a temperatura mais baixa, antes das demais, e tenta se retrair, provocando a tendência de configuração ilustrada na figura 3.21 . 


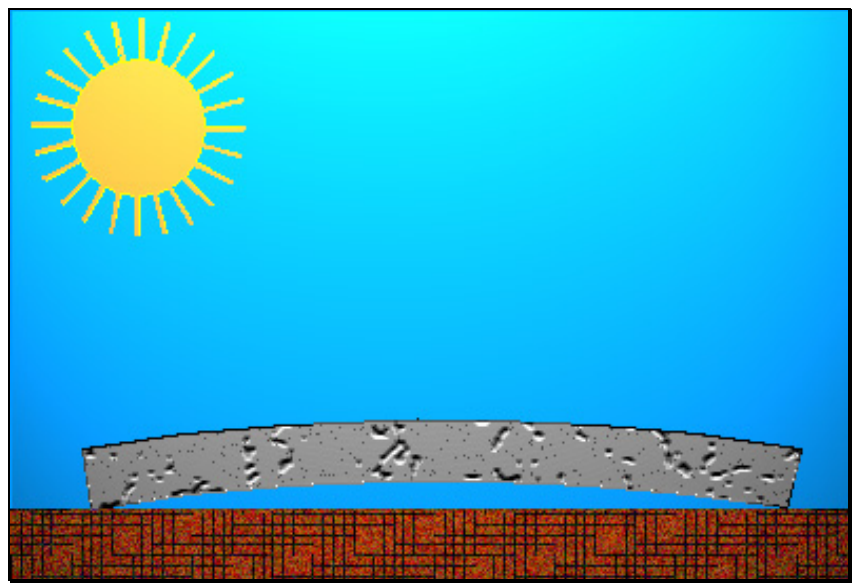

Figura 3.20 - Tendência de empenamento das placas de concreto, durante o dia

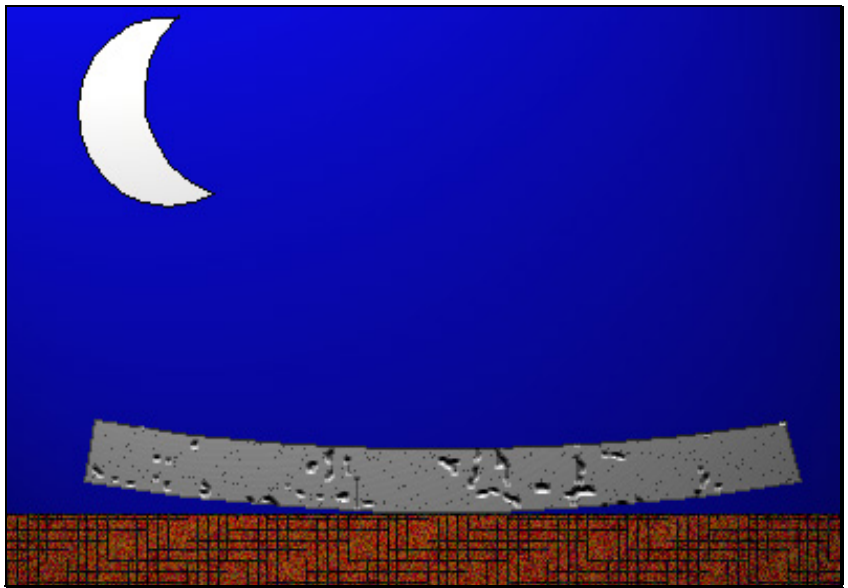

Figura 3.21 - Tendência de empenamento das placas de concreto, durante a noite

O impedimento de que essas deformações ocorram, devido ao peso próprio, provoca, durante o dia, tensões de tração na fibra inferior e de compressão na superior. No período da noite ocorre o inverso: compressão na fibra inferior e tração na fibra superior. Desta maneira, durante o dia há uma soma dos esforços introduzidos pelo tráfego com as tensões induzidas pelo empenamento da placa. Durante a noite, os dois efeitos se subtraem. 


\subsection{CONSIDERAÇÕES GERAIS}

Grande parte das ações que solicitam os pavimentos são dinâmicas. Portanto, é importante considerar, não apenas o esforço que atua sobre a estrutura, mas a fadiga que a repetição dessas ações pode provocar no material.

Os efeitos de retração, dilatação térmica e empenamento não são considerados nos métodos de dimensionamento da espessura. $\mathrm{O}$ comprimento e a largura da placa, ou, no caso de pavimentos de concreto armado, a área de aço superior são definidos em função desses efeitos. Caso a região seja sujeita a grandes variações de temperatura entre o dia e a noite, torna-se necessário superpor as ações devidas ao empenamento às solicitações de tráfego, no dimensionamento da espessura ou da área de aço da armadura inferior. 


\section{Capítulo}

\section{MODELOS E TEORIAS}

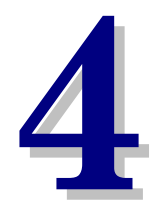

Para a determinação de esforços e deslocamentos, em qualquer tipo de estrutura, é necessária a utilização de modelos físicos e matemáticos que representem o comportamento dos materiais e da própria estrutura. Devido à complexidade da reologia dos materiais e da geometria das peças são adotadas simplificações que possibilitem a solução do problema. Neste capítulo são analisadas as características do solo e apresentados os modelos mais usuais para a representação da fundação e das placas de concreto.

A fim de determinar os esforços que as ações diretas ou indiretas provocam nas placas de concreto apoiadas sobre o solo, foram desenvolvidas diversas teorias. Os métodos de dimensionamento de pavimentos de concreto têm como base as equações desenvolvidas por Westergaard, que publicou artigos sobre determinação de deslocamentos, tensões e momentos fletores, em placas elásticas delgadas, apoiadas sobre líquido denso. Outros autores também propuseram equações com a finalidade de estabelecer valores aos esforços em placas de concreto. Neste trabalho será apresentado um resumo das teorias desenvolvidas por Westergaard e por Bradbury, devido a sua importância histórica. Serão mostradas, ainda, análises numéricas realizadas com auxílio do programa Ansys 5.5, desenvolvido com base no Método dos Elementos Finitos.

\subsection{FUNDAÇÃO}

O pavimento de concreto tem a característica de absorver os momentos impostos pelo carregamento, e transmitir à fundação esforços de 
baixa intensidade, não exigindo, portanto, grande capacidade de suporte do subleito. Apesar de não exigir solo de grande resistência mecânica, os pavimentos rígidos podem apresentar problemas quando construídos sobre solos expansivos, ou sobre camadas espessas de argila mole. A ocorrência de variações bruscas nas características do subleito também pode prejudicar o comportamento do pavimento.

A adoção de sub-bases estáveis e não bombeáveis pode corrigir as deficiências do subleito, e proporcionar um melhor comportamento do pavimento. As funções da sub-base são:

- aumentar a capacidade de suporte da fundação;

- impedir o bombeamento de solos finos plásticos saturados, na passagem de cargas pesadas;

- uniformizar a fundação;

- evitar os efeitos dos solos expansivos sobre o pavimento.

Normalmente as sub-bases são executadas com material granular, solo-cimento, solo melhorado com cimento ou concreto rolado.

Quando submetido à pressão aplicada através de uma placa, a deformação, em cada ponto do solo, depende da tensão no próprio ponto e nos pontos vizinhos, devido aos esforços de cisalhamento. Esse comportamento está ilustrado na figura 4.1.

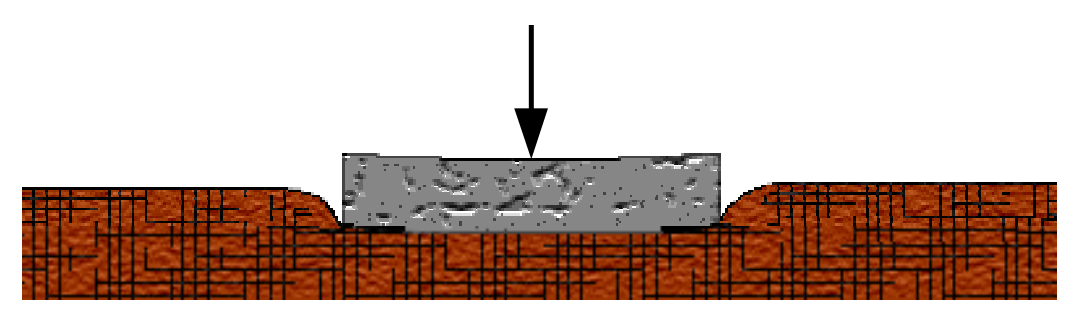

Figura 4.1 - Comportamento real do solo

As sub-bases têm comportamento semelhante ao do solo, com exceção do concreto rolado, que é melhor representado como material elástico, quando submetido a tensões de baixa intensidade.

Existem diversas maneiras de modelar o solo como camada de suporte de estruturas planas. As mais comuns são: 
- líquido denso;

- sólido elástico.

\subsubsection{Modelo líquido denso}

O modelo líquido denso é composto por uma série de molas, de constante $\mathrm{k}$, independentes. A tensão em um ponto depende da deformação no ponto e não é afetada pelas tensões nas regiões vizinhas. A constante de proporcionalidade das molas é conhecida como Coeficiente de Recalque ou Módulo de Reação da fundação. A figura 4.2 ilustra o modelo líquido denso.

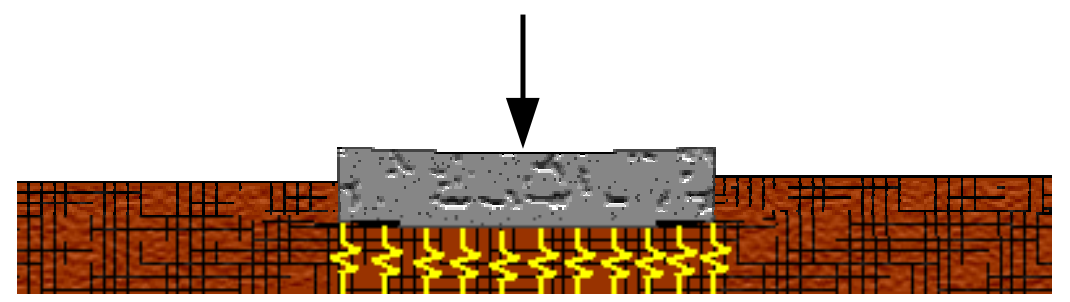

Figura 4.2 - Comportamento de líquido denso

\subsubsection{Modelo sólido elástico}

No modelo sólido elástico, o solo é caracterizado por suas propriedades elásticas: E - módulo de elasticidade e v - coeficiente de Poisson. Apesar de ainda não representar exatamente o comportamento do solo, esse modelo se aproxima mais da realidade, se comparado com o modelo de líquido denso. $\mathrm{O}$ modelo de sólido elástico considera, além de reações normais, esforços cisalhantes entre as partículas do material. O deslocamento num ponto é influenciado pela tensão no ponto e pela tensão em pontos próximos, sendo essa influência inversamente proporcional à distância. $\mathrm{O}$ modelo de sólido elástico é de solução mais complexa, problema que tem perdido importância devido aos avanços dos programas computacionais. A determinação dos parâmetros necessários para utilização do modelo de líquido denso é mais simples do que os de sólido elástico, tendo em vista que é mais fácil determinar o coeficiente de recalque do terreno do que as constantes elásticas do solo. A figura 4.3 representa o comportamento do modelo sólido elástico. 


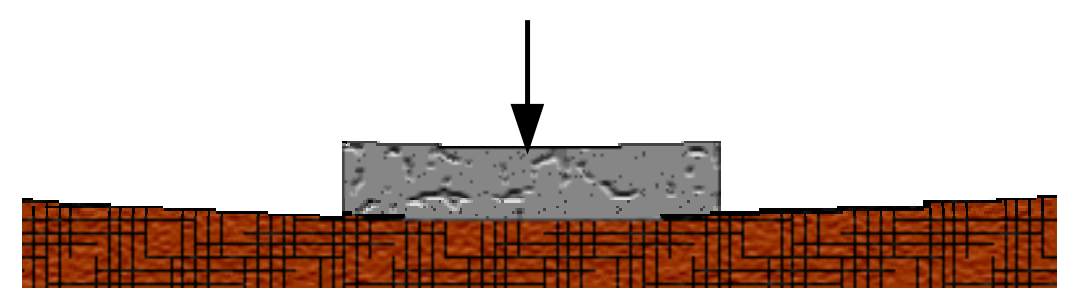

Figura 4.3 - Comportamento de sólido elástico

\subsubsection{Outros modelos}

O modelo de líquido denso considera a fundação como totalmente descontínua, enquanto o modelo de sólido elástico toma a fundação como perfeitamente contínua. O comportamento do solo está entre esses dois extremos. Modelos baseados em dois parâmetros foram desenvolvidos, tentando representar melhor as reações do solo. Segundo IOANNIDES apud RUFINO (1997) um dos maiores problemas dessa modelagem é a falta de significado físico desses parâmetros.

No modelo Filonenko-Borodich, a fundação é considerada como uma membrana elástica sobre molas verticais, sujeita a uma tensão de tração $T$ por unidade de comprimento. Dessa maneira a reação vertical das molas é representada pelo Coeficiente de Reação k, e a intensidade da interação das molas é função da tensão $T$.

O modelo de Pasternak considera a fundação como um conjunto de molas amarradas no topo. Esse modelo adota os parâmetros k - Coeficiente de Reação - e $G$ - parâmetro de rigidez que representa o cisalhamento.

A resposta do solo, principalmente quando submetido a carregamento cíclico, é não-linear e até certo ponto irreversível. O modelo de sólido elástico não-linear procura representar esse comportamento. A resposta elástica do solo é, normalmente, medida através do módulo resiliente, determinado através de ensaios triaxiais de forças repetidas.

${ }^{1}$ IOANNIDES, A.M. (1984). Analysis of Slabs-on-Grade for a Variety of Loading and Support Conditions. Illinois. Dissertation (Ph.D.) - University of Illinois. 
Também existem modelos de líquido denso não-lineares, nos quais o valor de $\mathrm{k}$ não é constante, ou seja, a curva pressão-deslocamento não é uma reta. Segundo IOANNIDES ${ }^{1}$ apud RUFINO (1997), os modelos não-lineares mais utilizados são o modelo hiperbólico e o modelo de Ramberg-Osgood.

\subsubsection{Determinação do Coeficiente de Recalque}

Até hoje, a maioria dos métodos de dimensionamento de pavimentos de concreto utilizam a modelagem da fundação como líquido denso. Portanto, o parâmetro mais utilizado para representação da resposta estrutural do solo, ou do conjunto subleito - sub-base, é o Coeficiente de Recalque.

O Coeficiente de Recalque ou Módulo de Reação, representado pela letra $\mathrm{k}$, tem unidade de tensão por unidade de comprimento $\left(\mathrm{F} / \mathrm{L}^{3}\right)$ e é determinado através da tensão necessária para produzir uma determinada deformação no terreno ensaiado. O Manual de pavimentos rígidos do DNER (1989) descreve os procedimentos para realização de prova de carga estática para determinação do coeficiente de recalque do subleito e da sub-base. Apesar de se tratar de uma simplificação, o valor de k é amplamente utilizado, já que a determinação das características particulares de cada camada sob o bulbo de tensões, ou seja, sob a influência do carregamento do pavimento, exigiria ensaios mais complicados e onerosos.

$\mathrm{O}$ valor de $\mathrm{k}$ pode ser determinado através da correlação com o índice de suporte Califórnia - CBR, quando a experiência, para o local da obra, comprovar a validade deste procedimento. No gráfico da figura A.1 (Anexo A) está apresentada esta relação.

$\mathrm{O}$ valor de $\mathrm{k}$ é utilizado tanto para representar a capacidade de reação do subleito como do sistema subleito/sub-base. Portanto, quando se utiliza subbase de solo melhorado, ou de concreto pobre, o valor de $\mathrm{k}$ no topo do sistema aumenta. Os valores do coeficiente de recalque no topo da fundação, para uma camada de espessura $e$ de sub-base granular, solo-cimento, solo melhorado com cimento e concreto rolado, estão apresentados nos gráficos das figuras A.2 a A.5 (Anexo A). 


\subsection{MATERIAIS}

O pavimento de concreto é composto de placas separadas por juntas longitudinais e transversais, devidamente espaçadas. O comportamento dos materiais utilizados na construção de pavimento de concreto simples e de concreto armado serão apresentados a seguir.

\subsubsection{Concreto}

Quando uma placa é carregada, são introduzidos esforços de compressão e de tração devidos à flexão. Como a resistência do concreto à compressão é muito maior que à tração, o parâmetro utilizado no dimensionamento da espessura de pavimentos de concreto simples, ou com armadura de retração, é a resistência à tração na flexão, $\mathrm{f}_{\mathrm{ctm}}$, determinada pelo módulo de ruptura, $\mathrm{M}_{\mathrm{R}}$, obtido no ensaio de corpos-de-prova prismáticos, preferencialmente carregados nos terços do vão (dois cutelos). Pode ser adotada a resistência característica, $\mathrm{f}_{\mathrm{ctm}, \mathrm{k}}$, obtida aos 28 dias, ou a resistência aos $j$ dias, $f_{c t m, j}$. Para casos em que a experiência e a importância da obra permitirem, é possível fazer correlações entre os valores obtidos em ensaios de compressão simples e os valores do módulo de ruptura. Segundo a Revisão da NB-1 (1999), o valor de $\mathrm{f}_{\mathrm{ct}}$ pode ser determinado através da expressão:

$$
\mathrm{f}_{\mathrm{ct}}=0,3 \cdot \mathrm{f}_{\mathrm{cj}}{ }^{2 / 3}
$$

sendo:

- $\mathrm{f}_{\mathrm{ct}}$ : resistência à tração, aos $j$ dias, em $\mathrm{MPa}$;

- $\mathrm{f}_{\mathrm{cj}}$ : resistência à compressão, aos $j$ dias, em MPa.

No dimensionamento de pavimentos de concreto é comum ser adotado o valor da resistência aos 28 dias, mas pode ser adotada a resistência aos 90 dias, tendo em vista que a maior parte do carregamento ocorrerá após esse 
período. Quando for prevista uma rápida abertura ao tráfego, pode ser necessário o conhecimento e a verificação da resistência do concreto aos 7 dias.

A experiência tem mostrado que valores do módulo de ruptura entre 4 e $5 \mathrm{MPa}$ proporcionam maior economia, se avaliadas a durabilidade e a variação da espessura em função da resistência do concreto. Valores de resistência muito baixos acarretam em espessuras elevadas, enquanto concretos com resistências muito altas são de difícil execução e de custo elevado, não compensado com a redução da espessura das placas.

O módulo de elasticidade secante a ser utilizado nas análises elásticas, caso não estejam disponíveis dados de ensaio, pode ser determinado, segundo a Revisão da NB-1 (1999), pela expressão:

$\mathrm{E}_{\mathrm{c}}=0,85 \cdot \mathrm{E}_{\mathrm{ci}}$

sendo:

- $\quad \mathrm{E}_{\mathrm{c}}$ : módulo de elasticidade secante;

- Eci: módulo de elasticidade inicial, dado por:

$\mathrm{E}_{\mathrm{ci}}=5600 \cdot \sqrt{\mathrm{f}_{\mathrm{ck}}}$

sendo:

- $\mathrm{f}_{\mathrm{ck}}$ : resistência característica à compressão, em MPa.

Para o concreto não fissurado, a Revisão da NB-1 (1999) apresenta o diagrama tensão-deformação bilinear da figura 4.4, para tração.

O diagrama tensão-deformação do concreto comprimido está mostrado na figura 4.5 .

Ainda segundo a Revisão da NB-1 (1999), o coeficiente de Poisson do concreto, para tensões de tração inferiores à tensão admissível, deve ser tomado igual a 0,2. Segundo o mesmo projeto de norma o coeficiente de dilatação térmica do concreto pode ser adotado igual a $10^{-5} /{ }^{\circ} \mathrm{C}$ e as massas específicas do 
concreto simples e do concreto armado são $2400 \mathrm{~kg} / \mathrm{m}^{3}$ e $2500 \mathrm{~kg} / \mathrm{m}^{3}$, respectivamente.

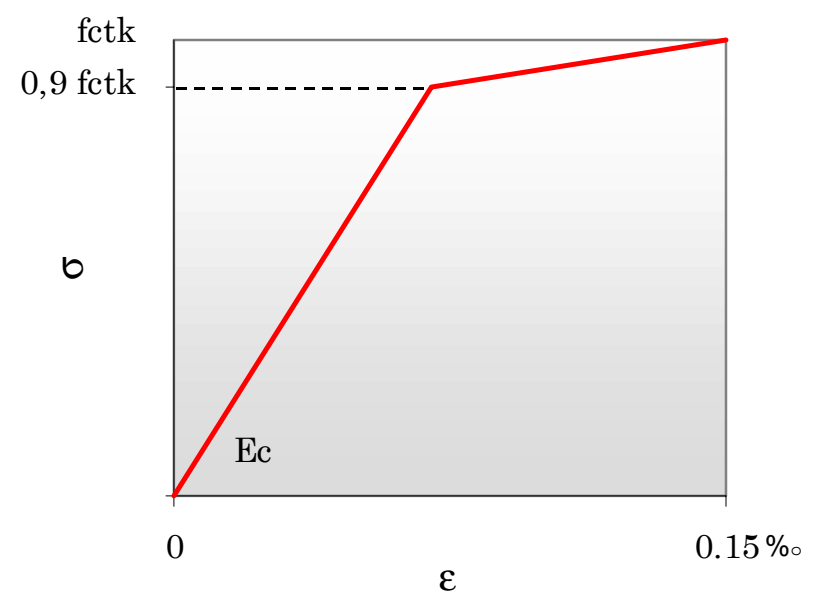

Figura 4.4 - Diagrama tensão-deformação do concreto, na tração, NB-1 (1999)

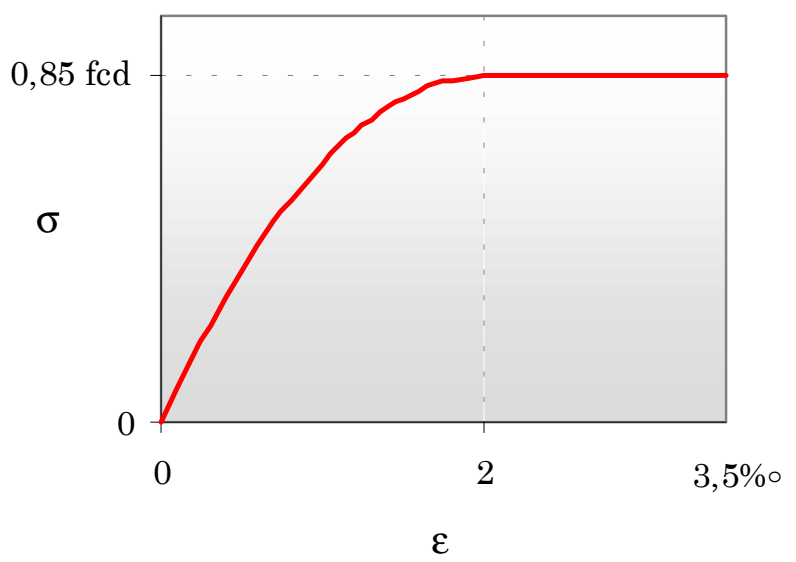

Figura 4.5 - Diagrama tensão-deformação do concreto, na compressão, NB-1 (1999)

A Revisão da NB-1 (1999) apresenta um procedimento semelhante ao CEB (1991) para determinação da retração do concreto, em função da umidade relativa do ar, da consistência do concreto, das dimensões da peça, da idade e do tempo de cura, ou seja, do início da retração.

$\mathrm{O}$ comportamento do concreto à fadiga é discutido no capítulo 5 , deste trabalho. 


\subsubsection{Aço}

O aço de armadura passiva possui coeficiente de dilatação térmica praticamente igual ao do concreto $\left(10^{-5 /} \mathrm{C}\right)$, para temperaturas entre -20 e $150^{\circ} \mathrm{C}$.

São utilizados, na pavimentação, aços CA-50, CA-60 e CA-25, com resistências iguais a $50 \mathrm{kN} / \mathrm{cm}^{2}, 60 \mathrm{kN} / \mathrm{cm}^{2}$ e $25 \mathrm{kN} / \mathrm{cm}^{2}$, respectivamente.

Para o módulo de elasticidade, a Revisão da NB-1 (1999) indica o valor de $210000 \mathrm{MPa}$, na falta de ensaios ou valores fornecidos pelo fabricante. Para cálculos no estado limite de serviço e no estado limite último, pode-se utilizar o diagrama tensão-deformação simplificado, mostrado na figura 4.6, tanto para aço tipo A quanto para tipo B.

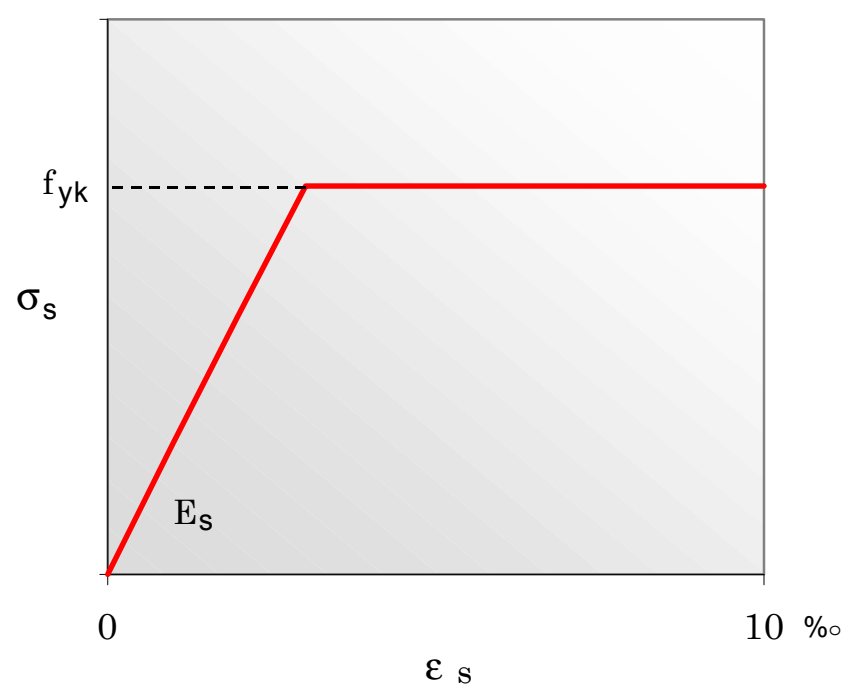

Figura 4.6 - Diagrama tensão-deformação do aço, NB-1 (1999)

O diagrama da figura 4.6 pode ser usado tanto na tração quanto na compressão.

Devido à facilidade de execução, tem-se adotado, ao invés de barras de aço, telas soldadas. As telas são malhas de aço pré-fabricadas, onde as barras transversais são soldadas, por caldeamento, às barras longitudinais, evitando assim o trabalho de amarração. As telas podem ser quadradas, quando possuem 
a mesma área de aço por unidade de comprimento, nas duas direções; ou retangulares, quando apresentam áreas de aço diferentes.

O comportamento do aço para concreto armado quando submetido a carregamento cíclico é discutido no capítulo 5.

\subsection{TEORIA DE WESTERGAARD}

WESTERGAARD (1926), utilizando o método de Ritz das aproximações sucessivas, baseado no princípio de mínima energia, investigou os deslocamentos em placas delgadas, elásticas, sob forças distribuídas em áreas circulares e semi-circulares, apoiados em líquido muito denso, nas posições indicadas na figura 4.7 .

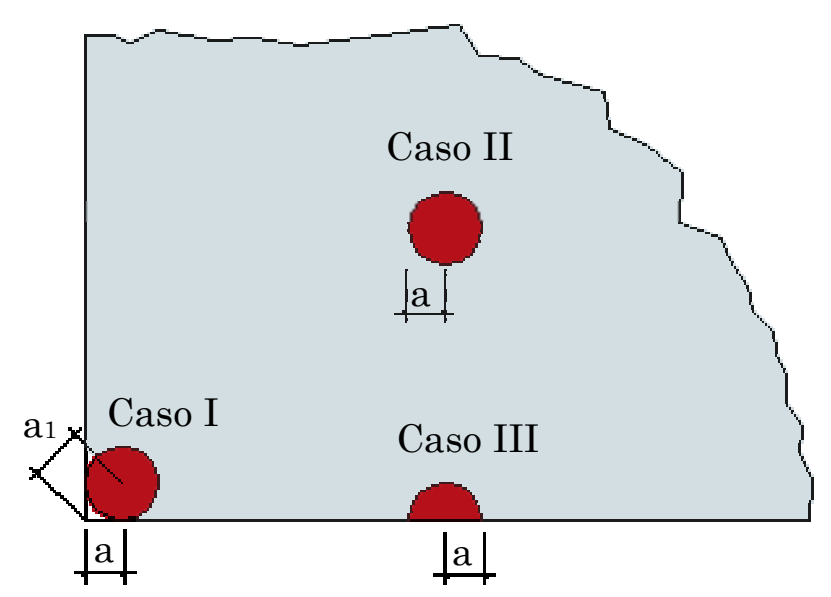

Figura 4.7 - Posições de configurações de carregamentos analisadas por Westergaard, em 1926

Foram consideradas as seguintes hipóteses:

- a placa é constituída de material homogêneo, isotrópico e elástico;

- as reações do subleito são verticais e proporcionais aos deslocamentos verticais da placa;

- a placa possui espessura constante;

- as forças no interior e no canto da placa são distribuídas uniformemente sobre áreas circulares;

- a força na borda da placa é distribuída uniformemente sobre área semi-circular. 
Segundo WESTERGAARD (1926) os deslocamentos nos pontos próximos ao canto da placa são dados por:

$\mathrm{z}_{\mathrm{c}}=\frac{\mathrm{P}}{\mathrm{k} \cdot \ell^{2}}\left(1,1 \cdot \mathrm{e}^{-\frac{\mathrm{x}}{\ell}}-\frac{\mathrm{a}_{1}}{\ell} \cdot 0,88 \cdot \mathrm{e}^{-\frac{2 \mathrm{x}}{\ell}}\right)$

sendo:

- $\quad \mathrm{z}_{\mathrm{c}}$ : deslocamento máximo para força no canto da placa;

- $\quad a_{1}$ : distância indicada na figura 4.7;

- $\quad \ell$ : raio de rigidez relativa, dado pela equação (4.5);

- P: força aplicada;

- $v$ : coeficiente de Poisson;

- $\quad$ : distância do ponto considerado do canto da placa;

- $\quad \mathrm{k}$ : módulo de reação da fundação.

O raio de rigidez relativa, $\ell$, ilustrado na figura 4.8, é a distância entre o ponto de aplicação da força e o ponto de momento nulo. Para placa apoiada em líquido denso é dado por:

$\ell=\sqrt[4]{\frac{E \cdot h^{3}}{12 \cdot\left(1-v^{2}\right) \cdot k}}$

sendo:

- E: módulo de elasticidade da placa;

- h: espessura da placa. 


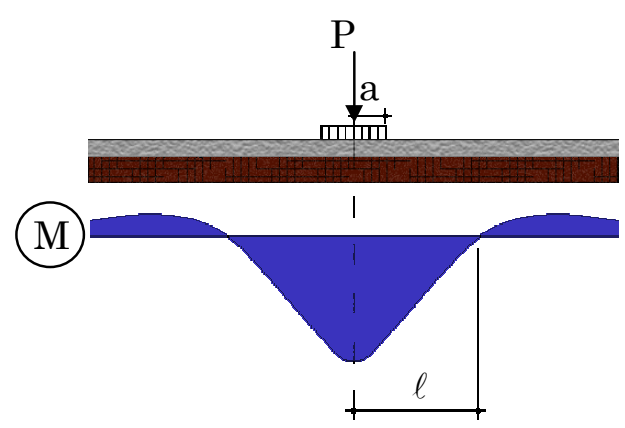

Figura 4.8 - Representação de $\ell$

$\mathrm{O}$ momento a uma distância $\mathrm{x}_{1}=2 \cdot \sqrt{\mathrm{a}_{1} \cdot l}$ é dado por:

$\mathrm{M}=-\frac{\mathrm{P}}{2} \cdot\left[1-\left(\frac{\mathrm{a}_{1}}{\ell}\right)^{0,6}\right]$

A tensão na face superior, devida à força no canto, é dado por (WESTERGAARD, 1926):

$\sigma_{\mathrm{c}}=\frac{3 \cdot \mathrm{P}}{\mathrm{h}^{2}} \cdot\left[1-\left(\frac{\mathrm{a}_{1}}{\ell}\right)^{0,6}\right]$

Para o caso de força no interior da placa, WESTERGAARD apresenta a seguinte equação:

$\sigma_{\mathrm{i}}=\frac{3 \cdot(1+v) \cdot \mathrm{P}}{2 \cdot \pi \cdot \mathrm{h}^{2}} \cdot\left(\ln \frac{\ell}{\mathrm{a}}+0,6159\right)$

sendo:

- $\sigma_{\mathrm{i}}$ : tensão de tração máxima para força no interior da placa;

- a: raio da área de aplicação da força.

Para força na borda da placa, módulo de elasticidade de $21360 \mathrm{MPa}$ e coeficiente de Poisson 0,15, WESTERGAARD (1926) apresenta a equação: 
$\sigma_{\mathrm{b}}=0,572 \cdot \frac{\mathrm{P}}{\mathrm{h}^{2}} \cdot\left[\log \mathrm{h}^{3}-4 \log \mathrm{b}-\log \mathrm{k}+5,767\right]$

sendo:

- $\sigma_{b}$ : tensão máxima de tração para força na borda da placa;

- b: raio equivalente da área de distribuição de pressão, dado pela equação (4.10);

$\mathrm{b}=\sqrt{1,6 \cdot \mathrm{a}^{2}+\mathrm{h}^{2}}-0,675 \cdot \mathrm{h}$, para $\mathrm{a}<1,724 . \mathrm{h}$

$\mathrm{b}=\mathrm{a}$, para $\mathrm{a} \geq 1,724 . \mathrm{h}$

Segundo WESTERGAARD (1926), o deslocamento, $\mathrm{Z}_{\mathrm{i}}$, para carregamento circular no interior da placa é muito próximo ao deslocamento para força concentrada $(a=0)$, dado por:

$\mathrm{z}_{\mathrm{i}}=\frac{\mathrm{P}}{8 \cdot \mathrm{k} \cdot \ell^{2}}$

No caso de força concentrada na borda, o deslocamento máximo, zb, é dado por (WESTERGAARD, 1926):

$\mathrm{z}_{\mathrm{b}}=\frac{1}{\sqrt{6}} \cdot(1+0,4 \cdot \mathrm{v}) \cdot \frac{\mathrm{P}}{\mathrm{k} \cdot \ell^{2}}$

Em 1933, Westergaard apresentou uma teoria suplementar, baseada na redistribuição de reações do subleito, em função de testes realizados para o carregamento no interior da placa.

Em 1939, Westergaard apresentou um trabalho sobre cálculo de tensões nos pavimentos de concreto para aeroportos.

WESTERGAARD (1948) apresentou novas equações, para determinação de tensões e deslocamentos em placas sobre apoio elástico, considerando três posições de carregamento: no interior da placa; próximo à borda ou a uma junta livre e próximo a uma junta com algum grau de 
transferência de carga. No trabalho de 1948 a aplicação do carregamento é distribuído uniformemente em área elíptica.

As tensões principais, na face inferior da placa, com força no interior, são dadas por (WESTERGAARD, 1948):

$$
\sigma_{i}=\frac{3 \cdot \mathrm{P}}{8 \pi \cdot \mathrm{h}^{2}} \cdot\left[(1+\mathrm{v}) \cdot \log \frac{\mathrm{E} \cdot \mathrm{h}^{3}}{\mathrm{k} \cdot\left(\frac{\mathrm{a}+\mathrm{b}}{2}\right)^{4}} \mp 2 \cdot(1-\mathrm{v}) \cdot \frac{\mathrm{a}-\mathrm{b}}{\mathrm{a}+\mathrm{b}}\right]
$$

sendo:

- a: maior semi-eixo da elipse;

- b: menor semi-eixo da elipse;

WESTERGAARD (1948) estendeu os estudos para uma área qualquer de aplicação de força, com dois eixos de simetria: x e y. Desta forma a tensão no interior da placa é dada por:

$\sigma_{\mathrm{i}}=\frac{3 \cdot \mathrm{P}}{2 \pi \cdot \mathrm{h}^{2}} \cdot\left[(1+\mathrm{v}) \cdot(\mathrm{K}+0,1159) \pm \frac{1-\mathrm{v}}{2} \cdot \mathrm{S}\right]$

sendo:

- K e S: coeficientes de área, dados pelas equações (4.15) e (4.16).

$$
\begin{aligned}
& K=-\frac{1}{A} \int \log \frac{r}{\ell} d A \\
& S=-\frac{1}{A} \int \cos (2 \theta) d A
\end{aligned}
$$

sendo:

- A: área de aplicação da força;

- r e $\theta$ : coordenadas polares. 
A tensão no ponto de tangência da elipse com a borda é dada por (WESTERGAARD, 1948):

$\sigma_{\mathrm{b}}=\frac{3(1+v) \mathrm{P}}{\pi(3+v) \mathrm{h}^{2}}\left(\log \frac{\mathrm{E} \cdot \mathrm{h}^{3}}{100 \mathrm{k}\left(\frac{\mathrm{a}+\mathrm{b}}{2}\right)^{4}}+1,84-\frac{4 \cdot v}{3}+(1+v) \frac{\mathrm{a}-\mathrm{b}}{\mathrm{a}+\mathrm{b}}+2(1-v) \frac{\mathrm{ab}}{(\mathrm{a}+\mathrm{b})^{2}}+1,18(1+2 v) \frac{\mathrm{b}}{\ell}\right)$

sendo:

- a: maior semi-eixo da elipse;

- b: menor semi-eixo da elipse;

Para área qualquer de carregamento, a tensão na borda, passa a ser (WESTERGAARD, 1948):

$\sigma_{\mathrm{b}}=\frac{3(1+v) \mathrm{P}}{\pi(3+v) \mathrm{h}^{2}}\left[4 \mathrm{~K}-0,28-\frac{4}{3} v-v^{2}+(1-v) \mathrm{S}+1,18(1+2 v) \frac{\overline{\mathrm{y}}}{\ell}\right]$

sendo:

- $\quad \bar{y}$ : distância da borda ao centro de gravidade do carregamento;

No caso de juntas com transferência de carga, WESTERGAARD (1948) apresenta as seguintes equações:

$\sigma_{j}=\left(1-\frac{1}{2} \cdot \varepsilon_{\text {junta }}\right) \cdot \sigma_{\mathrm{e}}+\frac{1}{2} \cdot \varepsilon_{\text {junta }} \cdot \sigma_{\mathrm{e}}^{\prime}$
$\sigma_{\mathrm{j}}^{\prime}=\frac{1}{2} \cdot \varepsilon_{\text {junta }} \cdot \sigma_{\mathrm{e}}+\left(1-\frac{1}{2} \cdot \varepsilon_{\text {junta }}\right) \cdot v_{\mathrm{e}}^{\prime}$

sendo:

- $\sigma_{j}$ e $\sigma_{j}:$ tensões nos dois lados da junta com transferência de carga;

- $\sigma_{\mathrm{e}}$ e $\sigma_{\mathrm{e}}$ : tensões nos dois lados da junta sem transferência de carga;

- $\varepsilon_{\text {junta }}$ : eficiência da junta. 
Westergaard foi o primeiro a apresentar um desenvolvimento lógico para determinação de esforços em pavimentos rígidos. Seus trabalhos constituem a base dos métodos utilizadas atualmente para dimensionamento de pavimentos de concreto.

PICKETT e RAY (1951), propuseram um método gráfico, através de cartas de influência, para determinar as tensões, os momentos e os deslocamentos verticais, simplificando a aplicação das expressões de Westergaard. Os mesmos autores construíram ábacos equivalentes às cartas de influência, para eixos simples e tandem duplo, típicos dos Estados Unidos. PITTA (1978) apresenta ábacos semelhantes aos de Pickett e Ray, desenvolvidos para eixos tandem triplos, para eixos de 1,80 metros de comprimento, módulo de elasticidade do concreto igual a $28000 \mathrm{MPa}$, coeficiente de Poisson de 0,15 e raio de rigidez 25,4 .

A utilização das equações de Westergaard é limitada, pois consideram apenas duas camadas: pavimento e fundação semi-infinita, desprezando a possibilidade da existência de camadas intermediárias, rígidas, ou semi-rígidas. Segundo IOANNIDES e outros, citados por RUFINO (1997), as soluções de Westergaard fornecem resultados próximos às observações de campo para força no interior, mas não fornecem bons resultados para carregamento na borda ou no canto da placa.

\subsection{TEORIA DE BRADBuRY PARA DETERMinaÇÃO DE TENSÕES DE EMPENAMENTO}

BRADBURY (1938) considerou uma laje retangular, de lados $l_{\mathrm{x}}$ e $l_{\mathrm{y}} \mathrm{e}$ de espessura $h$, e apresentou equações para o cálculo das tensões de

2 IOANNIDES, A.M.; THOMPSON, M.R.; BARENBERG, E.J. (1985). Finite Element Analysis of Slabs-on-Grade Using a Variety of Support Models. In: International Conference on Concrete Pavement Design and Rehabilitation, 3., 1985. Proceedings, Purdue University, p. 309-324. 
empenamento, durante o dia (situação mais desfavorável). A rigor as tensões de empenamento deveriam ser combinadas às tensões devidas ao tráfego, no dimensionamento de pavimentos. As equações apresentadas por Bradbury são:

- tensão na borda da placa

$\sigma_{\mathrm{x}, \mathrm{b}}=\frac{\mathrm{C}_{\mathrm{x}} \cdot \mathrm{E} \cdot \alpha \cdot \partial \mathrm{T}}{2}$

- tensão no interior da placa

$\sigma_{\mathrm{x}, \mathrm{i}}=\frac{\mathrm{E} \cdot \alpha \cdot \partial \mathrm{T} \cdot\left(\mathrm{C}_{\mathrm{x}}+v \cdot \mathrm{C}_{\mathrm{y}}\right)}{2 \cdot\left(1-v^{2}\right)}$

$\sigma_{\mathrm{y}, \mathrm{i}}=\frac{\mathrm{E} \cdot \alpha \cdot \partial \mathrm{T} \cdot\left(\mathrm{C}_{\mathrm{y}}+v \cdot \mathrm{C}_{\mathrm{x}}\right)}{2 \cdot\left(1-v^{2}\right)}$

sendo:

- $\sigma_{\mathrm{xb}}$ - tensão de tração na borda da placa, devida ao empenamento;

- $\sigma_{x, i}$ - tensão de tração no interior da placa, na direção do comprimento;

- $\sigma_{y, i}$ - tensão de tração no interior da placa, na direção da largura;

- $\mathrm{C}_{\mathrm{x}}$ e $\mathrm{C}_{\mathrm{y}}$ - coeficientes determinados através do gráfico da figura 4.9 ;

- $\quad \alpha$ - coeficiente de dilatação térmica do concreto;

- $\delta \mathrm{T}$ - gradiente de temperatura.

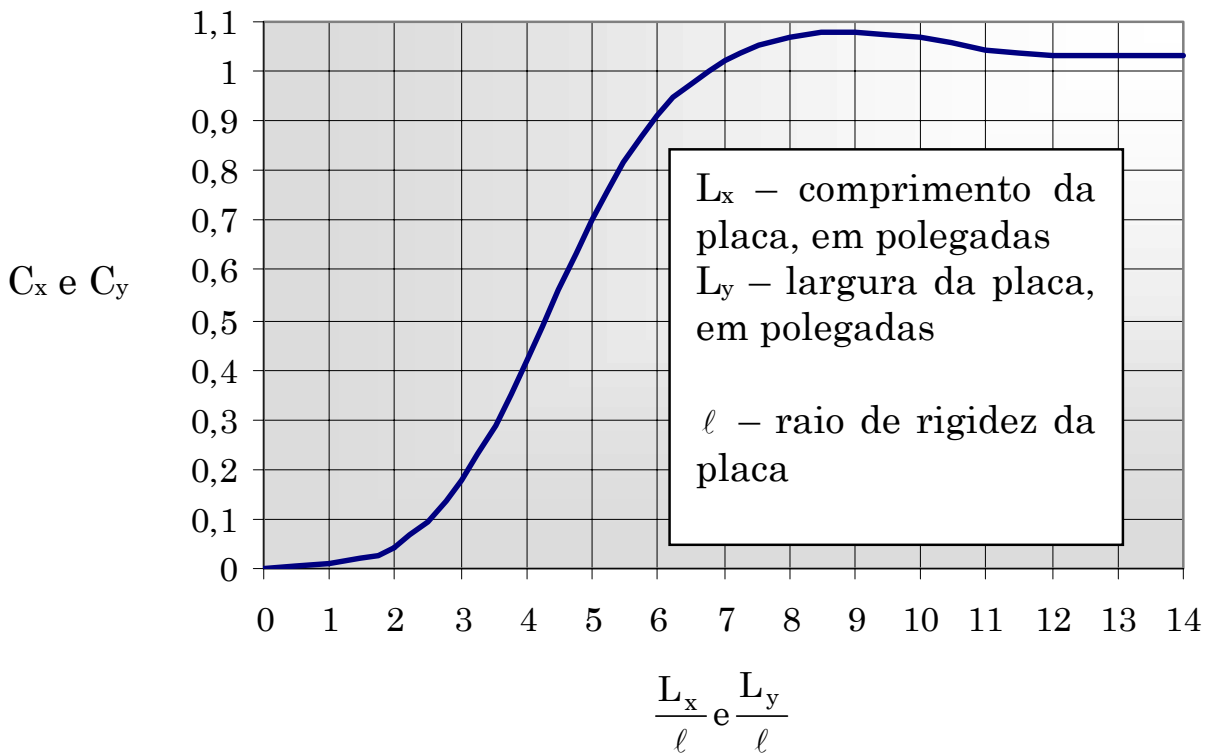

Figura 4.9 - Coeficientes para as tensões de empenamento devidas ao gradiente de 
temperatura BRADBURY (1938)

É adotado o raio de rigidez da placa sobre líquido denso, definido pela expressão (4.5).

\subsection{ANÁLISE NUMÉRICA}

Atualmente, estão disponíveis softwares desenvolvidos através de processos numéricos como Elementos Finitos, Diferenças Finitas e Elementos de Contorno, que facilitam a aplicação da Teoria da Elasticidade, ou demais teorias, na determinação de esforços sob quaisquer configurações do carregamento, em diversas posições das placas. Podem ser adotados diversos modelos para o solo e a espessura das placas pode ser variável. É possível também, modelar, com certa facilidade, as várias camadas do pavimento.

A fim de estudar o comportamento das placas de pavimentos rígidos, foi realizada uma análise numérica, aplicando o modelo elástico de placa delgada, utilizando o software Ansys 5.5, versão universitária, que foi desenvolvido com base no processo dos elementos finitos. Verificou-se a distribuição das tensões em uma placa isolada apoiada sobre líquido denso, sob carregamento de eixos rodoviários, nas posições indicadas na figura 4.10.

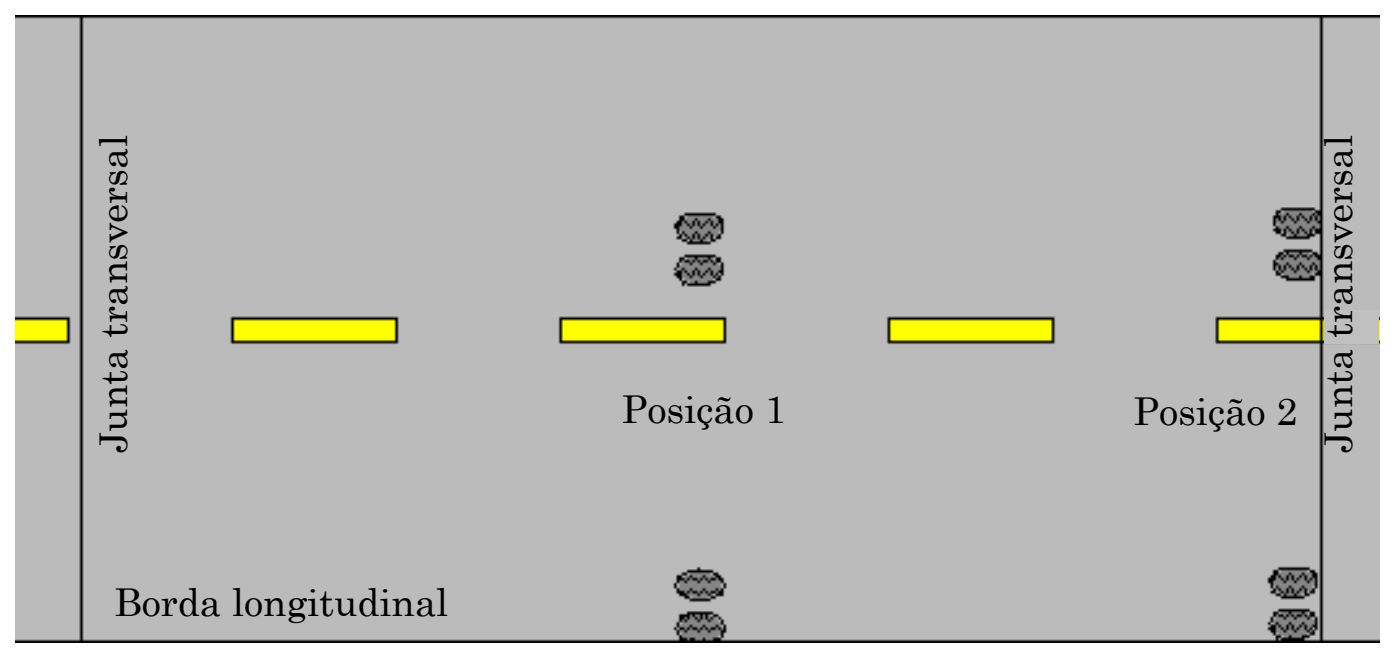

Figura 4.10 - Posições de carregamento 
O elemento utilizado foi o SHELL63. Este elemento possui 6 graus de liberdade: translação e rotação na direção de três eixos coordenados. É composto por quatro nós, podendo ser quadrilátero ou triangular (superpondo dois nós). O SHELL63 é utilizado para análise elástico-linear, onde se fornece o módulo de elasticidade $E$ e o coeficiente de Poisson $v$ do material. O próprio elemento admite base elástica, sendo necessário indicar apenas o valor do módulo elástico da fundação, equivalente ao coeficiente de recalque $\mathrm{k}$. As características físicas e geométricas do problema estão apresentadas na tabela 4.1 .

Tabela 4.1 - Dados do problema

\begin{tabular}{|c|c|}
\hline Variável & Valor adotado \\
\hline Coeficiente de recalque $-\mathrm{k}$ & $50 \mathrm{Mpa} / \mathrm{m}$ \\
Módulo de elasticidade do concreto - E & $33660 \mathrm{MPa}$ \\
Coeficiente de Poisson do concreto - $v$ & 0,2 \\
Pressão nos pneus - $\mathrm{q}$ & $0,7 \mathrm{MPa}$ \\
Dimensões da placa - comprimento x largura x espessura & $6,0 \times 3,5 \times 0,15 \mathrm{~m}$ \\
\hline
\end{tabular}

As análises foram desenvolvidas para forças máximas admitidas pelo DNER, com coeficiente de segurança de 1,2. A área de contato dos pneu é retangular. A tabela 4.2 mostra os valores de força e área de contato para os quatro tipos de eixos analisados.

Tabela 4.2 - Força e área de contato adotados no problema

\begin{tabular}{|c|c|c|}
\hline Eixo & Força máxima $(\mathrm{tf})$ & Área de contato $\left(\mathrm{m}^{2}\right)$ \\
\hline Simples de rodagem simples & 6 & 0,0504 \\
Simples de rodagem dupla & 10 & 0,0420 \\
Tandem duplo & 17 & 0,0357 \\
Tandem triplo & 25,5 & 0,0357 \\
\hline
\end{tabular}

A seguir serão mostrados os momentos fletores em duas direções: x e y. Os momentos em x provocam a flexão longitudinal da placa. Os momentos em y provocam a flexão transversal da placa. Nas figuras 4.11 e 4.12 estão apresentados os resultados obtidos para eixo simples de rodagem dupla, tangente à borda longitudinal. 


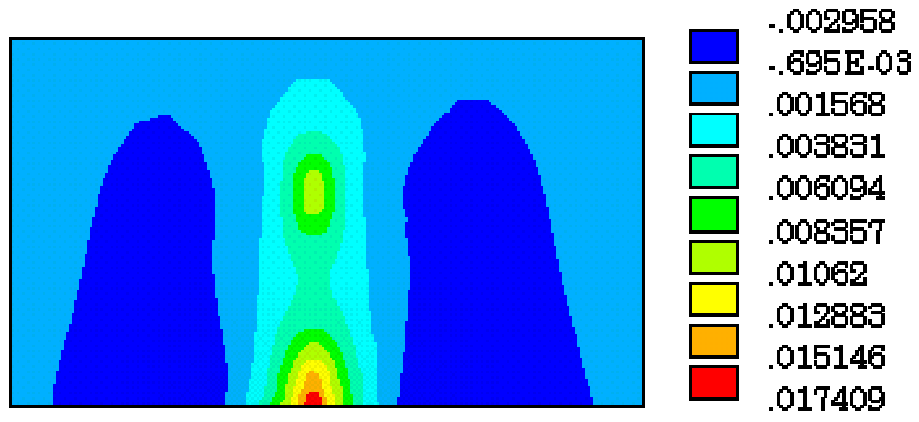

Figura 4.11 - Distribuição dos momentos fletores (MN.m), na direção x, para carregamento na borda da placa - eixo simples de rodagem dupla

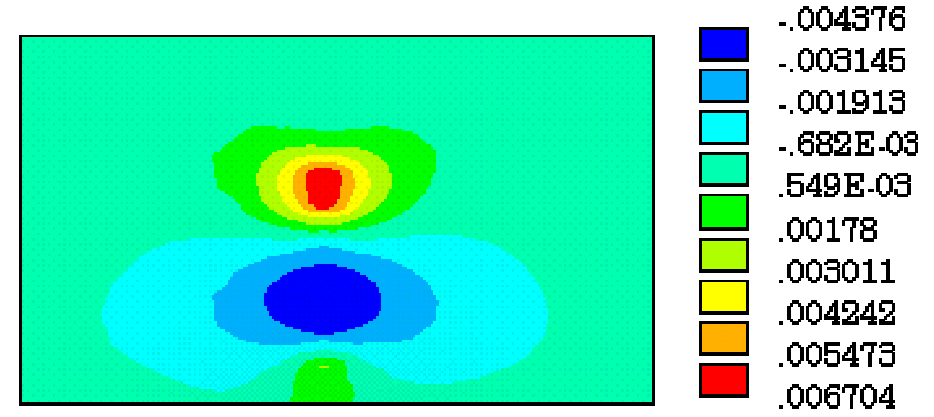

Figura 4.12 - Distribuição dos momentos fletores (MN.m), na direção y, para carregamento na borda da placa - eixo simples de rodagem dupla

Pode-se observar que o momento fletor, na direção $x$, no interior da placa, é de aproximadamente 50\% do valor máximo obtido na borda da placa. $\mathrm{O}$ momento fletor máximo na direção y, obtido no interior da placa, equivale a cerca de $40 \%$ do momento fletor máximo, na direção x. Nota-se ainda que existe uma área de momento negativo (tracionando as fibras superiores), onde o momento fletor atinge $25 \%$ do valor máximo.

Para eixo simples tangente à junta transversal, foram obtidos os resultados das figuras 4.13 e 4.14 .

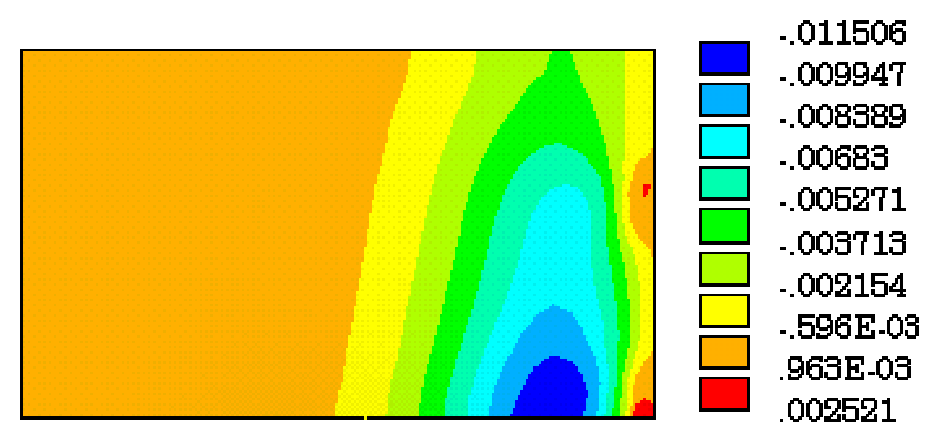

Figura 4.13 - Distribuição dos momentos fletores (MN.m), na direção x, para carregamento tangente à junta transversal - eixo simples de rodagem dupla 


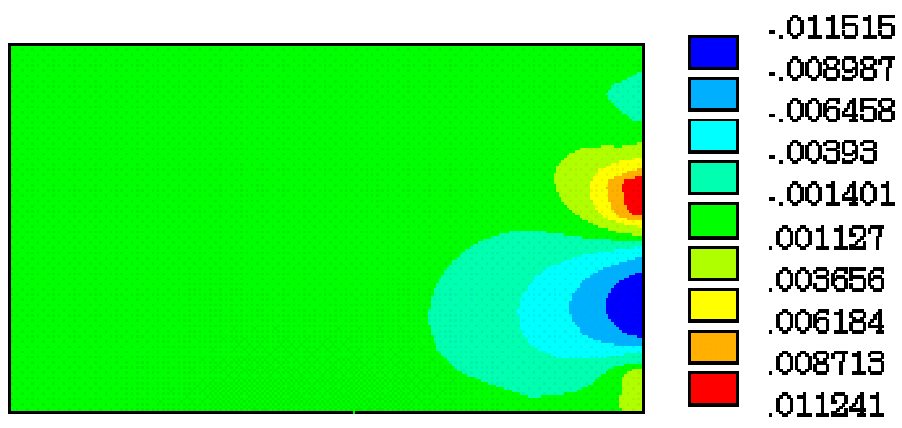

Figura 4.14 - Distribuição dos momentos fletores (MN.m), na direção y, para carregamento tangente à junta transversal - eixo simples de rodagem dupla

Em uma placa isolada, o momento fletor positivo na direção x, para força próxima à junta, é muito pequeno, enquanto na direção y chega a valores da ordem de $70 \%$ do momento máximo, para força na borda. No caso de carregamento no canto da placa, tornam-se significativos os valores de momentos fletores negativos que, para o caso de eixos simples, chegam a atingir cerca de 70\% do valor máximo. Os esforços de tração, nesse caso, ocorrem nas fibras superiores, a uma distância de aproximadamente 1 metro do canto da placa. Os resultados obtidos para eixos simples de rodagem simples, tandem duplo e tandem triplo são apresentados no anexo B.

Utilizando o mesmo modelo, foram realizadas análises variando a posição dos semi-eixos desde a borda até o interior e desde o canto até o meio da junta transversal da placa. No gráfico da figura 4.15 é mostrada a variação do momento fletor máximo, desde a borda externa até o interior da placa, para semi-eixo simples de rodagem dupla.

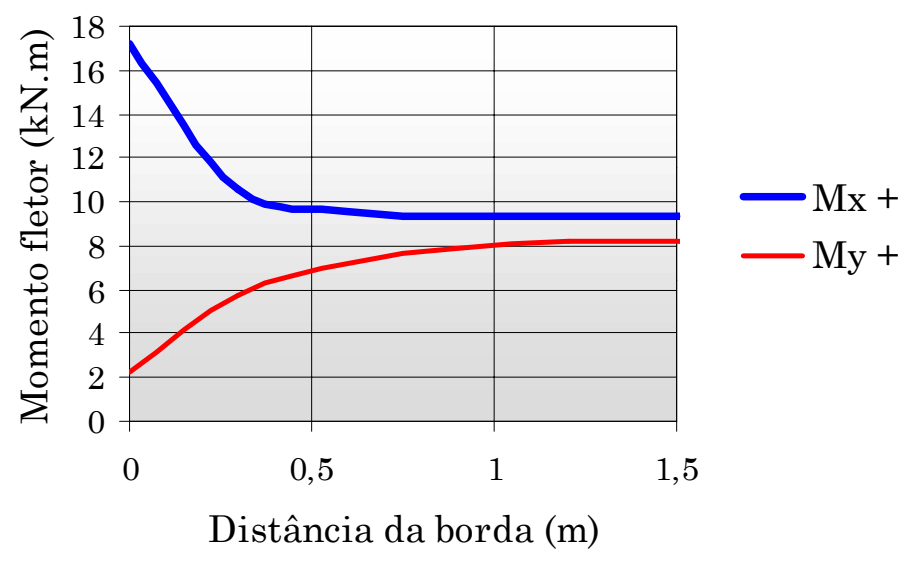

Figura 4.15 - Variação do momento fletor máximo, em função da posição da força, borda - interior, semi-eixo simples de rodagem dupla 
No gráfico, é possível perceber que o momento fletor, na direção x, decresce rapidamente nos 50 centímetros mais próximos à borda, sendo praticamente constante deste ponto até o interior da placa. O momento fletor na direção y, que é muito pequeno na borda, se aproxima do momento na direção $\mathrm{x}$, quando a força caminha para o interior.

Variando o carregamento desde o canto da placa até o centro da junta transversal, obtém-se a variação de momentos fletores máximos positivos e negativos apresentados nas figuras 4.16 e 4.17, respectivamente.

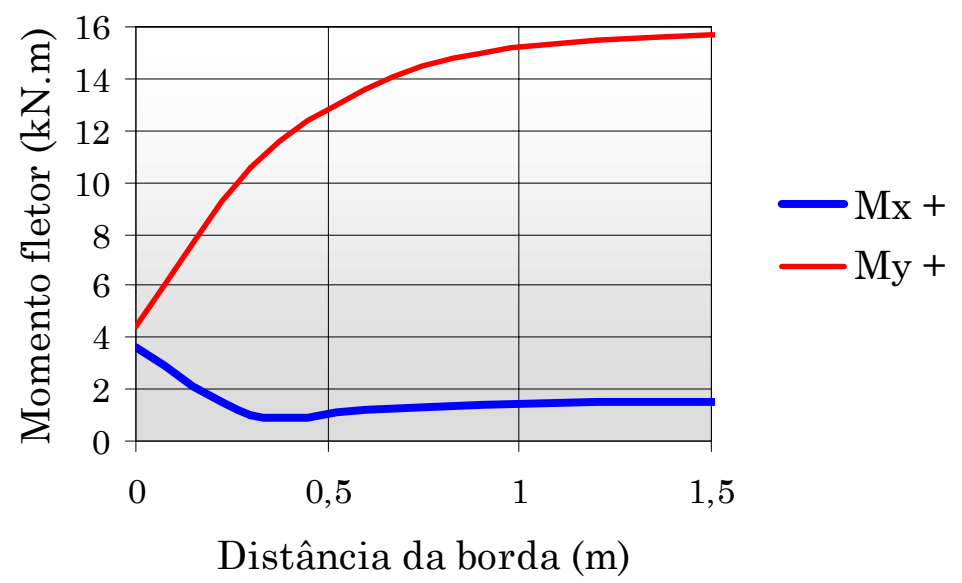

Figura 4.16 - Variação do momento fletor máximo positivo, em função da posição da força, canto - centro da junta transversal, semi-eixo simples de rodagem dupla

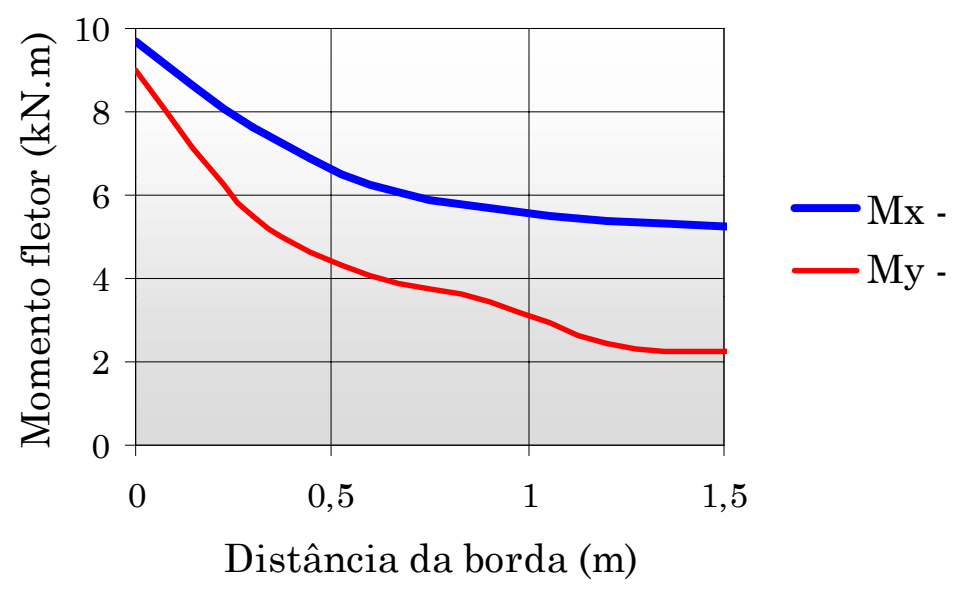

Figura 4.17 - Variação do momento fletor máximo negativo, em função da posição da força, canto - centro da junta transversal, semi-eixo simples de rodagem dupla

Como já foi verificado anteriormente, quando a força é tangente à junta transversal, os maiores esforços de tração da fibra inferior ocorrem na 
direção y. No gráfico da figura 4.17, pode-se perceber que os momentos que tracionam as fibras superiores ocorrem com valores semelhantes na direção $\mathrm{x} e$ na direção y, quando a força se encontra no canto da placa, e tendem a se diferenciar conforme a força caminha para o meio da junta, onde atingem valores pequenos.

Os gráficos obtidos para eixos simples de rodagem simples, tandem duplos e tandem triplos estão apresentados no anexo B.

A influência da consideração de apenas um semi-eixo, em relação aos esforços provocados pela aplicação do carregamento em todo eixo, também está apresentada no anexo B.

\subsection{CONSIDERAÇÕES GERAIS}

Além de softwares gerais como o Ansys ou o SAP, existem softwares específicos para análise de tensões ou para dimensionamento de pavimentos de concreto, podendo ser citados:

- SLAB, desenvolvido na Universidade do Texas, entre 1966 e 1967;

- MWELP15, desenvolvido na Universidade de Illinois, publicado em 1972 ;

- ILLI-SLAB, apresentado por Tabatabaie, em 1977, na Universidade de Illinois.

- BISAR, desenvolvido da Holanda, pela SHELL, publicado em 1978;

- J-SLAB, desenvolvido pela PCA, publicado em 1981;

- WESTER, apresentado por Ioannides em 1984;

- MEDCONP, apresentado por WU e TIA (1989);

- RIGIPAVE, desenvolvido por BALBO (1989);

- FEACONS, desenvolvido na Universidade da Flórida, quarta versão apresentada em 1993;

- DIPLOMAT, apresentado por Khazanovich em 1994;

RUFINO (1997) faz uma análise de diversos programas computacionais para dimensionamento de pavimentos de concreto. 


\section{Capítulo}

\section{FADIGA EM PAVIMENTOS DE CONCRETO}

A fadiga é um processo de modificações progressivas e permanentes que ocorre nos materiais sob tensões repetidas. Portanto, é associada às ações dinâmicas ou aos carregamentos cíclicos. Essas modificações podem ser danosas, resultando em aumento progressivo de fissuras internas, que implica na perda de rigidez da estrutura. A deterioração pode evoluir a eventuais fraturas do material, caso a repetição seja suficientemente grande. Uma peça é capaz de romper por fadiga, sem que o nível de tensões ultrapasse a resistência do material.

\subsection{TIPOS DE AÇÕES CÍCLICAS}

O carregamento cíclico pode ocorrer de quatro formas diferentes:

- Solicitações repetidas: a tensão varia de zero a um máximo em ciclos constantes (figura 5.1);

- Solicitações alternadas: a tensão varia de um valor negativo a um valor positivo de mesma intensidade (figura 5.2);

- Solicitações onduladas: a tensão varia de um valor mínimo a um valor máximo, de mesmo sinal (figura 5.3);

- Solicitações com tipo de ondas quaisquer: a variação das tensões é aleatória (figura 5.4). 


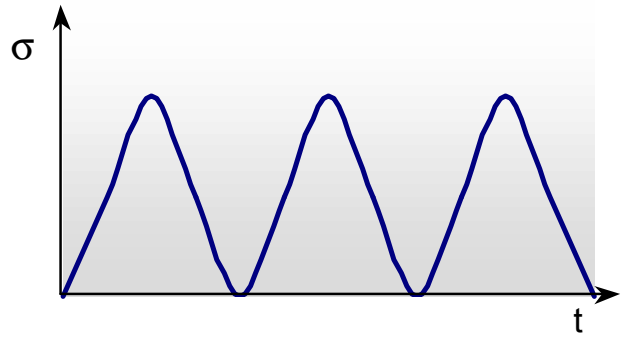

Figura 5.1 - Solicitações repetidas

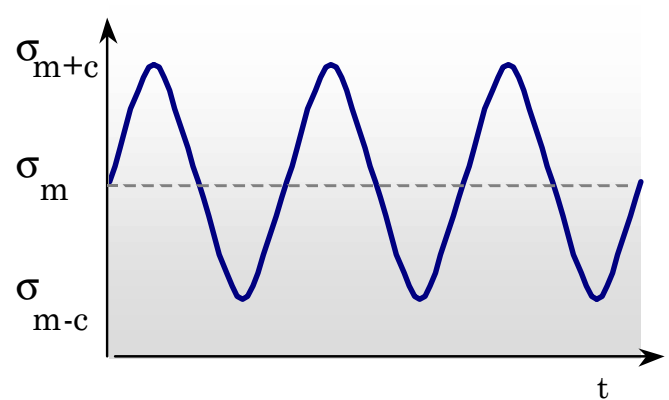

Figura 5.3 - Solicitações onduladas

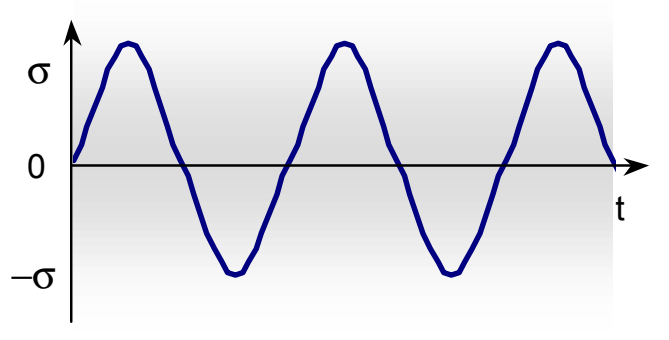

Figura 5.2 - Solicitações alternadas

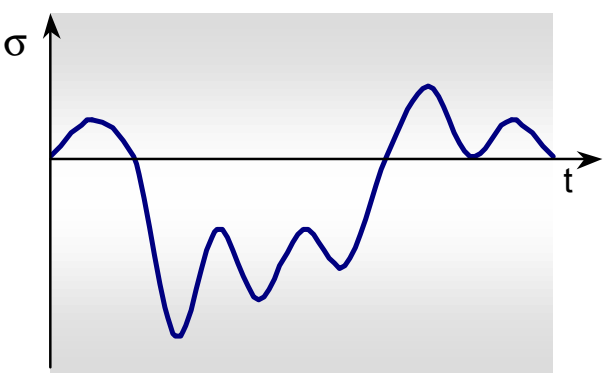

Figura 5.4 - Solicitações por ondas quaisquer

Nos pavimentos, a solicitação é aleatória, pois tanto as ações móveis quanto as variações de volume ocorrem de formas e intensidades diferentes com o decorrer do tempo.

\subsection{COMPORTAMENTO DO CONCRETO À FADIGA}

O concreto sujeito a ações repetidas pode apresentar fissuração excessiva e romper após um grande número de ciclos, mesmo que o nível de solicitações seja menor que a resistência monotônica do material. Estruturas de concreto sujeitas a carregamento cíclico apresentam, além de maior grau de fissuração, maiores deformações, se comparadas com estruturas submetidas a carregamento estático de mesma intensidade. O FATIGUE of concrete structures - CEB (1988) cita que, através de ensaios executados em 1979, Holmen concluiu que, a cada etapa de recarregamento, a deformação elástica 
aumenta progressivamente em decorrência da redução do módulo de elasticidade secante. Segundo este pesquisador, a deformabilidade transversal também é afetada, pois o coeficiente de Poisson aumentou a cada ciclo, para todos os modelos ensaiados até a ruptura.

A resistência à fadiga é definida como uma fração da resistência estática que pode ser suportada para um certo número de ciclos. Ela é normalmente apresentada em diagramas que indicam o número admissível de ciclos, ou o logaritmo desse número, em função da relação de tensão, $R_{T}$, dada por:

$R_{\mathrm{T}}=\sigma / \sigma_{\mathrm{adm}}$

sendo:

- $\sigma$ : tensão solicitante;

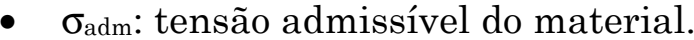

Esses diagramas são conhecidos como diagramas de Wöhler, ou curvas S-N (Stress - Number). Na figura 5.5 é mostrada a curva S-N para o concreto simples, apresentada por LARANJEIRAS (1990), para diversos valores da relação entre tensão mínima e tensão máxima, $R$, dada por:

$\mathrm{R}=\sigma_{\min } / \sigma_{\max }$

sendo:

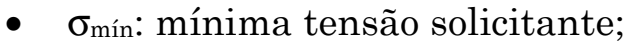

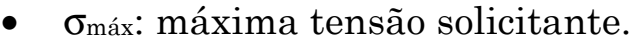

As curvas da figura 5.5 evidenciam que a redução da diferença entre as tensões mínima e máxima resulta em aumento da resistência à fadiga. Testes comprovam que a resistência à fadiga também é aumentada pelo alívio dos níveis de tensão e pela existência de "períodos de folga" - períodos em que a 
estrutura não está sujeita a carregamentos cíclicos. A frequência do ciclo de tensão tem efeito insignificante na resistência à fadiga.

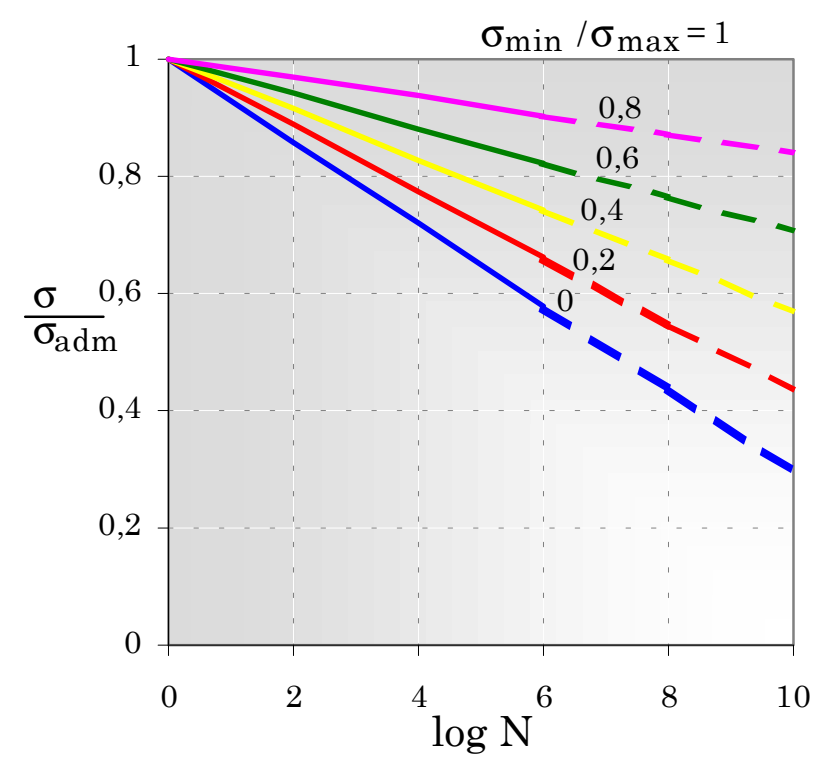

Figura 5.5 - Curva S-N para o concreto simples, adaptado de LARANJEIRAS (1990)

Segundo Fatigue of concrete structures - CEB (1988), um estudo objetivando estimar a vida à fadiga de elementos estruturais de concreto pode ser feita baseando-se na mecânica da fratura, que considera a propagação da fissura para um dado estágio de carregamento. Porém, tendo em vista a necessidade prática de um método simples de avaliação do fenômeno, vêm sendo utilizados os diagramas de Wöhler.

Segundo proposta do ACI (1992), o dimensionamento à ruptura por fadiga do concreto pode ser facilitado pelo uso do diagrama modificado de Goodman, ilustrado na figura 5.6. O diagrama é válido tanto para esforços de compressão quanto de tração ou flexão.

Segundo essa proposta, para o nível de tensão mínima igual a zero, a tensão máxima que o concreto pode suportar para um milhão de ciclos é adotada igual a $50 \%$ da resistência estática. Com o aumento do nível de tensões, diminui a relação entre tensões mínima e máxima que o concreto pode suportar. 


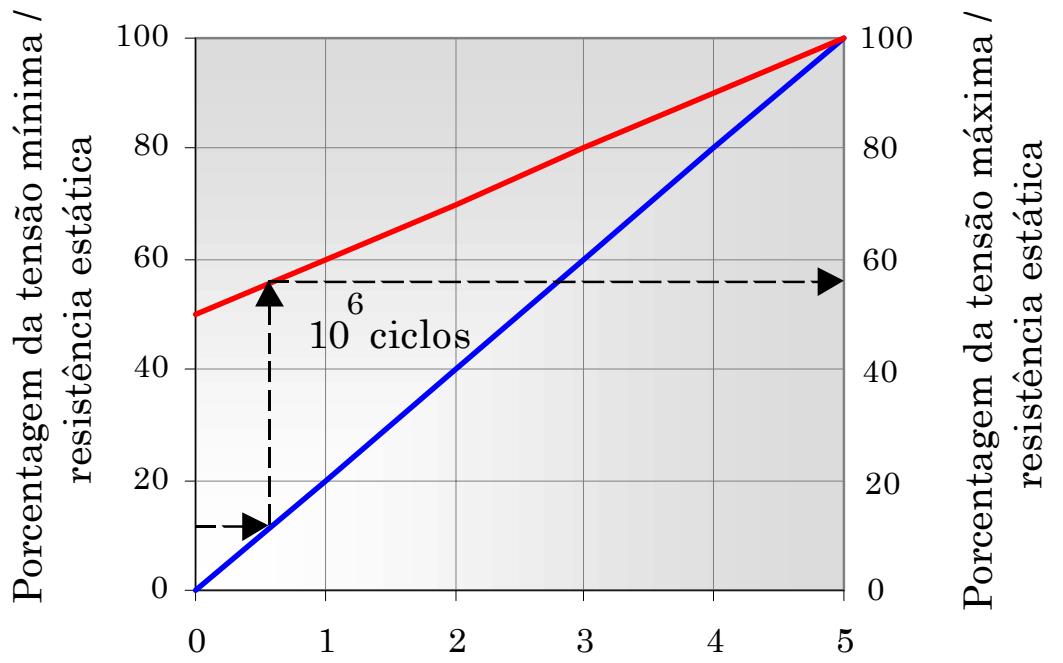

Figura 5.6 - Resistência do concreto à fadiga, adaptado de ACI 215R-81 (1992)

\subsection{COMPORTAMENTO À FADIGA DO AÇO PARA CONCRETO ARMADO}

A diminuição na tensão máxima admissível com a aplicação de carregamento cíclico, em barras de aço, deve-se ao fato desse material não ser um sólido idealmente homogêneo. A cada ciclo de carregamento, são produzidas pequeníssimas deformações localizadas, que não são totalmente reversíveis. Desta maneira, ao invés de se ter um comportamento elástico ideal e reversível do material, tem-se deformação plástica não uniforme. Estas deformações irreversíveis localizam-se ao longo dos planos de deslizamento, nos contornos dos grãos e ao redor das irregularidades das superfícies. Portanto, pode ocorrer ruptura do material mesmo que a solicitação seja mantida a um nível de tensão abaixo da tensão de escoamento.

O comportamento do aço para concreto armado, sob carregamento cíclico, é influenciado pelos seguintes fatores:

- geometria das nervuras;

- diâmetro das barras;

- dobramentos;

- emendas;

- soldas. 
As curvas S-N, para barras de aço para concreto armado, relacionam o número de ciclos com a máxima variação de tensão admissível, $\Delta \mathrm{f}_{\text {sd,fad. }}$ A figura 5.7 ilustra o diagrama de Wöhler, traçado a partir de valores de $\Delta \mathrm{f}_{\text {sd,fad }}$ e de $\mathrm{N}-$ número de ciclos -, apresentado pelo CEB-FIP/90 (1991), para barras retas ou com diâmetro de dobramento superior a 25 vezes o diâmetro da barra. A Revisão da NB-1 (1999) apresenta um diagrama semelhante, com pequenas diferenças nos valores de $\Delta \mathrm{f}_{\text {sd,fad. }}$

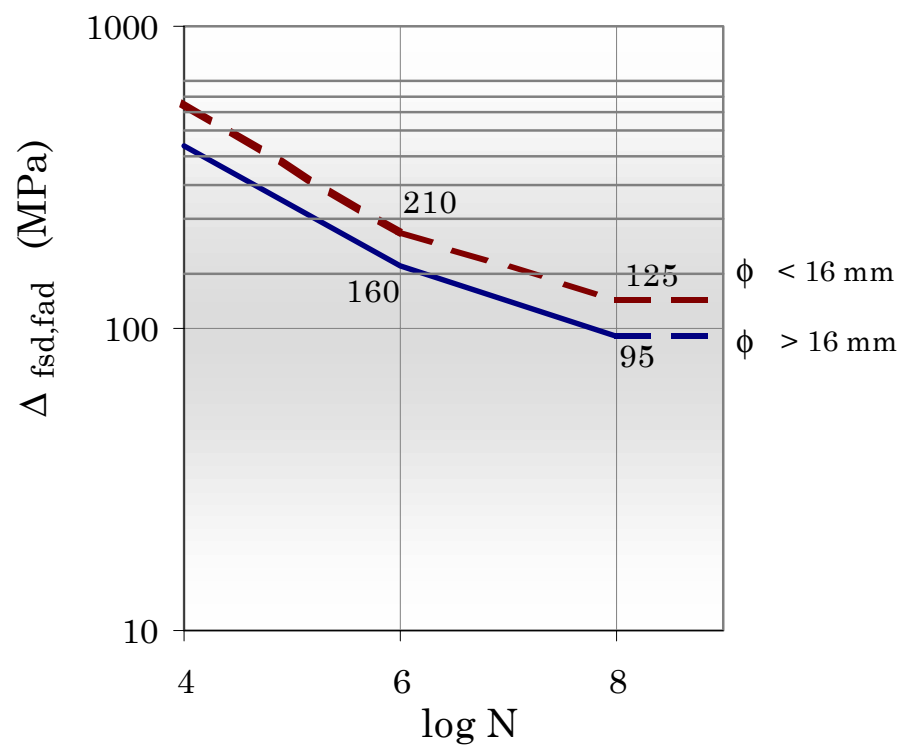

Figura 5.7 - Curvas S-N, do aço para concreto armado, traçadas a partir de valores fornecidos pelo CEB-FIP/90 (1991)

\subsection{REGRA DE PALMGREN-MINER}

A maioria dos ensaios de fadiga em laboratório restringe-se à aplicação de forças com diferenças constantes entre os níveis de tensões máxima e mínima (amplitude constante). Nas estruturas reais, entretanto, as tensões variam em grandeza, número e sequência, de modo aleatório. Na realidade, a ruptura da estrutura, por fadiga, é o resultado da acúmulo do dano causado por uma multiplicidade de ciclos de carregamento, com diferentes frequências e amplitudes. 
O tratamento do dano acumulado nos estudos da fadiga tem recebido uma larga atenção nos últimos anos. Entretanto, o dano não está associado diretamente com a perda de rigidez do material, mas sim com uma diminuição da vida à fadiga. Palmgren foi quem primeiro sugeriu o que é conhecido como “modelo linear de dano", em 1924, seguindo-se estudos feitos por Langer, em 1937, e Miner, em 1945. Porém, sabe-se que, apesar do mérito de um tratamento simples para histórias complexas de carregamento, as previsões realizadas com modelo linear são frequentemente pessimistas.

No modelo linear, dano é definido como sendo proporcional à relação de ciclos $n_{i} / N_{i}$, onde $n_{i}$ é o número de ciclos de tensão $\sigma_{i}$ durante o período em análise e $\mathrm{N}_{\mathrm{i}}$ é o número de ciclos correspondente à ruptura para um mesmo nível de tensão, conforme ilustra a figura 5.8.

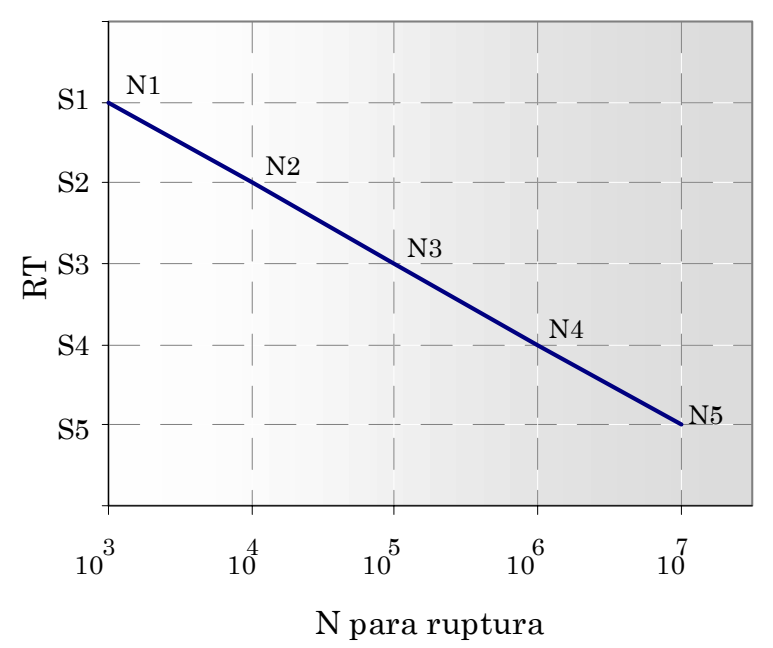

Figura 5.8 - Regra linear para acúmulo de dano por fadiga

Como critério geral, assume-se que a ruptura em consequência de vários níveis de carregamento deve ocorrer quando a soma das relações entre o número de ciclos realizados e o número de ciclos correspondentes à ruptura, para cada nível de tensão atuante, é igual a unidade:

$\mathrm{D}=\sum_{\mathrm{i}=1}^{\mathrm{n}} \frac{\mathrm{n}_{\mathrm{i}}}{\mathrm{N}_{\mathrm{i}}}=1$ 
sendo:

- $\quad \mathrm{n}_{\mathrm{i}}$ : número de ciclos com variação $\Delta \sigma_{\mathrm{i}}$

- $\quad \mathrm{N}_{\mathrm{i}}$ : número de ciclos que produz ruptura com $\Delta \sigma_{\mathrm{i}}$

- $\mathrm{n}_{\mathrm{i}} / \mathrm{N}_{\mathrm{i}}$ : dano produzido para o bloco i, independente dos demais

A relação de ciclos $n_{i} / N_{i}$ é também chamada de vida relativa à fadiga. Esse critério de ruptura não pode ser considerado como uma regra matematicamente exata, mas para amplitudes de tensão não tão diferentes entre si, a aproximação obtida é suficiente para a previsão de vida. Por outro lado, eventuais altos picos de tensão em meio a pequenos ciclos podem provocar uma considerável variação em relação à unidade, na soma das relações $\mathrm{n}_{\mathrm{i}} / \mathrm{N}_{\mathrm{i}}$.

Uma boa razão para o desvio de $D$ da unidade é o efeito da sequência de carregamento. De acordo com o modelo de acúmulo de dano de Miner, o dano causado por $\mathrm{n}_{\mathrm{i}}$ independe da história do carregamento. Entretanto, mesmo testes simples de dois níveis de solicitação têm mostrado que a soma de dano para ruptura depende da sequência de carregamento e não é a mesma para uma sequência A-B (aplicando-se primeiro o nível mais alto) e uma sequência B-A (aplicando-se primeiro o nível mais baixo):

$\sum\left(\frac{\mathrm{n}}{\mathrm{N}}\right)_{\mathrm{A}-\mathrm{B}}<\sum\left(\frac{\mathrm{n}}{\mathrm{N}}\right)_{\mathrm{B}-\mathrm{A}}$

A literatura contém grande número de teorias que tentam explicar a não-linearidade do acúmulo de dano, o efeito de carregamento, as tensões residuais e alguns outros efeitos não considerados pelo modelo de dano linear. Porém, segundo O’Neill (1970) citado por DRIEMEIER (1995) "não há evidência de que algumas das mais complexas teorias sejam superiores à regra linear em situações de interesse prático, e todas requerem mais dados experimentais". Essa opinião é apoiada por outros autores, cujo objetivo são regras menos precisas mas de grande praticidade. Para estes, apesar da relação de ciclos não ser sempre igual à unidade na ruptura, esta ainda é a melhor medida de perigo de ruptura por solicitação cíclica, tanto para o aço quanto para o concreto. 


\subsection{Modelos DE FAdiga APLICAdos A PAVIMENTOS DE CONCRETO}

Existem diversos modelos empíricos e semi-empíricos, para representação do comportamento do concreto à fadiga. Os modelos experimentais são desenvolvidos a partir de ensaios de laboratório. Os modelos semi-empíricos têm como base os resultados observados em pistas monitoradas ao longo de sua vida útil, que recebem tratamento teórico. A figura 5.9 apresenta o diagrama de Wöhler para os seguintes modelos:

- Modelo da PCA / 66;

- Modelo da PCA / 84;

- Modelo probabilístico;

- Modelo ARE;

- Modelo de Vesic e Saxena;

- Modelo RISC.

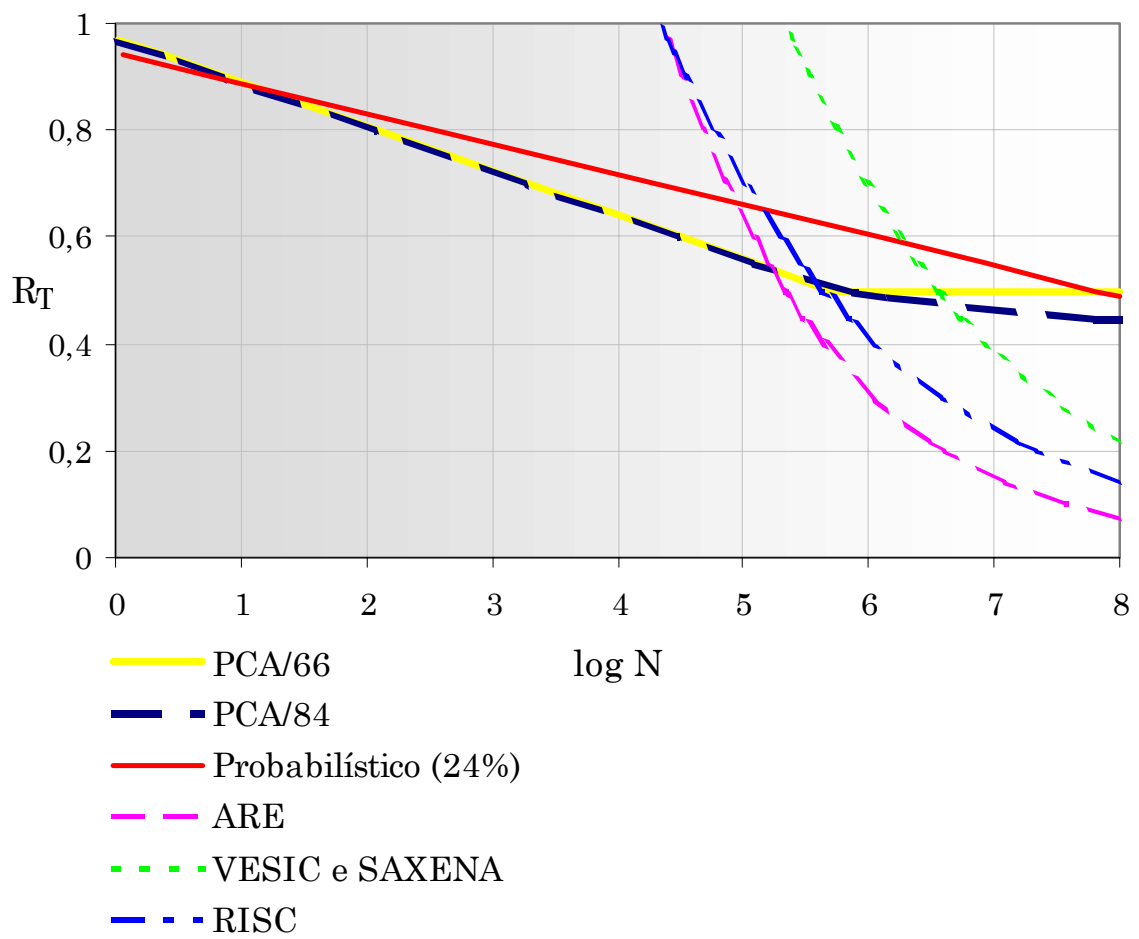

Figura 5.9 - Curvas S-N, para pavimentos de concreto

Observa-se uma grande variação entre os diversos modelos. Isso se deve a diferentes considerações sobre as características dos materiais, dados de 
desempenho, tipos de carregamento e teoria adotada para determinação das tensões no pavimento.

O modelo apresentado pelo método da PCA/66 (1966) considera que, para um nível de tensões abaixo de $50 \%$ da resistência do material, o número admissível de ciclos é ilimitado. Para uma relação de tensões entre 0,5 e 1, o número de ciclos é dado por:

$\log \mathrm{N}=11,737-12,077 \mathrm{R}_{\mathrm{T}}$

sendo:

- $\mathrm{N}$ : número admissível de ciclos;

- $\quad \mathrm{R}_{\mathrm{T}}$ : relação de tensões dada por (5.1), onde $\sigma_{\text {adm }}$ é igual ao módulo de ruptura ou resistência à tração na flexão do concreto aos 90 dias.

O método da PCA/84 (1984) reduziu para 45\% da resistência do material, o limite para o qual o número de repetições pode ser considerado ilimitado. Para outros valores da relação de tensões, a curva de fadiga é determinada pelas equações:

$\log \mathrm{N}=11,737-12,077 \mathrm{R}_{\mathrm{T}}$, para $\mathrm{R}_{\mathrm{T}}>0,55$

$\log \mathrm{N}=2,056-3,268 . \log \left(\mathrm{R}_{\mathrm{T}}-0,4325\right)$, para $0,45<\mathrm{R}_{\mathrm{T}}<0,55$

O modelo Probabilístico adota a seguinte equação:

$\log \mathrm{N}=\mathrm{f}_{1}-\mathrm{f}_{2} \mathrm{R}_{\mathrm{T}}$

Os coeficientes $\mathrm{f}_{1}$ e $\mathrm{f}_{2}$ são determinados em função da probabilidade de ruptura. Darter propôs que, para uma probabilidade de ruptura por fadiga de $24 \%$, os coeficientes deveriam assumir os seguintes valores: $f_{1}=16,61$ e $f_{2}=17,61$.

O modelo de fadiga ARE baseia-se em análises de seções da Pista Experimental da AASHO. Para a determinação da tensão máxima foi utilizada a teoria das camadas elásticas. A equação obtida foi a seguinte: 
$\log \mathrm{N}=4,37-3,21 \log \mathrm{R}_{\mathrm{T}}$

O modelo de fadiga de Vesic e Saxena também é baseado na Pista Experimental da AASHO. Foi utilizada a teoria de Westergaard para a determinação das tensões. Este modelo apresenta a equação:

$\log \mathrm{N}=5,35-4 \log \mathrm{R}_{\mathrm{T}}$

O modelo RISC foi baseado no estudo de seções rompidas e não rompidas da Pista Experimental da AASHO. Desenvolvido por Ilves e Majidzadeh, em 1983, utiliza a teoria de placas e a teoria de camadas elásticas para análise das tensões no pavimento. $\mathrm{O}$ modelo de fadiga é representado pela equação:

$\log \mathrm{N}=4,347-4,29 \log \mathrm{R}_{\mathrm{T}}$

Segundo BALBO (1999), os modelos experimentais são conservadores, pelos seguintes motivos:

- Nos pavimentos ocorrem variações nas trajetórias dos veículos, que podem reduzir as solicitações no ponto mais carregado; em laboratório o ponto de aplicação da força é fixo;

- A frequência do carregamento, em laboratório, é elevada, não permitindo a relaxação do material, que normalmente ocorre nas pistas;

- Em laboratório, são aplicadas forças e pressões constantes, enquanto nas pistas as ações são desiguais.

BALBO (1999) cita Majidzadeh" ${ }^{1}$, que afirma que os modelos de fadiga resultantes de testes com vigas de concreto sujeitas à flexão parecem ser inadequados, visto que as vigas são sujeitas a um estado uniaxial de tensões, enquanto os pavimentos são submetidos a um estado triaxial de tensões.

${ }^{1}$ MAJIDZADEH, K. (1988). A mechanistic approach to rigid pavement design. Concrete Pavements. p. 11-56, London and New York, Elsevier Applied Science. 
Quanto aos modelos semi-empíricos, segundo BALBO (1999), as limitações se devem ao fato do campo de validade ser restrito às condições de tráfego e ambientais dos pavimentos estudados.

\subsection{CRITÉRIOS DE SEGURANÇA}

O CEB-FIP/90 (1991) apresenta três critérios para verificação da segurança. A adoção de cada procedimento depende da disponibilidade de dados e do grau de precisão exigido pelo projeto.

Através do Processo Simplificado são limitadas as tensões atuantes, tanto no aço quanto no concreto, de tal maneira que o máximo esforço, para a combinação frequente das ações, não ultrapasse a resistência à fadiga para $10^{8}$ ciclos de carregamento. Desta maneira é preciso conhecer apenas um ponto do diagrama de Wöhler: a tensão, ou variação de tensão, que equivale a $10^{8}$ ciclos.

O segundo processo é mais preciso, pois dimensiona a estrutura para um número de ciclos qualquer, diferente do Processo Simplificado, que restringe as tensões aos valores equivalentes a $10^{8}$ ciclos. Neste caso a variação de tensões do aço, calculada para a combinação frequente das ações, é limitada à variação equivalente ao número $\mathrm{N}$ de ciclos considerado. Através desse procedimento é considerado um único nível de carregamento e é necessário conhecer o número de ciclos que solicitará a estrutura durante sua vida útil, para esse carregamento. Determinada a tensão máxima no concreto, assim como no aço, através da combinação frequente das ações, a segurança à fadiga estará garantida se o número admissível de ciclos para esse nível de tensão for superior ao número de ciclos que solicitará a estrutura durante o período de projeto.

O terceiro procedimento é o mais preciso. Por esse processo é calculado o dano acumulado através da regra de Palmgren-Miner. Desta forma é preciso conhecer o número admissível de ciclos para cada nível de tensão que solicitará a estrutura durante a vida útil. 


\subsection{CONSIDERAÇÕES GERAIS}

A consideração da fadiga é fundamental no dimensionamento de pavimentos de concreto, já que esse tipo de estrutura está sujeito a um número muito grande de repetições do carregamento. Os valores de tensões produzidas pelas ações rodoviárias são muito variáveis, o que torna importante a estimativa do número de repetições de cada nível de carregamento, a fim de permitir a utilização da regra de Palmgren-Miner, o que proporciona um dimensionamento mais adequado, levando em conta a vida útil do pavimento. No caso de pisos industriais, a variação das ações é menor, o que permite a utilização de critérios de segurança mais simples.

Apesar da dificuldade na determinação de um modelo de fadiga preciso, para os pavimentos rígidos, sabe-se que os modelos experimentais estão a favor da segurança, visto que estão sujeitos a condições de carregamento mais desfavoráveis que as pistas. Estudos estatísticos sobre as flutuações do carregamento podem reduzir o grau de imprecisão dos modelos de fadiga.

Pode-se verificar que a diferença entre a tensão mínima e a tensão máxima tem grande influência no número de repetições admissíveis. Embora o empenamento das placas de concreto provoquem aumento das tensões máximas na placa, durante o dia, a tensão mínima também é maior. Portanto, a variação de tensão não sofre o mesmo aumento que a tensão máxima. Durante a noite o efeito é contrário, a tensão mínima é de compressão e a máxima de tração, a inversão de sinal aumenta o efeito da fadiga, mas o nível de tensão é menor. 


\section{Capítulo}

\section{MÉTOdOS DE \\ DIMENSIONAMENTO DA ESPESSURA}

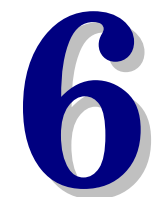

Entre os métodos para determinação da espessura de pavimentos rodoviários de concreto, o Departamento Nacional de Estradas e Rodagem (DNER) apresenta:

- Método da AASHTO (1986);

- Método da PCA (1966);

- Método da PCA (1984).

Para o dimensionamento de pisos industriais, é bastante utilizado o método apresentado por PACKARD (1976).

DARTER (1999) recomenda que, no dimensionamento da espessura de um pavimento rígido, sejam empregados mais de um método. Deve-se avaliar as considerações feitas em cada um e realizar uma análise de sensibilidade dos parâmetros adotados, a fim de determinar a melhor solução para o projeto, tendo em vista que cada método foi desenvolvido com base em ensaios e experiências particulares, não devendo ser generalizados para qualquer situação, sem as devidas adaptações.

Neste capítulo serão apresentados os métodos de dimensionamento da espessura, citados acima. Será apresentada ainda uma metodologia de verificação de punção de pisos industriais, submetidos a forças elevadas, aplicadas em pequenas áreas. 


\subsection{MÉTODO DA AASHTO}

O método de dimensionamento da AASHTO - Americam Association of State Highway and Transportation Officials - foi publicado em 1986, com base em testes realizados a partir de 1958, na pista experimental da então AASHO, próxima a Ottawa, Illinois, nos Estados Unidos. Uma nova versão desse método foi publicada em 1993, sem alterações significativas nos procedimentos para dimensionamento dos pavimentos rígidos.

\subsubsection{Número de eixos equivalentes}

O método da AASHTO prevê o cálculo do número admissível de eixos equivalentes que uma determinada espessura de pavimento é capaz de suportar. Para comparar o número admissível com o número de carregamentos previstos é necessário transformar cada eixo em um número equivalente de eixos simples de rodagem dupla com 8,16 tf. Os fatores de equivalência de eixos estão apresentados nas tabelas A.2 a A.10.

O tráfego final de projeto é dado por:

$\mathrm{N}_{\text {total }}=\mathrm{N}_{\mathrm{eq}} \cdot \mathrm{F}$

$\mathrm{F}=10^{\mathrm{ZR} \cdot \mathrm{s}_{\mathrm{O}}}$

sendo:

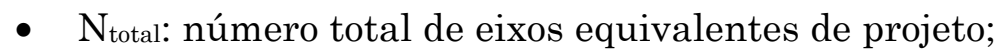

- $\mathrm{N}_{\text {eq }}$ : número de eixos equivalentes resultante da contagem e da projeção de tráfego;

- F: fator de segurança de tráfego;

- $\mathrm{Z}_{\mathrm{R}}$ : coeficiente de Student;

- $\mathrm{S}_{\mathrm{o}}$ : desvio padrão devido ao erro da estimativa de tráfego e do modelo de deterioração adotado. 
O coeficiente de Student é definido a partir do nível de confiabilidade, R. O nível de confiabilidade de um projeto de pavimento é a probabilidade de que ele tenha um comportamento igual ou melhor que o previsto, durante o período de projeto. Valores de $\mathrm{R}$, recomendados pela AASHTO, estão apresentados na tabela A.11.

Valores de $Z_{R}$ e F, em função de R, são apresentados na tabela A.12.

\subsubsection{Fórmula geral}

Para determinação do número admissível de repetições do eixo equivalente é utilizada a seguinte fórmula:

$\mathrm{N}_{\text {eq,adm }}=\left(\frac{\mathrm{h}+2,54}{2,588}\right)^{7,35} \cdot 10^{\mathrm{a}} \cdot \mathrm{B}^{(4,22-0,32 \cdot \mathrm{s} \mathrm{f}}$

com:

$$
\begin{aligned}
& \mathrm{a}=\frac{\log (0,33 \cdot \Delta \mathrm{s})}{1+\left(\frac{18,078}{\mathrm{~h}+2,54}\right)^{8,46}} \\
& \mathrm{~B}=\frac{\mathrm{f}_{\mathrm{ct}, \mathrm{eq}}}{15,185} \cdot\left(\frac{\mathrm{h}^{0,75}-2,278}{\mathrm{~h}^{0,75}-46,79 \cdot\left(\frac{\mathrm{k}}{\mathrm{E}}\right)^{0,75}}\right) \\
& \mathrm{f}_{\mathrm{ct}, \mathrm{eq}}=\frac{\mathrm{f}_{\mathrm{ctm}} \cdot \mathrm{C}_{\mathrm{d}}}{\mathrm{J}} \\
& \Delta \mathrm{s}=\mathrm{s}_{\mathrm{i}}-\mathrm{s}_{\mathrm{f}}
\end{aligned}
$$

sendo: 


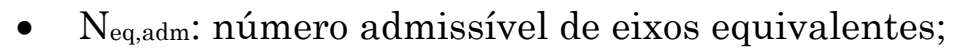

- h: espessura da placa, em centímetros;

- $\Delta$ s: perda de serventia;

- $\quad$ si: índice de serventia inicial;

- $\quad$ sf: índice de serventia final;

- $\mathrm{f}_{\mathrm{ct}, \mathrm{eq}}$ : resistência equivalente, do concreto, em $\mathrm{kgf} / \mathrm{cm}^{2}$;

- $\mathrm{f}_{\mathrm{ctm}}$ : resistência do concreto à tração na flexão, aos 28 dias;

- $\mathrm{k}$ : coeficiente de recalque do solo, em $\mathrm{kgf} / \mathrm{cm}^{2} / \mathrm{cm}$;

- E: módulo de elasticidade do concreto;

- $\mathrm{C}_{\mathrm{d}}$ : coeficiente de drenagem da sub-base;

- J: coeficiente de transferência de carga.

Para os índices de serventia é comum a adoção dos seguintes valores:

- $\mathrm{Si}_{\mathrm{i}}=4,5$ (valor adotado para a maioria dos casos reais);

- $\quad \mathrm{Sf}_{\mathrm{f}}=2,0$ ou 2,5 (para auto-estradas).

Valores para o coeficiente de drenagem e o coeficiente de transferência de carga, utilizados na determinação da resistência equivalente do concreto, estão apresentados nas tabelas A.13 e A.15.

Para iniciar o procedimento, o manual do DNER (1989) apresenta a fórmula da espessura tentativa:

$\mathrm{h}=20 \cdot \frac{\mathrm{N}_{\text {total }}^{0,136}}{\mathrm{k}^{0,07} \cdot \mathrm{f}_{\mathrm{ctm}}^{0,51}}-3$

Para utilização da equação (6.8) é necessário conhecer o número de eixos, função da espessura. Portanto, o cálculo da espessura tentativa depende de uma espessura inicial arbitrada. Neste trabalho recomenda-se a adoção de uma espessura tentativa e verificação através da fórmula geral (6.3), desprezando a equação (6.8). 


\subsubsection{Determinação do coeficiente de recalque da fundação}

O manual do DNER (1989) apresenta uma sequência para determinação do coeficiente de recalque da fundação diferente do método original da AASHTO (1986).

Segundo o manual, podem ser usadas as figuras A.1 a A.5, na determinação de $k_{0}$ (coeficiente de recalque do subleito) e $k_{1}$ (coeficiente de recalque no topo da fundação). No método original, o solo é caracterizado pelo módulo resiliente, e o material da sub-base é caracterizado pelo módulo de elasticidade. O guia da AASHTO (1986) propõe a seguinte relação entre módulo resiliente e CBR:

$\mathrm{MR}(\mathrm{psi})=1.500 \cdot \mathrm{CBR}$

sendo:

- MR: módulo resiliente;

- CBR: índice de suporte Califórnia.

Caso o pavimento seja colocado diretamente sobre o subleito, o módulo de reação é dado por (AASHTO, 1986):

$\mathrm{k}_{\mathrm{o}}=\frac{\mathrm{MR}}{19,4}$

$\mathrm{O}$ coeficiente de recalque no topo da sub-base, $\mathrm{k}_{1}$, segundo o método original, é determinado através da figura A.6. O módulo resiliente e, consequentemente, $\mathrm{k}_{1}$ devem ser determinados para cada período do ano.

Se houver estrato rígido (material de resistência muito alta a menos de 3 metros do nível do subleito) o valor de $\mathrm{k}_{1}$ é alterado, gerando $\mathrm{k}_{2}$, que também é determinado para cada período do ano. A determinação de $\mathrm{k}_{2}$, segundo DNER (1989) é feita através da seguinte fórmula: 
$\mathrm{k}_{2}=\mathrm{F}_{\mathrm{Z}} \cdot \mathrm{k}_{1}$

sendo:

- $\mathrm{k}_{2}$ : coeficiente de recalque corrigido pela presença de estrato rígido a uma profundidade $z$;

- $\mathrm{k}_{1}$ : coeficiente de recalque corrigido pela presença de sub-base;

- Fz: fator de correção devido à presença de estrato rígido.

$\mathrm{O}$ valor de $\mathrm{Fz}$ é determinado através da fórmula:

$\mathrm{F}_{\mathrm{Z}}=\mathrm{e}^{0,386 \cdot(3-\mathrm{Z}) \cdot \mathrm{k} 1}{ }^{(-0,294)}$

sendo:

- Z: profundidade do estrato rígido em relação ao nível do subleito, em metros.

O guia da AASHTO (1986) apresenta o gráfico da figura A.7, para determinação de $\mathrm{k}_{2}$.

Devido à ocorrência de variações sazonais, obtém-se $\mathrm{k}_{3}$, definido por (DNER, 1989):

$\mathrm{k}_{3}=3,7-34,5 \cdot \log \overline{\mathrm{u}}$

sendo:

- $\quad \mathrm{k}_{3}$ : coeficiente de recalque efetivo;

- $\overline{\mathrm{u}}$ : fator de dano médio.

O fator de dano, calculado para cada período do ano, é dado por (DNER, 1989):

$\mathrm{u}=1,28 \cdot 10^{\left(-0,029 \cdot \mathrm{k}_{2}\right)}$ 
O fator de dano médio, $\overline{\mathrm{u}}$, é dado pela média dos fatores de dano relativos a cada período do ano. Caso tenha sido adotado apenas um valor para k, não é necessário proceder a correção devida ao dano relativo, pois o valor de $\mathrm{k}_{3}$ será igual a $\mathrm{k}_{2}$.

Pelo método da AASHTO (1986), os valores de u são obtidos da figura A.8. Depois de calculada o fator de dano médio, retorna-se à figura A.8 e determina-se o valor de $\mathrm{k}_{3}$.

Finalmente, é feita a correção no valor de $\mathrm{k}$ devido à perda de suporte da fundação (DNER, 1989):

$\mathrm{k}_{\mathrm{d}}=\mathrm{F}_{\mathrm{ps}} \cdot \mathrm{k}_{3}$

sendo:

- $\mathrm{k}_{\mathrm{d}}$ : coeficiente de recalque corrigido por perda de suporte;

- $\mathrm{F}_{\mathrm{ps}}$ : fator de perda de suporte.

O fator de perda de suporte é calculado por (DNER, 1989):

$\mathrm{F}_{\mathrm{ps}}=10^{\left(-0,33 \cdot \mathrm{p}_{\mathrm{s}}\right) \cdot \mathrm{k}_{3}}\left(-0,17 \cdot \mathrm{p}_{\mathrm{s}}\right)$

sendo:

- $\quad p_{s}$ : perda de suporte, que depende do tipo de sub-base.

Os valores de $\mathrm{p}_{\mathrm{s}}$ estão apresentados na tabela A.14.

A correção de k devida à perda de suporte, segundo AASHTO (1986), é realizada com o auxílio do gráfico da figura A.9. Apesar de determinarem o mesmo parâmetro, as equações 6.15 e 6.16 não fornecem valores iguais aos da figura A.9. 


\subsection{MÉTODO DA PCA / 66}

O método para determinação da espessura de pavimentos de concreto, publicado pela Portland Cement Association, em 1966, tem base no critério de fadiga. A determinação das tensões é feita com o auxílio de ábacos.

\subsubsection{Critério de fadiga}

A análise de fadiga é feita com a utilização da regra de Miner, ou seja, através do acúmulo do consumo de fadiga de todas as forças consideradas, sendo o consumo de resistência à fadiga dado por:

$\mathrm{C}_{\text {total }}=\sum_{\mathrm{i}} \frac{\mathrm{N}_{\mathrm{sol}, \mathrm{i}}}{\mathrm{N}_{\mathrm{adm}, \mathrm{i}}}$

sendo:

- $\mathrm{C}_{\text {total: }}$ consumo total da resistência à fadiga;

- i: relação de tensões

- $\quad \mathrm{N}_{\text {sol,i: }}$ número de repetições previstas para a relação de tensões i;

- $\mathrm{N}_{\mathrm{adm}, \mathrm{i}}$ número admissível de repetições para a relação de tensões i.

Como se verifica um aumento da resistência à fadiga, quando há períodos de folga entre as aplicações de carregamento, a PCA (1966) indica um consumo máximo de fadiga de 125\%. O Manual do DNER (1989) adota um consumo máximo e 100\%. O curva S-N adotada pela PCA/66 foi discutida no capítulo 5 e está reproduzida na figura 6.1. 


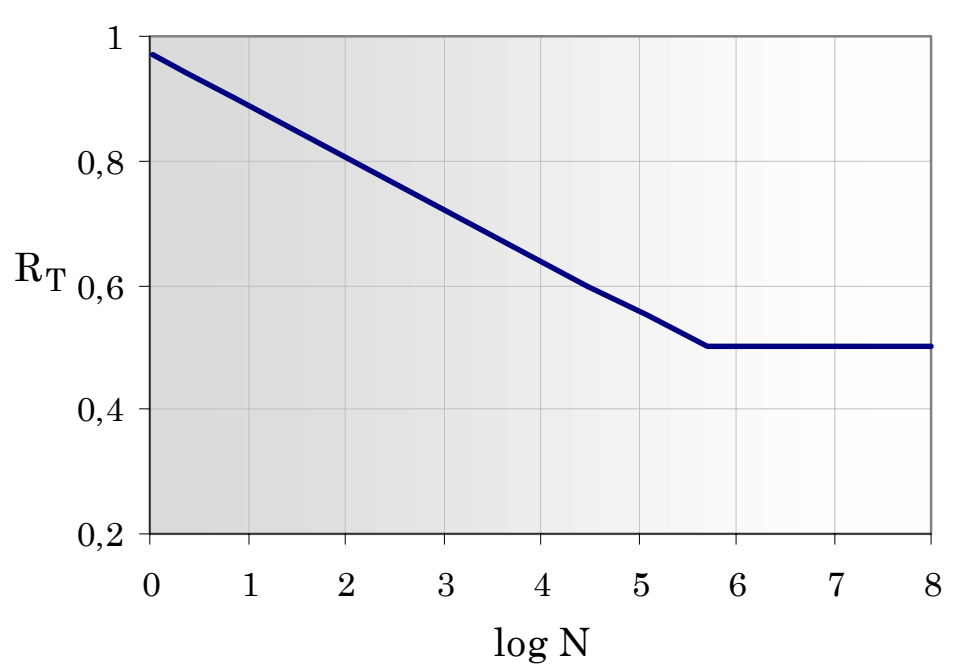

Figura 6.1 - Critério de fadiga adotado pela PCA/66

A relação de tensões é a tensão de tração máxima produzida por uma força, dividida pelo módulo de resistência do concreto, $M_{R}$. É adotado o módulo de resistência, no mínimo, aos 28 dias e, no máximo, aos 90 dias. Quando não se conhece os valores de $\mathrm{M}_{\mathrm{R}, 90}$, é comum fazer:

$\mathrm{M}_{\mathrm{R}, 90}=1,10 \cdot \mathrm{M}_{\mathrm{R}, 28}$

sendo:

- $\mathrm{M}_{\mathrm{R}, 90}$ : módulo de ruptura do concreto aos 90 dias;

- $\mathrm{M}_{\mathrm{R}, 28}$ : módulo de ruptura do concreto aos 28 dias;

O método prevê a verificação do consumo de fadiga, para uma dada espessura, ou seja, o dimensionamento é feito por tentativas.

\subsubsection{Determinação das tensões}

Para determinação das tensões atuantes nos pavimentos, a fundação é considerada como líquido denso e o coeficiente de recalque $\mathrm{k}$ é determinado por meio de prova de carga, ou por correlações com o CBR (figura A.1). A PCA/66 
analisou três posições de aplicação da força e obteve uma distribuição estatística do carregamento, conforme ilustrado na figura 6.2 .

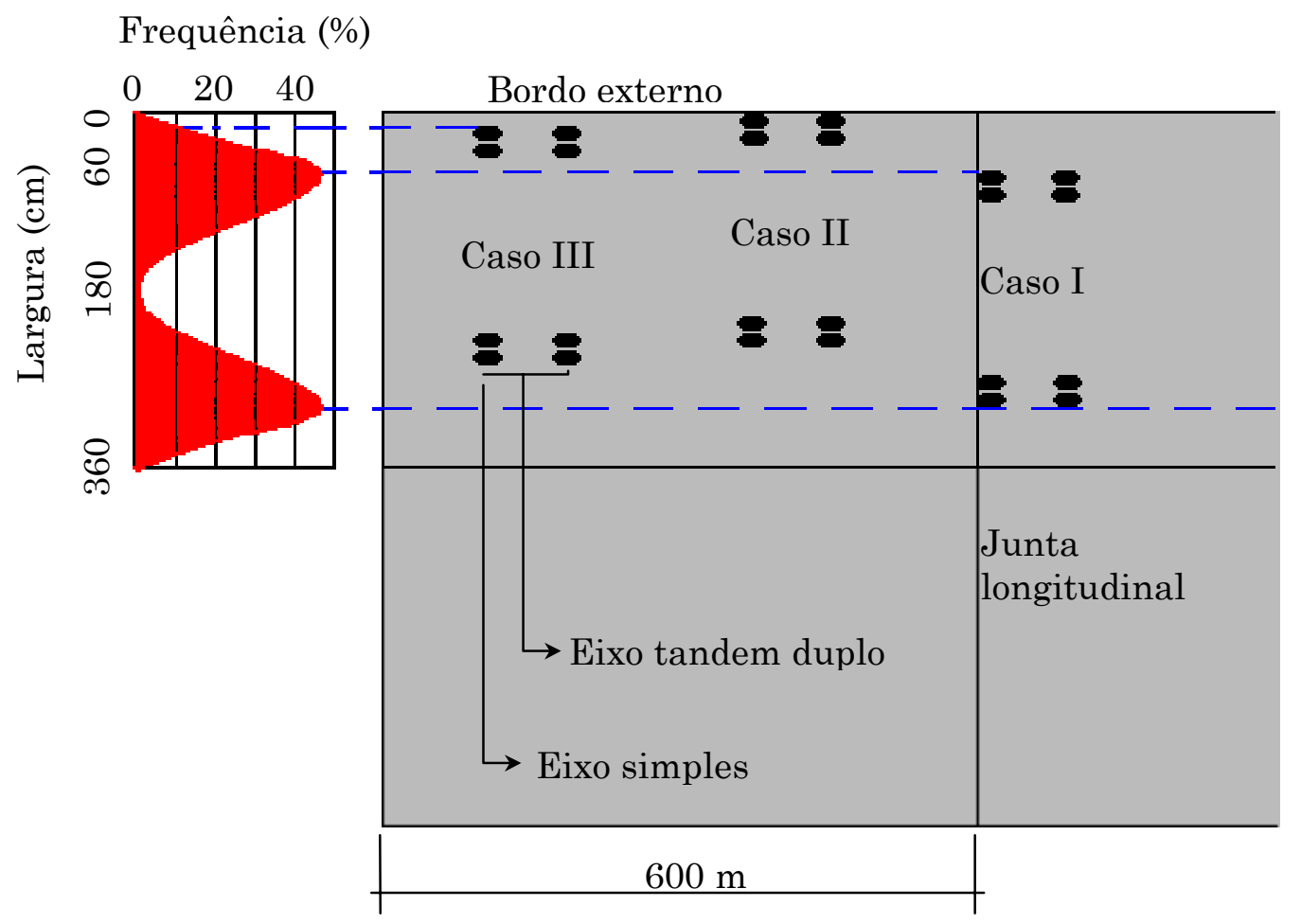

Figura 6.2 - Distribuição percentual do carregamento nas posições em relação à placa

As tensões de tração provenientes do Caso II são maiores que nos outros dois casos, sendo que a posição mais favorável é da força no interior da placa (Caso III). A determinação das tensões é realizada com auxílio de ábacos desenvolvidos por PICKETT e RAY (1951), para eixos simples e tandem duplo, e por PITTA (1978), para eixos tandem triplo. Verificou-se que, para eixos simples, o Caso I é mais desfavorável, quando o eixo está a mais de $7,5 \mathrm{~cm}$ da borda, e para eixo tandem, quando o eixo está a mais de 2,5cm da borda. Assim sendo, o Caso I é mais desfavorável para 99,8\% do tráfego de eixos simples e 99,9\% do tráfego de eixos tandem duplo. Portanto, o método despreza a parcela devido ao Caso II e dimensiona o pavimento para forças tangentes à junta transversal. 


\subsubsection{Segurança}

O método aplica fator de segurança devido à imprecisão da estimativa do número de repetições das solicitações, de acordo com a finalidade e o tipo de tráfego, conforme indicado na tabela A.16.

\subsubsection{Procedimento de cálculo}

Preenchendo o quadro 6.1, é obtido o consumo total da resistência à fadiga e é feita, dessa forma, a verificação da espessura tentativa.

Quadro 6.1 - Cálculo da espessura de pavimento de concreto

Projeto:

Espessura tentativa:

$\mathrm{k}$ :

$\mathrm{F}_{\mathrm{SC}}$ :

$\mathrm{M}_{\mathrm{R}}$ :

Período de Projeto
Nome do projeto

Valor da espessura tentativa $(\mathrm{cm})$

Valor de k no todo da fundação $(\mathrm{MPa} / \mathrm{m})$

Coeficiente de segurança adotado para o projeto

Valor do módulo de resistência da concreto $(\mathrm{MPa})$

Período de projeto para o qual foi estimado o $\mathrm{N}_{\text {solicitante }}$

\begin{tabular}{|c|c|c|c|c|c|c|}
\hline $\begin{array}{c}\text { Peso por } \\
\text { eixo } \\
(\mathrm{tf})\end{array}$ & $\begin{array}{c}\text { Peso por } \\
\text { eixo. F } \\
(\mathrm{tf})\end{array}$ & $\begin{array}{c}\text { Tensão na } \\
\text { placa } \\
(\mathrm{MPa})\end{array}$ & $\begin{array}{c}\text { Relação } \\
\text { de } \\
\text { tensões }\end{array}$ & $\mathrm{N}_{\mathrm{adm}}$ & $\mathrm{N}_{\text {sol }}$ & $\begin{array}{c}\mathrm{C} \\
(\%)\end{array}$ \\
\hline$(1)$ & $(2)=(1)$. Fs & $(3)$ & $(4)=(3) / \mathrm{M}_{\mathrm{R}}$ & $(5)$ & $(6)$ & $(7)=(6) /(5)$ \\
\hline
\end{tabular}

Eixos simples

\begin{tabular}{|l|l|l|l|l|l|l|}
\hline & & & & & & \\
\hline & & & & & & \\
\hline & & & & & & \\
\hline
\end{tabular}

Eixos tandem duplos

\begin{tabular}{|l|l|l|l|l|l|l|}
\hline & & & & & & \\
\hline & & & & & & \\
\hline & & & & & & \\
\hline
\end{tabular}

Eixos tandem triplos

\begin{tabular}{|l|l|l|l|l|l|l|}
\hline & & & & & & \\
\hline & & & & & & \\
\hline
\end{tabular}

Ctotal:

A tensão na placa (coluna 3) é determinada com auxílio dos ábacos das figuras A.10 a A.12. O número admissível de solicitações, $\mathrm{N}_{\text {adm }}$ (coluna 5) é determinado a partir da tabela A.17. 


\subsection{MÉTODO DA PCA / 84}

O método apresentado pela Portland Cement Association, em 1984, acrescenta diversos conhecimentos adquiridos na área de cálculo de tensões, projeto geométrico, construção e gerência de pavimentos. Enquanto no método da PCA/66 adota-se a teoria de Westergaard para determinação das tensões, no método de 1984 são realizadas análises estruturais com o uso do método dos elementos finitos, levando em conta:

- Grau de transferência de carga nas juntas transversais;

- Efeitos da existência ou não de acostamento de concreto;

- Contribuição estrutural das sub-bases de solo melhorado ou de concreto pobre;

- Ação de eixos tandem triplos.

Assim como no método anterior, o valor de suporte da fundação é o coeficiente de recalque $\mathrm{k}$, discutido na capítulo 4. Quanto à resistência do concreto, deve-se utilizar os valores medidos aos 28 dias, tendo em vista que as tabelas e os ábacos que compõem o método já incorporam o crescimento da resistência do concreto com o tempo.

O método considera três modelos de ruptura do pavimento:

- Fadiga;

- Erosão;

- Escalonamento.

O método da PCA/84 pode ser aplicado na determinação de espessuras de pavimentos simples, com ou sem juntas de transferência, ou em pavimentos com armadura distribuída contínua ou descontínua.

Não foram feitas mudanças, em relação ao método apresentado em 1966, nos critérios para determinação do coeficiente de segurança das ações. 


\subsubsection{Critério de fadiga}

O modelo de fadiga foi apresentado no capítulo 5. Assim como no método da PCA/66, utiliza o conceito de dano acumulado, segundo a regra de Miner, sendo o consumo total máximo da resistência à fadiga igual a 100\%. A curva S-N, adotada pela PCA (1984), está reproduzida na figura 6.3.

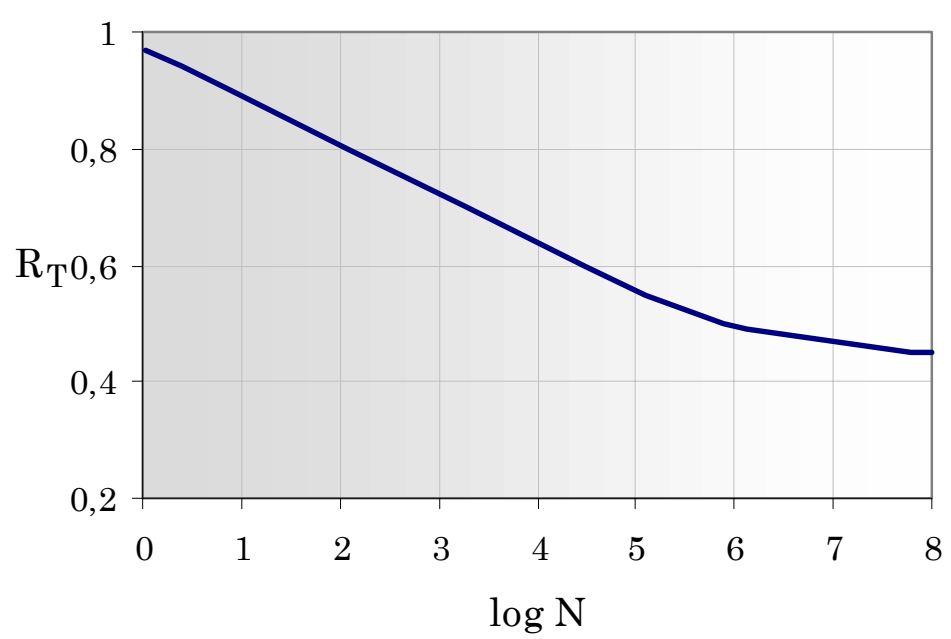

Figura 6.3 - Critério de fadiga adotado pela PCA/84

A posição crítica de aplicação de força passa a ser tangente à borda longitudinal, diferente do método de 1966, que dimensionava para o Caso I, desprezando as forças atuantes na borda do pavimento. Sabe-se, que apenas um pequeno número de caminhões trafegam nessa posição. Dessa forma, foram calculadas porcentagens de caminhões trafegando desde a borda até o interior da placa. No procedimento da PCA/84 está implícita uma taxa de 6\% de caminhões trafegando junto à borda longitudinal.

A existência de acostamento de concreto diminui o valor da tensão máxima, já que a força atuante na borda do pavimento será distribuída entre a placa da pista e do acostamento. O método considera uma eficiência das juntas de $65 \%$, no caso de haver ligação entre a pista e o acostamento. A conceito de eficiência de junta é definido no capítulo 8. 
Mesmo não havendo ligação entre a pista e o acostamento, na existência deste, a tensão máxima equivale a $96,7 \%$ da tensão calculada para força na borda, sem acostamento de concreto. Esse fato já está incorporado ao método.

\subsubsection{Critério de erosão e escalonamento}

A erosão é a perda de material do topo da camada imediatamente sob a placa de concreto. Ocorre devido à ação combinada da água e da passagem de forças elevadas. Na análise da erosão, também se utiliza o conceito de dano acumulado, dado por:

$\mathrm{D}_{\text {total }}=\sum_{\mathrm{i}} \mathrm{C}_{2} \frac{\mathrm{N}_{\text {sol,i }}}{\mathrm{N}_{\mathrm{adm}, \mathrm{i}}}$

sendo:

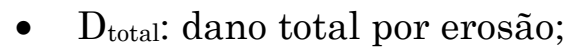

- i: relação de tensões

- $\mathrm{N}_{\text {sol,i: }}$ número de repetições previstas para a relação de tensões $\mathrm{i}$, devido à força na borda, quando não houver acostamento de concreto, ou devido à força no interior da placa, quando houver acostamento de concreto;

- $\quad \mathrm{N}_{\mathrm{adm}, \mathrm{i}}$ número admissível de repetições para a relação de tensões i, nas mesmas condições citadas acima;

- $\mathrm{C}_{2}$ : coeficiente de distribuição de tráfego tomado 0,06 para pavimentos sem acostamento de concreto e 0,94 para pavimentos com acostamento de concreto.

O parâmetro de erosão é chamado de potência, taxa de trabalho ou fator de erosão e é representado pela letra $P$. O valor de $P$ mede o poder que uma certa força tem de produzir deformação vertical na placa. Tomando-se fatores oriundos de correlações em pistas experimentais, para índice de serventia final igual a 3 , obteve-se a seguinte expressão para $\mathrm{P}$ : 
$\mathrm{P}=\frac{268,7 \cdot \mathrm{p}^{2}}{\mathrm{~h} \cdot \mathrm{k}^{0,73}}$

sendo:

- P: fator de erosão;

- p: pressão vertical exercida na fundação sob o canto da placa, em psi;

- h: espessura da placa em polegadas;

- $\mathrm{k}$ : coeficiente de recalque, em libras por polegada cúbica.

Incorporando ao modelo de erosão os danos pela formação de degraus, ou escalonamento, nas juntas transversais, foram incluídos fatores como juntas sem barras de transferência e sub-bases estáveis, não considerados nos modelos que se baseiam exclusivamente na pista experimental da AASHO. Obteve-se então a expressão que representa o modelo de escalonamento associado ao de erosão:

$\log \mathrm{N}=14,524-6,777 \cdot\left(\mathrm{C}_{1} \cdot \mathrm{P}-9,0\right)^{0,013}$

sendo:

- N: número admissível de passagens da força;

- P: fator de erosão;

- $\mathrm{C}_{1}$ : constante de ajustamento relacionada ao tipo de sub-base, igual a 1,0 se granular e cerca de 0,9 se tratada com cimento.

Os eixos tandem são os maiores responsáveis pelo dano por erosão. Observa-se que o dano por erosão está intimamente ligado às condições climáticas regionais e à eficiência da drenagem, não sendo esses fatores cobertos pelo método. Por isso, o critério de erosão é uma diretriz básica, que poderá ser modificada em função de dados locais, como pluviosidade, tipo e eficácia da drenagem, DNER (1989). O dano por erosão total recomendado pela PCA/84 é de 100\%, que, segundo DNER (1989) merece análise do projetista.

A posição crítica na análise da erosão e do escalonamento é o canto da placa. Desta forma, tanto a existência de bons dispositivos de transferência de 
carga entre as placas da pista como entre a pista e o acostamento, possibilitam uma redução da espessura final, devido à menor tensão desenvolvida na região tangente à junta transversal e à borda longitudinal.

\subsubsection{Procedimento de cálculo}

O preenchimento do quadro 6.2 possibilita a verificação do consumo de fadiga e do dano por erosão e escalonamento, para uma determinada espessura tentativa.

Quadro 6.2 - Dimensionamento de pavimento de concreto - PCA/84

Projeto:

Nome do projeto

Espessura tentativa: Valor da espessura tentativa (cm)

$\mathrm{k}$ :

Fsc:

Valor de $\mathrm{k}$ no todo da fundação $(\mathrm{MPa} / \mathrm{m})$

$\mathrm{M}_{\mathrm{R}}$ :

Coeficiente de segurança adotado para o projeto

Juntas com barras de transferência sim não

Acostamento de concreto

$\operatorname{sim}$

não

Período de Projeto $\quad$ Período de projeto para o qual foi estimado o $\mathrm{N}_{\text {sol }}$

\begin{tabular}{|c|c|c|c|c|c|c|}
\cline { 3 - 6 } \multicolumn{2}{c|}{} & \multicolumn{2}{c|}{ Análise de Fadiga } & \multicolumn{2}{c|}{ Análise de Erosão } \\
\hline $\begin{array}{c}\text { Peso por } \\
\text { eixo } \\
(\mathrm{tf})\end{array}$ & $\begin{array}{c}\text { Peso por } \\
\text { eixo . FSC } \\
(\mathrm{tf})\end{array}$ & $\mathrm{N}_{\mathrm{sol}}$ & $\mathrm{N}_{\mathrm{adm}}$ & $\begin{array}{c}\text { Consumo } \\
\text { de fadiga } \\
(\%)\end{array}$ & $\mathrm{N}_{\mathrm{adm}}$ & $\begin{array}{c}\text { Dano por } \\
\text { erosão } \\
(\%)\end{array}$ \\
\hline$(1)$ & $(2)=(1)$. FS & $(3)$ & $(4)$ & $(5)$ & $(6)$ & $(7)=(6) /(5)$ \\
\hline
\end{tabular}

Eixos simples

8- Tensão equivalente:

9- Fator de fadiga:

10- Fator de erosão:

\begin{tabular}{|l|l|l|l|l|l|l|}
\hline & & & & & & \\
\hline
\end{tabular}

Eixos tandem duplos

11- Tensão equivalente:

12- Fator de fadiga:

13- Fator de erosão:

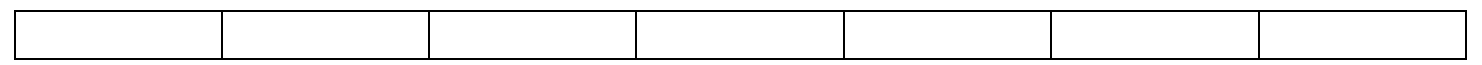

Eixos tandem triplos

14- Tensão equivalente:

15- Fator de fadiga:

16- Fator de erosão:

\begin{tabular}{l}
\hline \\
\hline
\end{tabular}


O número admissível de repetições à fadiga (coluna 4) é obtido através do ábaco da figura A.13, tendo como parâmetros de entrada a força por eixo (coluna 2) e os fatores de fadiga (9, 12 e 15), dados por:

$\mathrm{f}_{\text {fad }}=\frac{\sigma_{\mathrm{eq}}}{\mathrm{M}_{\mathrm{R}}}$

$(9)=(8) / M_{R}$

$(12)=(11) / \mathrm{M}_{\mathrm{R}}$

$(15)=(14) / \mathrm{M}_{\mathrm{R}}$

sendo:

- $f_{\text {fad: fator de fadiga; }}$

- $\sigma_{\text {eq: }}$ tensão equivalente determinada através das tabelas A.18 e A.19.

O número admissível de repetições devido à erosão (coluna 6) é obtido através dos ábacos das figura A.14 e A.15, tendo como parâmetros de entrada a força por eixo (coluna 2) e os fatores de erosão (10, 13 e 16), determinados através das tabelas A.20 a A.23.

Como não foram desenvolvidos ábacos específicos para eixos tandem triplos, as colunas referentes aos valores de força por eixo (1 e 2), para eixos tandem triplos, é preenchida pela força total dividida por 3 e multiplicada pelo fator de segurança. Utiliza-se, então, os ábacos referentes aos eixos simples.

\subsection{MÉTODO DE PACKARD (1976)}

A configuração das forças que solicitam os pisos industriais são, conforme apresentado no capítulo 3, diferentes dos carregamentos rodoviários. No caso de empilhadeiras, o comprimento do eixo é muito variável, sendo mais comuns os de, aproximadamente, 1 metro, o que obriga a aplicação da força em todas as rodas, e não apenas em um semi-eixo. No anexo B, é mostrado um exemplo da influência da aplicação da força em todo eixo, ou em apenas um 
semi-eixo, para empilhadeiras. Além das ações móveis, os pisos industriais devem ser verificados para carregamentos distribuídos e forças concentradas. $\mathrm{O}$ método apresentado por PACKARD (1976) pode ser usado no dimensionamento de pisos industriais de concreto simples ou com armadura sem função estrutural. Os ábacos são limitados, pois não abrangem forças muito elevadas.

O método é derivado do dimensionamento de rodovias e aeroportos, devido às inúmeras pesquisas realizadas nestes tipos de pavimentos.

As variáveis de projeto são:

- coeficiente de recalque da fundação;

- módulo de ruptura do concreto;

- natureza e frequencia das ações.

PACKARD (1976) apresenta ábacos para o dimensionamento, onde as tensões foram determinadas com auxílio de um software. Foi adotado o módulo de elasticidade do concreto igual a 28.000MPa e o coeficiente de Poisson igual a 0,15. Segundo PACKARD (1976), a influência do módulo de elasticidade e do coeficiente de Poisson, nos valores das tensões, é muito pequena. Foi adotada a hipótese de carregamento no interior das placas, obrigando a existência de um bom dispositivo de transferência de carga. Se houver bordas carregadas, deve-se aumentar a espessura em 20 a 25\%. As tensões devidas à retração são desprezadas. Segundo PACKARD (1976), exceto em pavimentos de concreto continuamente armados, as tensões devidas à retração, que realmente ocorrem nas placas, equivalem a apenas um terço, ou metade, da tensão calculada.

\subsubsection{Ações móveis}

O método de dimensionamento apresentado por PACKARD (1976) prevê uma redução na resistência do concreto à tração, devido ao efeito da fadiga. A tabela A.24 fornece os valores dos coeficientes de segurança, em função do número de repetições das solicitações. O critério de fadiga adotado é o 
mesmo da PCA/66, sendo o fator de fadiga o inverso da relação de tensões. Dessa maneira, a tensão de tração admissível do concreto é dada por:

$\sigma_{\mathrm{adm}}=\frac{\mathrm{f}_{\mathrm{ctM}, \mathrm{k}}}{\gamma_{\mathrm{fad}}}$

sendo:

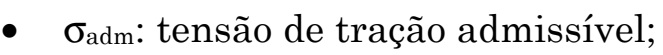

- $\mathrm{f}_{\mathrm{ctM}, \mathrm{k}}$ : resistência característica do concreto à tração na flexão, também conhecido como módulo de ruptura, $\mathrm{M}_{R}$;

- $\gamma_{\mathrm{fad}}$ : coeficiente de segurança devido à fadiga.

PACKARD (1976) define como tensão de trabalho a relação entre a tensão admissível e a força do eixo mais carregado:

$\mathrm{Q}=\frac{\sigma_{\mathrm{adm}}}{\mathrm{P}}$

sendo:

- Q: tensão de trabalho, em $\mathrm{Pa} / \mathrm{N}$

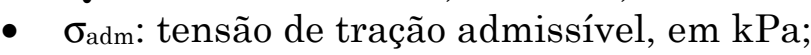

- P: peso do eixo mais carregado, em $\mathrm{kN}$.

A área de contato dos pneus é determinada, como já foi visto no capítulo 3, por:

$\mathrm{A}=\frac{\mathrm{P}_{\mathrm{r}}}{\mathrm{q}}$

sendo:

- $P_{r}$ - peso atuante em uma roda;

1 PACKARD, R. G. (1967). Computer Program for Airport Pavement Design, SR029P, Portland Cement Association. 
- $\quad$ - pressão de enchimento dos pneus.

Quando a área $A$ calculada é inferior a $600 \mathrm{~cm}^{2}$, deve-se fazer uma correção, utilizando a figura A.16, obtendo $A^{\prime}$. Arbitrando-se uma espessura tentativa, a ser verificada posteriormente. Verifica-se que a correção é mais significativa para as maiores espessuras de placas. Segundo PACKARD (1976) a razão para essa correção é que as tensões em placas para áreas de contato muito pequenas são superestimadas, quando determinadas pela teoria convencional.

PACKARD (1976) apresenta o ábaco da figura A.17 para dimensionamento de pisos industriais submetido a ações de empilhadeiras com eixo de rodagem simples. Os parâmetros de entrada são:

- $\mathrm{Q}$ - tensão e trabalho, em $\mathrm{Pa} / \mathrm{N}$;

- $\mathrm{s}$ - espaçamento entre as rodas, em $\mathrm{cm}$;

- A - área de contato efetiva dos pneus, em $\mathrm{cm}^{2}$;

- $\mathrm{k}$ - coeficiente de recalque da fundação, determinado conforme indicado no item 4.1.4, em $\mathrm{MPa}$.

Do gráfico, obtém-se a espessura da placa, em cm.

$\mathrm{O}$ eixo de rodagem dupla provoca tensões inferiores, se comparado com um eixo de rodagem simples com o mesmo peso. PACKARD (1976) propõe uma redução no valor do peso, $P$, a ser utilizado para calcular a tensão de trabalho, $Q$, dando origem a um peso corrigido:

$\mathrm{P}_{\text {cor }}=\mathrm{f}_{\text {red }} \cdot \mathrm{P}$

sendo:

- $\mathrm{P}_{\text {cor - peso do eixo, corrigido; }}$

- $\mathrm{f}_{\text {red }}$ - fator de redução, obtido da figura A.18;

O valor da tensão de trabalho passa a ser calculado por:

$\mathrm{Q}_{\mathrm{cor}}=\frac{\sigma_{\mathrm{adm}}}{\mathrm{P}_{\mathrm{cor}}}$ 
sendo:

- Qcor: tensão de trabalho calculada a partir do peso corrigido, em $\mathrm{Pa} / \mathrm{N}$

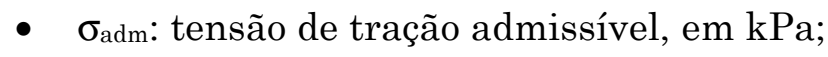

Para a utilização da figura A.18, a fim de determinar o valor de $f_{\text {red, é }}$ necessário arbitrar uma espessura inicial para a placa. A verificação da espessura tentativa é feita com o auxílio do ábaco da figura A.17, com os seguintes parâmetros:

- $\mathrm{Q}_{\text {cor, }}$ em $\mathrm{Pa} / \mathrm{N}$;

- $\mathrm{s}$ - espaçamento entre as rodas, em $\mathrm{cm}$;

- A - área de contato efetiva dos pneus, em $\mathrm{cm}^{2}$;

- $\mathrm{k}$ - coeficiente de recalque da fundação.

Caso a espessura obtida seja diferente da arbitrada, o processo deve ser repetido, com uma nova espessura tentativa.

\subsubsection{Carregamento de montantes}

No dimensionamento de pisos de concreto, solicitados por montantes de prateleiras, ou por patolas, deve-se conhecer:

- o menor espaçamento entre os montantes, $x$;

- o maior espaçamento entre os montantes, y;

- área de contato, $\mathrm{A}$, ou área de contato efetiva, $\mathrm{A}^{\prime}$;

- peso do montante, Pmont; $_{\text {- }}$

- resistência do concreto à tração na flexão, $\mathrm{f}_{\mathrm{ctm}, \mathrm{k}}$;

- coeficiente de recalque da fundação, $\mathrm{k}$;

Devido ao desconhecimento da posição das prateleiras e à deformação lenta do concreto, PACKARD (1976) recomenda a adoção de um coeficiente de segurança que varia entre 2 e 5 . Os montantes podem ser apoiados próximos às juntas, produzindo esforços até $50 \%$ maiores que no interior das placas, dependendo do grau de transferência de carga. 
Os ábacos das figuras A.19 a A.21 possibilitam a determinação da espessura das placas em função dos valores de $x, y, k, A$ e Q. O valor de $Q$ é calculado pela equação 6.24. Neste caso a tensão admissível é dada por:

$\sigma_{\mathrm{adm}}=\frac{\mathrm{f}_{\mathrm{ctm}, \mathrm{k}}}{\mathrm{F}_{\mathrm{S}}}$

sendo:

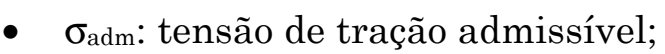

- $\mathrm{f}_{\mathrm{ctm}, \mathrm{k}}$ : resistência característica do concreto à tração na flexão;

- Fs: fator de segurança entre 2 e 5 .

PACKARD (1976) recomenda que a tensão de contato entre a área de apoio e a placa seja inferior a 4,2 vezes o módulo de ruptura do concreto, para forças no interior da placa, e 2,1 vezes, para forças de borda ou de canto. A tensão de cisalhamento, devida aos esforços de puncionamento, não devem ser superiores a 0,27 vezes o módulo de ruptura do concreto.

Segundo MELGES (1995), “o fenômeno da punção de uma placa é basicamente a sua perfuração devida às altas tensões de cisalhamento, provocadas por forças concentradas ou agindo em pequenas áreas". A ruína por punção é do tipo frágil.

Em pisos de concreto, existem duas maneiras de evitar a ruptura por puncionamento:

- Aumentar a área de apoio;

- Aumentar a espessura do piso.

Segundo BRAESTRUP \& REGAN², citado por MELGES e PINHEIRO (1999), com relação ao formato dos apoios, pode-se observar que, para apoios circulares, a resistência é cerca de 15\% maior quando comparada à resistência de apoios quadrados com área equivalente. Isto se deve ao fato de que, nos

2 BRAESTRUP, M.W.; REGAN, P.E. (1985). Punching shear in reinforced concrete: a state of the art report. CEB Bulletin d'Information, n.168. 
apoios quadrados e nos retangulares, existe uma concentração de tensões nos cantos.

Segundo a Revisão da NB-1 (1999), existem duas superfícies críticas para ruína por punção, indicadas nas figuras 6.4 e 6.5.

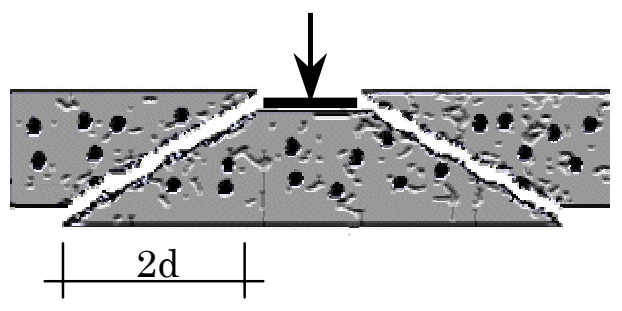

Figura 6.4 - Ruína por punção a 2d da área de aplicação da força

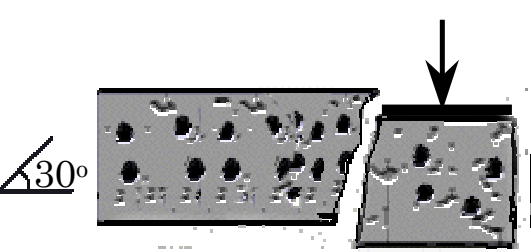

Figura 6.5 - Ruína por punção na face da área de aplicação da força

Para verificação da punção deve ser respeitada a inequação:

$\tau_{\mathrm{Sd}} \leq \tau_{\mathrm{Rd}}$

sendo:

- $\tau_{\mathrm{Sd}}$ : tensão atuante de cálculo;

- $\tau_{\mathrm{Rd}}$ : tensão resistente de cálculo;

A tensão atuante de cáculo é dada por (Revisão da NB-1, 1999):

$\tau_{\mathrm{Sd}}=\frac{\mathrm{F}_{\mathrm{Sd}}}{\mathrm{u} \cdot \mathrm{d}}$

sendo:

- Fd: força atuante de cálculo;

- u: perímetro crítico; para área retangular é dado pelas expressões (6.31) e (6.35);

- d: altura útil

Para verificação da punção a $2 \mathrm{~d}$ da face da área de aplicação da força, o perímetro crítico é dado por: 
$\mathrm{u}=2 \cdot\left(\mathrm{c}_{1}+\mathrm{c}_{2}\right)+2 \cdot \pi \cdot(2 \cdot \mathrm{m})$

sendo:

- $\quad c_{1}$ e $c_{2}$ : lados da área retangular de aplicação da força;

- m: média entre os lados da área de aplicação da força.

Para a verificação da punção a $2 \mathrm{~d}$ da força, a tensão resistente de cálculo é dada por:

$\tau_{\mathrm{Rd}}=0,13 \cdot\left(1+\sqrt{\frac{20}{d}}\right) \cdot \sqrt[3]{100 \cdot \rho \cdot f_{\mathrm{ck}}}$

sendo:

- $\quad \rho$ : taxa de armadura de flexão, dada pela equação (6.33);

- $\mathrm{f}_{\mathrm{ck}}$ : resistência característica do concreto.

$\rho=\sqrt{\rho_{x} \cdot \rho_{y}}$

sendo:

- $\rho_{\mathrm{x}}$ : taxa de armadura de flexão, na direção x;

- $\rho_{y}$ : taxa de armadura de flexão, na direção y.

Esta verificação, proposta pela Revisão da NB-1 (1999), é possível somente quando houver armadura de flexão. No caso de concreto simples, é possível adotar a proposta do ACI 318 (1989), onde a tensão resistente é dada pelo menor dos valores:

$$
\begin{aligned}
\tau_{\mathrm{Rd}} & =0,85 \cdot 0,08303 \cdot\left(2+\frac{4}{\beta_{\mathrm{c}}}\right) \sqrt{\mathrm{f}_{\mathrm{ck}}} \\
\tau_{\mathrm{Rd}} & =0,85 \cdot 0,08303 \cdot\left(2+\frac{\alpha_{\mathrm{s}} \cdot \mathrm{d}}{\mathrm{b}_{\mathrm{o}}}\right) \sqrt{\mathrm{f}_{\mathrm{ck}}}
\end{aligned}
$$


$\tau_{\mathrm{Rd}}=0,85 \cdot 0,3321 \cdot \sqrt{\mathrm{f}_{\mathrm{ck}}}$

sendo:

- $\quad \beta_{c}$ : razão entre os lados mais longo e mais curto do pilar;

- $b_{o}$ : perímetro crítico localizado a d/2 do contorno do pilar;

- $\alpha_{s}$ : constante que assume os valores: 40 para forças internas, 30 para forças de borda e 20 para forças de canto;

A seção crítica, segundo proposta da ACI 318 (1989), está a uma distância $d / 2$ da face da área da aplicação da força e tem formato retangular.

Para verificação da punção na face da área de aplicação da força, o perímetro crítico é dado por (Revisão da NB-1, 1999):

$\mathrm{u}=2 \cdot\left(\mathrm{c}_{1}+\mathrm{c}_{2}\right)$

Para a verificação da punção na face do pilar, a tensão resistente de cálculo é dada por (Revisão NB-1, 1999):

$\tau_{\mathrm{Rd}}=0,27 \cdot\left(1-\frac{\mathrm{f}_{\mathrm{ck}}}{250}\right) \cdot \mathrm{f}_{\mathrm{cd}}$

\subsubsection{Carregamento distribuído}

Como já foi discutido no capítulo 3, nos corredores de circulação entre áreas de carregamento distribuído, ocorrem momentos negativos (tração nas fibras superiores). Caso o comprimento desses corredores fosse conhecido, seria possível fazer um dimensionamento mais otimizado, mas como é difícil fixar essa dimensão, realizam-se os cálculos adotando a largura que produza o máximo esforço. PACKARD (1976) apresenta a seguinte expressão:

$\mathrm{q}_{\mathrm{adm}}=1,03 \cdot \mathrm{f}_{\mathrm{ctm}, \mathrm{d}} \cdot \sqrt{\mathrm{h} \cdot \mathrm{k}}$

sendo: 
- qadm: carregamento uniformemente distribuído admissível, em $\mathrm{kN} / \mathrm{m}^{2}$;

- $\mathrm{f}_{\mathrm{ctm}, \mathrm{d}}$ : resistência de cálculo do concreto à tração na flexão, dado pela equação (6.38), em MPa;

- h: espessura da placa, em cm;

- $\mathrm{k}$ : coeficiente de recalque da fundação, em $\mathrm{MPa} / \mathrm{m}$.

$\mathrm{f}_{\mathrm{ctm}, \mathrm{d}}=\frac{\mathrm{f}_{\mathrm{ctm}, \mathrm{k}}}{\gamma_{\mathrm{c}}}$

sendo:

- $\gamma_{c}$ : coeficiente de segurança do concreto.

A Revisão da NB-1 (1999) recomenta a adoção de $\gamma_{c}$ igual a 1,4. Segundo PACKARD (1976), $\gamma_{c}$ varia entre 1,5 e 2,0.

O objetivo da verificação do máximo carregamento distribuído é evitar fissuras nos corredores de circulação. Caso essas fissuras sejam admissíveis, ou existam juntas nos corredores, o fator determinante do carregamento distribuído admissível passa a ser somente o recalque admissível do solo.

\subsection{CONSIDERAÇÕES GERAIS}

Os parâmetros utilizados no método da AASHTO são diferentes dos utilizados no método da PCA. Portanto é difícil estabelecer uma comparação direta entre eles. Enquanto o método da AASHTO aplica conceitos de confiabilidade, utiliza uma carga padrão e não distingue os motivos que levam à ruptura, o método da PCA/84 indica coeficientes de segurança de carga, adota curva de fadiga e diferencia a ruptura por fadiga da ruptura por erosão. Dependendo dos dados de projeto, um ou outro método pode ser mais eficiente. Para avaliar essa eficiência, pode-se realizar uma análise de sensibilidade. RUFINO (1997) apresenta uma análise de sensibilidade para os parâmetros 
utilizados pelo método da AASHTO. MOURA (1999) faz uma comparação numérica entre os métodos indicados pelo DNER e o método original da AASHTO. 


\section{Capítulo}

\section{DIMENSIONAMENTO DA ARMADURA}

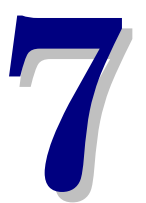

No Brasil, são utilizados dois tipos de pavimentos de concreto armado:

- Pavimento de concreto com armadura distribuída descontínua;

- Pavimento de concreto estruturalmente armado.

O primeiro tipo utiliza a armadura para impedir a propagação das fissuras que se formam devido à retração do concreto, permitindo a execução de juntas mais espaçadas. No segundo, a armadura, colocada na parte inferior das placas, tem a função de resistir aos esforços provocados pelo tráfego, o que possibilita a construção de placas menos espessas.

Neste capítulo serão expostas formas de dimensionamento desses dois tipos de armadura.

\subsection{ARMADURA DE RETRAÇÃO}

PACKARD (1973) recomenda o posicionamento da armadura de retração a, aproximadamente, $6 \mathrm{~cm}$ da face superior da placa. A área de aço é determinada em função da força de atrito, apresentada no capítulo 3 como:

$\mathrm{F}_{\mathrm{at}, \max }=\mu . \mathrm{N}$

sendo: 


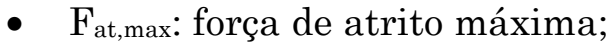

- $\mu$ : coeficiente de atrito entre a placa e a sub-base (tabela A.1);

- $\mathrm{N}$ : força normal; para a estrutura descarregada, equivale ao peso da metade da placa, ou seja:

$\mathrm{N}=\gamma_{\mathrm{c}} \cdot \mathrm{B} \cdot \mathrm{h} \cdot \frac{\mathrm{L}}{2}$

sendo:

- $\quad \mathrm{N}$ : força normal para a estrutura descarregada;

- $\gamma_{c}$ : peso específico do concreto armado, adotado pela Revisão da NB-1 (1999) como $2500 \mathrm{~kg} / \mathrm{m}^{3}$;

- B: largura da placa;

- h: espessura da placa;

- L: comprimento da placa.

A área de aço é obtida através da relação:

$\mathrm{A}_{\mathrm{s}}=\frac{\mathrm{F}_{\mathrm{d}}}{\mathrm{f}_{\mathrm{yd}}}$

sendo:

- $\mathrm{A}_{\mathrm{s}}$ : área de aço;

- $\mathrm{F}_{\mathrm{d}}$ : força de cálculo atuante na armadura;

- $\mathrm{f}_{\mathrm{yd}}$ : resistência de cálculo do aço.

Desta maneira a área de aço da armadura de retração, por unidade de comprimento, é dada por:

$$
\begin{aligned}
& \frac{A_{s, r e t}}{B}=\frac{F_{a t, m a x, d}}{f_{y d} \cdot B} \\
& A_{s, \text { ret }}=\frac{\gamma_{\varepsilon} \cdot \mu \cdot \gamma \cdot h \cdot L}{2 \cdot f_{y d}}
\end{aligned}
$$

sendo: 
- $\mathrm{A}_{\mathrm{s}, \mathrm{ret}}$ : área de aço de retração;

- $\gamma_{\varepsilon}$ : coeficiente de segurança da força devida à retração;

- $\mu$ : coeficiente de atrito entre a placa e a sub-base;

- $\gamma$ : peso específico do concreto armado;

- h: espessura da placa;

- L: comprimento da placa;

- $f_{y d}$ : resistência de cálculo do aço.

PACKARD (1973) recomenda a adoção de fyd igual a $75 \%$ da tensão de escoamento do aço. Dessa forma a área de aço é dada por:

$\mathrm{A}_{\mathrm{s}, \mathrm{ret}}=\frac{\mu \cdot \gamma \cdot \mathrm{h} \cdot \mathrm{L}}{2 \cdot 0,75 \cdot \mathrm{f}_{\mathrm{yk}}}$

ou

$\mathrm{A}_{\mathrm{s}, \mathrm{ret}}=\frac{1,33 \cdot \mu \cdot \gamma \cdot \mathrm{h} \cdot \mathrm{L}}{2 \cdot \mathrm{f}_{\mathrm{yk}}}$

RODRIGUES e CASSARO (1998) adotam $f_{y d}$ igual a 2/3 da tensão de escoamento. Dessa forma a área de aço é dada por:

$\mathrm{A}_{\mathrm{s}, \mathrm{ret}}=\frac{\mu \cdot \gamma \cdot \mathrm{h} \cdot \mathrm{L}}{2 \cdot \frac{2}{3} \cdot \mathrm{f}_{\mathrm{yk}}}$

ou

$\mathrm{A}_{\mathrm{s}, \mathrm{ret}}=\frac{1,5 \cdot \mu \cdot \gamma \cdot \mathrm{h} \cdot \mathrm{L}}{2 \cdot \mathrm{f}_{\mathrm{yk}}}$

Segundo o Revisão da NB-1 (1999), quando uma peça de concreto armado está sendo dimensionada para Estado Limite Último, a resistência de cálculo do aço é determinada por:

$f_{y d}=\frac{f_{y k}}{\gamma_{s}}$ 
sendo:

- $f_{y d}$ : resistência de cálculo do aço;

- $\mathrm{f}_{\mathrm{yk}}$ : resistência característica do aço, igual à tensão de escoamento no diagrama tensão-deformação;

- $\gamma_{s}$ : coeficiente de segurança do aço, adotado igual a 1,15 .

O coeficiente de majoração da ação de retração, $\gamma_{\varepsilon}$, segundo a Revisão da NB-1 (1999), deve ser igual a 1,2. Portanto a área de aço fica sendo determinada por:

$$
\mathrm{A}_{\mathrm{s}, \mathrm{ret}}=\frac{1,2 \cdot \mu \cdot \gamma \cdot \mathrm{h} \cdot \mathrm{L}}{2 \cdot \frac{\mathrm{f}_{\mathrm{ck}}}{1,15}}
$$

ou, para efeito de comparação,

$$
\mathrm{A}_{\mathrm{s}, \mathrm{ret}}=\frac{1,38 \cdot \mu \cdot \gamma \cdot \mathrm{h} \cdot \mathrm{L}}{2 \cdot \mathrm{f}_{\mathrm{yk}}}
$$

O Corps of Engineers apresentou um método de dimensionamento da armadura de retração com base em ensaios que simularam as condições de carregamento mais usuais. O método permite a redução da espessura da placa em função do uso dessa armadura. A explicação é que embora possam ocorrer fissuras, devidas à ação do carregamento, com a presença da malha de aço, as aberturas permanecerão pequenas, garantindo a transferência de força por entrosagem de agregados. O ábaco apresentado pelo Corps of Engineers está reproduzido na figura A.22. Segundo RODRIGUES e CASSARO (1998), os melhores resultados são obtidos para:

$\frac{\mathrm{h}_{\mathrm{arm}}}{\mathrm{h}_{\mathrm{s}}}=0,8$

sendo: 
- $h_{\text {arm: }}$ espessura do pavimento com armadura de retração;

- $h_{s}$ : espessura do pavimento simples.

O método da Corps of Engineers deve ser usado apenas para as ações móveis, sendo que, em hipótese alguma, pode-se fazer a redução da espessura necessária para carregamentos de montantes ou para forças distribuídas.

Segundo PACKARD (1973) a redução da espessura devido ao emprego de armadura de retração não é recomendável, pois diminui a transferência de esforços nas juntas longitudinais e aumenta as deformações, aumentando consequentemente a fissuração. A FAA (1995) também recomenda que a espessura de um pavimento de concreto com armadura de retração seja calculada da mesma forma que de um pavimento de concreto simples.

\subsection{ARMADURA POSITIVA}

A armadura de flexão deve ser dimensionada para o Estado Limite Último de esgotamento da capacidade resistente e verificada para o Estado Limite Último de fadiga do aço.

7.2.1 Determinação da área de aço, para o estado limite último de esgotamento da capacidade resistente da estrutura

Segundo PINHEIRO (1993), a armadura de uma peça submetida a flexão simples pode ser determinada por:

$$
\mathrm{A}_{\mathrm{s}}=\frac{\mathrm{k}_{\mathrm{s}} \cdot \mathrm{M}_{\mathrm{d}}}{\mathrm{d}}
$$

sendo:

- $\mathrm{A}_{\mathrm{s}}$ : área de aço, em $\mathrm{cm}^{2}$; 
- $\mathrm{k}_{\mathrm{s}}$ : coeficiente dimensional, obtido da tabela A.25, em função do $\mathrm{f}_{\mathrm{ck}}$ e de $\mathrm{k}_{\mathrm{c}}$, determinado pela equação 7.15 , em $\mathrm{cm}^{2} / \mathrm{kN}$;

- $\mathrm{M}_{\mathrm{d}}$ : momento de cálculo, em kN . cm;

- d: altura útil da placa dada pela espessura h menos o cobrimento, em $\mathrm{cm}$.

$\mathrm{k}_{\mathrm{c}}=\frac{\mathrm{B} \cdot \mathrm{d}^{2}}{\mathrm{M}_{\mathrm{d}}}$

sendo:

- $\mathrm{k}_{\mathrm{c}}$ : coeficiente dimensional, em $\mathrm{cm}^{2} / \mathrm{kN}$;

- $\mathrm{M}_{\mathrm{d}}$ : momento de cálculo, em kN . cm;

- B: largura da seção;

- d: altura útil da placa dada pela espessura h menos o cobrimento, em $\mathrm{cm}$.

A tabela para determinação do $k_{s}$ já inclui os seguintes coeficientes de segurança:

- $\gamma_{c}=1,4-$ minoração da resistência do concreto;

- $\gamma_{\mathrm{s}}=1,15-$ minoração da resistência do aço.

A área de aço é determinada para a força que produz o máximo momento fletor na placa.

\subsubsection{Estado limite último de fadiga do aço}

Para realizar a verificação do Estado Limite de Fadiga do Aço, pode ser adotado o critério usado nas pontes de concreto armado, que aplica um coeficiente de fadiga sobre a área de aço calculada, caso a variação de tensão no aço seja superior à variação admissível, dada pelo gráfico 5.7.

O coeficiente de fadiga é determinado por (PFEIL, 1979):

$\gamma_{\text {fad }}=\frac{\Delta \sigma_{\mathrm{s}}}{\Delta \mathrm{f}_{\mathrm{sd}, \mathrm{fad}}}$ 
sendo:

- $\gamma_{\mathrm{fad}}$ coeficiente de fadiga;

- $\Delta \sigma_{\mathrm{s}}$ : variação de tensão no aço;

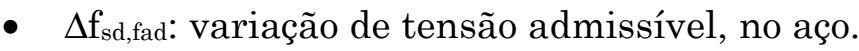

No caso de não se ter dados estatísticos sobre a porcentagem de veículos que passam em cada ponto do pavimento, para o caso de rodovias, é possível adotar o critério da PCA (1984), que considera que 6\% do tráfego solicita a borda, enquanto $94 \%$ solicita o interior das placas. No caso de pisos industriais, é recomendável armar as placas externas para o tráfego na borda, e as placas internas para força no interior das placas, considerando que serão utilizados mecanismos eficientes para transferência de carga entre as juntas.

\subsection{DETAlHAMENTO DA ARMADURA}

A Revisão da NB-1 não apresenta critérios específicos para detalhamento de pisos e de pavimentos de concreto armado. Portanto serão utilizados os valores apresentados para lajes e vigas.

\subsubsection{Cobrimento}

O cobrimento exigido pela Revisão da NB-1 (1999), de acordo com a classe de agressividade do ambiente, está apresentado na tabela 7.1.

Tabela 7.1 - Cobrimento nominal em função da classe de agressividade do meio

\begin{tabular}{|c|c|c|c|c|}
\hline Classe de agressividade & I & II & III & IV \\
\hline Cobrimento $(\mathrm{cm})$ & 1,5 & 2,0 & 3,0 & 4,0 \\
\hline
\end{tabular}

O solo seco, como no caso do Nordeste Brasileiro ou em ambientes protegidos da chuva, pode ser considerado de classe de agressividade I. Solos úmidos, com ciclos de molhagem e secagem, ambientes quimicamente 
agressivos, armazéns de fertilizantes e indústrias químicas variam entre as classes II E IV. Zonas onde há respingos de maré são de agressividade IV.

Para pavimentos de concreto é comum a adoção de 5 centímetros de cobrimento.

\subsubsection{Emenda}

A largura padronizada das telas soldadas é de 2,45 metros. Portanto, para armar as placas, que chegam a ter 30 metros de comprimento, é preciso construir a emenda, que comumente é feita por transpasse. Segundo a Revisão da NB-1, o diâmetro máximo das barras para esse tipo de emenda é de $25 \mathrm{~mm}$. O comprimento do transpasse, quando a distância livre entre barras emendadas estiver compreendida entre 0 e 4.申, é dado por:

$\ell_{\mathrm{t}}=\alpha_{1} \cdot \alpha_{2} \cdot \ell_{\mathrm{b}, \text { nec }}$

sendo:

- $\ell_{\mathrm{t}}$ : comprimento do transpasse;

- $\alpha_{1}$ : coeficiente de redução devido a barras transversais soldadas, igual a 0,7 ;

- $\alpha_{2}$ : coeficiente de majoração devido à presença de várias barras emendadas na mesma seção; no caso de telas soldadas é igual a 2.

- $\ell_{\mathrm{b}, \text { nec }}$ : comprimento de ancoragem necessário, dado pela equação (7.18).

$\ell_{\mathrm{b}, \mathrm{nec}}=\frac{\phi}{4} \cdot \frac{\mathrm{f}_{\mathrm{yd}}}{\tau_{\mathrm{bu}}} \cdot \frac{\mathrm{A}_{\mathrm{s}, \mathrm{cal}}}{\mathrm{A}_{\mathrm{s}, \mathrm{ef}}}$

sendo:

- $\phi$ : diâmetro da barra;

- $f_{\text {yd: }}$ tensão de cálculo do aço;

- $\tau_{\mathrm{bu}}$ : tensão máxima de aderência, dado pela equação (7.19)

- $\mathrm{A}_{\mathrm{s}, \mathrm{cal}}$ : área de aço calculada; 
- $\mathrm{A}_{\mathrm{s}, \mathrm{ef}}$ área de aço efetiva.

Os valores de $\tau_{\text {bu }}$ são definidos pela Revisão da NB-1 (1999), para situação de boa aderência e aço tipo CA-50 e CA-60, como:

$\tau_{\mathrm{bu}}=\eta_{1} \cdot \eta_{2} \cdot \eta_{3} \cdot \mathrm{f}_{\mathrm{ctd}}$

sendo:

- $\tau_{\mathrm{bu}}$ : tensão máxima de aderência, em $\mathrm{MPa}$;

- $\eta_{1}=2,25$ para barras nervuradas;

- $\eta_{2}=1$ para situações de boa aderência, como no caso de barras de ligação;

- $\eta_{3}=1$ para diâmetros inferiores a $32 \mathrm{~mm}$; para diâmetros maiores que $32 \mathrm{~mm}$, o valor é dado pela expressão (7.20);

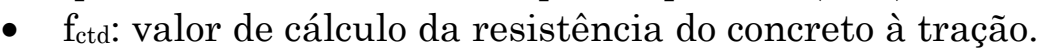

$\eta_{3}=\frac{132-\phi}{100}$

sendo:

- $\phi$ : diâmetro da barra, em mm.

O valor mínimo do comprimento de transpasse é dado por:

$\ell_{\mathrm{t}, \text { mín }}=0,3 \cdot \alpha_{1} \cdot \alpha_{2} \cdot \ell_{\mathrm{b}}$

sendo:

- $\ell_{\mathrm{t}}$ : comprimento do transpasse;

- $\ell_{\mathrm{b}}$ : comprimento de ancoragem, dado pela equação (7.22).

$\ell_{\mathrm{b}}=\frac{\phi}{4} \cdot \frac{\mathrm{f}_{\mathrm{yd}}}{\tau_{\mathrm{bu}}}$ 
Quando a distância livre entre barras emendadas for maior que 4.申, o comprimento do transpasse é dado por:

$\ell_{\mathrm{t}}=\alpha_{1} \cdot \alpha_{2} \cdot \ell_{\mathrm{b}, \text { nec }}+\mathrm{d}_{\mathrm{l}}$

sendo:

- $\quad \ell_{\mathrm{t}}$ : comprimento do transpasse;

- dl: distância livre entre as barras emendadas.

Quando as barras têm diâmetros diferentes, o comprimento de transpasse deve ser calculado para a barra de maior diâmetro.

\subsection{CONSIDERAÇÕES GERAIS}

Hoje em dia ainda é usado o método das tensões admissíveis, no dimensionamento de pavimentos de concreto, mas este método tende a ser substituído pelo método dos estados limites, pois este permite um melhor domínio do comportamento da estrutura e uma maior compreensão dos fatores de segurança que estão sendo adotados.

No caso de pavimentos de concreto com armadura distribuída descontínua, as fissuras devidas à retração funcionam como juntas transversais sem barras de transferência, onde os esforços são divididos entre os dois lados da fissura por entrosagem dos agregados. Portanto é coerente dimensionar o pavimento para esse tipo de junta, mesmo que as juntas serradas possuam barras de transferência. 


\section{Capítulo}

\section{8 \\ JUNTAS}

A função das juntas, nos pavimentos de concreto, é promover a fissuração com geometria pré-definida, a fim de garantir o funcionamento estrutural previsto e manter o nível estético do pavimento.

\subsection{MECANISMO DE APARECIMENTO DE FISSURAS}

Os principais motivos para o aparecimento das fissuras são:

- retração;

- empenamento.

A retração, estudada no capítulo 3, provoca o aparecimento de fissuras transversais, com espaçamentos que, normalmente, variam de 9 a 45 metros, de configuração aleatória, conforme ilustrado na figura 8.1.

O empenamento restringido, discutido no capítulo 3 , provoca o aparecimento de fissuras longitudinais e de novas fissuras transversais, conforme ilustra a figura 8.2.

A adoção de juntas moldadas, ou, como é mais usual hoje em dia, juntas serradas, promove uma adequada geometria de placas, permitindo a adoção de dispositivos de transferência de força, por ser possível prever as posições das fissuras. No local onde deve ser construída a junta, enfraquece-se a seção, através de molde ou serragem, induzindo a fissuração. 


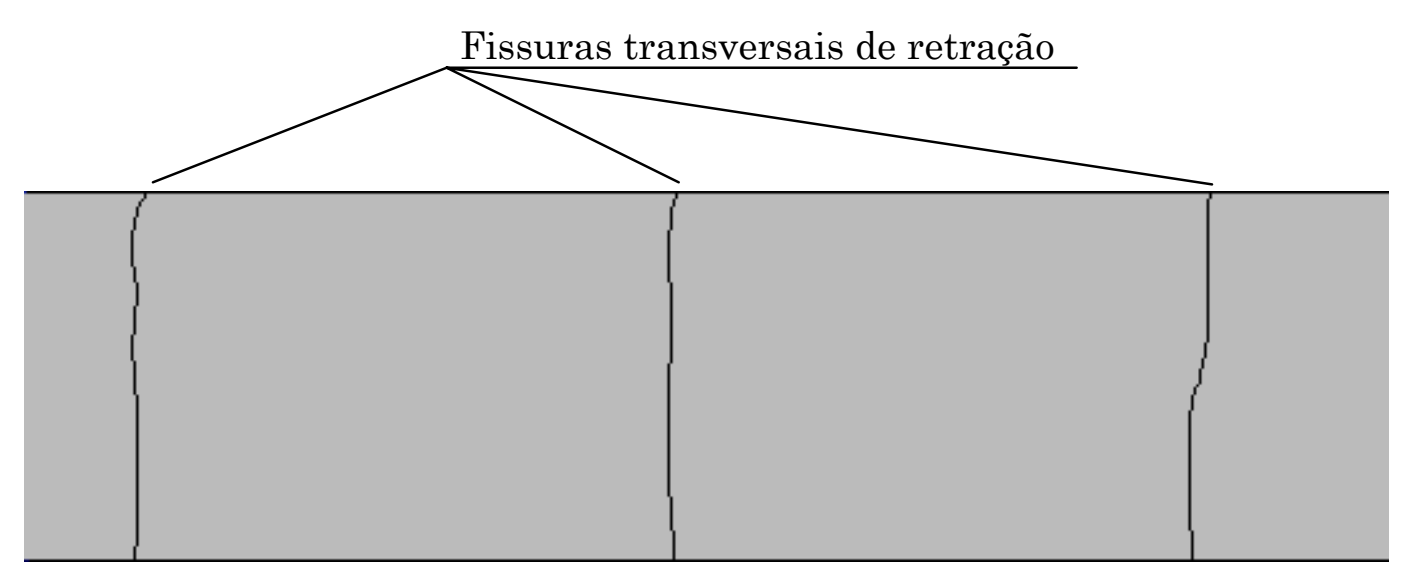

Figura 8.1 - Fissuras transversais de retração

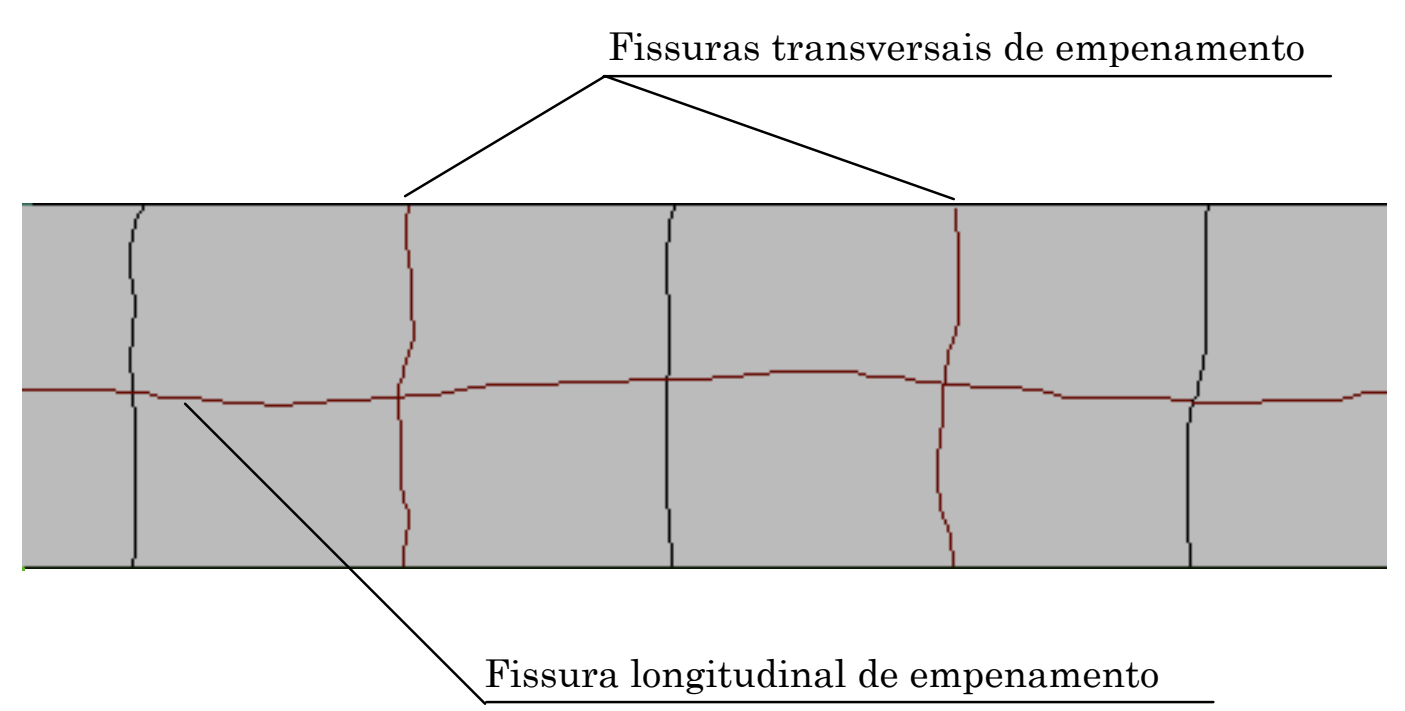

Figura 8.2 - Fissuras devidas ao empenamento

\subsection{JUNTAS TRANSVERSAIS}

O espaçamento entre as juntas deve ser definido em função do tipo de agregado utilizado no concreto. PITTA (1987) afirma que "a experiência brasileira mostra que uma distância máxima de 6 metros entre as juntas transversais é perfeitamente adequada às nossas condições gerais", para 
pavimentos de concreto simples. BALBO (1999) estuda a possibilidade da adoção de placas de concreto simples, com dimensões maiores. No caso dos pavimentos de concreto armado, é possível executar placas de até 30 metros de comprimento.

Normalmente são construídas juntas transversais perpendiculares ao eixo longitudinal, mas em alguns casos, quando não são utilizados mecanismos de transferência de força, podem ser adotadas juntas inclinadas, conforme ilustrado na figura 8.3. O ângulo de inclinação deve ser de aproximadamente $10^{\circ}$. A vantagem da utilização dessa geometria é que as rodas dos veículos não tangenciam a junta transversal simultaneamente, proporcionando um rolamento mais confortável e reduzindo as tensões na região.

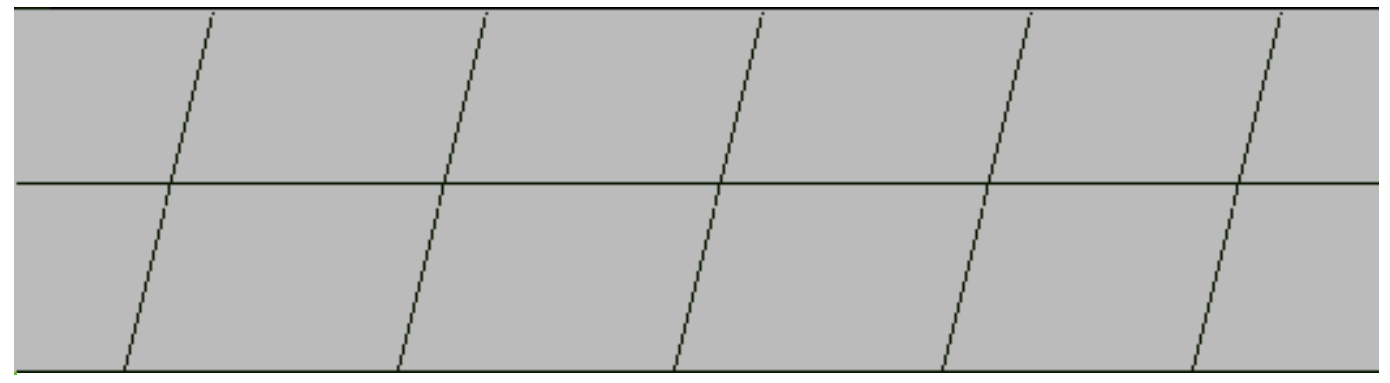

Figura 8.3 - Pavimento de concreto com juntas transversais inclinadas

Além das juntas de retração (figura 8.4), podem ser necessárias as juntas de dilatação (figura 8.5), onde houver o encontro do pavimento com outras estruturas, como por exemplo: pilares, bases de máquinas, pistas com direções diferentes, ou no caso de juntas desencontradas.

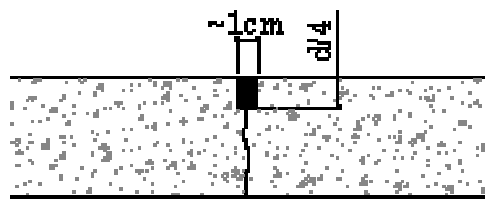

Figura 8.4 - Junta serrada, de contração

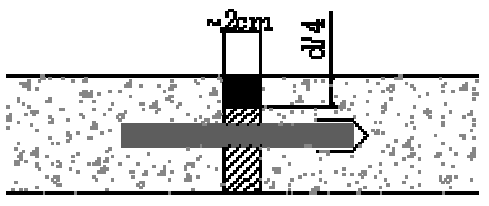

Figura 8.5 - Junta de dilatação

1 BALBO, José Tadeu (1999). (Departamento de Transportes, Escola Politécnica, Universidade de São Paulo). Informação pessoal. 
A transferência de força entre as juntas transversais pode se dar por entrosagem de agregados ou através de barras de transferência. A segunda é mais eficiente e tem sido cada vez mais utilizada, por proporcionar redução na espessura das placas e por minimizar os problemas de erosão e de escalonamento.

\subsection{JUNTAS LONGITUDINAIS}

Além de controlarem a fissuração devida ao empenamento, as juntas longitudinais, normalmente, funcionam também como junta de construção. Por esse motivo é bastante comum a adoção da geometria tipo macho-fêmea (figura 8.6), que funciona como dispositivo de transferência de força. Caso haja necessidade de junta longitudinal, mas o equipamento não exija junta de construção, pode-se optar pela junta serrada (figura 8.4).

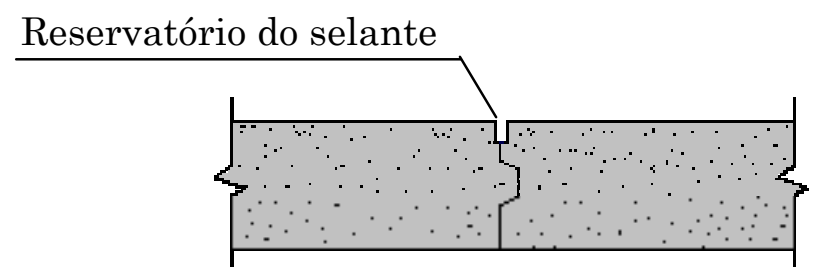

Figura 8.6 - Junta longitudinal com encaixe tipo macho-fêmea

\subsection{BARRAS DE TRANSFERÊNCIA}

As barras de transferência constituem-se de barras de aço tipo CA-25, de seção circular, maciças e lisas, com metade de seu comprimento mais 2 centímetros pintado e engraxado, a fim de proporcionar a transferência de forças verticais sem impedir a retração e a dilatação da placa. Na figura 8.7 é mostrada uma junta serrada, com barra de transferência. 


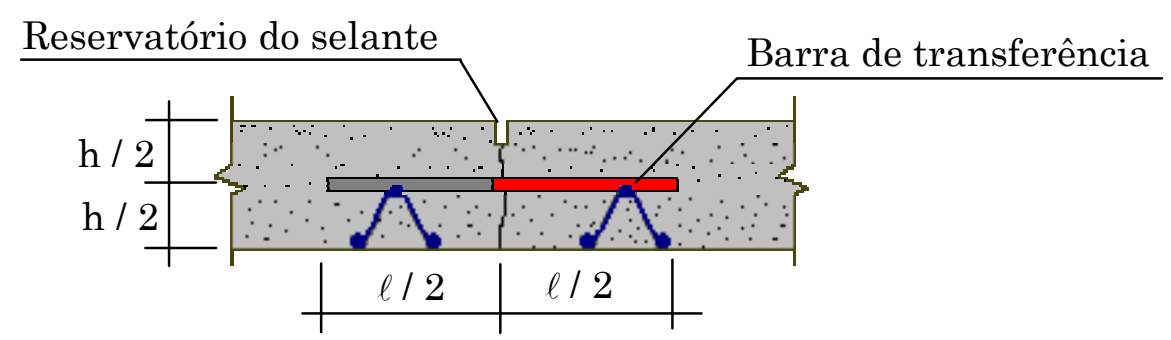

Figura 8.7 - Junta transversal com barra de transferência

Encontram-se, na literatura, tabelas que fornecem os valores do diâmetro e do espaçamento das barras de transferência, em função da espessura da placa. Uma dessas tabelas está reproduzida na tabela A.26. Sabe-se que outros parâmetros, como o coeficiente de recalque da fundação, a elasticidade da placa e a abertura da junta também influenciam no dimensionamento das barras de transferência. Além disso, essas tabelas foram estabelecidos para pavimentos e pisos de concreto simples.

A barra sob o carregamento sofre o maior esforço. As barras vizinhas recebem uma parcela da força proporcional à distância. Segundo FRIBERG (1940), a influência da força se dá até uma distância de 1,8 vezes o raio de rigidez relativo, conforme ilustrado na figura 8.8 .

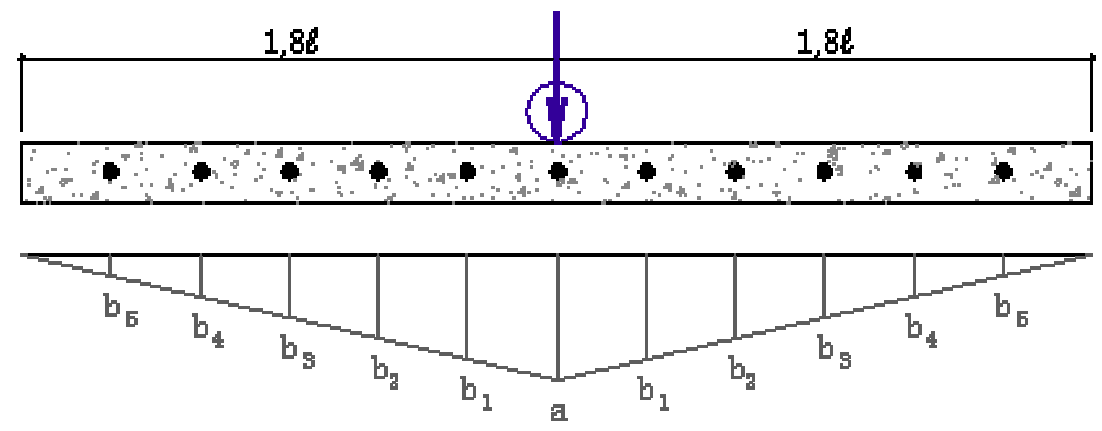

Figura 8.8 - Distribuição da força nas barras de transferência

O valor de $a$ é igual a 1 . Os valores de $b$ são dados por:

$\mathrm{b}_{\mathrm{n}}=1-\frac{\mathrm{n} \cdot \mathrm{x}}{\ell}$ 
sendo:

- n: número de barras carregadas de cada lado da força;

- $\mathrm{x}$ : distância entre as barras;

- $\quad \ell$ : raio de rigidez relativa da placa.

Desta forma, segundo FRIBERG (1940), considerando a junta 100\% eficiente, a força atuante na barra mais solicitada será dada por:

$\mathrm{P}_{\mathrm{a}}=\frac{0,5 \cdot \mathrm{P}}{1+2 \cdot \sum_{1}^{\mathrm{n}} \mathrm{b}_{\mathrm{i}}}$

No caso da força atuar próxima à borda livre, a força na barra mais carregada será:

$\mathrm{P}_{\mathrm{a}}=\frac{0,5 \cdot \mathrm{P}}{1+\sum_{1}^{\mathrm{n}} \mathrm{b}_{\mathrm{i}}}$

sendo:

- $\mathrm{P}_{\mathrm{a}}$ : força na barra mais carregada;

- P: força aplicada;

- n: número de barras carregadas em cada lado da força;

- $\quad b_{i}$ : coeficiente de cada barra, calculado pela equação 8.1.

Segundo TIMOSHENKO (1925), uma barra mergulhada em concreto, submetida a uma força, perpendicular a seu comprimento, deforma-se conforme ilustrado na figura 8.9 . 


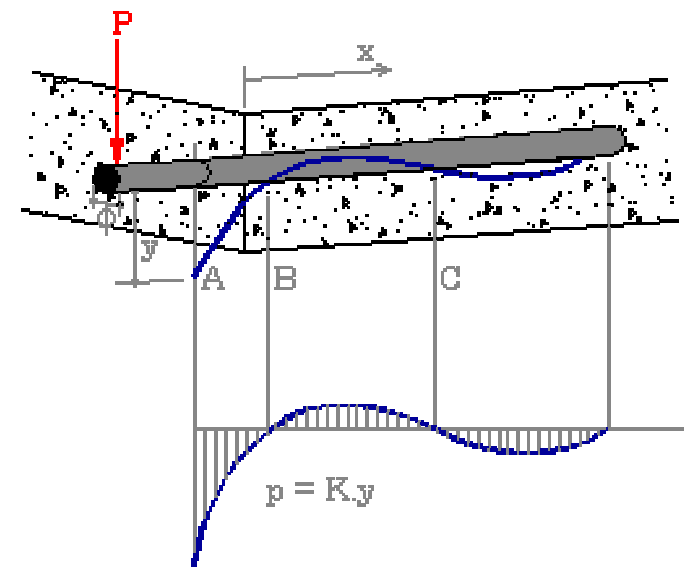

Figura 8.9 - Deformação de barra de aço mergulhada em concreto, sob carregamento perpendicular ao comprimento, fonte YODER \& WITCZAK (1975)

Com base nos princípios apresentados por TIMOSHENKO (1925), BRADBURY (1938) e FRIBERG (1940) apresentaram análises matemáticas para o dimensionamento de barras de transferência.

A rigidez relativa de uma barra mergulhada em concreto é dada por:

$\beta=\sqrt[4]{\frac{\mathrm{K} \cdot \phi}{4 \cdot \mathrm{E} \cdot \mathrm{I}}}$

sendo:

- $\quad \beta$ : rigidez relativa da barra mergulhada em concreto;

- K: módulo de suporte da barra; pode ser considerado, segundo HUANG (1993), igual a $0,41.10^{6} \mathrm{MPa} / \mathrm{m}$;

- $\phi$ : diâmetro da barra;

- E: módulo de elasticidade da barra;

- I: momento de inércia da barra, dado pela equação 8.5.

$I=\frac{\pi \cdot \phi^{4}}{64}$

De acordo com TIMOSHENKO (1925), o deslocamento da barra é dado por: 
$y=\frac{e^{-\beta \cdot x}}{2 \cdot \beta^{2} \cdot E \cdot I}\left\{P \cdot \cos (\beta \cdot x)-\beta \cdot M_{o} \cdot[\cos (\beta \cdot x)-\operatorname{sen}(\beta \cdot x)]\right\}$

sendo:

- $\quad \mathrm{x}$ : distância da junta até o ponto considerado;

- $\mathrm{M}_{0}$ : momento fletor na barra, na junta, determinado por FRIBERG (1940), pela equação (8.7).

$\mathrm{M}_{\mathrm{o}}=-\frac{\mathrm{P} \cdot \mathrm{z}_{\mathrm{j}}}{2}$

sendo:

- $\quad z_{j}:$ abertura da junta.

No caso de pavimento de concreto simples, a abertura das juntas de retração podem ser dadas pela equação adaptada de YODER \& WITCZAK (1975):

$\mathrm{z}_{\mathrm{j}}=\mathrm{L} \cdot\left(\alpha \cdot \Delta \mathrm{t}+\varepsilon_{\mathrm{cc}}\right)$

sendo:

- zj: abertura da junta, em milímetros;

- L: comprimento da placa, em milímetros;

- $\quad \alpha$ : coeficiente de dilatação térmica do concreto;

- $\Delta \mathrm{t}$ : variação total da temperatura;

- $\varepsilon_{\text {cc: }}$ coeficiente de retração.

A tensão de suporte do concreto na face da junta é dada por (FRIBERG, 1940):

$\sigma=\mathrm{K} \cdot \mathrm{y}_{\mathrm{o}}$

sendo: 
- $\mathrm{y}_{0}$ : deslocamento da barra na face da junta $(\mathrm{x}=0)$.

Assim sendo, a tensão de suporte é dada por:

$\sigma=\frac{\mathrm{K} \cdot \mathrm{P}}{4 \cdot \beta^{3} \cdot \mathrm{E} \cdot \mathrm{I}}(2+\beta \cdot \mathrm{z})$

Segundo HUANG (1993), a tensão de suporte máxima, para que não haja esmagamento do concreto, é dada por:

$\sigma_{\mathrm{adm}}=\left(\frac{10-\phi}{7,5}\right) \cdot \mathrm{f}_{\mathrm{ck}}$

O máximo momento na barra ocorre quando o cisalhamento é igual a zero, e é dado por (FRIBERG, 1940):

$\mathrm{M}_{\max }=-\frac{\mathrm{P} \cdot \mathrm{e}^{-\beta \cdot \mathrm{x}}}{2 \cdot \beta} \cdot \sqrt{1+(1+\beta \cdot \mathrm{z})^{2}}$

O máximo momento admissível pode ser calculado pela expressão:

$\mathrm{M}_{\mathrm{adm}}=\frac{\mathrm{f}_{\mathrm{yd}} \cdot \mathrm{I} \cdot 2}{\phi}$

sendo:

- $\quad f_{y d}$ : tensão admissível de cálculo do aço;

Segundo HUANG (1993), quando o concreto atinge a tensão de apoio admissível, o momento fletor que atua na barra é muito menor que sua resistência à flexão. Portanto, o dimensionamento das barras de transferência deve ser feito através das equações (8.10) e (8.11). 


\subsection{BARRAS DE LIGAÇÃO}

Quando há possibilidade de separação entre as placas, devido a movimentos laterais, pode-se optar por empregar dispositivos de ligação, que impeçam essa separação, a fim de assegurar a transferência de força pela entrosagem dos agregados ou pelo encaixe tipo macho-fêmea. Os dispositivos de ligação mais comuns são as barras de aço CA-50 ou CA-60, corrugadas, espaçadas de 30 centímetros. A figura 8.10 ilustra uma junta longitudinal serrada, com barra de ligação.

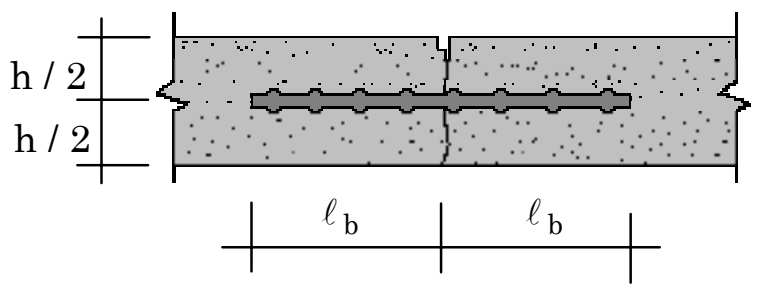

Figura 8.10 - Junta longitudinal serrada, com barra de ligação

A área de aço é calculada a partir da força de arrancamento das barras, igual à força de retração:

$\mathrm{a}_{\mathrm{s}, \mathrm{bl}}=\frac{\gamma_{\varepsilon} \cdot \mu \cdot \gamma_{\mathrm{c}} \cdot \mathrm{h} \cdot \mathrm{c}_{\mathrm{jb}}}{2 \cdot \mathrm{f}_{\mathrm{yd}}}$

sendo:

- $a_{\mathrm{s}, b l}$ : área de aço de retração por unidade de comprimento;

- $\gamma_{\varepsilon}$ : coeficiente de segurança da força devida à retração;

- $\mu$ : coeficiente de atrito entre a placa e a sub-base;

- $\gamma_{c}$ : peso específico do concreto armado;

- h: espessura da placa;

- $\quad c_{j b}$ : distância entre a junta longitudinal e a borda livre;

- $f_{y d}$ : resistência de cálculo do aço.

O comprimento das barras de ligação é determinado através da equação de ancoragem: 
$\ell_{\text {lig }}=2 \cdot \ell_{\mathrm{b}}$

$\ell_{\mathrm{b}}=\frac{\phi}{4} \cdot \frac{\mathrm{f}_{\mathrm{yd}}}{\tau_{\mathrm{bu}}} \cdot \frac{\mathrm{A}_{\mathrm{s}, \mathrm{cal}}}{\mathrm{A}_{\mathrm{s}, \mathrm{ef}}}$

sendo:

- $\ell_{\text {lig }}$ : comprimento das barras de ligação;

- $\ell_{\mathrm{b}}$ : comprimento de ancoragem;

- $\phi$ : diâmetro da barra;

- $\tau_{\mathrm{bu}}$ : tensão máxima de aderência;

- $\mathrm{A}_{\mathrm{s}, \mathrm{cal}}$ área de aço calculada;

- $\mathrm{A}_{\mathrm{s}, \mathrm{ef}}$ área de aço efetiva.

A NBR-6118 (1978) impõe os seguintes valores mínimos para $\ell_{\mathrm{b}}$ :

$\ell_{\mathrm{b}} \geq\left\{\begin{array}{l}0,3 . \ell_{\mathrm{b} 1} \\ 10 \cdot \phi \\ 10 \mathrm{~cm}\end{array}\right.$

sendo:

- $\quad \ell_{\mathrm{b} 1}$ : comprimento de ancoragem para o caso de $\mathrm{A}_{\mathrm{s}, \mathrm{cal}}=\mathrm{A}_{\mathrm{s}, \mathrm{ef}}$, dado pela equação 8.16 ;

$\ell_{\mathrm{b} 1}=\frac{\phi}{4} \cdot \frac{\mathrm{f}_{\mathrm{yd}}}{\tau_{\mathrm{bu}}}$

sendo:

- $\tau_{\mathrm{bu}}$ : tensão máxima de aderência, em $\mathrm{MPa}$;

\subsection{JUNTAS DE ENCONTRO}

As juntas de encontro são juntas de dilatação, construídas quando o pavimento tangencia estruturas como pontes, pilares e bases de máquinas. A 
junta tem a função de impedir a troca de esforços entre o pavimento e essas estruturas. As juntas de encontro têm cerca de 2 centímetros de abertura, são preenchidas com material compressível e acabadas com material selante, com a finalidade de impedir a entrada de água e de materiais imcompressíveis.

\subsection{EFICIÊNCIA DE UMA JUNTA}

A eficiência da junta representa o grau de transferência de esforços entre as placas. É definida como:

$\varepsilon_{\text {junta }}=\frac{2 \cdot \mathrm{z}^{\prime}}{\mathrm{z}+\mathrm{z}^{\prime}} \cdot 100$

sendo:

- $\varepsilon_{\text {junta: }}$ eficiência da junta em \%;

- z: deslocamento vertical do lado carregado da junta;

- z': deslocamento vertical do lado descarregado da junta.

A utilização de barras de transferência com diâmetro, comprimento, espaçamento e alinhamento corretos permite a consideração da eficiência das juntas de $100 \%$. Neste caso, o momento próximo à junta transversal é igualado ao momento no interior da placa.

RODRIGUES e PITTA (1998) recomendam que, na ausência de dados específicos, seja considerada uma eficiência de $45 \%$ nas juntas.

No capítulo 4 foram apresentadas análises de placas isoladas, sob carregamento de eixos rodoviários. A seguir serão analisadas placas com juntas de eficiência igual a $100 \%$ e $45 \%$, a fim de verificar a influência do tipo de junta no esforço provocado nas placas. As características do problema e os carregamentos são os mesmos das tabelas 4.1 e 4.2 . 
Nas figuras 8.11 e 8.12 são mostradas as distribuições dos momentos fletores para eixo rodoviário simples de rodagem dupla, tangente à junta e à borda, simultaneamente, quando a eficiência da junta é de $100 \%$.
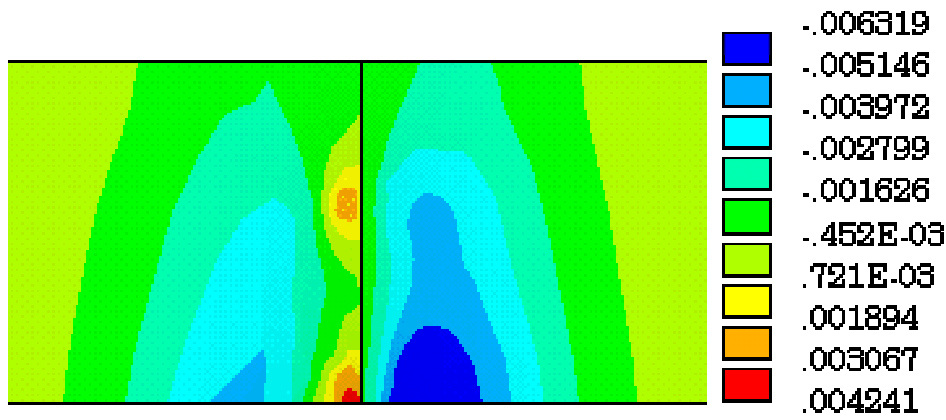

Figura 8.11 - Distribuição dos momentos fletores (MN.m), na direção x, para carregamento tangente à junta transversal - eixo simples de rodagem dupla, eficiência da junta: $100 \%$

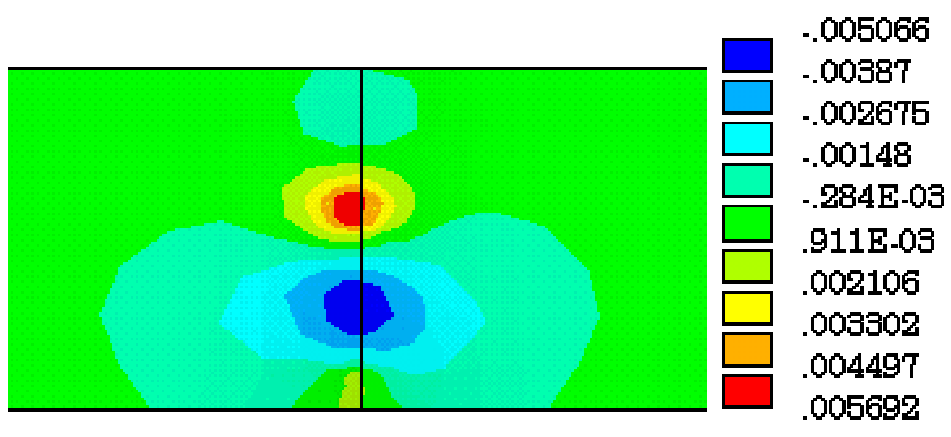

Figura 8.12 - Distribuição dos momentos fletores (MN.m), na direção y, para carregamento tangente à junta transversal - eixo simples de rodagem dupla, eficiência da junta: $100 \%$

Com junta de eficiência igual a 100\% obteve-se uma redução de aproximadamente $50 \%$ para os máximos momentos fletores positivo e negativo. O esforço obtido no meio da junta é $25 \%$ inferior ao esforço para carregamento no interior da placa.

Nas figuras 8.13 e 8.14 são mostradas as distribuições dos momentos fletores para eixo rodoviário simples de rodagem dupla, tangente à junta e à borda, simultaneamente, quando a eficiência da junta é de $45 \%$. 


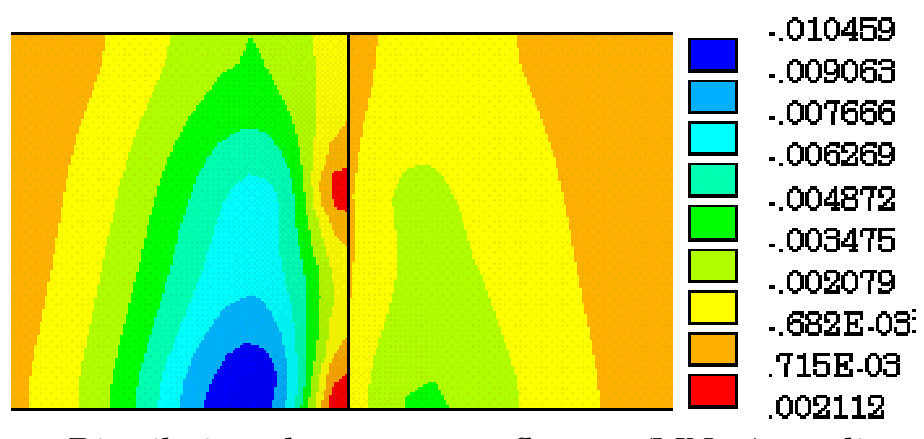

Figura 8.13 - Distribuição dos momentos fletores (MN.m), na direção x, para carregamento tangente à junta transversal - eixo simples de rodagem dupla, eficiência da junta: $45 \%$
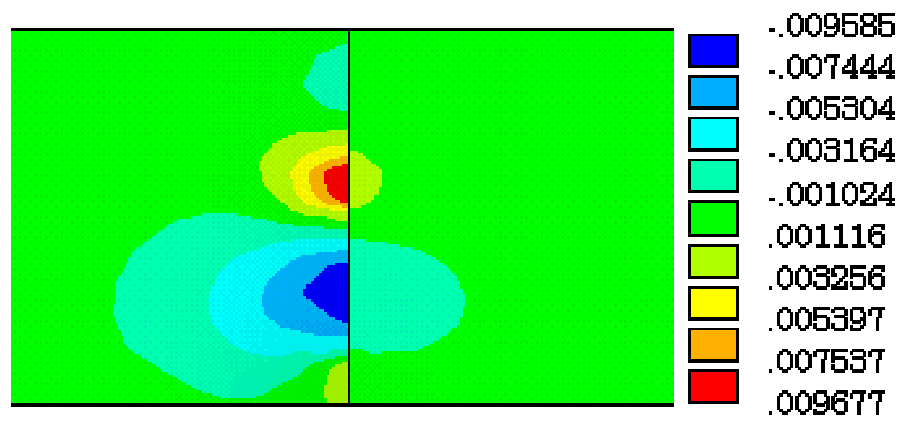

Figura 8.14 - Distribuição dos momentos fletores (MN.m), na direção y, para carregamento tangente à junta transversal - eixo simples de rodagem dupla, eficiência da junta: $45 \%$

No caso de junta com eficiência de $45 \%$ a redução obtida no máximo momento fletor negativo foi de apenas $10 \%$. O momento fletor positivo na junta foi reduzido em 14\%, e equivale a $56 \%$ do momento fletor máximo, para carregamento na borda.

RODRIGUES E PITTA (1998) apresentam equações que relacionam os momentos fletores, de acordo com a eficiência da junta. O momento na placa, próximo à junta transversal, é dado por (RODRIGUES E PITTA, 1998):

$\mathrm{M}_{\mathrm{jt}}=0,7 \cdot \mathrm{M}_{\mathrm{b}} \cdot\left(1-\frac{\varepsilon_{\mathrm{junta}}}{350}\right)$

sendo:

- $\mathrm{M}_{\mathrm{b}}$ : momento na borda do pavimento. 
O momento na placa, próximo à junta longitudinal, é dado por (RODRIGUES E PITTA, 1998):

$\mathrm{M}_{\mathrm{j} \ell}=\mathrm{M}_{\mathrm{b}} \cdot\left(1-\frac{\varepsilon_{\mathrm{junta}}}{200}\right)$

RODRIGUES E PITTA (1998) afirmam que o esforço máximo para força aplicada no interior da placa é igual a 50\% do esforço para força na borda.

Pequenas variações entre os valores obtidos com as análises numéricas e os valores calculados através da equação apresentada por RODRIGUES E PITTA (1998) podem ser justificadas pela configuração da área de aplicação da força e pela influência entre as rodas do eixo, já que neste trabalho foram apresentados os resultados para forças aplicadas em todas as rodas.

\subsection{CONSIDERAÇÕES GERAIS}

As juntas constituem a parte mais delicada e mais cara do pavimento rígido. Tem-se buscado soluções que reduzam o número de juntas e que garantam a eficiência, a fim de reduzir os custos. As barras de transferência podem reduzir os esforços nas juntas para valores próximos aos esforços no interior da placa, reduzindo em até $50 \%$ o esforço considerado no dimensionamento.

Assim como nas juntas transversais, a adoção de mecanismos de transferência de carga nas juntas longitudinais, inclusive com a construção de acostamento de concreto, com boa ligação ao pavimento, proporciona significante redução na espessura, ou na área de aço do pavimento. 


\section{Capítulo}

\section{EXEMPLOS}

Neste capítulo são desenvolvidos exemplos numéricos sobre o dimensionamento de pavimentos de concreto, de acordo com os métodos apresentados nos capítulos 6,7 e 8. São dimensionados:

- Pavimento rodoviário de concreto simples;

- Piso industrial de concreto simples;

- Piso industrial de concreto com armadura distribuída descontínua;

- Piso industrial de concreto estruturalmente armado;

- Barras de ligação;

- Barras de transferência.

\subsection{PAVIMENTO RODOVIÁRIO DE CONCRETO SIMPLES}

De acordo com o que foi exposto no capítulo 6, é apresentado a seguir o dimensionamento de um pavimento rodoviário de concreto simples. Serão utilizados os métodos da PCA/66, da PCA/88 e da AASHTO, indicando a diferença entre o módulo de reação da fundação, determinado pelo método original e pelo método indicado pelo DNER (1989). 


\subsubsection{Dados do problema}

\section{Condições gerais}

- Auto-estrada, com quatro faixas de rolamento de 3,5 metros cada uma;

- Equipamento: vibro-acabadora;

- Largura de concretagem: 7 metros;

- Junta longitudinal de construção: encaixe tipo macho-fêmea;

- Juntas longitudinais serradas com barras de ligação;

- Acostamento de concreto asfáltico;

- Juntas transversais serradas a cada 6 metros;

- Juntas transversais com barras de transferência;

- Boa eficiência da drenagem;

- Condições climáticas leves.

A geometria do pavimento está esquematizada na figura 9.1.

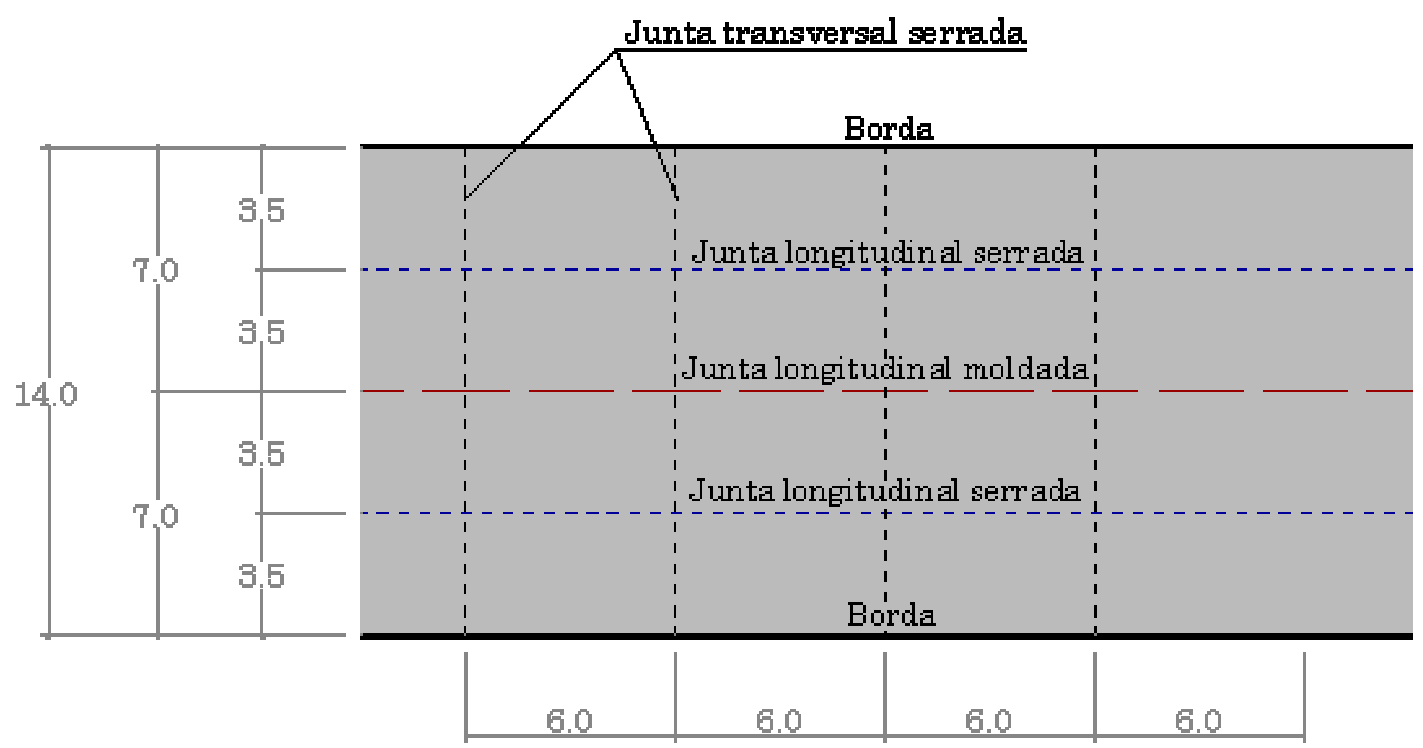

Figura 9.1 - Geometria do pavimento

\section{Tráfego}

Será adotado o tráfego indicado na tabela 9.1, para cada faixa de rolamento. 
Tabela 9.1 - Tráfego da rodovia

\begin{tabular}{|c|c|c|}
\hline Classe de eixo & $\begin{array}{c}\text { Peso por eixo } \\
\text { (tf) }\end{array}$ & $\begin{array}{c}\text { Frequência no período de } \\
\text { projeto } \\
\text { (número de repetições) }\end{array}$ \\
\hline Eixo simples de rodagem simples & 6 & 1.000 .000 \\
\hline Eixo simples de rodagem dupla & 10 & 800.000 \\
\hline Eixo tandem duplo & 17 & 200.000 \\
\hline Eixo tandem triplo & 25,5 & 50.000 \\
\hline
\end{tabular}

\section{Fundação}

Serão adotados os seguintes valores:

- $\mathrm{CBR}=4,5 \%$;

- $20 \mathrm{~cm}$ de sub-base granular

Não há presença de extrato rígido a menos de 3 metros do nível do subleito.

\section{Materiais}

Será utilizado um concreto de resistência à tração na flexão, aos 28 dias, de 4,5 MPa.

As barras de transferência serão de aço tipo CA-25, pintadas e engraxadas em metade do comprimento mais 2 centímetros.

As barras de ligação serão de aço tipo CA-60.

\subsubsection{Método da AASHTO}

Índices de serventia

O índice de serventia inicial deve ser 4,5, e o índice de serventia final, deve ser 2 . 
Espessura tentativa

Para iniciar o procedimento será adotada uma espessura tentativa de 20 centímetros.

Número de eixos equivalentes

Através das tabelas A.2 a A.10 são obtidos os fatores de equivalência de carga. O número de eixos equivalentes estão apresentados na tabela 9.2.

Tabela 9.2 - Número de eixos equivalentes

\begin{tabular}{|c|c|c|c|c|}
\hline Classe de eixo & $\begin{array}{c}\text { Carga por } \\
\text { eixo } \\
(\mathrm{tf})\end{array}$ & $\begin{array}{c}\text { Frequência } \\
\text { no período } \\
\text { de projeto } \\
\text { (número de } \\
\text { repetições) }\end{array}$ & $\begin{array}{c}\text { Fator de } \\
\text { equivalência }\end{array}$ & $\begin{array}{c}\text { Número de } \\
\text { eixos } \\
\text { equivalentes }\end{array}$ \\
\hline $\begin{array}{c}\text { Eixo simples de } \\
\text { rodagem simples }\end{array}$ & 6 & 1.000 .000 & 0,286 & 286.000 \\
\hline $\begin{array}{c}\text { Eixo simples de } \\
\text { rodagem dupla }\end{array}$ & 10 & 800.000 & 2,350 & 1.880 .000 \\
\hline Eixo tandem duplo & 17 & 200.000 & 2,932 & 586.444 \\
\hline Eixo tandem triplo & 25,5 & 50.000 & 4,843 & 242.167 \\
\hline
\end{tabular}

Da tabela A.11 tira-se que o nível de confiabilidade exigido para uma auto estrada é de $80 \%$.

Da tabela A.12 obtém-se que para um desvio padrão, so, de 0,30 , o fator de segurança, F, vale 1,79.

Desta maneira, o tráfego final de projeto é dado por:

$$
\begin{aligned}
& \mathrm{N}_{\text {total }}=2.994 .611 \cdot 1,79 \\
& \mathrm{~N}_{\text {total }}=5.360 .354
\end{aligned}
$$


Coeficiente de drenagem da sub-base e coeficiente de transferência de carga

Considerando que o pavimento estará exposto à saturação em $15 \%$ do seu tempo de vida útil, da tabela A.13, obtém-se que o coeficiente de drenagem $\mathrm{C}_{\mathrm{d}}$ é igual a 1,05 .

Da tabela A.15, obtém-se que o coeficiente de transferência de carga, J. Para as faixas externas, sem acostamento de concreto, J vale 3,0. Para as faixas internas, considera-se a faixa externa como acostamento de concreto. Nesse caso J é igual a 2,9.

Coeficiente de recalque da fundação

- $\quad$ Segundo DNER (1998):

Do gráfico da figura A.1, obtém-se que para um CBR de 4,5\%, o coeficiente de recalque da fundação, $\mathrm{k}_{0}$, vale $35 \mathrm{MPa} / \mathrm{m}$. De acordo com a figura A.2, o valor de $\mathrm{k}_{1}$, devido à sub-base granular, com 20 centímetros de espessura, é de $50 \mathrm{MPa} / \mathrm{m}$.

Como não há presença de extrato rígido, o valor de $\mathrm{k}_{2}$ é igual $50 \mathrm{MPa} / \mathrm{m}$.

Como é utilizado apenas um valor de $\mathrm{k}, \mathrm{k}_{3}$ é igual a $\mathrm{k}_{2}$, igual a $50 \mathrm{MPa} / \mathrm{m}$

Para sub-base granular, da tabela A.14a, obtém-se que a perda de suporte, $\mathrm{p}_{\mathrm{s}}$, varia entre 1 e 2 . Neste exemplo será adotada perda igual a 1,5. Assim sendo, o fator de perda de suporte, $\mathrm{F}_{\mathrm{ps}}$, é:

$\mathrm{F}_{\mathrm{ps}}=10^{(-0,33 \cdot 1,5) \cdot 50^{(-0,17 \cdot 1,5)}}$

$\mathrm{F}_{\mathrm{ps}}=0,657$

$\mathrm{O}$ coeficiente de recalque da fundação, $\mathrm{k}_{\mathrm{d}}$, é dado por:

$\mathrm{k}_{\mathrm{d}}=0,657.50$ 
$\mathrm{k}_{\mathrm{d}}=32,85 \mathrm{MPa} / \mathrm{m}$

$\mathrm{k}_{\mathrm{d}}=3,35 \mathrm{kgf} / \mathrm{cm}$

- Segundo AASHTO (1986):

$\mathrm{MR}=1.500 \cdot 4,5$

$\mathrm{MR}=6750 \mathrm{psi}$

Pode-se considerar que a sub-base granular tem módulo de elasticidade igual a 40.000psi (tabela A.14b). Da figura A.6, $\mathrm{k}_{1}$ é igual a 500 pci.

Como não há extrato rígido e é utilizado apenas um valor de $\mathrm{k}, \mathrm{k}_{3}=\mathrm{k}_{2}$ $=\mathrm{k}_{1}=500$ pci.

Da tabela A.14b, tem-se que a perda de suporte é igual a 1,5. Da figura A.9, $\mathrm{k}_{\mathrm{d}}$ é igual a $90 \mathrm{pci}$, equivalente a $24,3 \mathrm{MPa} / \mathrm{m}$. Observa-se que o valor obtido das tabelas originais da AASHTO é $26 \%$ menor que o valor obtido pelo método apresentado pelo DNER.

Neste exemplo será adotado o valor obtido pelo método do DNER.

Perda de serventia

$\Delta \mathrm{s}=4,5-2,0$

$\Delta \mathrm{s}=2,5$

Resistência equivalente do concreto e módulo de elasticidade

Faixa externa:

$\mathrm{f}_{\text {ct,eq }}=\frac{4,5 \cdot 1,05}{2,7}$

$\mathrm{f}_{\text {ct,eq }}=1,575 \mathrm{MPa}$

$\mathrm{f}_{\mathrm{ct}, \mathrm{eq}}=16,07 \mathrm{kgf} / \mathrm{cm}^{2}$

Faixa interna: 
$\mathrm{f}_{\mathrm{ct}, \mathrm{eq}}=\frac{4,5 \cdot 1,05}{2,9}$

$\mathrm{f}_{\text {ct,eq }}=1,629 \mathrm{MPa}$

$\mathrm{f}_{\mathrm{ct}, \mathrm{eq}}=16,62 \mathrm{kgf} / \mathrm{cm}^{2}$

$\mathrm{E}_{\mathrm{c}}=0,85 \cdot 5600 \cdot \sqrt{58}$

$\mathrm{E}_{\mathrm{c}}=36280 \mathrm{MPa}$

$\mathrm{E}_{\mathrm{c}}=370204 \mathrm{kgf} / \mathrm{cm}^{2}$

Fórmula geral

$$
\mathrm{a}=\frac{\log (0,33 \cdot 2,5)}{1+\left(\frac{18,078}{20+2,54}\right)^{8,46}}
$$

$a=-0,072$

Faixa externa:

$\mathrm{B}=\frac{16,07}{15,185} \cdot\left(\frac{20^{0,75}-2,278}{20^{0,75}-46,79 \cdot\left(\frac{3,35}{370204}\right)^{0,75}}\right)$

$\mathrm{B}=0,804$

$\mathrm{N}_{\text {eq,adm }}=\left(\frac{20+2,54}{2,588}\right)^{7,35} \cdot 10^{-0,072} \cdot(0,804)^{(4,22-0,32 \cdot 2)}$

$\mathrm{N}_{\text {eq,adm }}=3.145 .868$

Tendo em vista que o pavimento suporta 3.145 .868 repetições do eixo equivalente, e está prevista a passagem de 5.360.354, a adoção da espessura de $20 \mathrm{~cm}$ não satisfaz o problema. Deve ser realizada uma segunda tentativa.

Faixa interna: 
$\mathrm{B}=\frac{16,62}{15,185} \cdot\left(\frac{20^{0,75}-2,278}{20^{0,75}-46,79 \cdot\left(\frac{3,35}{370204}\right)^{0,75}}\right)$

$\mathrm{B}=0,832$

$\mathrm{N}_{\text {eq,adm }}=\left(\frac{20+2,54}{2,588}\right)^{7,35} \cdot 10^{-0,072} \cdot(0,832)^{(4,22-0,32 \cdot 2)}$

$\mathrm{N}_{\text {eq,adm }}=3.556 .030$

Para faixa interna a espessura de 20 centímetros também não é suficiente.

Para refazer o procedimento será adotada uma espessura tentativa de 22 centímetros.

Tabela 9.3 - Número de eixos equivalentes

\begin{tabular}{|c|c|c|c|c|}
\hline Classe de eixo & $\begin{array}{c}\text { Carga por } \\
\text { eixo } \\
(\mathrm{tf})\end{array}$ & $\begin{array}{c}\text { Frequência } \\
\text { no período } \\
\text { de projeto } \\
\text { (número de } \\
\text { repetições) }\end{array}$ & $\begin{array}{c}\text { Fator de } \\
\text { equivalência }\end{array}$ & $\begin{array}{c}\text { Número de } \\
\text { eixos } \\
\text { equivalentes }\end{array}$ \\
\hline $\begin{array}{c}\text { Eixo simples de } \\
\text { rodagem simples }\end{array}$ & 6 & 1.000 .000 & 0,284 & 284.133 \\
\hline $\begin{array}{c}\text { Eixo simples de } \\
\text { rodagem dupla }\end{array}$ & 10 & 800.000 & 2,374 & 1.899 .200 \\
\hline Eixo tandem duplo & 17 & 200.000 & 2,977 & 595.333 \\
\hline Eixo tandem triplo & 25,5 & 50.000 & 4,949 & 247.456 \\
\cline { 2 - 5 } & & & $\mathrm{N}_{\mathrm{eq}}$ & 3.026 .122 \\
\hline
\end{tabular}

$\mathrm{N}_{\text {total }}=3.026 .122 \cdot 1,79$

$\mathrm{N}_{\text {total }}=5.416 .759$

$a=\frac{\log (0,33 \cdot 2,5)}{1+\left(\frac{18,078}{22+2,54}\right)^{8,46}}$

$a=-0,078$

Faixa externa 
$\mathrm{B}=\frac{16,07}{15,185} \cdot\left(\frac{22^{0,75}-2,278}{22^{0,75}-46,79 \cdot\left(\frac{3,35}{370204}\right)^{0,75}}\right)$

$\mathrm{B}=0,822$

$\mathrm{N}_{\text {eq,adm }}=\left(\frac{22+2,54}{2,588}\right)^{7,35} \cdot 10^{-0,078} \cdot(0,822)^{(4,22-0,32 \cdot 2)}$

$\mathrm{N}_{\mathrm{eq}, \mathrm{adm}}=6.273 .815$

Com a espessura de 22 centímetros, o pavimento suporta 6.273.815 repetições do eixo equivalente Como está prevista a passagem de 5.416 .759 essa espessura resolve o problema, para a faixa externa.

Faixa interna

$\mathrm{B}=\frac{16,62}{15,185} \cdot\left(\frac{22^{0,75}-2,278}{22^{0,75}-46,79 \cdot\left(\frac{3,35}{370204}\right)^{0,75}}\right)$

$\mathrm{B}=0,850$

$\mathrm{N}_{\text {eq,adm }}=\left(\frac{22+2,54}{2,588}\right)^{7,35} \cdot 10^{-0,078} \cdot(0,850)^{(4,22-0,32 \cdot 2)}$

$\mathrm{N}_{\text {eq,adm }}=7.073 .109$

Para a faixa interna, a espessura de 22 centímetros também é suficiente. Como houve uma sobra de eixos equivalentes admissíveis, será verificado se uma espessura intermediária também verifica o problema.

Será verificada, a seguir, a espessura de 21 centímetros. 
Tabela 9.4 - Número de eixos equivalentes

\begin{tabular}{|c|c|c|c|c|}
\hline Classe de eixo & $\begin{array}{c}\text { Carga por } \\
\text { eixo } \\
(\mathrm{tf})\end{array}$ & $\begin{array}{c}\text { Frequência } \\
\text { no período } \\
\text { de projeto } \\
\text { (número de } \\
\text { repetições) }\end{array}$ & $\begin{array}{c}\text { Fator de } \\
\text { equivalência }\end{array}$ & $\begin{array}{c}\text { Número de } \\
\text { eixos } \\
\text { equivalentes }\end{array}$ \\
\hline $\begin{array}{c}\text { Eixo simples de } \\
\text { rodagem simples }\end{array}$ & 6 & 1.000 .000 & 0,285 & 285.067 \\
\hline $\begin{array}{c}\text { Eixo simples de } \\
\text { rodagem dupla }\end{array}$ & 10 & 800.000 & 2,362 & 1.889 .600 \\
\hline Eixo tandem duplo & 17 & 200.000 & 2,954 & 590.889 \\
\hline Eixo tandem triplo & 25,5 & 50.000 & 4,896 & 244.811 \\
\cline { 2 - 4 } & & & $\mathrm{N}_{\mathrm{eq}}$ & 3.010 .367 \\
\hline
\end{tabular}

$\mathrm{N}_{\text {total }}=3.010 .367 \cdot 1,79$

$\mathrm{N}_{\text {total }}=5.388 .557$

$a=\frac{\log (0,33 \cdot 2,5)}{1+\left(\frac{18,078}{21+2,54}\right)^{8,46}}$

$\mathrm{a}=-0,075$

Faixa externa

$\mathrm{B}=\frac{16,07}{15,185} \cdot\left(\frac{21^{0,75}-2,278}{21^{0,75}-46,79 \cdot\left(\frac{3,35}{370204}\right)^{0,75}}\right)$

$\mathrm{B}=0,813$

$\mathrm{N}_{\mathrm{eq}, \mathrm{adm}}=\left(\frac{21+2,54}{2,588}\right)^{7,35} \cdot 10^{-0,075} \cdot(0,813)^{(4,22-0,32 \cdot 2)}$

$\mathrm{N}_{\text {eq,adm }}=4.473 .158$

Com a espessura de 21 centímetros, o pavimento suporta 4.473 .158 repetições do eixo equivalente. O tráfego previsto é de 5.388.557, portanto essa espessura não é suficiente, devendo ser adotada igual a 22 centímetros.

Faixa interna 
$\mathrm{B}=\frac{16,62}{15,185} \cdot\left(\frac{21^{0,75}-2,278}{21^{0,75}-46,79 \cdot\left(\frac{3,35}{370204}\right)^{0,75}}\right)$

$\mathrm{B}=0,841$

$\mathrm{N}_{\text {eq,adm }}=\left(\frac{21+2,54}{2,588}\right)^{7,35} \cdot 10^{-0,075} \cdot(0,841)^{(4,22-0,32.2)}$

$\mathrm{N}_{\text {eq,adm }}=5.049 .632$

Para a faixa interna também deverá ser adotada espessura de 22 centímetros, visto que, com 21 centímetros, o número de eixos admissíveis é inferior ao número de eixos solicitantes.

\subsubsection{Método da PCA/66}

Espessura tentativa

Será adotada uma espessura inicial de 20 centímetros.

Coeficiente de recalque da fundação

$\mathrm{O}$ valor de $\mathrm{k}$ é determinado através dos gráficos A.1 e A.2. Para o CBR de 4,5\%, com 20 centímetros de sub-base granular, o valor de $\mathrm{k}$, no topo do sistema, é de $50 \mathrm{MPa} / \mathrm{m}$ 
Coeficiente de segurança

Através da tabela A.16, verifica-se que deve ser utilizado um coeficiente de segurança de 1,2 .

Módulo de resistência do concreto

$\mathrm{M}_{\mathrm{R}}=4,5 \mathrm{MPa}$

Preenchimento do quadro, para verificação da fadiga

Quadro 9.1 - Cálculo da espessura de pavimento de concreto pelo método da PCA/66

Projeto:

Exemplo 9.1.3

Espessura tentativa: $20 \mathrm{~cm}$

$\mathrm{k}$ :

FS:

$50 \mathrm{MPa} / \mathrm{m}$

$\mathrm{M}_{\mathrm{R}}$ :

Período de Projeto

1,2

$4,5 \mathrm{MPa}$

\begin{tabular}{|c|c|c|c|c|c|c|}
\hline $\begin{array}{c}\text { Peso por } \\
\text { eixo } \\
(\mathrm{tf})\end{array}$ & $\begin{array}{c}\text { Peso por } \\
\text { eixo . F FC } \\
(\mathrm{tf})\end{array}$ & $\begin{array}{c}\text { Tensão na } \\
\text { placa } \\
(\mathrm{MPa})\end{array}$ & $\begin{array}{c}\text { Relação } \\
\text { de } \\
\text { tensões }\end{array}$ & $\mathrm{N}_{\mathrm{adm}}$ & $\mathrm{N}_{\text {sol }}$ & $\begin{array}{c}\mathrm{C} \\
(\%)\end{array}$ \\
\hline$(1)$ & $(2)=(1)$. FS & $(3)$ & $(4)=(3) / \mathrm{M}_{\mathrm{R}}$ & $(5)$ & $(6)$ & $(7)=(6) /(5)$ \\
\hline
\end{tabular}

Eixos simples

\begin{tabular}{|c|c|c|c|c|c|c|}
\hline 6 & 7,2 & 1,56 & 0,35 & ilimitado & 1.000 .000 & 0 \\
\hline 10 & 12 & 2,06 & 0,46 & ilimitado & 800.000 & 0 \\
\hline
\end{tabular}

Eixos tandem duplos 20 anos

\begin{tabular}{|c|c|c|c|c|c|c|}
\hline 17 & 20,4 & 1,76 & 0,39 & ilimitado & 200.000 & 0 \\
\hline \multicolumn{7}{|c|}{ Eixos tandem triplos } \\
\hline 25,5 & 30,6 & 1,96 & 0,43 & ilimitado & 50.000 & 0 \\
\hline
\end{tabular}

\begin{tabular}{c|c|}
$\mathrm{C}_{\text {total: }}$ & 0 \\
\hline
\end{tabular}

A espessura tentativa levou a tensões inferiores a 0,5 , permitindo um número ilimitado de repetições de carga.

Será adotada nova espessura, de 19 centímetros. 
Quadro 9.2 - Cálculo da espessura de pavimento de concreto pelo método da PCA/66

Projeto:

Exemplo 9.1.3

Espessura tentativa: $19 \mathrm{~cm}$

$\mathrm{k}$ :

$50 \mathrm{MPa} / \mathrm{m}$

FS:

$\mathrm{M}_{\mathrm{R}}$ :

Período de Projeto

1,2

$4,5 \mathrm{MPa}$

20 anos

\begin{tabular}{|c|c|c|c|c|c|c|}
\hline $\begin{array}{c}\text { Peso por } \\
\text { eixo } \\
(\mathrm{tf})\end{array}$ & $\begin{array}{c}\text { Peso por } \\
\text { eixo . FSC } \\
(\mathrm{tf})\end{array}$ & $\begin{array}{c}\text { Tensão na } \\
\text { placa } \\
(\mathrm{MPa})\end{array}$ & $\begin{array}{c}\text { Relação } \\
\text { de } \\
\text { tensões }\end{array}$ & $\mathrm{N}_{\mathrm{adm}}$ & $\mathrm{N}_{\text {sol }}$ & $\begin{array}{c}\mathrm{C} \\
(\%)\end{array}$ \\
\hline$(1)$ & $(2)=(1)$. Fs & $(3)$ & $(4)=(3) / \mathrm{M}_{\mathrm{R}}$ & $(5)$ & $(6)$ & $(7)=(6) /(5)$ \\
\hline
\end{tabular}

Eixos simples

\begin{tabular}{|c|c|c|c|c|c|c|}
\hline 6 & 7,2 & 1,66 & 0,37 & ilimitado & 1.000 .000 & 0 \\
\hline 10 & 12 & 2,16 & 0,48 & ilimitado & 800.000 & 0 \\
\hline
\end{tabular}

Eixos tandem duplos

\begin{tabular}{|c|c|c|c|c|c|c|}
\hline 17 & 20,4 & 2,30 & 0,51 & 400.000 & 200.000 & 50 \\
\hline \multicolumn{7}{|c|}{ Eixos tandem triplos } \\
\hline 25,5 & 30,6 & 2,107 & 0,47 & ilimitado & 50.000 & 0 \\
\hline
\end{tabular}

$\mathrm{C}_{\text {total: }} \quad 50$

Para a espessura de 19 centímetros o consumo de fadiga foi de apenas $50 \%$. Deve-se refazer os cálculos para tentar obter um resultado mais econômico.

Quadro 9.3 - Cálculo da espessura de pavimento de concreto pelo método da PCA/66 Projeto: $\quad$ Exemplo 9.1.3

Espessura tentativa: $18 \mathrm{~cm}$ $\mathrm{k}$ : $50 \mathrm{MPa} / \mathrm{m}$

FS: $\quad 1,2$

$\mathrm{M}_{\mathrm{R}}$ : $\quad 4,5 \mathrm{MPa}$

Período de Projeto 20 anos

\begin{tabular}{|c|c|c|c|c|c|c|}
\hline $\begin{array}{c}\text { Peso por } \\
\text { eixo } \\
(\mathrm{tf})\end{array}$ & $\begin{array}{c}\text { Peso por } \\
\text { eixo. Fsc } \\
(\mathrm{tf})\end{array}$ & $\begin{array}{c}\text { Tensão na } \\
\text { placa } \\
(\mathrm{MPa})\end{array}$ & $\begin{array}{c}\text { Relação } \\
\text { de } \\
\text { tensões }\end{array}$ & $\mathrm{N}_{\mathrm{adm}}$ & $\mathrm{N}_{\mathrm{sol}}$ & $\begin{array}{c}\mathrm{C} \\
(\%)\end{array}$ \\
\hline$(1)$ & $(2)=(1) \cdot \mathrm{FSC}_{\mathrm{SC}}$ & $(3)$ & $(4)=(3) / \mathrm{M}_{\mathrm{R}}$ & $(5)$ & $(6)$ & $(7)=(6) /(5)$ \\
\hline
\end{tabular}

Eixos simples

\begin{tabular}{|c|c|c|c|c|c|c|}
\hline 6 & 7,2 & 1,70 & 0,38 & ilimitado & 1.000 .000 & 0 \\
\hline 10 & 12 & 2,35 & 0,52 & 300.000 & 800.000 & 267 \\
\hline \multicolumn{7}{|c|}{ Eixos tandem duplos } \\
\hline 17 & 20,4 & 2,45 & 0,54 & 180.000 & 200.000 & 111 \\
\hline \multicolumn{7}{|c|}{ Eixos tandem triplos } \\
\hline 25,5 & 30,6 & 2,303 & 0,51 & 400.000 & 50.000 & 12,5 \\
\hline & & & & & $\mathrm{C}_{\text {total }}:$ & 390,5 \\
\hline
\end{tabular}


O aumento da tensão provocada pelos eixos simples de rodagem dupla de 2,16 MPa para 2,35 $\mathrm{MPa}$ quando adotada espessura de 18 centímetros, ao invés de 19, provocou um aumento da relação de tensões de 0,48 para 0,52. Para relações de tensão inferiores a 0,5 o número de repetições é ilimitado, mas o número de repetições admissível decresce rapidamente, quando a relação de tensões ultrapassa esse valor. Devido ao elevado tráfego de veículos de 10tf, a espessura de 18 centímetros não satisfaz o critério de fadiga. Assim sendo, será adotada espessura de 19 centímetros. É possível fazer a verificação para espessuras intermediárias, como por exemplo 18,5 cm.

\subsubsection{Método da PCA/84}

\section{Espessura tentativa}

Será adotada uma espessura inicial de 22 centímetros, para as faixas externas, e 19 centímetros para as faixas internas.

Coeficiente de recalque da fundação

$\mathrm{O}$ valor de $\mathrm{k}$ é determinado através dos gráficos A.1 e A.2. Para o CBR de 4,5\%, com 20 centímetros de sub-base granular, o valor de $\mathrm{k}$, no topo do sistema, é de $50 \mathrm{MPa} / \mathrm{m}$

Coeficiente de segurança

O coeficiente de segurança é o mesmo que para o método de 1966: 1,2.

Módulo de resistência do concreto

$\mathrm{M}_{\mathrm{R}}=4,5 \mathrm{MPa}$ 
Preenchimento do quadro, para verificação da fadiga

\section{a. Faixa externa}

Quadro 9.4 - Cálculo da espessura de pavimento de concreto pelo método da PCA/84

Projeto:

Exemplo 9.1.4

Espessura tentativa: $22 \mathrm{~cm}$

$\mathrm{k}$ :

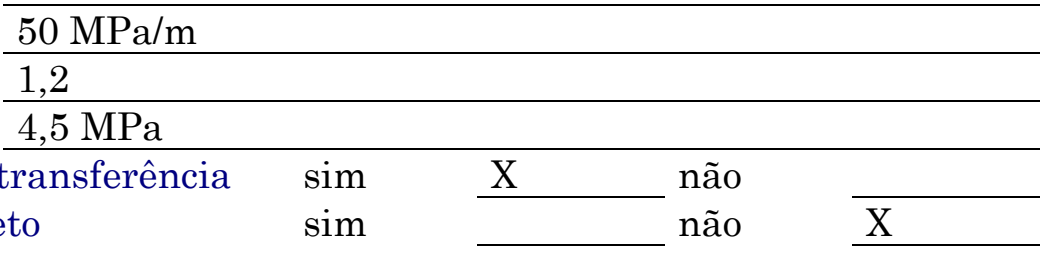

FS:

$\mathrm{M}_{\mathrm{R}}$ :

Período de Projeto 20 anos

\begin{tabular}{|c|c|c|c|c|c|c|}
\cline { 3 - 7 } \multicolumn{2}{c|}{} & \multicolumn{2}{c|}{ Análise de Fadiga } & \multicolumn{2}{c|}{ Análise de Erosão } \\
\hline $\begin{array}{c}\text { Peso por } \\
\text { eixo } \\
(\mathrm{tf})\end{array}$ & $\begin{array}{c}\text { Peso por } \\
\text { eixo . FSC } \\
(\mathrm{tf})\end{array}$ & $\mathrm{N}_{\mathrm{sol}}$ & $\mathrm{N}_{\mathrm{adm}}$ & $\begin{array}{c}\text { Consumo } \\
\text { de fadiga } \\
(\%)\end{array}$ & $\mathrm{N}_{\mathrm{adm}}$ & $\begin{array}{c}\text { Dano por } \\
\text { erosão } \\
(\%)\end{array}$ \\
\hline$(1)$ & $(2)=(1)$. Fsc & $(3)$ & $(4)$ & $(5)$ & $(6)$ & $(7)=(6) /(5)$ \\
\hline
\end{tabular}

Eixos simples

8- Tensão equivalente:

1,515

9- Fator de fadiga:

10- Fator de erosão:

2,70

\begin{tabular}{|c|c|c|c|c|c|c|}
\hline 6 & 7,2 & 1.000 .000 & ilimitado & 0 & ilimitado & 0 \\
\hline 10 & 12 & 800.000 & 1.500 .000 & 53 & 4.200 .000 & 19 \\
\hline
\end{tabular}

Eixos tandem duplos

11- Tensão equivalente:

12- Fator de fadiga:

1,34

13- Fator de erosão:

\begin{tabular}{c}
1,34 \\
\hline 0,298 \\
\hline 2,85 \\
\hline
\end{tabular}

17

\begin{tabular}{l|l|}
17 & 20,4 \\
\hline
\end{tabular}
200.000

Eixos tandem triplos
14- Tensão equivalente:

15- Fator de fadiga:

16- Fator de erosão:
1,01

0,251

2,975

\begin{tabular}{|c|c|c|c|c|c|c|}
\hline 25,5 & 10,2 & 50.000 & ilimitado & 0 & 1.600 .000 & 3,1 \\
\hline
\end{tabular}

\begin{tabular}{r|l|l|l}
$\mathrm{C}_{\text {total: }}$ & 53 & $\mathrm{D}_{\text {total }}:$ & 27,8
\end{tabular}

Segundo o método da PCA/84, a espessura de 22 centímetros, sob o carregamento estudado, teria o consumo de fadiga igual a $53 \%$, no período de projeto. Quanto a erosão o consumo seria de apenas $27,8 \%$. Será verificada uma 
espessura menor. Será desenvolvida uma nova tentativa, para a faixa externa com 21 centímetros.

Quadro 9.5 - Cálculo da espessura de pavimento de concreto pelo método da PCA/84 Projeto: Exemplo 9.1.4

Espessura tentativa: $21 \mathrm{~cm}$

$\mathrm{k}$ :

FSC:

$\mathrm{M}_{\mathrm{R}}$ :

$$
50 \mathrm{MPa} / \mathrm{m}
$$

$4,5 \mathrm{MPa}$

Juntas com barras de transferência

Acostamento de concreto

$\operatorname{sim}$

Período de Projeto

20 anos

$\operatorname{sim}$

$\underline{\mathrm{X}}$ não

não

$\mathrm{X}$

\begin{tabular}{|c|c|c|c|c|c|c|}
\cline { 3 - 6 } \multicolumn{2}{c|}{} & \multicolumn{2}{c|}{ Análise de Fadiga } & \multicolumn{2}{c|}{ Análise de Erosão } \\
\hline $\begin{array}{c}\text { Peso por } \\
\text { eixo } \\
\text { (tf) }\end{array}$ & $\begin{array}{c}\text { Peso por } \\
\text { eixo. FSC } \\
\text { (tf) }\end{array}$ & $\mathrm{N}_{\text {sol }}$ & $\mathrm{N}_{\text {adm }}$ & $\begin{array}{c}\text { Consumo } \\
\text { de fadiga } \\
(\%)\end{array}$ & $\mathrm{N}_{\text {adm }}$ & $\begin{array}{c}\text { Dano por } \\
\text { erosão } \\
(\%)\end{array}$ \\
\hline$(1)$ & $(2)=(1)$. Fsc & $(3)$ & $(4)$ & $(5)$ & $(6)$ & $(7)=(6) /(5)$ \\
\hline
\end{tabular}

Eixos simples

8- Tensão equivalente:

1,62

9- Fator de fadiga:

0,36

10- Fator de erosão:

2,76

\begin{tabular}{|c|c|c|c|c|c|c|}
\hline 6 & 7,2 & 1.000 .000 & ilimitado & 0 & ilimitado & 0 \\
\hline 10 & 12 & 800.000 & 300.000 & 266 & 2.800 .000 & 28,6 \\
\hline
\end{tabular}

Eixos tandem duplos

11- Tensão equivalente:

12- Fator de fadiga:

1,415

13- Fator de erosão:

0,314

2,90

17

20,4

200.000

ilimitado

0

2.600 .000

7,7

Eixos tandem triplos

14- Tensão equivalente:

15- Fator de fadiga:

16- Fator de erosão:

1,07

0,238

3,02

25,5 10,2 \begin{tabular}{l|l}
50.000 & ilimitado
\end{tabular}

0

900.000

5,6

$\mathrm{C}_{\text {total: }} \quad 266$

$\mathrm{D}_{\text {total: }}$

41,9

Para espessura de 21 centímetros a resistência à fadiga do pavimento é superada em $266 \%$. Portanto, para faixa externa, será adotada a espessura de 22 centímetros. 


\section{b. Faixa interna}

Quadro 9.6 - Cálculo da espessura de pavimento de concreto pelo método da PCA/84

Projeto:

Espessura tentativa: $19 \mathrm{~cm}$

$\mathrm{k}$ :

FS:

$50 \mathrm{MPa} / \mathrm{m}$

$\mathrm{M}_{\mathrm{R}}$ :

1,2

Juntas com barras de transferência

Acostamento de concreto

$\operatorname{sim}$

Período de Projeto

20 anos

$\operatorname{sim}$

$\frac{X}{X}$

não

Periodo de Projeto 20 anos

\begin{tabular}{|c|c|c|c|c|c|c|}
\cline { 3 - 6 } \multicolumn{2}{c|}{} & \multicolumn{2}{c|}{ Análise de Fadiga } & \multicolumn{2}{c|}{ Análise de Erosão } \\
\hline $\begin{array}{c}\text { Peso por } \\
\text { eixo } \\
\text { (tf) }\end{array}$ & $\begin{array}{c}\text { Peso por } \\
\text { eixo. Fsc } \\
\text { (tf) }\end{array}$ & $\mathrm{N}_{\text {sol }}$ & $\mathrm{N}_{\mathrm{adm}}$ & $\begin{array}{c}\text { Consumo } \\
\text { de fadiga } \\
(\%)\end{array}$ & $\mathrm{N}_{\text {adm }}$ & $\begin{array}{c}\text { Dano por } \\
\text { erosão } \\
(\%)\end{array}$ \\
\hline$(1)$ & $(2)=(1)$. Fsc & $(3)$ & $(4)$ & $(5)$ & $(6)$ & $(7)=(6) /(5)$ \\
\hline
\end{tabular}

Eixos simples

8- Tensão equivalente:

9- Fator de fadiga:

1,515

10- Fator de erosão:

$\begin{array}{r}1,515 \\ \hline 0,337 \\ \hline 2,445 \\ \hline\end{array}$

\begin{tabular}{|c|c|c|c|c|c|c|}
\hline 6 & 7,2 & 1.000 .000 & ilimitado & 0 & ilimitado & 0 \\
\hline 10 & 12 & 800.000 & 1.500 .000 & 53,3 & 2.200 .000 & 36,4 \\
\hline
\end{tabular}

Eixos tandem duplos

11- Tensão equivalente:

12- Fator de fadiga:

1,285

13- Fator de erosão:

0,286

2,525

\begin{tabular}{|c|c|c|c|c|c|c|}
\hline 17 & 20,4 & 200.000 & ilimitado & 0 & 3.900 .000 & 5,1 \\
\hline
\end{tabular}

Eixos tandem triplos

14- Tensão equivalente:

15- Fator de fadiga:

1,01

16- Fator de erosão:

0

2.000 .000

2,5

$\mathrm{C}_{\text {total: }} \quad 53,3$

$\mathrm{D}_{\text {total: }} \quad 44$

Para as faixas internas, com espessura de 19 centímetros, o consumo de fadiga é de $53,3 \%$ e de erosão é $44 \%$.

Será verificada uma nova espessura, para a faixa interna, com 18 centímetros. 
Quadro 9.7 - Cálculo da espessura de pavimento de concreto pelo método da PCA/84

Projeto:

Exemplo 9.1.4

Espessura tentativa: $18 \mathrm{~cm}$

$\mathrm{k}$ :

FS:

$\mathrm{M}_{\mathrm{R}}$ :

$50 \mathrm{MPa} / \mathrm{m}$

Juntas com barras de transferência

Acostamento de concreto

$\operatorname{sim}$

$\operatorname{sim}$

Período de Projeto 20 anos

\begin{tabular}{|c|c|c|c|c|c|c|}
\cline { 4 - 6 } \multicolumn{2}{c|}{} & \multicolumn{2}{c|}{ Análise de Fadiga } & \multicolumn{2}{c|}{ Análise de Erosão } \\
$\begin{array}{c}\text { Peso por } \\
\text { eixo } \\
(\mathrm{tf})\end{array}$ & $\begin{array}{c}\text { Peso por } \\
\text { eixo . F } \\
(\mathrm{tf})\end{array}$ & $\mathrm{N}_{\mathrm{sol}}$ & $\mathrm{N}_{\mathrm{adm}}$ & $\begin{array}{c}\text { Consumo } \\
\text { de fadiga } \\
(\%)\end{array}$ & $\mathrm{N}_{\mathrm{adm}}$ & $\begin{array}{c}\text { Dano por } \\
\text { erosão } \\
(\%)\end{array}$ \\
\hline$(1)$ & $(2)=(1) . \mathrm{Fsc}_{\mathrm{SC}}$ & $(3)$ & $(4)$ & $(5)$ & $(6)$ & $(7)=(6) /(5)$ \\
\hline
\end{tabular}

Eixos simples

8- Tensão equivalente:

1,63

9- Fator de fadiga:

10- Fator de erosão:

0,362

2,51

\begin{tabular}{|c|c|c|c|c|c|c|}
\hline 6 & 7,2 & 1.000 .000 & ilimitado & 0 & ilimitado & 0 \\
\hline 10 & 12 & 800.000 & 290.000 & 275 & 1.400 .000 & 57,1 \\
\hline
\end{tabular}

Eixos tandem duplos

11- Tensão equivalente:

12- Fator de fadiga:

1,375

13- Fator de erosão:

0,306

2,57

\section{7}

20,4

200.000

ilimitado

0

2.100 .000

9,5

Eixos tandem triplos

14- Tensão equivalente:

15- Fator de fadiga:

16- Fator de erosão:

\begin{tabular}{c}
1,085 \\
\hline 0,241 \\
\hline 2,625 \\
\hline
\end{tabular}

25,5 10,2 50.000 ilimitado

0

1.100 .000

4,5

$\mathrm{C}_{\text {total: }}$

275

Dtotal:

71,1

Para as faixas internas com espessura de 18 centímetros, o consumo de fadiga é de $275 \%$. Desta forma será adotada a espessura de 19 centímetros.

\subsubsection{Considerações sobre os resultados}

Neste exemplo, verificou-se que, para o método da AASHTO, apesar de ter sido considerada a existência de acostamento de concreto, no cálculo das 
faixas internas, a espessura necessária foi a mesma que para as faixas externas: 22 centímetros, mas as faixas internas suportam a passagem de 799.294 eixos equivalentes a mais que as faixas externas. Se a construção de faixas com 0,5 centímetros de diferença na espessura for viável, pode-se verificar se a faixa interna resiste ao número de eixos solicitantes, com uma espessura de 21,5 centímetros.

O método da PCA/66 não considera a existência de barras de transferência e de acostamento de concreto. Além disso existe uma descontinuidade na curva de fadiga que provoca uma grande diferença no consumo da resistência entre espessuras muito próximas.

O método da PCA/84 é mais conservador que o da PCA/66, a descontinuidade da curva de fadiga foi corrigida e já é considerada a existência de barras de transferência e de acostamento de concreto. Verifica-se uma grande influência do acostamento de concreto no dimensionamento. Verifica-se também que uma pequena variação na espessura altera consideravelmente o consumo de fadiga. Neste exemplo, onde o tráfego de eixos simples é muito maior que o de eixos tandem, a fadiga tem maior importância no dimensionamento. Para o caso de haver um grande número de veículos pesados, a erosão pode tornar-se o fator preponderante no dimensionamento.

Comparando os resultados dos três métodos, verifica-se que o método da PCA/84 forneceu valores intermediários. Além disso, este método considera melhor a presença de acostamento de concreto e de barras de transferência. Portanto será adotada espessura de 22 centímetros para as faixas externas e de 19 centímetros para as faixas internas.

\subsection{PISO INDUSTRIAL DE CONCRETO SIMPLES}

Será apresentado, a seguir, um exemplo de dimensionamento de piso industrial de concreto simples pelos métodos de PACKARD (1976). 


\subsubsection{Dados do problema}

\section{Condições gerais}

- Piso industrial de área igual a 150 x 140 metros;

- Equipamento: vibro-acabadora;

- Largura de concretagem: 4 metros;

- Junta longitudinal de construção: encaixe tipo macho-fêmea, com barras de ligação nas três faixas externas;

- Juntas transversais com barras de transferência, a cada 6 metros.

\section{Solicitações}

O piso é solicitado por empilhadeiras de rodagem simples de carga máxima igual a 10tf. $\mathrm{O}$ eixo tem 1,00 metro de comprimento e a pressão de enchimento dos pneus pode ser considerada igual a $1,75 \mathrm{MPa}$.

Estão previstas áreas de carregamento distribuído com $80 \mathrm{kN} / \mathrm{m}^{2}$.

Deverão ser utilizadas prateleiras com apoios de 20 × $20 \mathrm{~cm}$ e $6 \mathrm{tf}$ por apoio. A distância entre os montantes é de 1,20 e 2,40 metros.

Nas placas internas o tráfego previsto é de 1.000.000 de eixos. Nas placas internas, calcula-se a passagem de 60.000 eixos.

\section{Fundação}

Serão adotados os seguintes valores:

- $\mathrm{CBR}=4,5 \%$;

- $20 \mathrm{~cm}$ de sub-base granular.

\section{Materiais}

Será utilizado concreto de resistência à tração na flexão, aos 28 dias, de 4,5 MPa. 
As barras de transferência serão de aço tipo CA-25, pintadas e engraxadas em metade do comprimento mais 2 centímetros.

As barras de ligação serão de aço tipo CA-60A.

\subsubsection{Dimensionamento pelo método de PACKARD}

Ações móveis

A tabela A.24 fornece o valor dos coeficientes de segurança, em função do número de repetições das solicitações. Para 1.000 .000 repetições, o coeficiente de segurança é igual a 2. Para 10.000, o coeficiente de segurança é de 1,74.

$$
\begin{aligned}
& \mathrm{P}=10 \mathrm{tf} \cdot \frac{9,8 \mathrm{kN}}{1 \mathrm{tf}} \\
& \mathrm{P}=98 \mathrm{kN} \\
& \mathrm{P}_{\mathrm{r}}=\frac{10 \mathrm{tf}}{2} \cdot \frac{9800 \mathrm{~N}}{1 \mathrm{tf}} \\
& \mathrm{P}_{\mathrm{r}}=49000 \mathrm{~N} \\
& \mathrm{q}=1,75 \mathrm{MPa} \cdot \frac{1000 \mathrm{kP}}{1 \mathrm{MPa}} \\
& \mathrm{q}=1750 \mathrm{kPa} \\
& A=10 \cdot \frac{49000}{1750} \\
& A=280 \mathrm{~cm}^{2}<600 \mathrm{~cm}^{2}
\end{aligned}
$$

- Placas internas:

$$
\begin{aligned}
\sigma_{\mathrm{adm}} & =\frac{4500}{2} \\
\sigma_{\mathrm{adm}} & =2250 \mathrm{kPa}
\end{aligned}
$$




$$
\begin{aligned}
& \mathrm{Q}=\frac{2250}{98} \\
& \mathrm{Q}=22,96 \mathrm{~Pa} / \mathrm{N}
\end{aligned}
$$

Figura A. $16 \Rightarrow$ para $\mathrm{h}=20 \mathrm{~cm}, \mathrm{~A}^{\prime}=305 \mathrm{~cm}^{2}$

Figura A. $17 \Rightarrow$ para $\mathrm{A}^{\prime}=305 \mathrm{~cm}^{2}, \mathrm{~h}=17,8 \mathrm{~cm}$

Figura A. $16 \Rightarrow$ para $\mathrm{h}=18 \mathrm{~cm}, \mathrm{~A}^{\prime}=290 \mathrm{~cm}^{2}$

Figura A. $17 \Rightarrow$ para A' $=290 \mathrm{~cm}^{2}, \mathrm{~h}=18 \mathrm{~cm} \checkmark$

- Placas externas:

$$
\begin{aligned}
& \sigma_{\text {adm }}=\frac{4500}{1,74} \\
& \sigma_{\text {adm }}=2586 \mathrm{kPa} \\
& \mathrm{Q}=\frac{2586}{98} \\
& \mathrm{Q}=26,40 \mathrm{~Pa} / \mathrm{N}
\end{aligned}
$$

Figura A.16 $\Rightarrow$ para $\mathrm{h}=20 \mathrm{~cm}, \mathrm{~A}^{\prime}=305 \mathrm{~cm}^{2}$

Figura A.17 $\Rightarrow$ para $A^{\prime}=305 \mathrm{~cm}^{2}, \mathrm{~h}=16,3 \mathrm{~cm}$

Figura A.16 $\Rightarrow$ para $\mathrm{h}=16,5 \mathrm{~cm}, \mathrm{~A}^{\prime}=280 \mathrm{~cm}^{2}$

Figura A.17 $\Rightarrow$ para $A^{\prime}=280 \mathrm{~cm}^{2}, \mathrm{~h}=16,5 \mathrm{~cm} \checkmark$

Packard recomenda um aumento de 20 a 25\% na espessura, quando houver carregamento na borda. Neste caso, a espessura das placas externas devem ser de 20 centímetros, adotando um aumento de $25 \%$ na espessura calculada. 
Carregamento de montantes

Será adotado coeficiente de segurança igual a 2

$$
\begin{aligned}
& \sigma_{\text {adm }}=\frac{4500}{2} \\
& \sigma_{\text {adm }}=2250 \mathrm{kPa} \\
& \mathrm{P}=6 \mathrm{tf} \cdot \frac{9,8 \mathrm{kN}}{1 \mathrm{tf}} \\
& \mathrm{P}=58,8 \mathrm{kN} \\
& \mathrm{Q}=\frac{2250}{58,8} \\
& \mathrm{Q}=38,27 \mathrm{~Pa} / \mathrm{N}
\end{aligned}
$$

Figuras A1.21 $\Rightarrow \mathrm{h}=17 \mathrm{~cm}<18 \mathrm{~cm} \checkmark$

Verificação da tensão de apoio

- para força no interior da placa:

$$
\begin{aligned}
& \sigma_{\mathrm{ap}, \mathrm{adm}}=4,2 \cdot 4,5 \\
& \sigma_{\mathrm{ap}, \mathrm{adm}}=18,9 \mathrm{MPa}
\end{aligned}
$$

- para força na borda

$$
\begin{aligned}
\sigma_{\mathrm{ap}, \mathrm{adm}} & =2,1 \cdot 4,5 \\
\sigma_{\mathrm{ap}, \mathrm{adm}} & =9,45 \mathrm{MPa}
\end{aligned}
$$

Determinação da tensão de apoio: 
$\sigma_{\text {ap }}=\frac{0,0588}{0,2 \cdot 0,2}$

$\sigma_{\text {ap }}=1,47 \mathrm{MPa}<\sigma_{\text {ap,adm }}=9,45 \mathrm{MPa} \checkmark$

Verificação da punção

$$
\begin{aligned}
\tau_{\mathrm{adm}} & =0,27 \cdot 4,5 \\
\tau_{\mathrm{adm}} & =1,215 \mathrm{MPa}
\end{aligned}
$$

Determinação da tensão de cisalhamento:

$$
\begin{aligned}
\tau_{\text {sol }} & =\frac{0,0588}{4 \cdot 0,2 \cdot 0,18} \\
\tau_{\text {sol }} & =0,408 \mathrm{MPa}<\tau_{\text {adm }}=1,215 \mathrm{MPa} \checkmark
\end{aligned}
$$

\section{Carregamento distribuído}

Para o carregamento distribuído será adotado coeficiente de segurança igual a 1,5 .

$$
\begin{aligned}
& \mathrm{f}_{\text {ctM }, \mathrm{d}}=\frac{4,5}{1,5} \\
& \mathrm{f}_{\text {ctM }, \mathrm{d}}=3 \mathrm{MPa} \\
& \mathrm{q}_{\mathrm{adm}}=1,03 \cdot 3 \cdot \sqrt{18 \cdot 50} \\
& \mathrm{q}_{\mathrm{adm}}=92,7 \mathrm{kN} / \mathrm{m}^{2}>\mathrm{q}_{\mathrm{sol}}=80 \mathrm{kN} / \mathrm{m}^{2} \checkmark
\end{aligned}
$$


9.2.3 Verificação da punção, segundo Revisão da NB-1 (1999)

$\mathrm{u}=2 \cdot(0,2+0,2)$

$\mathrm{u}=0,8$

$\tau_{\mathrm{Sd}}=\frac{0,0588}{0,8 \cdot 0,18}$

$\tau_{\mathrm{Sd}}=0,408 \mathrm{MPa}$

$\tau_{\mathrm{Rd}}=0,27 \cdot\left(1-\frac{58}{250}\right) \cdot \frac{58}{1,4}$

$\tau_{\mathrm{Rd}}=8,591 \mathrm{MPa}>\tau_{\mathrm{Sd}}=0,408 \mathrm{MPa} \checkmark$

Nota-se que a verificação de punção pelo método de PACKARD (1976) é mais conservadora que a Revisão da NB-1.

9.2.4 Verificação da punção, segundo ACI

$\tau_{\mathrm{Sd}}=\frac{0,0588}{3,31 \cdot 0,18}$

$\tau_{\mathrm{Sd}}=0,099 \mathrm{MPa}$

$\mathrm{b}_{\mathrm{o}}=2 \cdot(20+20)+4 \cdot 10$

$\mathrm{b}_{\mathrm{o}}=120 \mathrm{~cm}$

$\tau_{\mathrm{Rd}}=0,85 \cdot 0,08303 \cdot\left(2+\frac{4}{1}\right) \cdot \sqrt{40}=2,678 \mathrm{MPa}>\tau_{\mathrm{Sd}}=0,099 \mathrm{MPa} \checkmark$

$\tau_{\mathrm{Rd}}=0,85 \cdot 0,08303 \cdot\left(2+\frac{20 \cdot 10}{120}\right) \cdot \sqrt{40}=1,004 \mathrm{MPa}>\tau_{\mathrm{Sd}} \mathrm{MPa} \checkmark$

$\tau_{\mathrm{Rd}}=0,85 \cdot 0,3321 \cdot \sqrt{40}=1,785 \mathrm{MPa}>\tau_{\mathrm{Sd}}=0,099 \mathrm{MPa} \checkmark$ 


\subsection{PISO INDUSTRIAL DE CONCRETO COM ARMADURA DISTRIBUÍDA DESCONTÍNUA}

Os dados são os mesmos do problema 9.2, com diferença apenas nas dimensões das placas: 15 metros de comprimento e 7 metros de largura.

\subsubsection{Segundo PACKARD (1973)}

A espessura do pavimento deve ser determinada da mesma forma que para concreto simples. Portanto será adotada a espessura de 18 centímetros para as placas internas e de 20 centímetros para as placas externas.

Adotando $\mu$ igual a 1,5 (tabela A.1):

$$
\begin{aligned}
& \gamma_{\mathrm{c}}=\frac{2500 \mathrm{kgf}}{\mathrm{m}^{3}} \cdot \frac{9,8 \mathrm{kN}}{1000 \mathrm{kgf}} \\
& \gamma_{\mathrm{c}}=24,5 \mathrm{kN} / \mathrm{m}^{3}
\end{aligned}
$$

- Para placas internas:

$\mathrm{A}_{\mathrm{s}, \mathrm{ret}}=\frac{1,5 \cdot 24,5 \cdot 0,18 \cdot 15}{2 \cdot 0,75 \cdot 60}$

$\mathrm{A}_{\mathrm{s}, \mathrm{ret}}=1,10 \mathrm{~cm}^{2} / \mathrm{m}$

- Para placas externas:

$$
\begin{aligned}
& \mathrm{A}_{\mathrm{s}, \mathrm{ret}}=\frac{1,5 \cdot 24,5 \cdot 0,20 \cdot 15}{2 \cdot 0,75 \cdot 60} \\
& \mathrm{~A}_{\mathrm{s}, \mathrm{ret}}=1,23 \mathrm{~cm}^{2} / \mathrm{m}
\end{aligned}
$$




\subsubsection{Segundo RODRIGUES e CASSARO (1998)}

Assim como no caso anterior, a espessura do pavimento deve ser determinada da mesma forma que para concreto simples. Portanto será adotada a espessura de 18 centímetros para as placas internas e de 20 centímetros para as placas externas.

- Para placas internas:

$$
\begin{aligned}
& \mathrm{A}_{\mathrm{s}, \mathrm{ret}}=\frac{1,5 \cdot 24,5 \cdot 0,18 \cdot 15}{2 \cdot \frac{2}{3} \cdot 60} \\
& \mathrm{~A}_{\mathrm{s}, \mathrm{ret}}=1,24 \mathrm{~cm}^{2} / \mathrm{m}
\end{aligned}
$$

- Para placas externas:

$$
\begin{aligned}
& \mathrm{A}_{\mathrm{s}, \mathrm{ret}}=\frac{1,5 \cdot 24,5 \cdot 0,20 \cdot 15}{2 \cdot \frac{2}{3} \cdot 60} \\
& \mathrm{~A}_{\mathrm{s}, \mathrm{ret}}=1,37 \mathrm{~cm}^{2} / \mathrm{m}
\end{aligned}
$$

\subsubsection{Segundo Revisão da NB-1 (1999)}

Assim como nos casos anteriores, a espessura do pavimento deve ser determinada da mesma forma que para concreto simples. Portanto será adotada a espessura de 18 centímetros para as placas internas e de 20 centímetros para as placas externas.

- Para placas internas:

$$
\mathrm{A}_{\mathrm{s}, \mathrm{ret}}=\frac{1,2 \cdot 1,5 \cdot 24,5 \cdot 0,18 \cdot 15}{2 \cdot \frac{60}{1,15}}
$$

$\mathrm{A}_{\mathrm{s}, \mathrm{ret}}=1,14 \mathrm{~cm}^{2} / \mathrm{m}$ 
- Para placas externas:

$\mathrm{A}_{\mathrm{s}, \mathrm{ret}}=\frac{1,2 \cdot 1,5 \cdot 24,5 \cdot 0,20 \cdot 15}{2 \cdot \frac{60}{1,15}}$

$\mathrm{A}_{\mathrm{s}, \mathrm{ret}}=1,26 \mathrm{~cm}^{2} / \mathrm{m}$

\subsubsection{Segundo Corps of Engineers}

Será adotada redução da espessura do pavimento armado para 17 centímetros, que foi a espessura encontrada para resistir aos montantes de prateleiras.

Verificação do carregamento distribuído, para a nova espessura

$$
\begin{aligned}
& \mathrm{q}_{\mathrm{adm}}=1,03 \cdot 3 \cdot \sqrt{17 \cdot 50} \\
& \mathrm{q}_{\mathrm{adm}}=90,1 \mathrm{kN} / \mathrm{m}^{2}<\mathrm{q}_{\mathrm{sol}}=80 \mathrm{kN} / \mathrm{m}^{2} \checkmark
\end{aligned}
$$

Determinação da área de aço

Figura A. $22 \Rightarrow$ para $h_{\text {arm }}=17 \mathrm{~cm}, \mathrm{~s}=0,07 \% \mathrm{~A}_{\mathrm{s}}=1,105 \mathrm{~cm}^{2} / \mathrm{m}$

\subsubsection{Considerações sobre os resultados}

Como já foi discutido no capítulo 7 , não se aconselha a redução da espessura do pavimento pela utilização de armadura de retração. Portanto, 
serão adotadas as espessuras calculadas para concreto simples: 18 e 20 centímetros.

A fórmula obtida a partir dos critérios da Revisão da NB-1 (1999) permite maior controle dos coeficientes de segurança. Portanto serão adotados os resultados obtidos de acordo com essa norma: 1,14 e 1,26 cm²/m.

\subsection{PISO INDUSTRIAL DE CONCRETO ESTRUTURALMENTE ARMADO}

Os dados são os mesmos do problema 9.3, exceto a resistência do concreto. Será utilizado fck igual a $30 \mathrm{MPa}$.

\subsubsection{Determinação da altura útil}

Visto que o carregamento uniformemente distribuído provoca tração nas fibras superiores, será adotada a espessura mínima para esse esforço.

$80=1,03 \cdot 3 \cdot \sqrt{\mathrm{h} \cdot 50}$

$\mathrm{h}=13,4 \approx 14 \mathrm{~cm}$

Adotando cobrimento de 4 centímetros, a altura útil é:

$\mathrm{d}=14-4$

$\mathrm{d}=10 \mathrm{~cm}$

9.4.2 Dimensionamento da armadura de flexão para estado limite último de esgotamento da capacidade resistente

No anexo B.4, tem-se os valores de momentos fletores para a empilhadeira analisada nesse exemplo. 
- Na borda: $\mathrm{M}_{\mathrm{b}}=24 \mathrm{kN} \cdot \mathrm{m}=2.400 \mathrm{kN} . \mathrm{cm}$

$\mathrm{k}_{\mathrm{c}}=\frac{100 \cdot 10^{2}}{2400}$

$\mathrm{k}_{\mathrm{c}}=4,16 \mathrm{~cm}^{2} / \mathrm{kN}$

Tabela A. $25 \Rightarrow \mathrm{k}_{\mathrm{s}}=0,020$
$\mathrm{A}_{\mathrm{S}}=\frac{0,02 \cdot 2400}{10}$

$\mathrm{A}_{\mathrm{s}}=4,8 \mathrm{~cm}^{2} / \mathrm{m}$

- No interior: $\mathrm{M}_{\mathrm{i}}=12 \mathrm{kN} . \mathrm{m}=1.200 \mathrm{kN} . \mathrm{cm}$

$$
\begin{aligned}
& \mathrm{k}_{\mathrm{c}}=\frac{100 \cdot 10^{2}}{1200} \\
& \mathrm{k}_{\mathrm{c}}=8,33 \mathrm{~cm}^{2} / \mathrm{kN}
\end{aligned}
$$

Tabela A. $25 \Rightarrow \mathrm{k}_{\mathrm{s}}=0,020$

$$
\begin{aligned}
& \mathrm{A}_{\mathrm{s}}=\frac{0,02 \cdot 1200}{10} \\
& \mathrm{~A}_{\mathrm{S}}=2,4 \mathrm{~cm}^{2} / \mathrm{m}
\end{aligned}
$$

9.4.3 Verificação da armadura de flexão para estado limite último de fadiga do aço

Para $10^{6}$ ciclos nas placas internas e $\phi<16 \mathrm{~mm}$ :

$$
\begin{aligned}
\gamma_{\text {fad }} & =\frac{60}{21} \\
\gamma_{\text {fad }} & =2,86
\end{aligned}
$$


$\mathrm{A}_{\mathrm{S}}=2,4 \cdot 2,86$

$\mathrm{A}_{\mathrm{s}}=6,87 \mathrm{~cm}^{2} / \mathrm{m}$

$\mathrm{A}_{\mathrm{ef}}=7,85 \mathrm{~cm}^{2} / \mathrm{m} \Rightarrow \phi 10 \mathrm{~mm} \mathrm{c/} 10 \mathrm{~cm}$

Para $6.10^{4}$ ciclos nas placas externas, na borda e $\phi<16 \mathrm{~mm}$ :

$\gamma_{\text {fad }}=\frac{60}{38}$

$\gamma_{\text {fad }}=1,58$

$\mathrm{A}_{\mathrm{s}}=4,8 \cdot 1,58$

$\mathrm{A}_{\mathrm{s}}=7,59 \mathrm{~cm}^{2} / \mathrm{m}$

$\mathrm{A}_{\mathrm{ef}}=7,85 \mathrm{~cm}^{2} / \mathrm{m} \Rightarrow \phi 10 \mathrm{~mm} \mathrm{c} / 10 \mathrm{~cm}$

9.4.4 Verificação da punção, segundo Revisão da NB-1

- Verificação da punção a 2d da face da área de aplicação da força:

$\mathrm{u}=2 \cdot(0,2+0,2)+2 \cdot \pi \cdot(2 \cdot 0,2)$

$\mathrm{u}=3,31 \mathrm{~m}$

$\tau_{\mathrm{Sd}}=\frac{0,0588}{3,31 \cdot 0,1}$

$\tau_{\mathrm{Sd}}=0,177 \mathrm{MPa}$

$\rho=\sqrt{2 \cdot 0,00785}$

$\rho=0,125$

$\tau_{\mathrm{Rd}}=0,13 \cdot\left(1+\sqrt{\frac{20}{10}}\right) \cdot \sqrt[3]{100 \cdot 0,125 \cdot 40}$ 


$$
\tau_{\mathrm{Rd}}=2,491 \mathrm{MPa}>\tau_{\mathrm{Sd}}=0,177 \mathrm{MPa} \checkmark
$$

- Verificação da punção na face da área de aplicação da força:

$$
\mathrm{u}=2 \cdot(0,2+0,2)
$$$$
\mathrm{u}=0,8
$$

$\tau_{\mathrm{Sd}}=\frac{0,0588}{0,8 \cdot 0,1}$

$\tau_{\mathrm{Sd}}=0,735 \mathrm{MPa}$

$$
\begin{aligned}
& \tau_{\mathrm{Rd}}=0,27 \cdot\left(1-\frac{30}{250}\right) \cdot \frac{30}{1,4} \\
& \tau_{\mathrm{Rd}}=5,091 \mathrm{MPa}>\tau_{\mathrm{Sd}}=0,735 \mathrm{MPa} \checkmark
\end{aligned}
$$

\subsubsection{Determinação do comprimento de transpasse}

Será utilizada tela soldada Q 758. A distância entre os fios é de 10 centímetros. Portanto será dimensionado o comprimento de transpasse para o caso de espaçamento maior que 4.ф.

$$
\begin{aligned}
& \tau_{\mathrm{bu}}=2,25 \cdot 1 \cdot 1 \cdot \frac{2,9}{1,4} \\
& \tau_{\mathrm{bu}}=4,66 \mathrm{MPa} \\
& \ell_{\mathrm{b}}=\frac{1}{4} \cdot \frac{522}{4,66} \\
& \ell_{\mathrm{b}}=28,0 \mathrm{~cm} \\
& \ell_{\mathrm{t}, \text { mín }}=0,3 \cdot 0,7 \cdot 2 \cdot 28 \\
& \ell_{\mathrm{t}, \text { mín }}=11,760 \mathrm{~cm}<\ell_{\mathrm{t}}=47,90 \mathrm{~cm} \checkmark
\end{aligned}
$$


$\ell_{\mathrm{b}, \text { nec }}=\frac{1}{4} \cdot \frac{522}{4,66} \cdot \frac{7,59}{7,85}$

$\ell_{\mathrm{b}, \text { nec }}=27,08 \mathrm{~cm}$

$\ell_{\mathrm{t}}=0,7 \cdot 2 \cdot 27,08+10$

$\ell_{\mathrm{t}}=47,90 \mathrm{~cm}$

Será adotado comprimento de transpasse igual a 48 centímetros.

A fim de evitar cortes nas telas soldadas, o comprimento das placas será alterado para $16,3 \mathrm{~cm}$.

\subsubsection{Determinação da armadura de retração}

Será adotada a fórmula desenvolvida de acordo com a Revisão da NB-

1 (1999).

$\mathrm{A}_{\mathrm{s}, \mathrm{ret}}=\frac{1,2 \cdot 1,5 \cdot 24,5 \cdot 0,14 \cdot 16,3}{2 \cdot \frac{60}{1,15}}$

$\mathrm{A}_{\mathrm{s}, \mathrm{ret}}=0,96 \mathrm{~cm}^{2} / \mathrm{m}$

$A_{\text {ef }}=1,13 \mathrm{~cm}^{2} / \mathrm{m} \Rightarrow \phi 3,8 \mathrm{~mm} \mathrm{c} / 10 \mathrm{~cm}$

O comprimento de transpasse necessário para armadura de retração é:

$\ell_{\mathrm{b}, \text { nec }}=\frac{0,38}{4} \cdot \frac{522}{4,66} \cdot \frac{0,96}{1,13}$

$\ell_{\mathrm{b}, \text { nec }}=9,04 \mathrm{~cm}$

$\ell_{\mathrm{t}}=0,7 \cdot 2 \cdot 9,04+10$

$\ell_{\mathrm{t}}=22,65 \mathrm{~cm}$ 
A fim de evitar cortes, será adotado comprimento de transpasse igual a 48 centímetros.

\subsubsection{Detalhamento}

Na figura 9.2 é mostrado o detalhamento da armadura de flexão e, na figura 9.3, da armadura de retração.

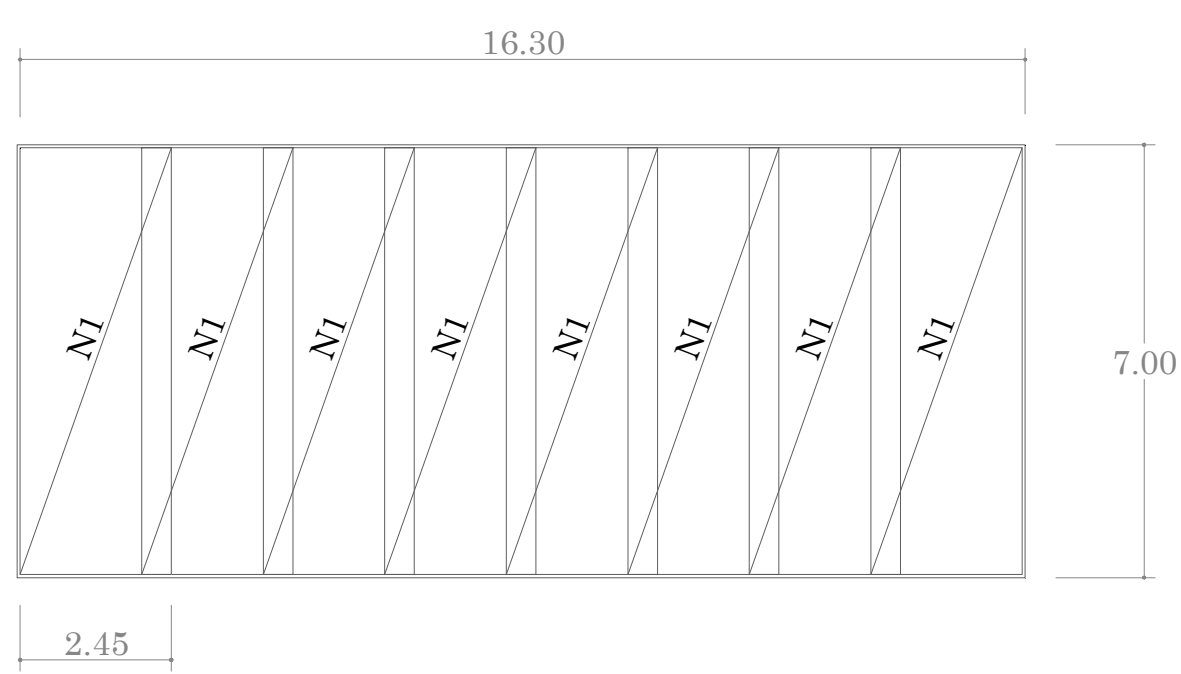

$\mathrm{N} 1=\mathrm{Q} 785$

$2,45 \times 6,92 \mathrm{~m}$

$\left(12,46 \mathrm{~kg} / \mathrm{m}^{2}\right)$

Figura 9.2 - Detalhamento da armadura de flexão

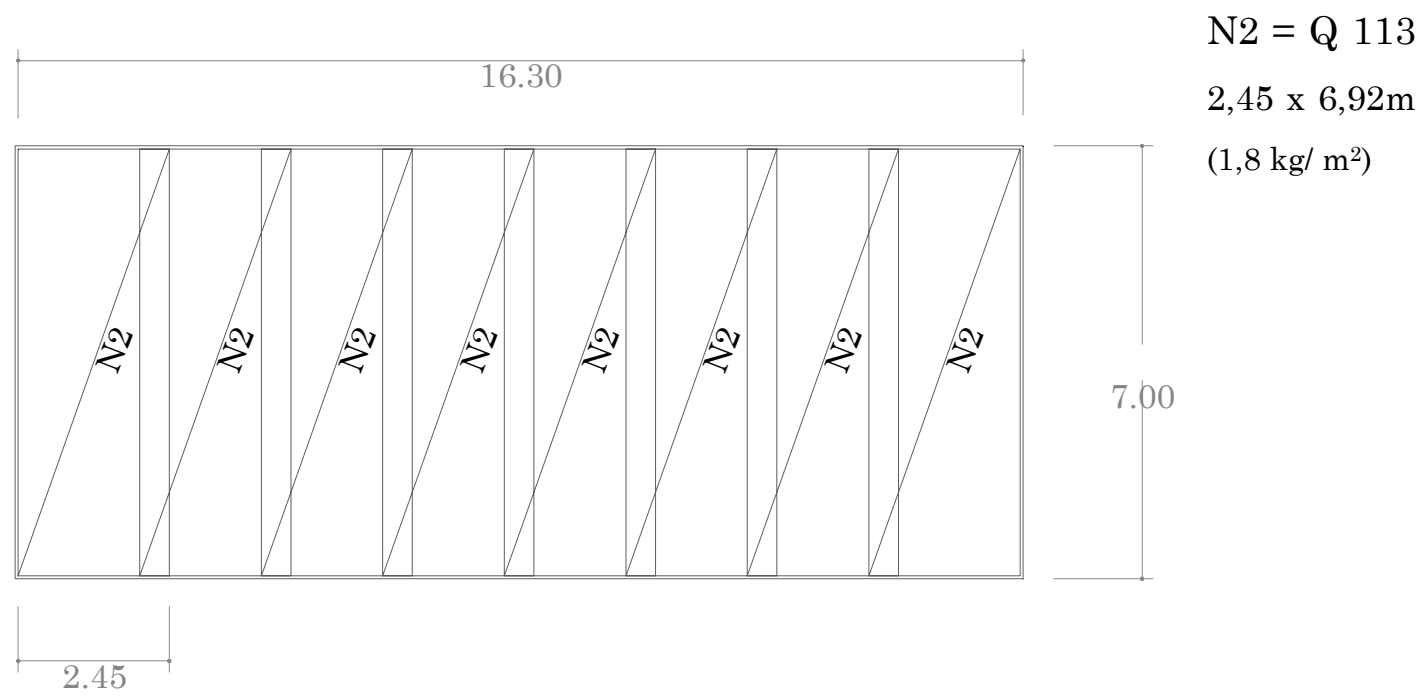

Figura 9.3 - Detalhamento da armadura de retração para placas de 16,29 metros 
Com a nova dimensão das placas, a área do piso industrial será dividida conforme ilustrado na figura 9.4.

Na figura 9.4, as abreviações significam:

- JL: junta longitudinal;

- JLBL: junta longitudinal com barra de ligação;

- JTBT: junta transversal com barra de transferência.

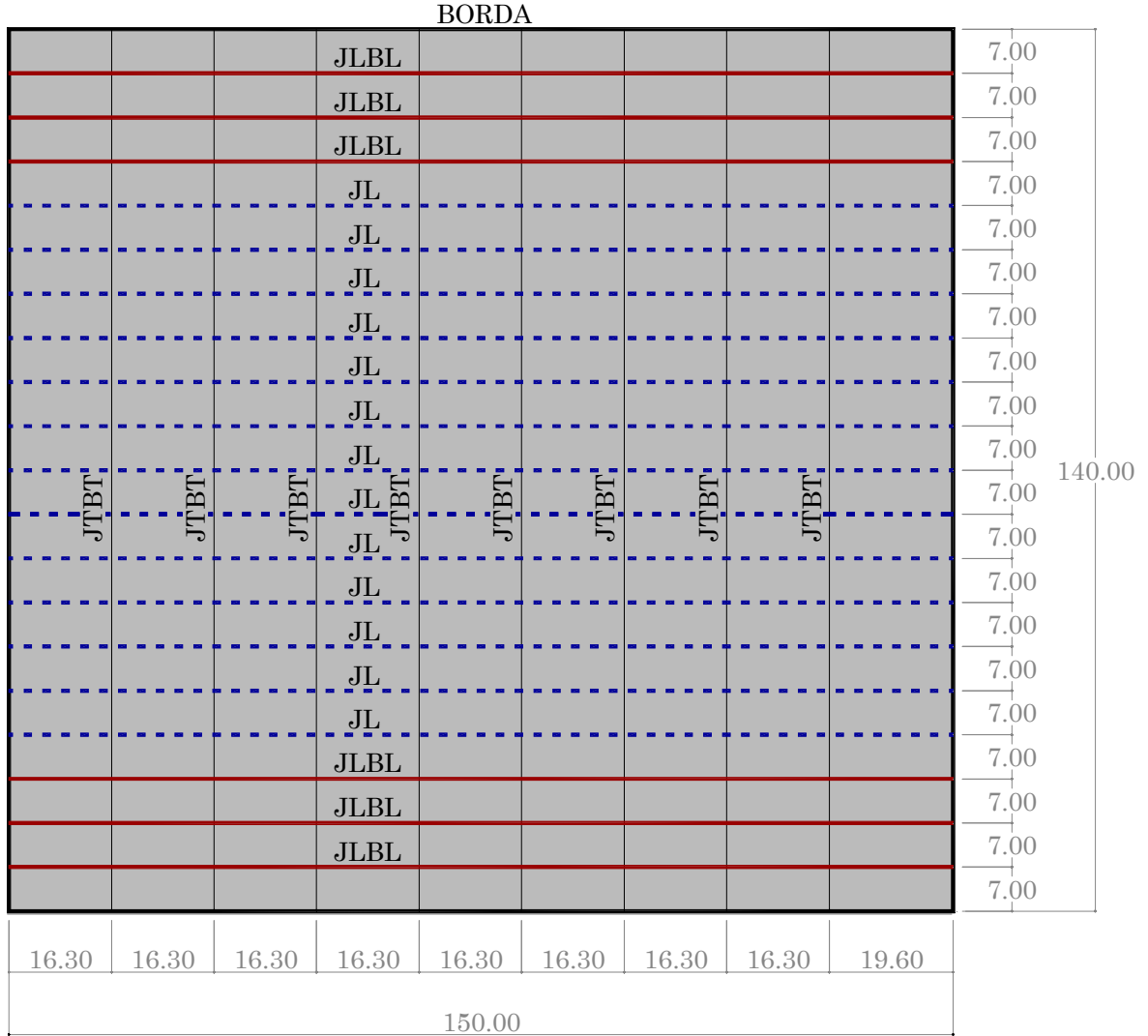

Figura 9.4 - Distribuição das placas

A armadura de retração para as placas de 19,60 metros é dada por:

$\mathrm{A}_{\mathrm{s}, \mathrm{ret}}=\frac{1,2 \cdot 1,5 \cdot 24,5 \cdot 0,14 \cdot 19,60}{2 \cdot \frac{60}{1,15}}$

$\mathrm{A}_{\mathrm{s}, \mathrm{ret}}=1,16 \mathrm{~cm}^{2} / \mathrm{m}$

$\mathrm{A}_{\mathrm{ef}}=1,38 \mathrm{~cm}^{2} / \mathrm{m} \Rightarrow \phi 4,2 \mathrm{~mm} \mathrm{c/} 10 \mathrm{~cm}$ 
O detalhamento das placas de 19,60 metros está representado na figura 9.5 .

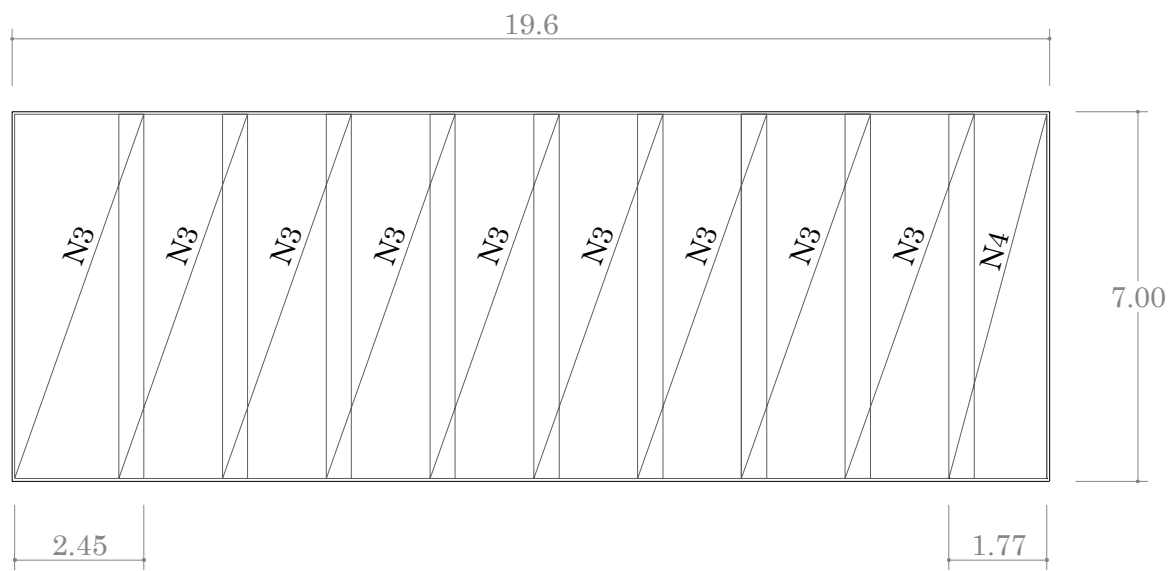
N3 - Q 138
$\mathrm{N} 4-\mathrm{Q} 138$
$2,45 \times 6,9 \mathrm{~m}$
$1,89 \times 6,9 \mathrm{~m}$
$\left(2,2 \mathrm{~kg} / \mathrm{m}^{2}\right)$
$\left(2,2 \mathrm{~kg} / \mathrm{m}^{2}\right)$

Figura 9.5 - Detalhamento da armadura de retração para placas de 19,60 metros

\subsection{DIMENSIONAMENTO DAS BARRAS DE LIGAÇÃO}

Neste item é mostrado o dimensionamento das barras de ligação para o piso industrial do exemplo 9.4.

$$
\begin{aligned}
& \mathrm{a}_{\mathrm{s}, \mathrm{bl}}=\frac{1,2 \cdot 1,5 \cdot 24,5 \cdot 0,14 \cdot 7}{2 \cdot \frac{60}{1,15}} \\
& \mathrm{a}_{\mathrm{s}, \mathrm{bl}}=0,42 \mathrm{~cm}^{2} / \mathrm{m} \\
& \mathrm{a}_{\mathrm{s}, \mathrm{bl}, \mathrm{ef}}=0,46 \mathrm{~cm}^{2} / \mathrm{m} \Rightarrow \phi 4,2 \mathrm{~mm} \mathrm{c} 30 \mathrm{~cm} \\
& \ell_{\mathrm{b}}=\frac{0,42}{4} \cdot \frac{522}{4,66} \cdot \frac{0,42}{0,46} \\
& \ell_{\mathrm{b}}=10,74 \mathrm{~cm}
\end{aligned}
$$


$\ell_{\text {lig }}=2 \cdot 10,74$

$\ell_{\text {lig }}=21,48 \mathrm{~cm}$

$\ell_{\mathrm{b} 1}=\frac{0,42}{4} \cdot \frac{522}{4,66}$

$\ell_{\mathrm{b} 1}=11,76 \mathrm{~cm}$

$\ell_{\mathrm{b}} \geq\left\{\begin{array}{l}0,3 \cdot \ell_{\mathrm{b} 1}=3,53 \mathrm{~cm} \\ 10 \cdot \phi=4,2 \mathrm{~cm} \\ 10 \mathrm{~cm}\end{array}\right.$

\subsection{DIMENSIONAMENTO DAS BARRAS DE TRANSFERÊNCIA}

Para realizar o pré-dimensionamento das barras de transferência, utiliza-se a tabela A.26. Serão adotadas barras de diâmetro igual a 20 milímetros, com 40 centímetros de comprimento e espaçadas de 30 centímetros.

O valor de $a$ é igual a 1 . Os valores de $b$ são dados por:

$$
\begin{aligned}
& \ell=\sqrt[4]{\frac{33660 \cdot 14^{3}}{12 \cdot\left(1-0,2^{2}\right) \cdot 0,50}} \\
& \ell=63,28 \mathrm{~cm}
\end{aligned}
$$

Considerando que há barra solicitada no canto da placa, n é igual e 4.

$$
\begin{aligned}
& \mathrm{a}=1 \\
& \mathrm{~b}_{1}=\frac{1,8 \cdot 63,28-1 \cdot 30}{1,8 \cdot 63,28}=0,74 \\
& \mathrm{~b}_{2}=\frac{1,8 \cdot 63,28-2 \cdot 30}{1,8 \cdot 63,28}=0,47
\end{aligned}
$$


$\mathrm{b}_{3}=\frac{1,8 \cdot 63,28-3 \cdot 30}{1,8 \cdot 63,28}=0,21$

$\mathrm{P}_{\mathrm{a}}=\frac{0,5 \cdot 5}{1+2 \cdot(0,74+0,47+0,21)}$

$\mathrm{P}_{\mathrm{a}}=0,65 \mathrm{tf}$

$\mathrm{P}_{\mathrm{a}}=0,0064 \mathrm{MN}$

$\mathrm{I}=\frac{\pi \cdot 0,02^{4}}{64}$

$\mathrm{I}=7,9 \cdot 10^{-9}$

$\beta=\sqrt[4]{\frac{0,41 \cdot 10^{6} .0,02}{4 \cdot 33660 \cdot 7,9 \cdot 10^{-9}}}$

$\beta=52,69$

$\sigma_{\mathrm{adm}}=\left(\frac{10-0,02}{7,5}\right) \cdot 30$

$\sigma_{\text {adm }}=39,92 \mathrm{MPa}$

Para uma abertura da junta de $4 \mathrm{~mm}$ :

$\sigma=\frac{0,41 \cdot 10^{6} \cdot 0,0064}{4 \cdot 52,69^{3} \cdot 33660 \cdot 7,9 \cdot 10^{-9}} \cdot(2+52,69 \cdot 0,004)$

$\sigma=37,28 \mathrm{MPa}<\sigma_{\text {adm }}=39,92 \mathrm{MPa} \checkmark$

Como a tensão de apoio calculada é menor que a tensão de apoio admissível, serão utilizadas barras de transferência de diâmetro igual a 20 milímetros, com 40 centímetros de comprimento, a cada 30 centímetros. 


\section{Capítulo}

\section{CONSIDERAÇÕES FINAIS}

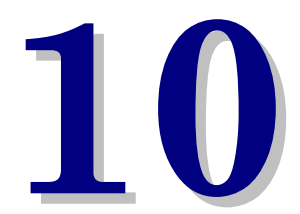

Neste capítulo são apresentadas as principais conclusões obtidas durante a realização deste trabalho e sugestões para pesquisas futuras.

\subsection{CONCLUSÕES}

Por estarem disponíveis tecnologias diferentes para execução de pavimentos, na realização de um projeto, devem ser analisadas as diversas opções, do ponto de vista de qualidade, de durabilidade e de custo. A principal vantagem apresentada pelo pavimento de concreto é a durabilidade, mesmo quando submetido a tráfego intenso. Pôde-se verificar que o número de solicitações tem grande importância no dimensionamento de pavimentos rígidos. Portanto, o trabalho de contagem e projeção de tráfego é fundamental para a execução de um bom projeto.

\subsubsection{Capacidade de suporte da fundação}

A variação da capacidade de suporte do solo tem pouca influência na espessura do pavimento de concreto, portanto ele pode ser construído sobre solos de baixa resistência, sendo aconselhável a adoção de sub-base para regularização da fundação e para reduzir o processo de bombeamento de finos. 
No exemplo apresentado neste trabalho, verificou-se uma diferença de $34 \%$ no valor de $\mathrm{k}$, calculado pelo método da AASHTO, descrito no manual do DNER, em relação ao valor de $\mathrm{k}$ calculado pelo método da PCA. A diferença entre o valor obtido pelo método da AASHTO-DNER em relação ao método original é de $26 \%$. A módulo de reação determinado pela PCA foi o dobro do valor determinado pelo método original da AASHTO. A variação entre esses valores se deve à consideração de diferentes fatores no cálculo da capacidade de suporte da fundação. A diferença pode ser ainda maior se existir extrato rígido e for considerado o dano por variações sazonais.

\subsection{2 Área de contato entre pneu e pavimento}

Verificou-se que, para uma mesma pressão e mesma área de contato entre pneu e pavimento, a adoção de diferentes configurações não interfere significativamente nos esforços. Portanto a simplificação de área retangular, adotada neste trabalho, fornece valores coerentes na análise dos esforços em placas sobre apoio elástico.

\subsubsection{Empenamento}

De acordo com o clima, o empenamento pode assumir valores significantes, que são desconsiderados nos métodos de dimensionamento da PCA. Por ser desenvolvido com base em pista experimental, o método da AASHTO já inclui os efeitos de empenamento, para as condições climáticas da região onde foi construída a pista.

Durante o dia, o empenamento provoca um aumento na tensão máxima e uma redução na variação de tensão do pavimento pois, devido ao empenamento, mesmo sem a passagem de veículo, as fibras inferiores já estão tracionadas. Deve-se adotar a curva de fadiga para uma relação entre as tensões máximas e tensões mínimas menor que no caso de desconsideração do empenamento. A soma das tensões devidas ao tráfego com as tensões devidas ao 
empenamento combinada à adoção de tensão mínima igual a zero é uma hipótese conservadora.

Durante a noite, a tensão devida ao empenamento é diminuída da tensão máxima devida ao trafego. A tensão máxima é menor, mas a variação de tensão aumenta. Quando há passagem de veículo, a fibra inferior do pavimento passa do estado de compressão, para o estado de tração, o que acelera o processo de fadiga.

10.1.4 Influência entre as rodas dos eixos

Verificou-se que, com exceção de força no canto de placas isoladas, nos veículos rodoviários se não obtém diferença significativa simplificando a configuração do eixo para apenas um semi-eixo.

No caso das empilhadeiras, essa simplificação implica em diferenças consideráveis. Na análise numérica (anexo B) realizada neste trabalho obteve-se uma redução de 10\% no momento fletor máximo, na borda do pavimento, quando se desprezou uma das rodas. A maior diferença ocorre no interior da placa. No exemplo do anexo B, o momento fletor, para roda no interior da placa, foi $70 \%$ maior que se for considerada uma roda no interior e outra tangente à borda. A análise do efeito de rodas isoladas pode ser importante quando não houver mecanismos eficientes de transferência de esforços e houver a possibilidade de cada roda passar por uma placa diferente do pavimento.

\subsubsection{Distribuição de esforços em placas isoladas}

O esforço provocado por carregamento na borda da placa é aproximadamente o dobro que para carregamento no interior e decresce rapidamente conforme a força se afasta da borda. Depois dos primeiros 50 centímetros o momento fletor é praticamente constante até o centro da placa.

Em placas isoladas, o momento fletor negativo, devido à força no canto da placa, assume valores da ordem de $60 \%$ do momento fletor máximo positivo. Portanto, em pavimentos estruturalmente armados, é aconselhável a adoção de 
barras de transferência, já que a presença da armadura positiva reduz a espessura e a placa poderia romper por tração nas fibras superiores.

Nas placas sem mecanismos de transferência de esforços, os momentos fletores, para força tangente à junta, tem a mesma ordem de grandeza do momento fletor máximo, para força na borda. Considerando que essa região é mais solicitada que a borda livre, a transferência de esforços entre as placas proporciona uma significativa redução na espessura necessária para o pavimento.

\subsubsection{Eficiência das juntas}

Com a análise numérica mostrada no capítulo 8, obteve-se uma redução de 50\% nos máximos momentos fletores, para juntas com eficiência igual a 100\%. Para eficiência de $45 \%$ a redução desses esforços foi de apenas $14 \%$, mas o momento fletor na borda diminuiu de aproximadamente 1 para 0,56 vezes o momento fletor na borda livre. Conclui-se, portanto, que os mecanismos de transferência de esforços devem ser considerados no dimensionamento, o que já é feito pelo método da PCA de 1984, mas não pelo método de 1966.

\subsubsection{Fadiga em pavimentos de concreto}

A maior dificuldade em estabelecer um modelo de fadiga para pavimentos é a grande variação na posição do carregamento. Estudos estatísticos sobre as flutuações do ponto de aplicação das forças podem contribuir para um dimensionamento mais adequado.

Há uma grande variação entre os diversos modelos de fadiga para pavimentos de concreto. Isso se deve às diferentes condições de ensaios, diferentes considerações dos esforços e adoção de parâmetros distintos. É difícil escolher o melhor modelo, tendo em vista que nem todas as informações sobre as condições de ensaios e considerações para desenvolvimento da curva de fadiga são conhecidos. 
Como o número de solicitações, tangentes à borda, costuma ser menor que no interior, dependendo da distribuição do tráfego, no dimensionamento de pavimento estruturalmente armado, considerando a fadiga do aço, podem ser obtidas áreas de aço próximas, nas duas posições, não sendo necessário adotar duas camadas de armadura positiva nas bordas.

\subsubsection{Métodos de dimensionamento}

Os métodos mais modernos para dimensionamento de pavimentos de concreto simples já analisam diversos parâmetros de projeto e utilizam ferramentas como programas computacionais desenvolvidos através de métodos numéricos, como elementos finitos, a fim de permitir o estudo mais detalhado e racional do comportamento do pavimento.

Os métodos divulgados pela AASHTO e pela PCA têm objetivos específicos, portanto não permitem muita flexibilidade ao projetista. O dimensionamento é feito com o uso de ábacos e tabelas, desenvolvidos para um número limitado de situações e para os eixos padrões americanos.

No caso do pavimento de concreto com armadura distribuída descontínua, pode-se perceber que não existe um consenso entre os diversos órgãos, como a Corps of Engineers e a Federal Aviation Administration, a respeito da redução da espessura do pavimento devida à utilização de armadura de retração. Como nesse tipo de pavimento aparecem fissuras, que embora bem costuradas, funcionam como juntas sem barras de transferência, aconselha-se manter a espessura do pavimento de concreto simples.

Embora na bibliografia encontre-se o método das tensões admissíveis para dimensionamento de pavimentos de concreto estruturalmente armados, neste trabalho foram adotados os critérios da Revisão da NB-1 (1999). No capítulo 7, é mostrado como dimensionar para estado limite último e como fazer a verificação de fadiga do aço. 


\subsubsection{Análise numérica}

Apesar da facilidade do uso de programas de computadores na análise de esforços em pavimentos, as cartas de influência ainda são largamente utilizadas. Como elas foram desenvolvidas para situações específicas, podem ser embutidos erros, normalmente de pequena escala. A partir das cartas de influência, foram desenvolvidos ábacos para eixos típicos americanos. Deve-se tomar cuidado para não generalizar o uso desses ábacos para qualquer configuração de carga.

Como o objetivo da análise numérica, neste trabalho, era verificar a distribuição dos esforços em placas e analisar algumas condições de carregamento, foi utilizado um modelo simples, considerando apenas uma camada de material elástico e fundação modelada como líquido denso. Alguns softwares, com base em métodos numéricos, têm capacidade de resolver modelos mais complexos, adotando diversas camadas, diferentes modelos para fundação, aplicando diferença de temperatura e realizando análise dinâmica.

\subsubsection{Punção em pavimentos de concreto}

Observou-se que a verificação de punção, de acordo com o método de PACKARD (1976), é mais conservadora que a norma brasileira, estando muito a favor da segurança. Como o método foi desenvolvido para pavimentos de concreto simples, no caso de pavimento de concreto estruturalmente armado, pode ser realizada a verificação da punção de acordo com a Revisão da NB-1.

\subsection{SUGESTÕES PARA NOVAS PESQUISAS}

A seguir, são apresentados assuntos que podem ser estudados em novas pesquisas, a fim de aumentar os conhecimentos necessários para o projeto de pavimentos rígidos. 


\subsubsection{Efeitos climáticos}

Diante das conclusões obtidas deste trabalho, pode-se verificar a necessidade de um estudo mais aprofundado sobre a importância dos efeitos climáticos no dimensionamento de pavimentos rígidos e a influência desses efeitos no processo de fadiga, visto que o empenamento pode submeter as placas a uma tensão mínima diferente de zero.

\subsubsection{Pavimento de concreto estruturalmente armado}

Os pavimentos de concreto estruturalmente armados foram introduzidos recentemente no Brasil. Ainda devem ser melhor estudados quanto ao comportamento sob carregamento estático e cíclico e quanto à influência das variações e gradientes de temperatura.

Sugere-se o desenvolvimento de modelo numérico e experimental para o estudo de pavimentos de concreto estruturalmente armados, verificando a influência dos diversos parâmetros de projeto, nos esforços gerados e na ruptura do pavimento.

\subsubsection{Juntas}

As tabelas e fórmulas para dimensionamento de barras de transferência consideram carregamento estático. Sugere-se a realização de pesquisa sobre o comportamento desse tipo de junta, sob carregamento repetido.

Quando uma junta possui barras de transferência, considera-se que ela tem eficiência de 100\%. É necessário confirmar essa afirmação e verificar o valor da eficiência de outras configurações de juntas, como por exemplo: juntas serradas sem barra de ligação, juntas serradas com barras de ligação, juntas moldadas com encaixe tipo macho-fêmea sem barras de ligação, juntas moldadas com encaixe tipo macho-fêmea com barras de ligação e juntas moldadas com barras de transferência. 


\section{Anexo}

\section{TABELAS E ÁBACOS}
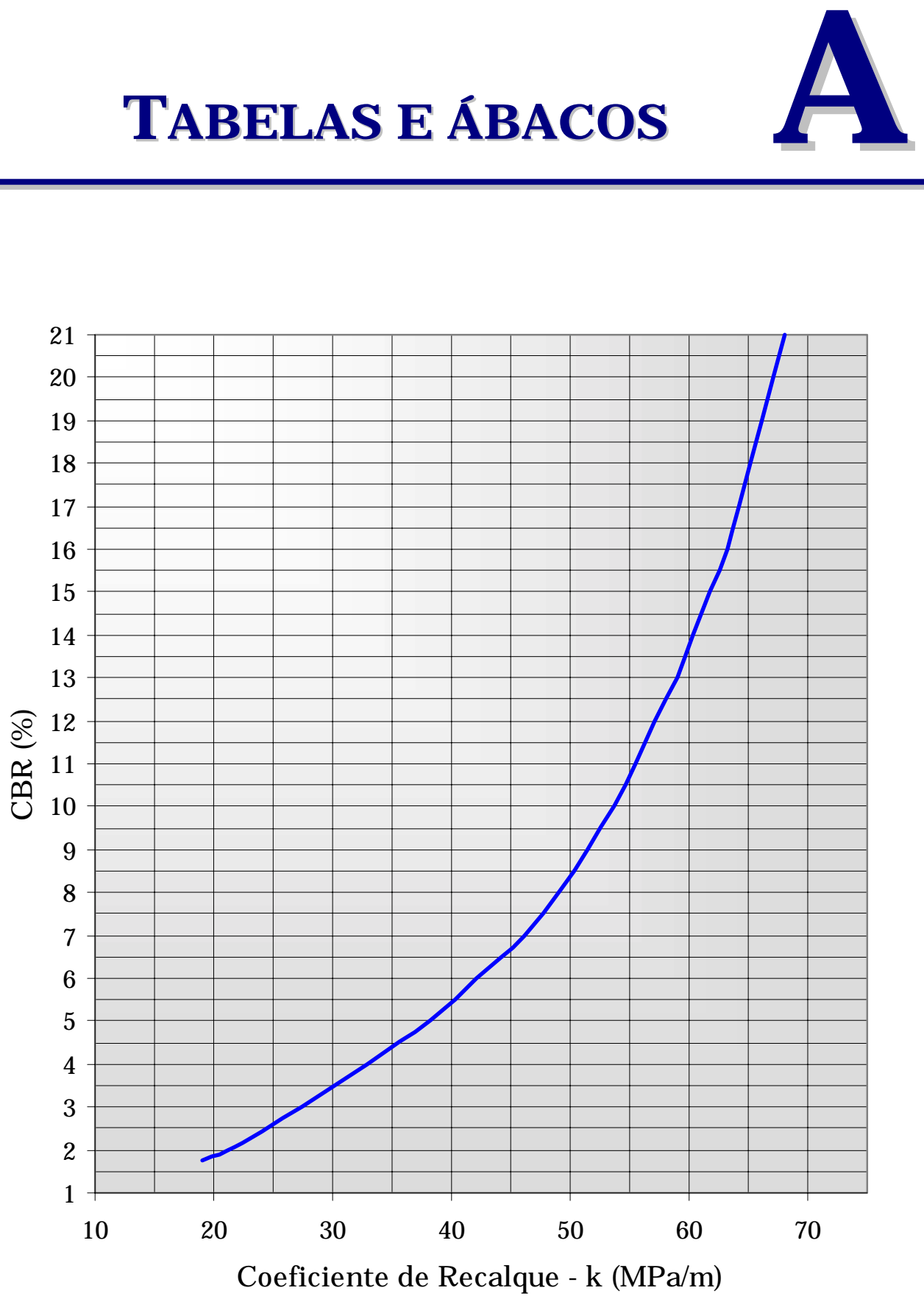

Figura A.1 - Relação entre índice de suporte Califórnia e coeficiente de recalque, adaptado de PITTA (1990) 


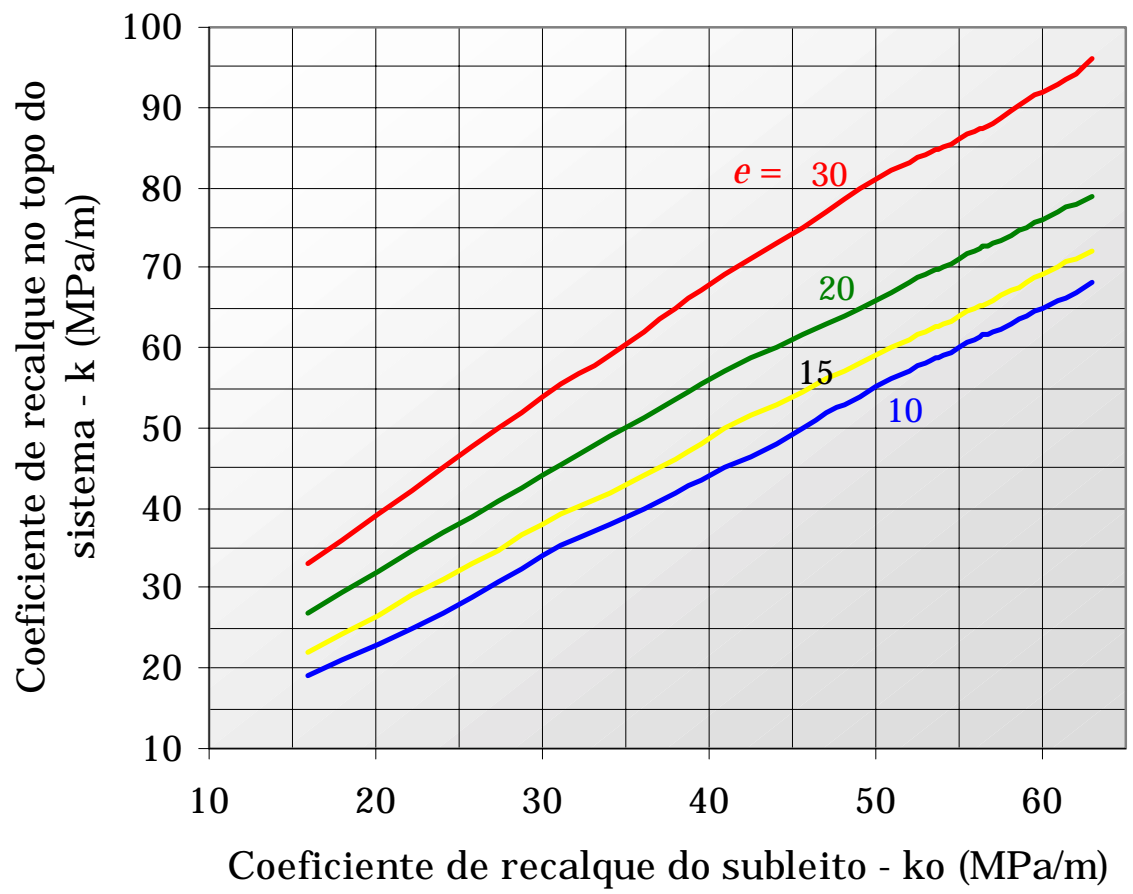

Figura A.2 - Aumento de k devido à sub-base granular, adaptado de PCA (1984)

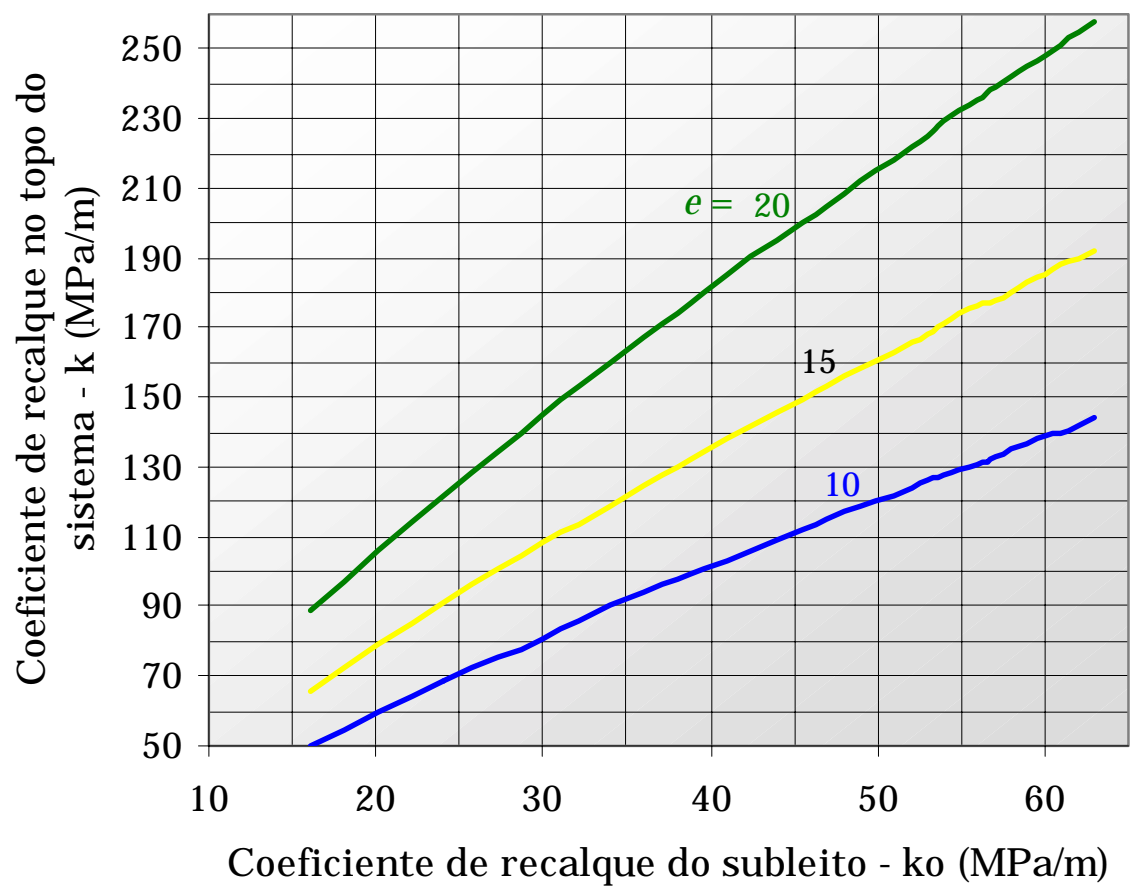

Figura A.3 - Aumento de k devido à sub-base de solo-cimento, adaptado de PCA (1984) 


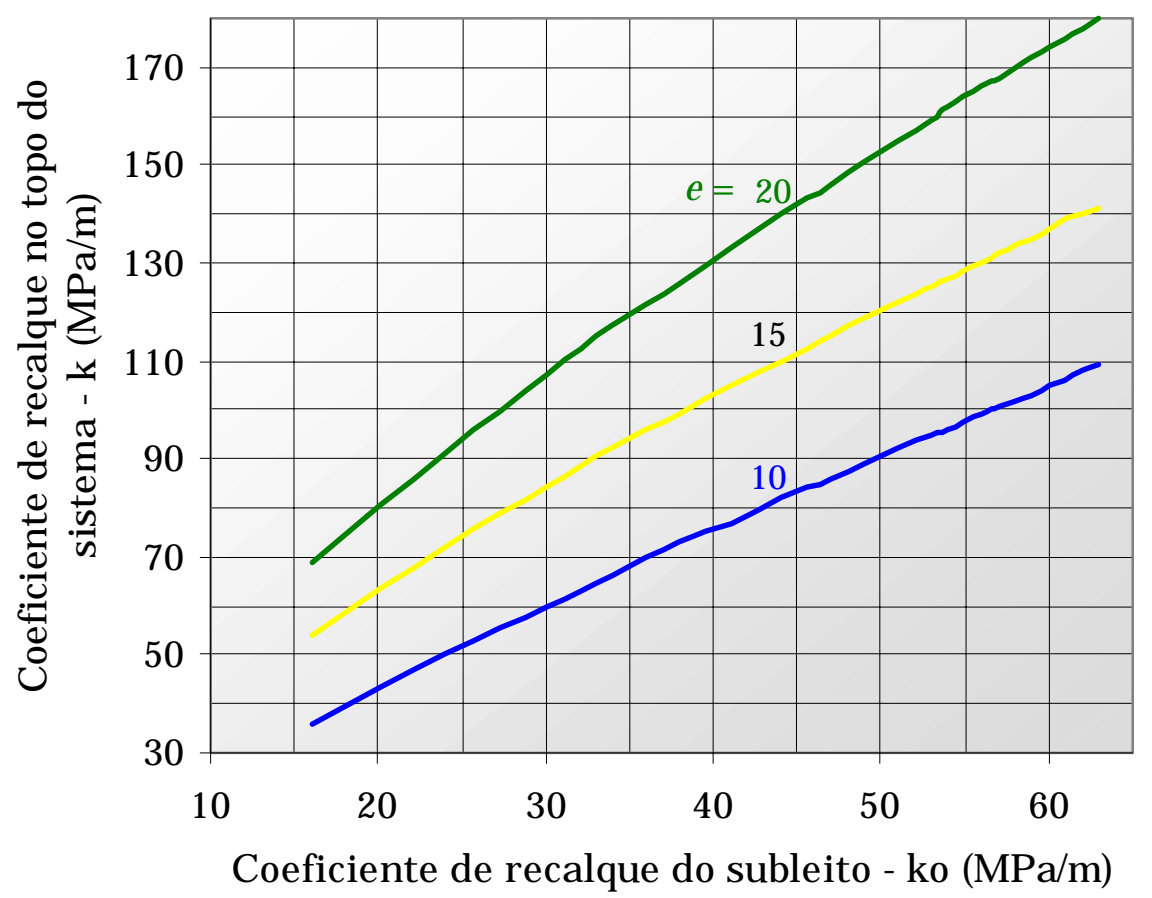

Figura A.4 - Aumento de k devido à sub-base de solo melhorado com cimento, adaptado de PITTA (1990)

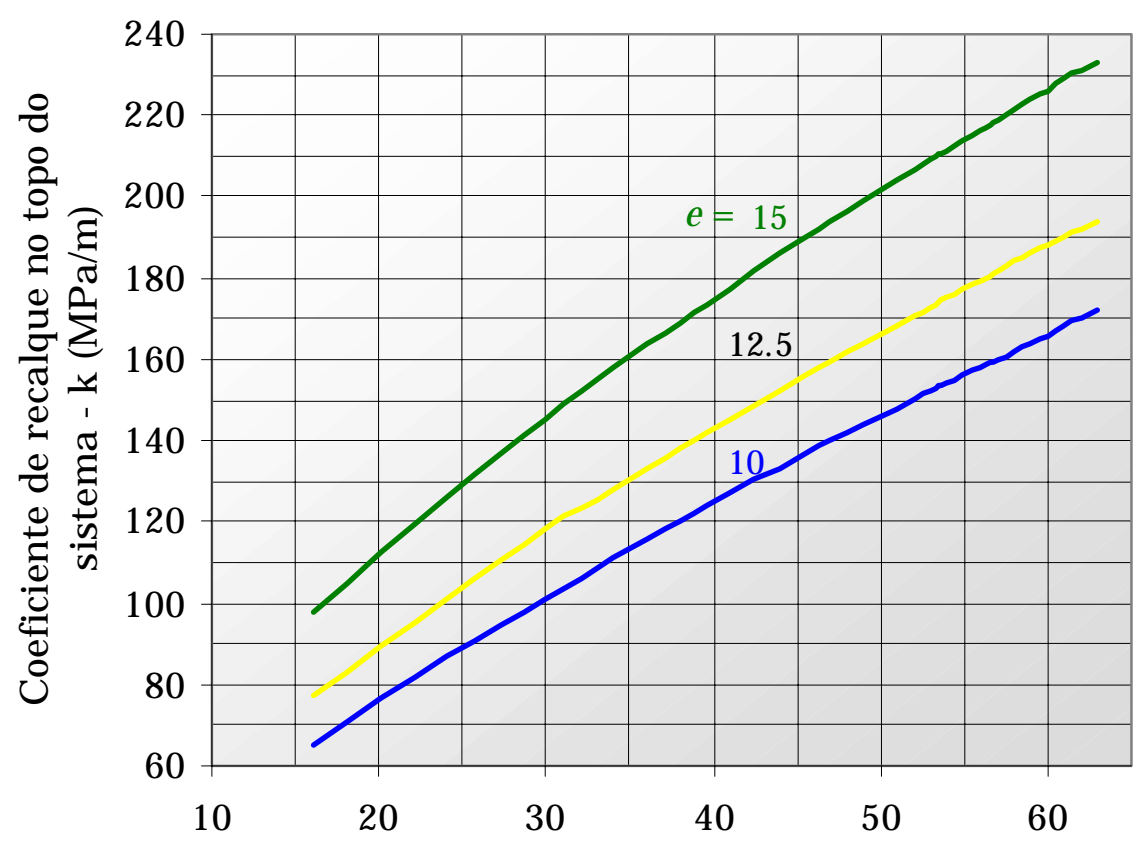

Coeficiente de recalque do subleito - ko $(\mathrm{MPa} / \mathrm{m})$

Figura A.5 - Aumento de k devido à sub-base de concreto rolado, adaptado de PITTA (1990) 


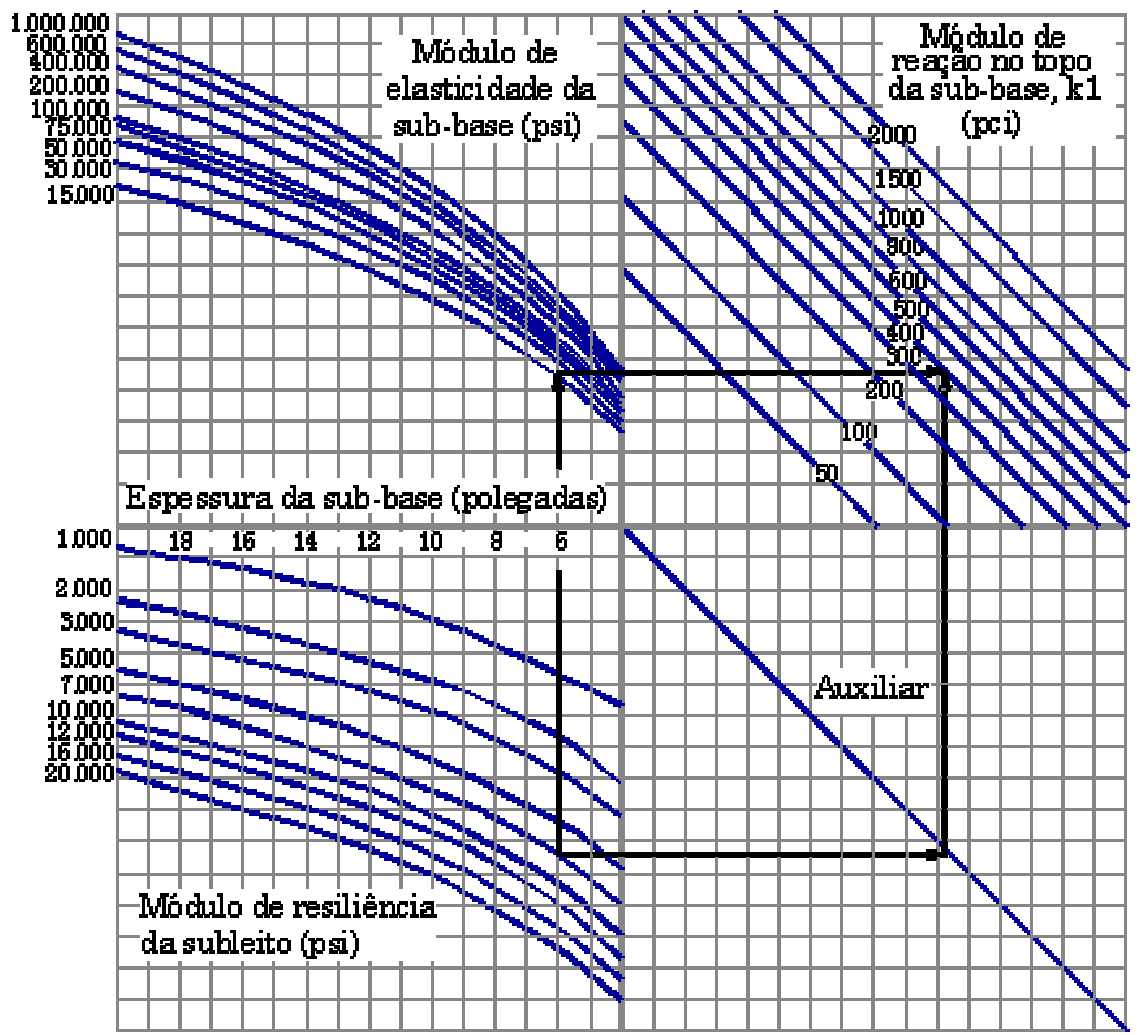

Figura A.6 - Aumento de k devido à presença de sub-base, adaptado de AASHTO (1986)

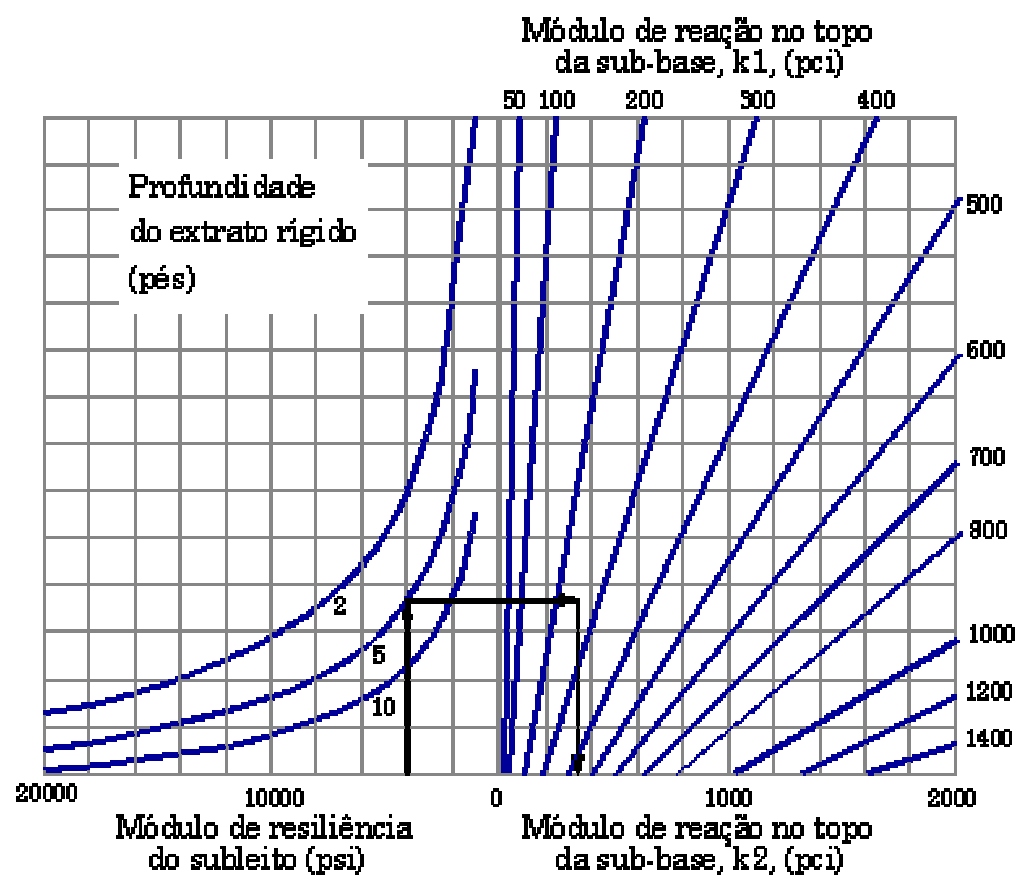

Figura A.7 - Modificação de k devido à de extrato rígido, adaptado de AASHTO (1986) 


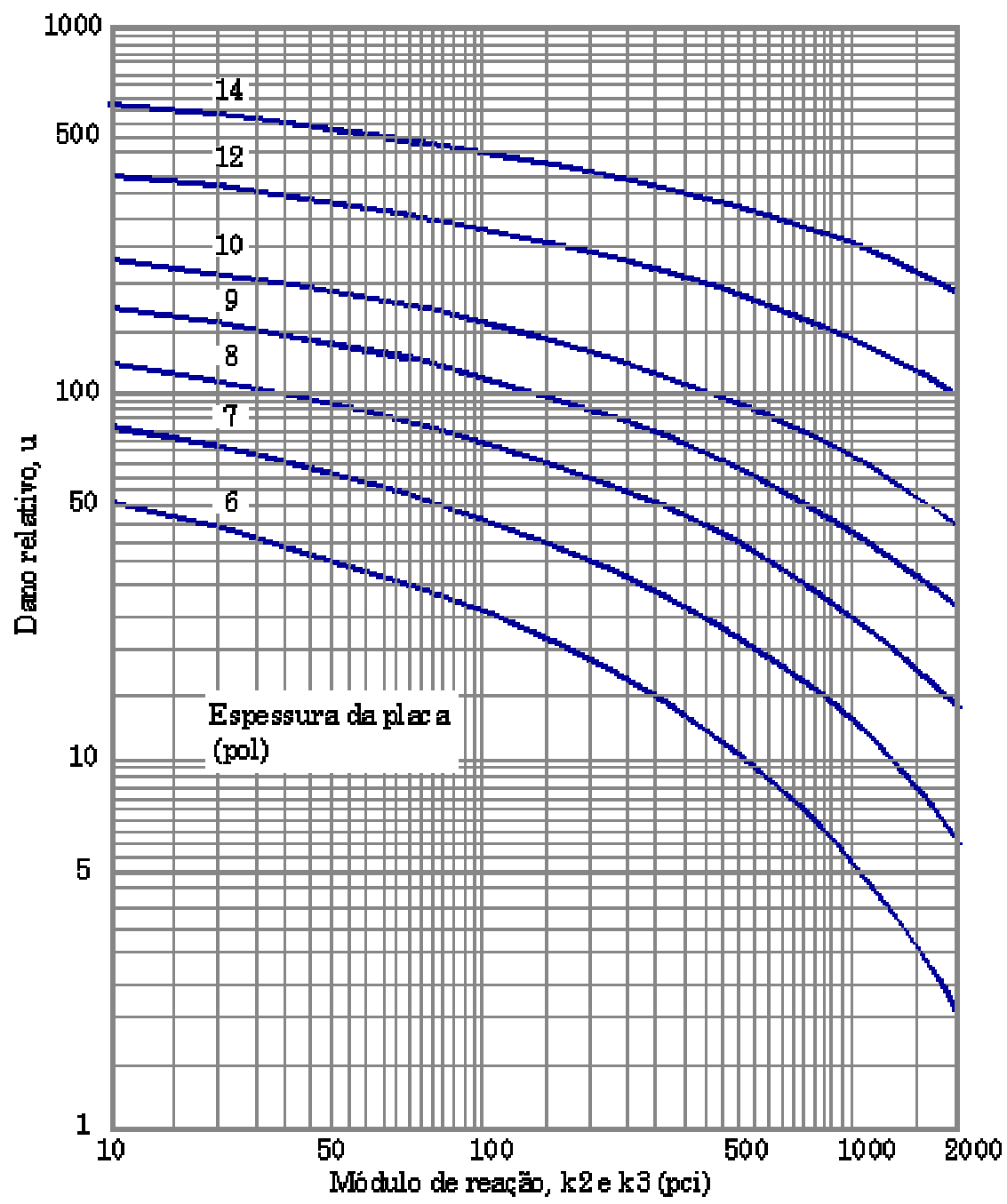

Figura A.8 - Dano relativo, adaptado de AASHTO (1986)

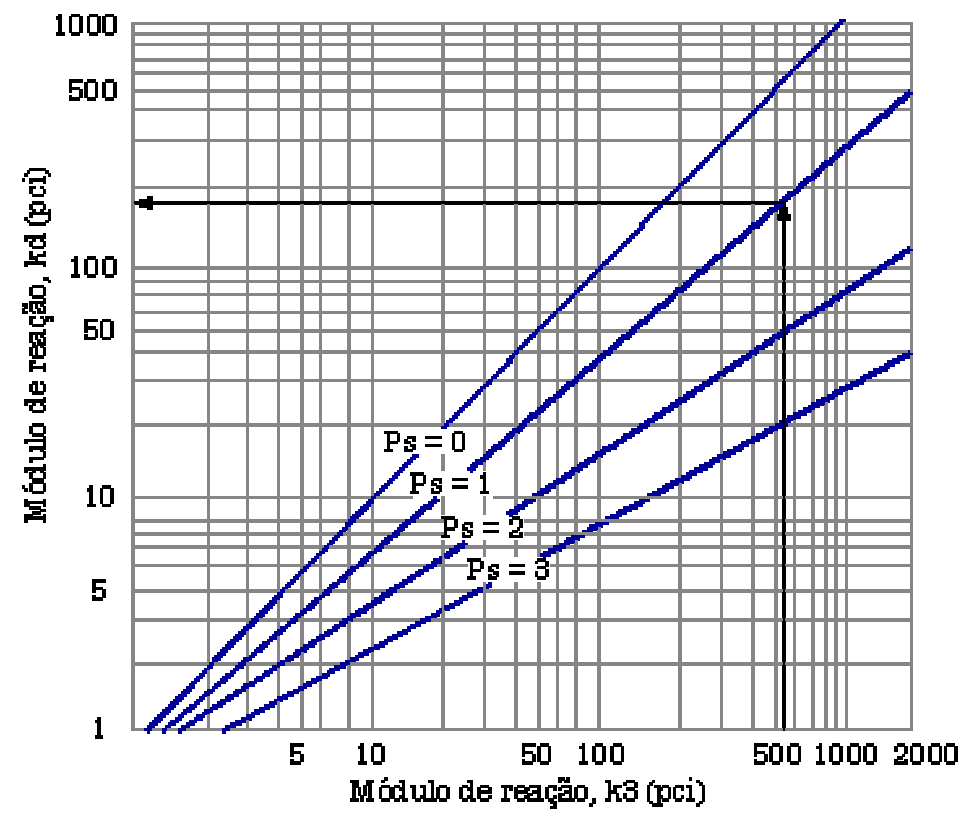

Figura A.9 - Redução de k devido à perda de serventia, adaptado de AASHTO (1986) 


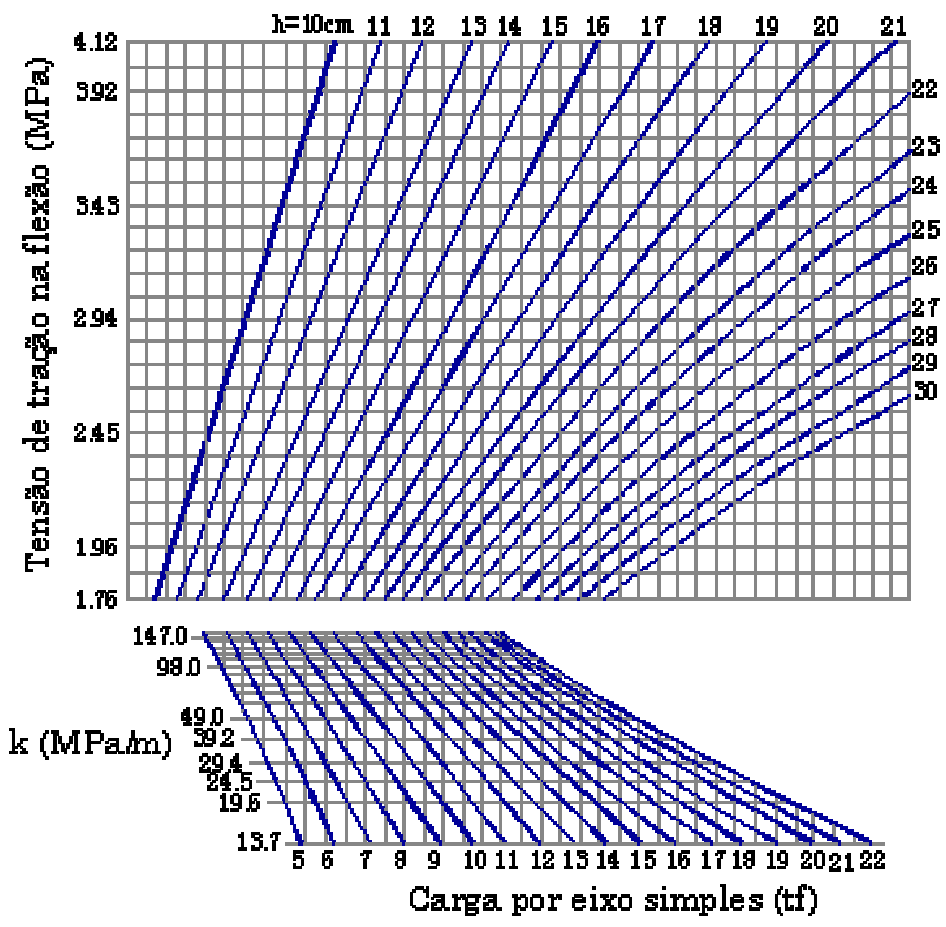

Figura A.10 - Ábaco para dimensionamento da espessura de pavimentos rodoviários de concreto (caso de eixos simples), DNER (1989)

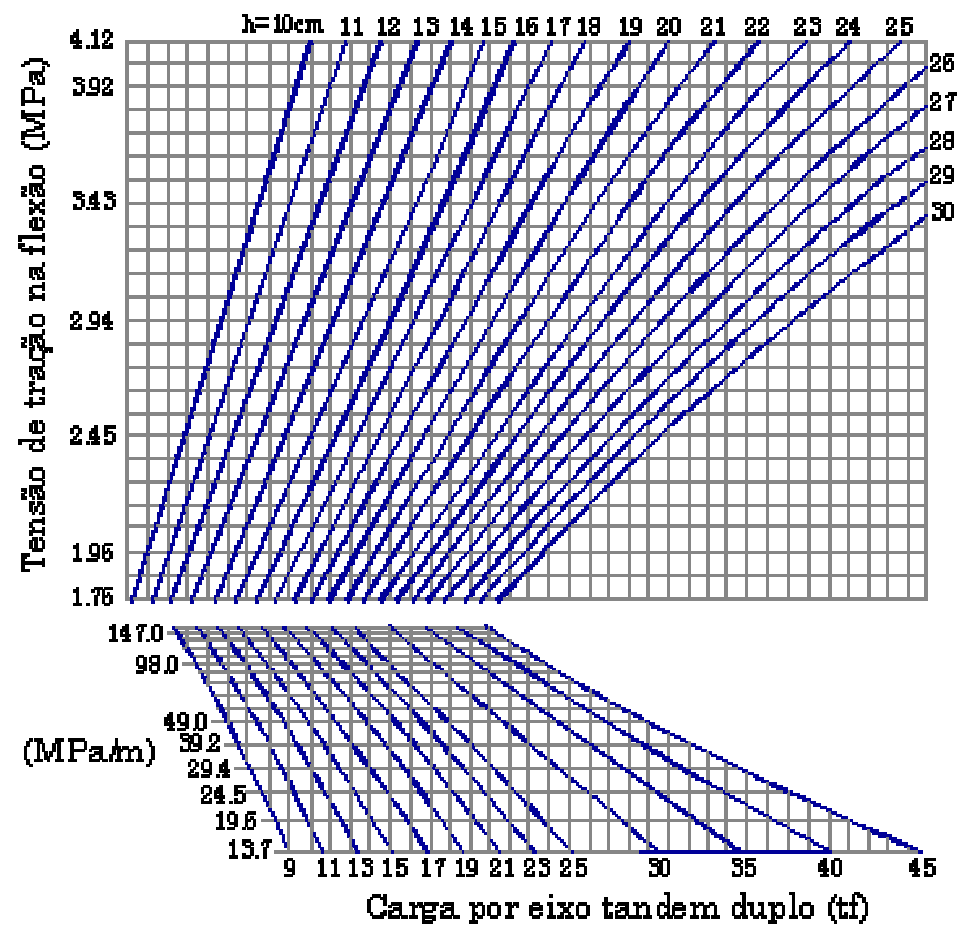

Figura A.11 - Ábaco para dimensionamento da espessura de pavimentos rodoviários de concreto (caso de eixos tandem duplos), DNER (1989) 


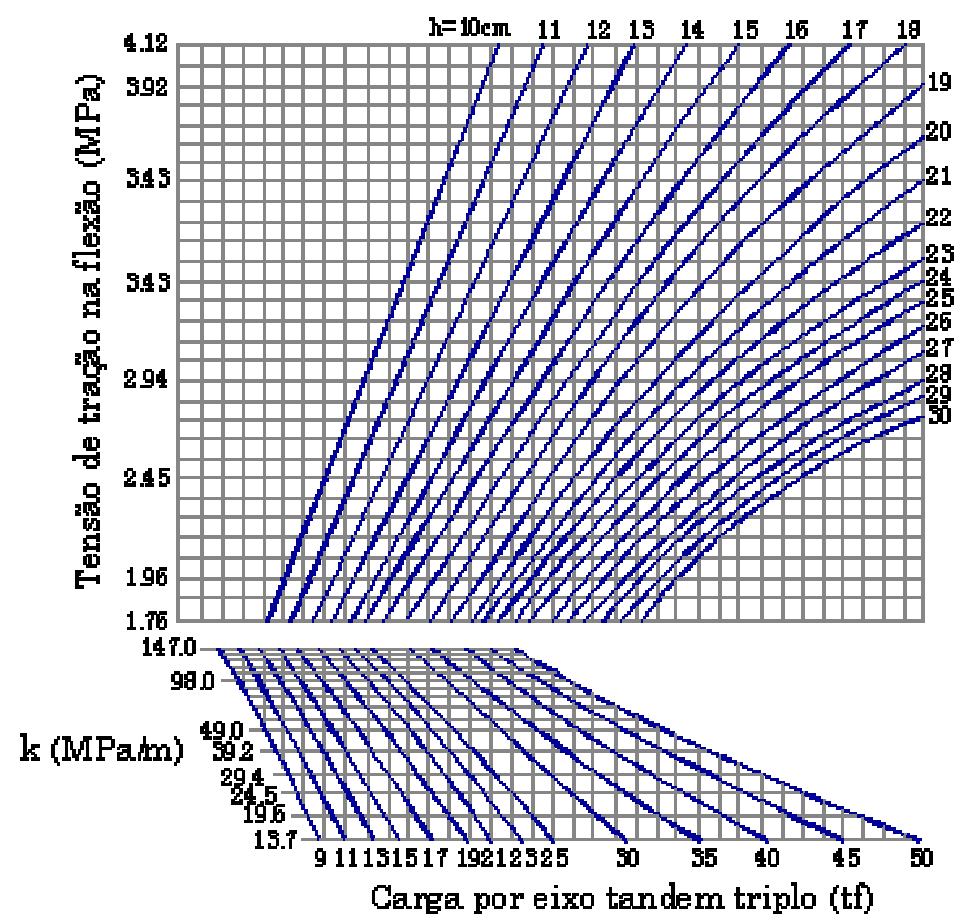

Figura A.12 - Ábaco para dimensionamento da espessura de pavimentos rodoviários de concreto (caso de eixos tandem triplos), DNER (1989)
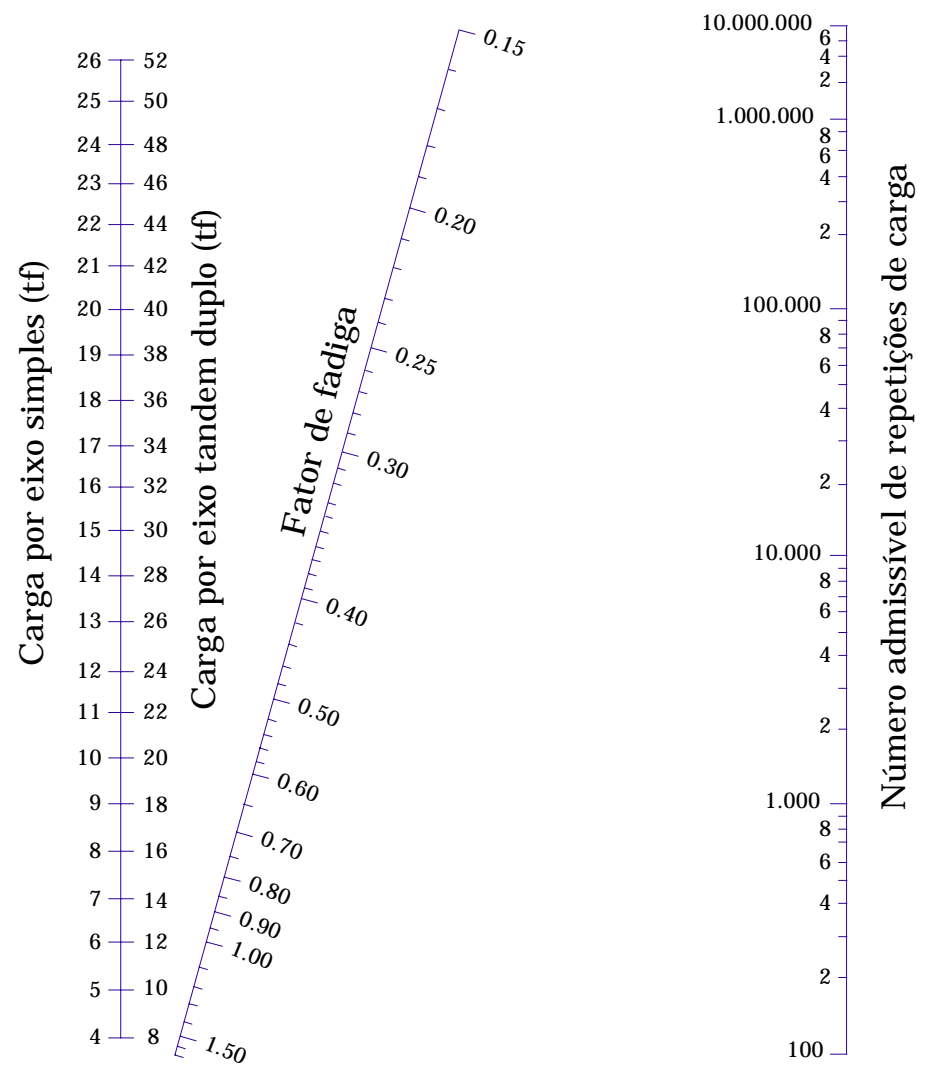

Figura A.13 - Número admissível de repetições de carga em função do fator de fadiga, DNER (1989) 

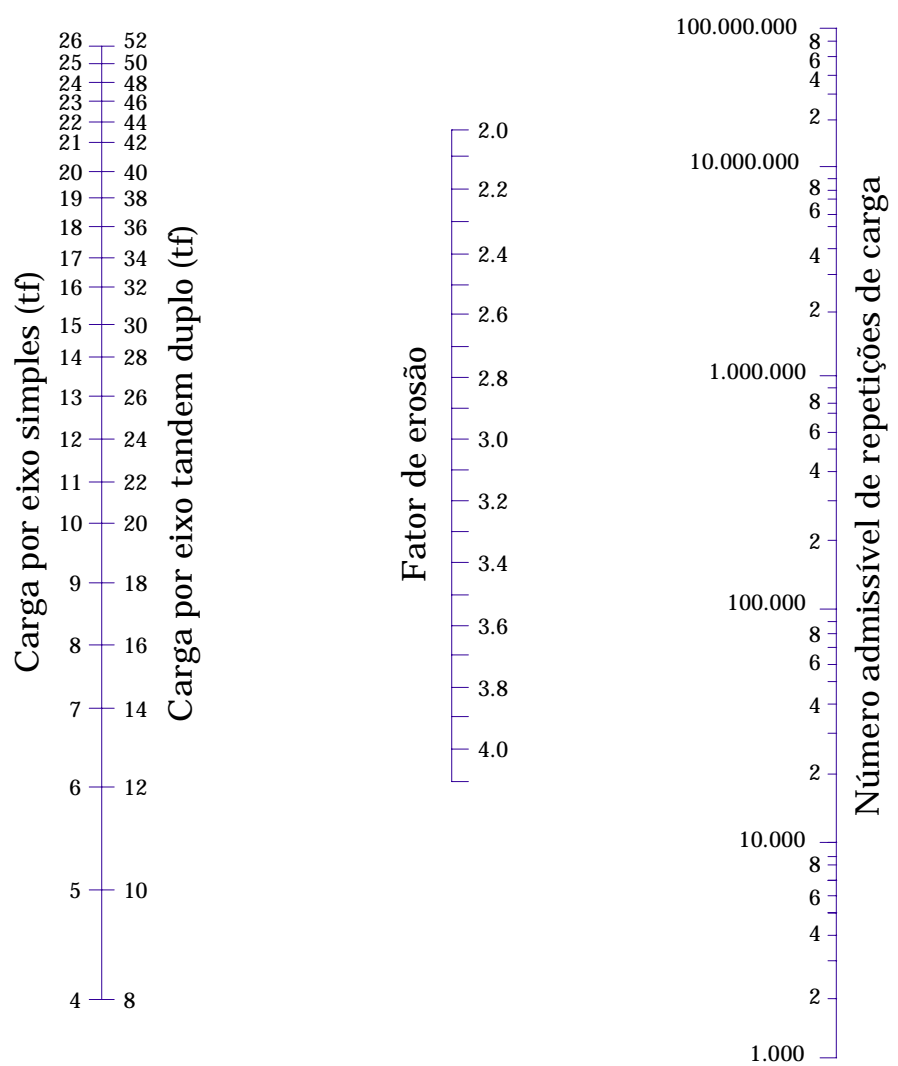

Figura A.14 - Análise de erosão: número admissível de repetições de carga em função do fator de erosão (sem acostamento de concreto), DNER (1989)
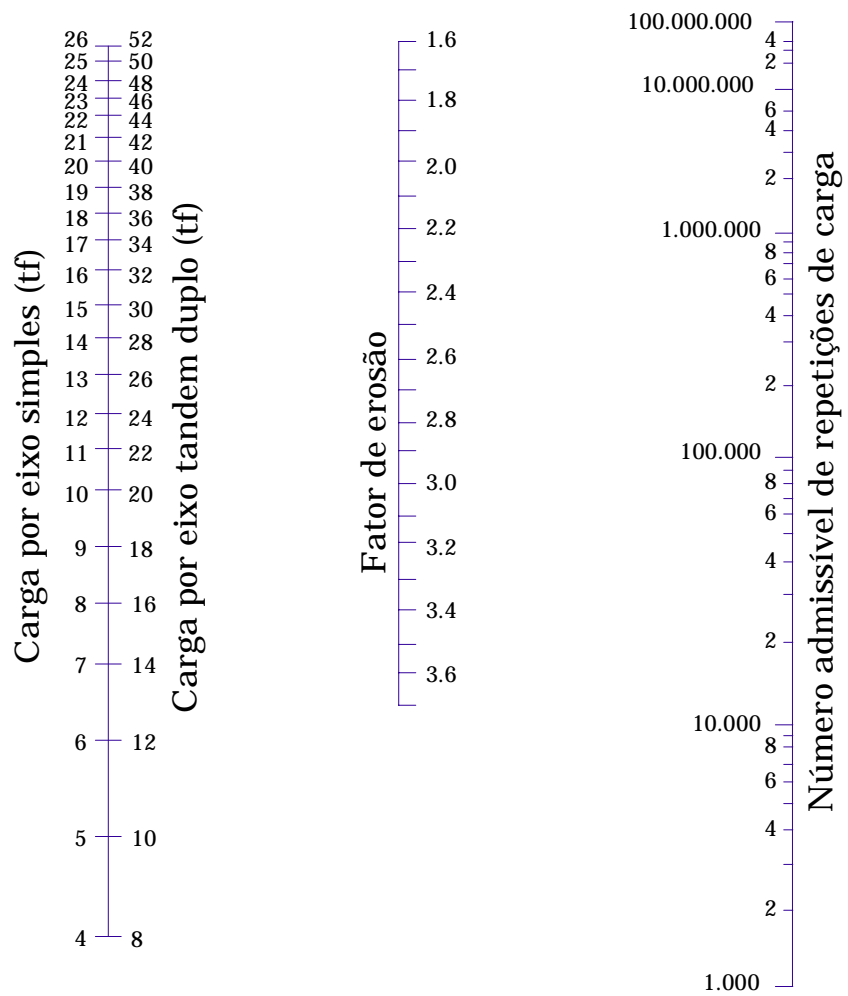

Figura A.15 - Análise de erosão: número admissível de repetições de carga em função do fator de erosão (com acostamento de concreto), DNER (1989) 


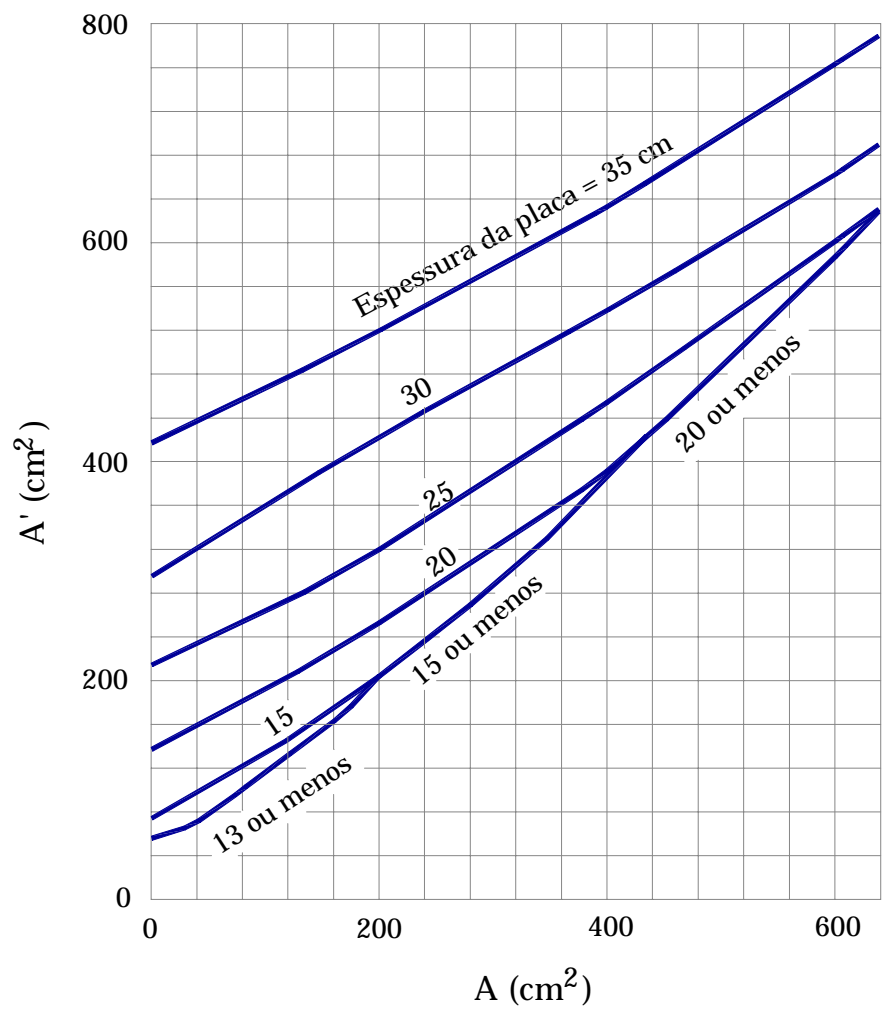

Figura A.16 - Área de contato efetiva

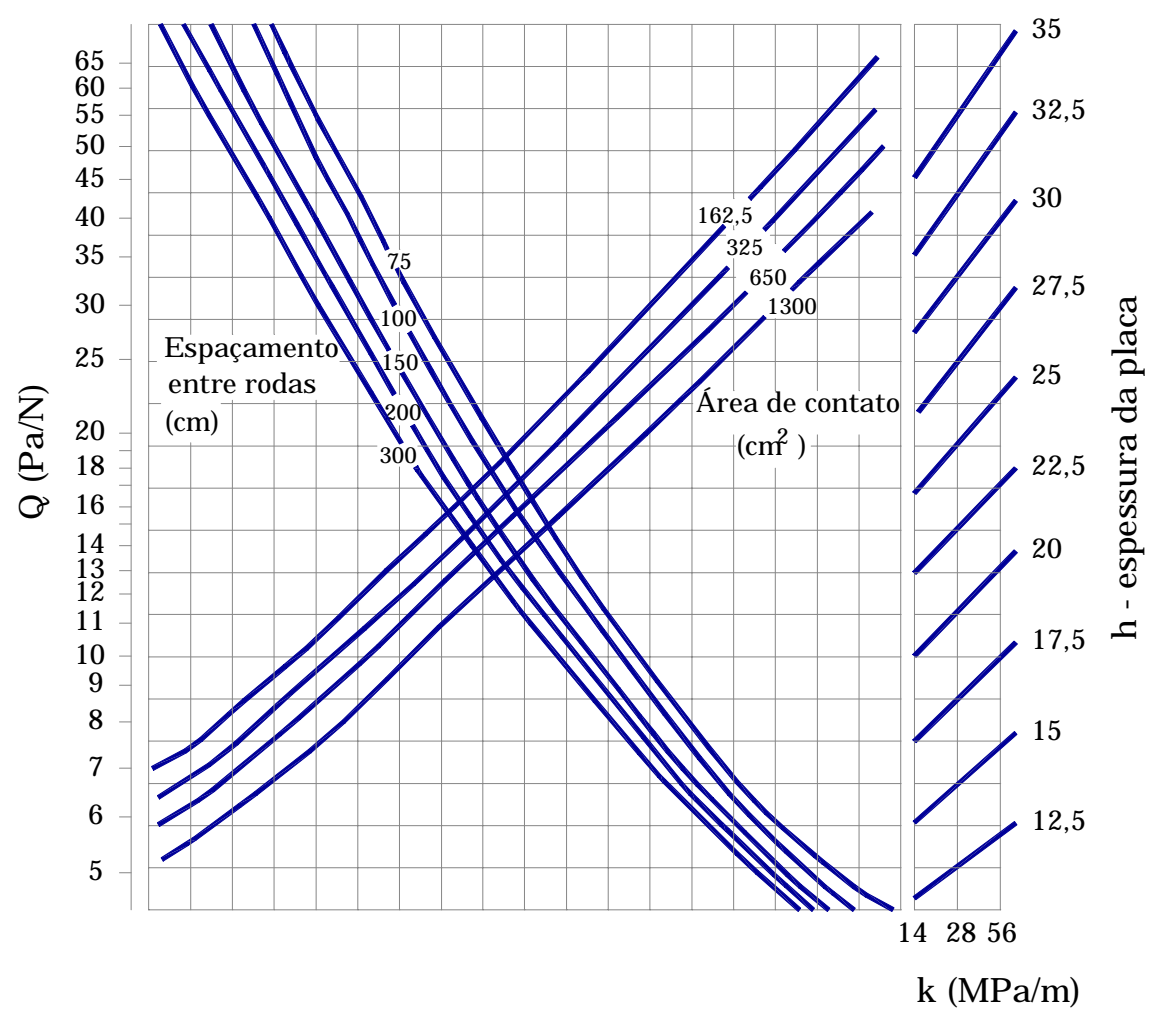

Figura A.17 - Ábaco para dimensionamento de pisos industriais, para empilhadeiras de rodagem simples, adaptado de PACKARD (1976) 


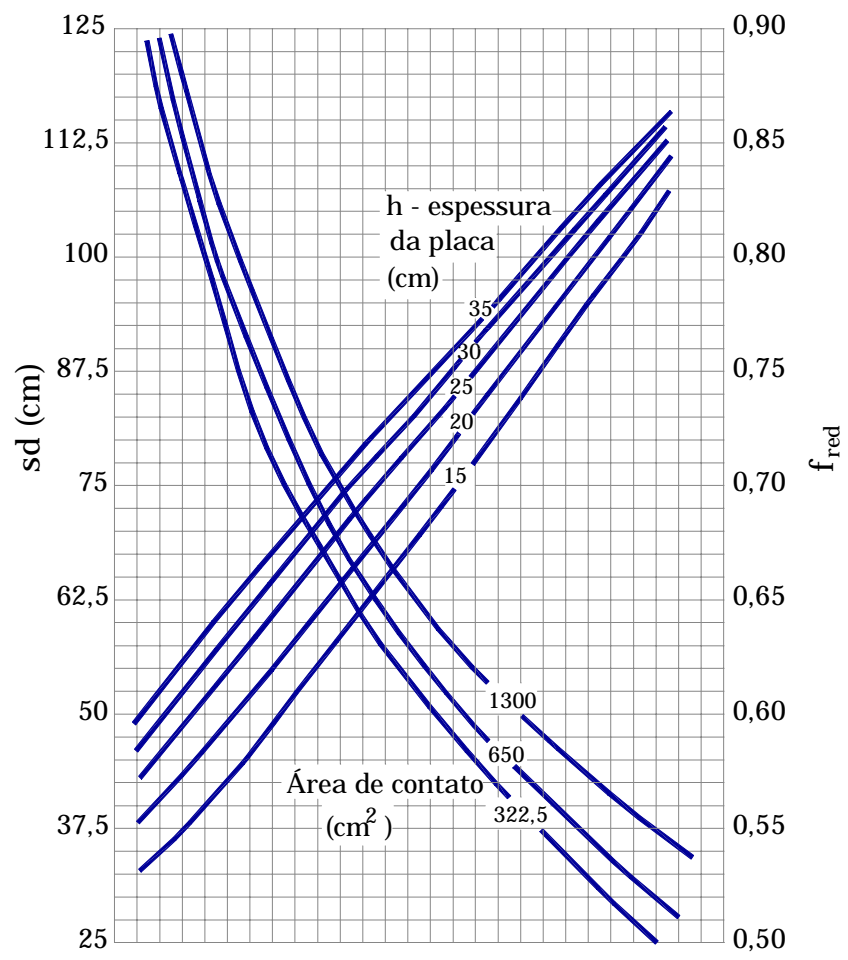

Figura A.18 - Ábaco para determinação do fator de redução para empilhadeiras de rodagem dupla, adaptado de PACKARD (1976)

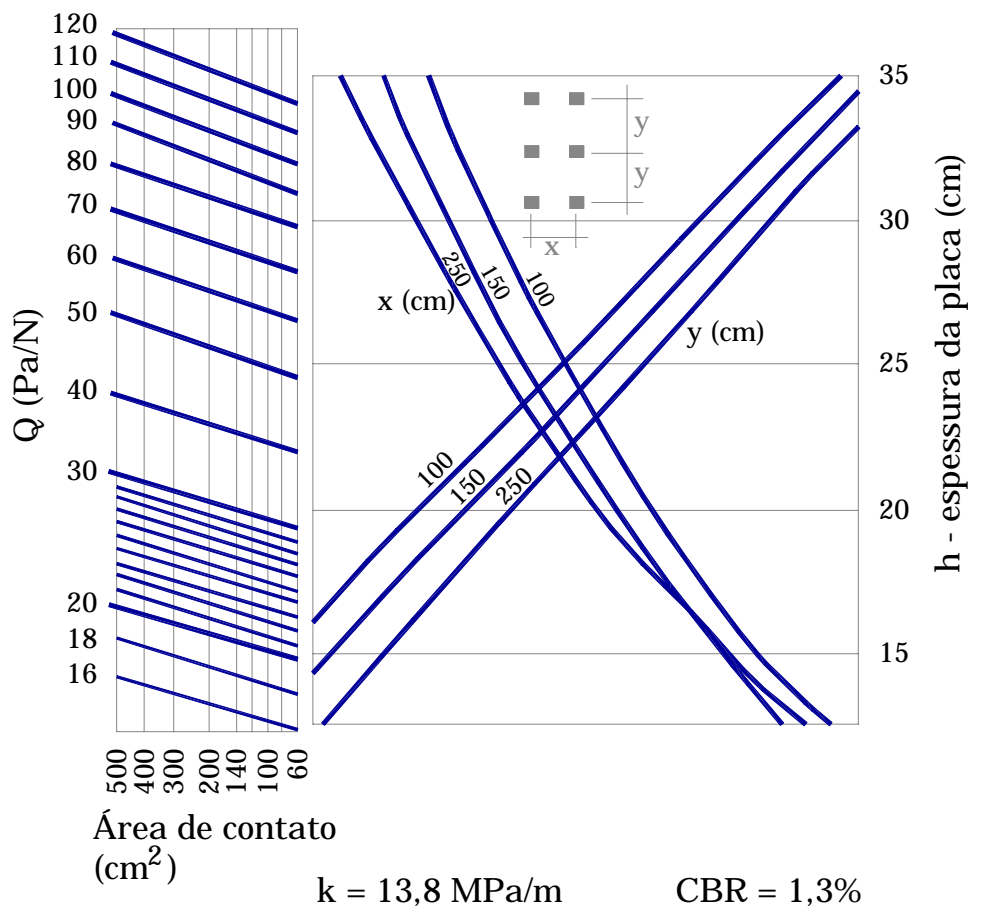

Figura A.19 - Ábaco para dimensionamento de pisos industriais, para cargas de montantes, $\mathrm{k}=13,8 \mathrm{MPa} / \mathrm{m}$, adaptado de PACKARD (1976) 


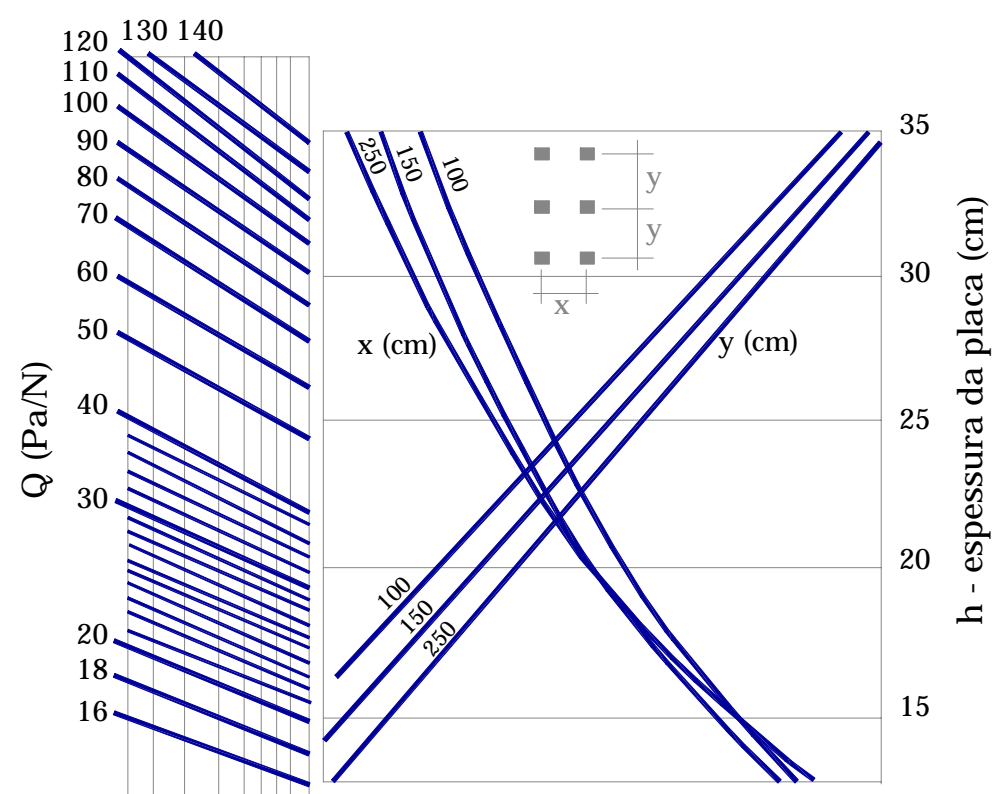

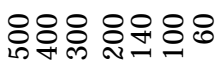

Área de contato $\left(\mathrm{cm}^{2}\right)$

$$
\mathrm{k}=28 \mathrm{MPa} / \mathrm{m} \quad \mathrm{CBR}=3 \%
$$

Figura A.20 - Ábaco para dimensionamento de pisos industriais, para cargas de montantes, $\mathrm{k}=28 \mathrm{MPa} / \mathrm{m}$, adaptado de PACKARD (1976)

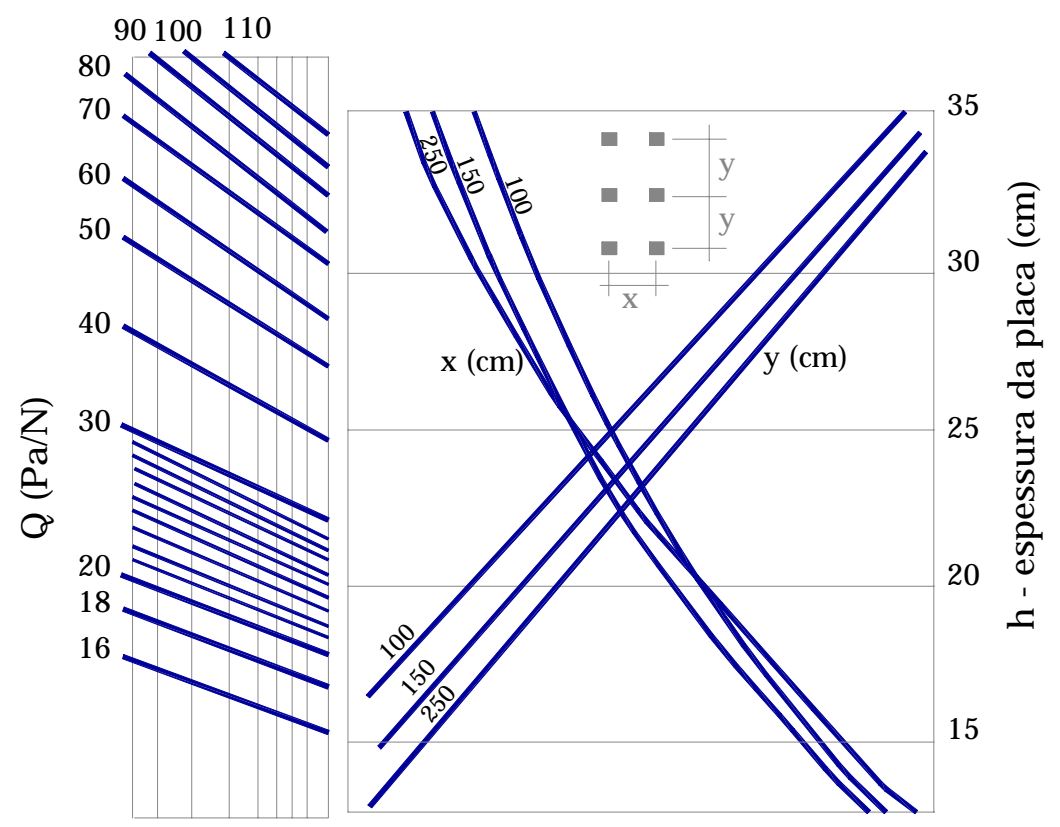

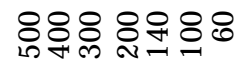

Área de contato $\left(\mathrm{cm}^{2}\right)$

$\mathrm{k}=55,4 \mathrm{MPa} / \mathrm{m} \quad \mathrm{CBR}=10 \%$

Figura A.21 - Ábaco para dimensionamento de pisos industriais, para cargas de montantes, $\mathrm{k}=55,4 \mathrm{MPa} / \mathrm{m}$, adaptado de PACKARD (1976) 
Tabela A.2 - Fatores de equivalência de carga por eixo simples, para índice de serventia final igual a 2,0

\begin{tabular}{|c|c|c|c|c|c|c|c|c|c|}
\hline Carga por & \multicolumn{10}{|c|}{ Espessura de placa (cm) } \\
\cline { 2 - 10 } eixo (tf) & 15 & 17,5 & 20 & 22,5 & 25 & 27,5 & 30 & 32,5 & 35 \\
\hline 0,9 & 0,0002 & 0,0002 & 0,0002 & 0,0002 & 0,0002 & 0,0002 & 0,0002 & 0,0002 & 0,0002 \\
1,8 & 0,002 & 0,002 & 0,002 & 0,002 & 0,002 & 0,002 & 0,002 & 0,002 & 0,002 \\
2,7 & 0,011 & 0,010 & 0,010 & 0,010 & 0,010 & 0,010 & 0,010 & 0,010 & 0,010 \\
3,6 & 0,035 & 0,033 & 0,032 & 0,032 & 0,032 & 0,032 & 0,032 & 0,032 & 0,032 \\
4,5 & 0,087 & 0,084 & 0,082 & 0,081 & 0,08 & 0,08 & 0,08 & 0,08 & 0,08 \\
5,4 & 0,186 & 0,18 & 0,176 & 0,175 & 0,174 & 0,174 & 0,173 & 0,173 & 0,173 \\
6,3 & 0,353 & 0,346 & 0,341 & 0,338 & 0,337 & 0,336 & 0,336 & 0,336 & 0,336 \\
7,2 & 0,614 & 0,609 & 0,604 & 0,601 & 0,599 & 0,599 & 0,598 & 0,598 & 0,598 \\
8,2 & 1,00 & 1,00 & 1,00 & 1,00 & 1,00 & 1,00 & 1,00 & 1,00 & 1,00 \\
9,1 & 1,55 & 1,56 & 1,57 & 1,58 & 1,58 & 1,59 & 1,59 & 1,59 & 1,59 \\
10,0 & 2,32 & 2,32 & 2,35 & 2,38 & 2,4 & 2,41 & 2,41 & 2,41 & 2,42 \\
10,9 & 3,37 & 3,34 & 3,4 & 3,47 & 3,51 & 3,53 & 3,54 & 3,55 & 3,55 \\
11,8 & 4,76 & 4,69 & 4,77 & 4,88 & 4,97 & 5,02 & 5,04 & 5,06 & 5,06 \\
12,7 & 6,58 & 6,44 & 6,52 & 6,70 & 6,85 & 6,94 & 7,00 & 7,02 & 7,04 \\
13,6 & 8,92 & 8,68 & 8,74 & 8,98 & 9,23 & 9,39 & 9,48 & 9,54 & 9,56 \\
14,5 & 11,9 & 11,5 & 11,5 & 11,8 & 12,2 & 12,4 & 12,6 & 12,7 & 12,7 \\
15,4 & 15,5 & 15,0 & 14,9 & 15,3 & 15,8 & 16,2 & 16,4 & 16,6 & 16,7 \\
16,3 & 20,1 & 19,3 & 19,2 & 19,5 & 20,1 & 20,7 & 21,1 & 21,4 & 21,5 \\
17,2 & 25,6 & 24,5 & 24,3 & 24,6 & 25,4 & 26,1 & 26,7 & 27,1 & 27,4 \\
18,1 & 32,2 & 30,8 & 30,4 & 30,7 & 31,6 & 32,6 & 33,4 & 34,0 & 34,4 \\
19,0 & 40,1 & 38,4 & 37,7 & 38,0 & 38,9 & 40,1 & 41,3 & 42,1 & 42,7 \\
20,0 & 49,4 & 47,3 & 46,4 & 46,6 & 47,6 & 49,0 & 50,4 & 51,6 & 52,4 \\
20,9 & 60,4 & 57,7 & 56,6 & 56,7 & 57,7 & 59,3 & 61,1 & 62,6 & 63,7 \\
21,8 & 73,2 & 69,9 & 68,4 & 68,4 & 69,4 & 71,2 & 73,3 & 75,3 & 76,8 \\
22,7 & 88,0 & 84,1 & 82,2 & 82,0 & 83,0 & 84,9 & 87,4 & 89,8 & 91,7 \\
\hline
\end{tabular}


Tabela A.3 - Fatores de equivalência de carga por eixo tandem duplo, para índice de serventia final igual a 2,0

\begin{tabular}{|c|c|c|c|c|c|c|c|c|c|}
\hline \multirow{2}{*}{$\begin{array}{c}\text { Carga por } \\
\text { eixo (tf) }\end{array}$} & \multicolumn{9}{|c|}{ Espessura de placa $(\mathrm{cm})$} \\
\hline & 15 & 17,5 & 20 & 22,5 & 25 & 27,5 & 30 & 32,5 & 35 \\
\hline 0,9 & 0,0001 & 0,0001 & 0,0001 & 0,0001 & 0,0001 & 0,0001 & 0,0001 & 0,0001 & 0,0001 \\
\hline 1,8 & 0,0006 & 0,0005 & 0,0005 & 0,0005 & 0,0005 & 0,0005 & 0,0005 & 0,0005 & 0,0005 \\
\hline 2,7 & 0,002 & 0,002 & 0,002 & 0,002 & 0,002 & 0,002 & 0,002 & 0,002 & 0,002 \\
\hline 3,6 & 0,006 & 0,006 & 0,005 & 0,005 & 0,005 & 0,005 & 0,005 & 0,005 & 0,005 \\
\hline 4,5 & 0,014 & 0,013 & 0,013 & 0,012 & 0,012 & 0,012 & 0,012 & 0,012 & 0,012 \\
\hline 5,4 & 0,028 & 0,026 & 0,026 & 0,025 & 0,025 & 0,025 & 0,025 & 0,025 & 0,025 \\
\hline 6,3 & 0,051 & 0,049 & 0,048 & 0,047 & 0,047 & 0,047 & 0,047 & 0,047 & 0,047 \\
\hline 7,2 & 0,087 & 0,084 & 0,082 & 0,081 & 0,081 & 0,080 & 0,080 & 0,080 &, 080 \\
\hline 8,2 & 0,141 & 0,136 & 0,133 & 0,132 & 0,131 & 0,131 & 0,131 & 0,131 & 0,131 \\
\hline 9,1 & 0,216 & 0,210 & 0,206 & 0,204 & 0,203 & 0,203 & 0,203 & 0,203 & 0,203 \\
\hline 10,0 & 0,319 & 0,313 & 0,307 & 0,305 & 0,304 & 0,303 & 0,303 & 0,303 & 0,303 \\
\hline 10,9 & 0,454 & 0,449 & 0,444 & 0,441 & 0,440 & 0,439 & 0,439 & 0,439 &, 439 \\
\hline 11,8 & 0,629 & 0,626 & 0,622 & 0,620 & 0,618 & 0,618 & 0,618 & 0,618 & 0,618 \\
\hline 12,7 & 0,852 & 0,851 & 0,850 & 0,850 & 0,850 & 0,849 & 0,849 & 0,849 & 0,849 \\
\hline 13,6 & 1,13 & 1,13 & 1,14 & 1,14 & 1,14 & 1,14 & 1,14 & 1,14 & 1,14 \\
\hline 14,5 & 48 & 1,48 & 1,49 & 1,50 & 1,51 & 51 & 1,51 &, 51 & 1,51 \\
\hline 15,4 & 1,90 & 1,90 & 1,93 & 1,95 & ,96 & 97 & 1,97 & ,97 & 1,97 \\
\hline 1( & 2,42 & 2,41 & 2,45 & 2,49 &, 51 & 52 & 2,53 &, 53 & 2,53 \\
\hline 17,2 & 3,04 & 02 & 3,07 & 3, & 3,17 & 19 & 3,20 &, 20 & 3,21 \\
\hline 18,1 & 3,79 & 3,74 & 3,80 & 3,89 & 3,95 & 3,98 & 4,00 & 4,01 & 4,01 \\
\hline 19,0 & 4,67 & 59 & 4,66 & 4,78 & 4,87 & 4,93 & 4,95 & 4,97 & 4,97 \\
\hline 20,0 & 72 & 59 & 5,67 & & ,95 & & ;,07 &, 09 & 6,10 \\
\hline 20,9 & 6,94 & 6,76 & 6,83 & 2 & 7,20 & 31 & 7,37 & 41 & 7,43 \\
\hline 2 & 8,36 & & 8,17 & & 8,63 & 8,79 & 8,88 & 8,93 & 8,96 \\
\hline 22,7 & 10,00 & ,69 & 9,72 & 9,98 & 10,27 & 10,49 & 10,62 & 10,69 & 10,73 \\
\hline 23,6 & 11,9 &, 5 & 11,5 & 11,8 & 12,1 & 12,4 & 12,6 & 12,7 & 12,8 \\
\hline 24 &, 0 &, 5 & 13,5 & 13,8 & 14,2 & 4,6 & 4,9 & 15,0 & 15,1 \\
\hline 25 , & ,5 & & 15,8 & & 6,6 & 7,1 & 7,4 & 7,6 & 17,7 \\
\hline 26,3 & 19,3 & 5 & 18,4 & & 9,3 & 9,8 & , & 0,5 & 20,7 \\
\hline 27,2 & & & 21,3 & & 22,3 & 9 & 23,5 & 8 & 24,0 \\
\hline 28 & & & 24,6 & 24,9 & 25,6 & 4 & 0 & 5 & 27,7 \\
\hline 29,0 &, 9 & 3,6 & 28,2 & 28,5 & 29,3 & 30,2 & 31,0 & 1,6 & 31,9 \\
\hline 30,0 & 34,3 & 32,8 & 32,3 & 32,6 & 33,4 & 34,4 & 35,4 & 36,1 & 36,5 \\
\hline $30, \varepsilon$ & 39,2 & 7,5 & 36,8 & 37,1 & 37,9 & 9,1 & 40,2 & 41,1 & 41,6 \\
\hline 31,7 & 44,6 & 2,7 & 41,9 & , 1 & 42,9 & 44,2 & 45,5 & 6,6 & 47,3 \\
\hline 32,6 & 50,6 & & 47,5 & & 48,5 & & 51,4 & 2,6 & 53,5 \\
\hline 33 , & & & 53,6 & & 54,6 & & 57,7 & 9,2 & 60,3 \\
\hline & & & 60,4 & & 61,2 & 8 & 64,7 & 6,4 & 67,7 \\
\hline 35,4 & 72,5 & 69,3 & 67,8 & 67,7 & 68,6 & 70,2 & 72,3 & 74,3 & 75,8 \\
\hline 36,3 & 81,3 & 776 & 75,9 & 75,7 & 76,6 & 78,3 & 80,6 & 82,8 & 84,7 \\
\hline 37,2 & 90,9 & 6,7 & 84,7 & 84,4 & 85,3 & 87,1 & 89,6 & 92,1 & 94,2 \\
\hline 38,1 & 101 & 97,0 & 94,0 & 94,0 & 95,0 & 97,0 & 99,0 & 102 & 105 \\
\hline 39,0 & 113 & 107 & 105 & 104 & 105 & 107 & 110 & 113 & 116 \\
\hline 39,9 & 125 & 119 & 116 & 116 & 116 & 118 & 121 & 125 & 128 \\
\hline 40,8 & 138 & 132 & 129 & 128 & 129 & 131 & 134 & 137 & 141 \\
\hline
\end{tabular}


Tabela A.4 - Fatores de equivalência de carga por eixo tandem triplo, para índice de serventia final igual a 2,0

\begin{tabular}{|c|c|c|c|c|c|c|c|c|c|}
\hline \multirow{2}{*}{$\begin{array}{c}\text { Carga por } \\
\text { eixo (tf) }\end{array}$} & \multicolumn{9}{|c|}{ Espessura de placa (cm) } \\
\hline & 15 & 17,5 & 20 & 22,5 & 25 & 27,5 & 30 & 32,5 & 35 \\
\hline 0,9 & 0,0001 & 0,0001 & 0,0001 & 0,0001 & 0,0001 & 0,0001 & 0,0001 & 0,0001 & 0,0001 \\
\hline $1, \varepsilon$ & 0,0003 & ,0003 & 0,0003 & 0,0003 & 0,0003 & 0,0003 & 0,0003 & 0,0003 & 0,0003 \\
\hline 2,7 & 001 & 0,0009 & 0,0009 & 0,0009 & 0,0009 & 0,0009 & 0,0009 & 0,0009 & 0,0009 \\
\hline 3,6 & 002 & 0,002 & 0,002 & 0,002 & 0,002 & 0,002 & 0,002 & 0,002 & 0,002 \\
\hline 4,5 & 005 & 0,005 & 0,005 & 0,005 & 0,005 & 0,005 & 0,005 & 0,005 & 0,005 \\
\hline 5,4 & 010 & 0,010 & 0,009 & 0,009 & 0,009 & 0,009 & 0,009 & 0,009 & 0,009 \\
\hline 6,3 & 018 & 0,017 & 0,017 & 0,016 & 0,016 & 0,016 & 0,016 & 0,016 &, 016 \\
\hline 7,2 & 0,030 & 0,029 & 0,028 & 0,027 & 0,027 & 0,027 & 0,027 & 0,027 & 0,027 \\
\hline 8,2 & 0,047 & 0,045 & 0,044 & 0,044 & 0,043 & 0,043 & 0,043 & 0,043 &, 043 \\
\hline 9,1 & 072 & 0,069 & 0,067 & 0,066 & 0,066 & 0,066 & 0,066 & 0,066 &, 066 \\
\hline 10,0 & 105 & 0,101 & 0,099 & 0,0 & 0,097 & 0,097 & 0,097 & 0,097 &, 097 \\
\hline 10,9 & 49 & 44 & 0,141 & 0 & 0,139 & 38 & 138 & 38 &, 138 \\
\hline 11,8 & 205 & 0,199 & 0,195 & 0,194 & 0,193 & 192 & 192 & 0,192 &, 192 \\
\hline 12,7 & 0,276 & 0,270 & 0,265 & 0,263 & 0,262 & 0,262 & 0,262 & 0,262 &, 261 \\
\hline 13,6 & 0,364 & 0,359 & 0,354 & 0,351 & 0,350 & 0,349 & 0,349 & 0,349 & 0,349 \\
\hline 14 & 472 & 0,468 & 0,463 & 0.460 & 0,459 & 0,458 & 0,458 & 0,458 & 0,458 \\
\hline 1 & 0,603 & 0,600 & 0,596 & 0,5 & 0,593 & 0,592 & 0,592 & 0,592 & 0,592 \\
\hline 1 & 9 & 0,7 & 0,757 & & 0,755 & & & 0,755 & 0,755 \\
\hline 17 & 0,946 & 0,947 & 0,949 & 0,950 & 0,951 & 0,951 & 0,951 & 0,951 & 0,951 \\
\hline 18,1 & 17 & & 1,18 & 1 & 1,18 & 18 & 1,18 & 1,18 & 1,18 \\
\hline 19, & 42 & & 1,44 & & ,46 & 46 & ,46 & ,46 & 1,46 \\
\hline & & & 76 & & ,78 & & 79 & 9 & 1,79 \\
\hline & & & 10 & & 5 & 16 & 6 & , 16 & 2,17 \\
\hline & & & 2,51 & & 58 & & 30 & ,60 & 2,61 \\
\hline 22 & 95 & & 2,97 & & 07 & & 0 & 1 & 3,11 \\
\hline 23, & 3,48 & 4 & 3,50 & 3 & ,63 & 66 & 3,68 & 9 & 3,69 \\
\hline 24 & 4,09 & 4,03 & 4,09 & 4 & ,27 & 4 & ,33 & 5 & 4,35 \\
\hline & & & 4,7 & & 0 & & 5,0 & 5,0 & 5,10 \\
\hline & & & 5,51 & & 79 & & & 4 & 5,95 \\
\hline & & & & & & & & 8 & 6,90 \\
\hline & & & 7 & & 9 & & 7 & 4 & 7,97 \\
\hline 29 & 54 & 8 & 8,32 & 8,5 & 8,80 & 8,97 & 9,07 & 9,13 & 9,16 \\
\hline 30 & 76 & 46 & 9,48 & 9,7 & 10,02 & 10,24 & 10,37 & 10,44 & 10,48 \\
\hline 30 & 10 &, 80 &, 80 & & 1,40 & & 1,80 & & 2,00 \\
\hline 31,7 & 12,60 & 12,20 & 12,20 & & 12,80 & & 3,40 & 13,50 & 3,60 \\
\hline 32,6 & & & & & & & & & 5,40 \\
\hline & & & & & & & & & \\
\hline & & & & & 18,20 & & 10 & 19,30 & 9,50 \\
\hline 35,4 & 20,40 & 19,60 & 19,40 & 19,70 & 20,30 & 20,90 & 21,40 & 21,70 & 1,80 \\
\hline 36 & 80 & 1,90 & 1,60 & 90 & 22,60 & 23,30 & 23,80 & 24,20 & 4,40 \\
\hline 37,2 & 25,40 & 24,40 & 24,10 & 24,40 & 25,00 & 25,80 & 26,50 & 26,90 & 27,20 \\
\hline 38,1 & 28,30 & 27,10 & 26,70 & 27,00 & 27,70 & 28,60 & 29,40 & 29,90 & 30,20 \\
\hline 39,0 & 31,40 & 30,10 & 29,60 & 29,90 & 30,70 & 31,60 & 32,50 & 33,10 & 3,50 \\
\hline 39, & 34,80 & 33,30 & 32,80 & 33,00 & 33,80 & 34,80 & 35,80 & 36,60 & 37,10 \\
\hline 40,8 & 38,50 & 36,80 & 36,20 & 36,40 & 37,20 & 36,30 & 39,40 & 40,30 & 40,90 \\
\hline
\end{tabular}


Tabela A.5 - Fatores de equivalência de carga por eixo simples, para índice de serventia final igual a 2,5

\begin{tabular}{|c|c|c|c|c|c|c|c|c|c|}
\hline Carga por & \multicolumn{10}{|c|}{ Espessura de placa (cm) } \\
\cline { 2 - 10 } eixo (tf) & 15 & 17,5 & 20 & 22,5 & 25 & 27,5 & 30 & 32,5 & 35 \\
\hline 0,9 & 0,0002 & 0,0002 & 0,0002 & 0,0002 & 0,0002 & 0,0002 & 0,0002 & 0,0002 & 0,0002 \\
1,8 & 0,003 & 0,002 & 0,002 & 0,002 & 0,002 & 0,002 & 0,002 & 0,002 & 0,002 \\
2,7 & 0,012 & 0,011 & 0,010 & 0,010 & 0,010 & 0,010 & 0,010 & 0,010 & 0,010 \\
3,6 & 0,039 & 0,035 & 0,033 & 0,032 & 0,032 & 0,032 & 0,032 & 0,032 & 0,032 \\
4,5 & 0,097 & 0,089 & 0,084 & 0,082 & 0,081 & 0,080 & 0,080 & 0,080 & 0,080 \\
5,4 & 0,203 & 0,189 & 0,181 & 0,176 & 0,175 & 0,174 & 0,174 & 0,173 & 0,173 \\
6,3 & 0,376 & 0,360 & 0,347 & 0,341 & 0,338 & 0,337 & 0,336 & 0,336 & 0,336 \\
7,2 & 0,634 & 0,623 & 0,610 & 0,604 & 0,601 & 0,604 & 0,601 & 0,599 & 0,598 \\
8,2 & 1,00 & 1,00 & 1,00 & 1,00 & 1,00 & 1,00 & 1,00 & 1,00 & 1,00 \\
9,1 & 1,51 & 1,52 & 1,55 & 1,57 & 1,58 & 1,58 & 1,59 & 1,59 & 1,59 \\
10,0 & 2,21 & 2,20 & 2,28 & 2,34 & 2,38 & 2,40 & 2,41 & 2,41 & 2,41 \\
10,9 & 3,16 & 3,10 & 3,22 & 3,36 & 3,45 & 3,50 & 3,53 & 3,54 & 3,55 \\
11,8 & 4,41 & 4,26 & 4,42 & 4,67 & 4,85 & 4,95 & 5,01 & 5,04 & 5,05 \\
12,7 & 6,05 & 5,76 & 5,92 & 6,29 & 6,61 & 6,81 & 6,92 & 6,98 & 7,01 \\
13,6 & 8,16 & 7,67 & 7,79 & 8,28 & 8,79 & 9,14 & 9,35 & 9,46 & 9,52 \\
14,5 & 10,8 & 10,1 & 10,1 & 10,7 & 11,4 & 12,0 & 12,3 & 12,6 & 12,7 \\
15,4 & 14,1 & 13,0 & 12,9 & 13,6 & 14,6 & 15,4 & 16,0 & 16,4 & 16,5 \\
16,3 & 18,2 & 16,7 & 16,4 & 17,1 & 18,3 & 19,5 & 20,4 & 21,0 & 21,3 \\
17,2 & 23,1 & 21,1 & 20,6 & 21,3 & 22,7 & 24,3 & 25,6 & 26,4 & 27,0 \\
18,1 & 29,1 & 26,5 & 25,7 & 26,3 & 27,9 & 29,9 & 31,6 & 32,9 & 33,7 \\
19,0 & 36,2 & 32,9 & 31,7 & 32,2 & 34,0 & 36,3 & 38,7 & 40,4 & 41,6 \\
20,0 & 44,6 & 40,4 & 38,8 & 39,2 & 41,0 & 43,8 & 46,7 & 49,1 & 50,8 \\
20,9 & 54,5 & 49,3 & 47,1 & 47,3 & 49,2 & 52,3 & 55,9 & 59,0 & 61,4 \\
21,8 & 66,1 & 59,7 & 56,9 & 56,8 & 58,7 & 62,1 & 66,3 & 70,3 & 73,4 \\
22,7 & 79,4 & 71,7 & 68,2 & 67,8 & 69,6 & 73,3 & 78,1 & 83,0 & 87,1 \\
\hline
\end{tabular}


Tabela A.6 - Fatores de equivalência de carga por eixo tandem duplo, para índice de serventia final igual a 2,5

\begin{tabular}{|c|c|c|c|c|c|c|c|c|c|}
\hline \multirow{2}{*}{$\begin{array}{c}\text { Carga por } \\
\text { eixo (tf) }\end{array}$} & \multicolumn{9}{|c|}{ Espessura de placa $(\mathrm{cm})$} \\
\hline & 15 & 17,5 & 20 & 22,5 & 25 & 27,5 & 30 & 32,5 & 35 \\
\hline 0,9 & 0,0001 & 0,0001 & 0,0001 & 0,0001 & 0,0001 & 0,0001 & 0,0001 & 0,0001 & 0,0001 \\
\hline 1,8 & 0,0006 & 0,0006 & 0,0005 & 0,0005 & 0,0005 & 0,0005 & 0,0005 & 0,0005 & 0,0005 \\
\hline 2,7 & 0,002 & 0,002 & 0,002 & 0,002 & 0,002 & 0,002 & 0,002 & 0,002 & 0,002 \\
\hline 3,6 & 0,007 & 0,006 & 0,006 & 0,005 & 0,005 & 0,005 & 0,005 & 0,005 & 0,005 \\
\hline 4,5 & 0,015 & 0,014 & 0,013 & 0,013 & 0,012 & 0,012 & 0,012 & 0,012 & ,012 \\
\hline 5,4 & 0,031 & 0,028 & 0,026 & 0,026 & 0,025 & 0,025 & 0,025 & 0,025 & 0,025 \\
\hline 6,3 & 0,057 & 0,052 & 0,049 & 0,048 & 0,047 & 0,047 & 0,047 & 0,047 &, 047 \\
\hline 7,2 & 0,097 & 0,890 & 0,084 & 0,082 & 0,081 & 0,081 & 0,080 & 0,080 & 0,080 \\
\hline 8,2 & 0,155 & 0,148 & 0,136 & 0,133 & 0,132 & 0,131 & 0,131 & 0,131 & 0,131 \\
\hline 9,1 & 0,234 & 0,220 & 0,211 & 0,206 & 0,204 & 0,203 & 0,203 & 0,203 & 0,203 \\
\hline 10,0 & 0,340 & 0,325 & 0,313 & 0,308 & 0,305 & 0,304 & 0,303 & 0,303 & 0,303 \\
\hline 10,9 & 0,475 & 0,462 & 0,450 & 0,444 & 0,441 & 0,440 & 0,439 & 0,439 & ,439 \\
\hline 11,8 & 0,644 & 0,637 & 0,627 & 0,622 & 0,620 & 0,619 & 0,618 & 0,618 & 0,618 \\
\hline 12,7 & 0,855 & 0,854 & 0,852 & 0,850 & 0,850 & 0,850 & 0,849 & 0,849 & 0,849 \\
\hline 13,6 & 1,11 & 1,12 & 1,13 & 1,14 & 1,14 & 1,14 & 1,14 & 1,14 & 1,14 \\
\hline 14,5 & 43 & 1,44 & 1,47 & 1,49 & 1,50 & 51 & 1,51 & 51 & 1,51 \\
\hline 15,4 & 1,82 & 1,82 & 1,87 & 1,92 & 1,95 & 1,96 & 1,97 & ,97 & 1,97 \\
\hline 16,3 & 2,29 & 2,27 & 2,35 & 2,4 & 2,48 & 2,51 & 2,52 & ,52 & 2,53 \\
\hline 17,2 & 2,85 & 2,80 & 2,91 & 3, & 3,12 & 3,16 & 3,18 & ,20 & 3,20 \\
\hline 18,1 & 3,52 & 3,42 & 3,55 & 3,47 & 3,87 & 3,94 & 3,98 & 00 & 4,01 \\
\hline 19,0 & 4,32 & 16 & 4,30 & 4,55 & 4,74 & 4,86 & 4,91 & ,95 & 4,96 \\
\hline 20,0 & 6 & 1 & 5,16 & & 5,75 & 92 & 01 & 6 & 6,09 \\
\hline 20,9 & 6 & 1 & 6,14 & 3 & 6,90 & 14 & 7,28 & 36 & 7,40 \\
\hline 21 & 7,64 & 6 & 7,27 & 7,73 & 8,21 & 5 & 8,75 & 8,86 & 8,92 \\
\hline 22,7 & 9,11 & 50 & 8,55 & 9,07 & 9,68 & 10,14 & 10,42 & 10,58 & 10,86 \\
\hline 23,6 & 10,8 & 10,0 & 10,0 & 10,6 & 11,3 & 11,9 & 12,3 & 12,5 & 12,7 \\
\hline 24,5 & 12,8 & 1,8 & 11,7 & 12,3 & 13,2 & 13,9 & 14,5 & 4,8 & 14,9 \\
\hline 25,4 & 5,0 & & 13,6 & & 15,2 & 6,2 & 16,8 & 7,3 & 17,5 \\
\hline 26,3 & 17,5 & 0 & 15,7 & & 17,5 & ,6 & 19,5 & 0,1 & 20,4 \\
\hline 27,2 & & & & & 20,0 & & 22,5 & 2 & 23,6 \\
\hline 28 & 5 & & 20,8 & & 22,8 & 4 & 25,7 & 6,7 & 27,3 \\
\hline 29,0 & ,0 & 6 & 23,8 &, 4 & 25,8 & 7,7 & 29,3 & 30,5 & 31,3 \\
\hline 30,0 & 31,0 & 28,1 & 27,1 & 27,6 & 29,2 & 31,3 & 33,2 & 34,7 & 35,7 \\
\hline 30,8 & 35,4 & 2,1 & 30,9 & 1,3 & 32,9 & 5,2 & 37,5 & 9,3 & 40,5 \\
\hline 31,7 & 40,3 & 36,5 & 35,0 & & 37,0 &, 5 & 42,1 & 4,3 & 45,9 \\
\hline 32,6 & 45,7 & & 39,6 & 39 , & 41,5 & & 47,2 & 9,8 & 51,7 \\
\hline 33,6 & & & & & 46,4 & & 52,7 & 7 & 58,0 \\
\hline 34 & & & 50,2 & & 51,8 & & 58,6 & 2,1 & 64,8 \\
\hline 35,4 & 65,5 & 59,1 & 56,3 & 56,1 & 57,7 & 60,9 & 65,0 & 69,0 & 72,3 \\
\hline 36,3 & 73,4 & & 62,9 & & 64,2 & 67,5 & 71,9 & 76,4 & 80,2 \\
\hline 37,2 & 82,0 & 73,9 & 70,2 & 69,6 & 71,2 & 74,7 & 79,4 & 84,4 & 88,8 \\
\hline 38,1 & 91,4 & 82,4 & 78,1 & 77,3 & 78,9 & 82,4 & 87,4 & 93,0 & 98,1 \\
\hline 39,0 & 102 & 92 & 87 & 86 & 87 & 91 & 96 & 102 & 108 \\
\hline 39,9 & 113 & 102 & 96 & 95 & 96 & 100 & 105 & 112 & 119 \\
\hline 40,8 & 125 & 112 & 106 & 105 & 106 & 110 & 115 & 123 & 130 \\
\hline
\end{tabular}


Tabela A.7 - Fatores de equivalência de carga por eixo tandem triplo, para índice de serventia final igual a 2,5

\begin{tabular}{|c|c|c|c|c|c|c|c|c|c|}
\hline \multirow{2}{*}{$\begin{array}{c}\text { Carga por } \\
\text { eixo (tf) }\end{array}$} & \multicolumn{9}{|c|}{ Espessura de placa $(\mathrm{cm})$} \\
\hline & 15 & 17,5 & 20 & 22,5 & 25 & 27,5 & 30 & 32,5 & 35 \\
\hline 0,9 & 0,0001 & 0,0001 & 0,0001 & 0,0001 & 0,0001 & 0,0001 & 0,0001 & 0,0001 & 0,0001 \\
\hline 1,8 & 0,0003 & 0,0003 & 0,0003 & 0,0003 & 0,0003 & 0,0003 & 0,0003 & 0,0003 & 0,0003 \\
\hline 2,7 & 0,001 & 0,001 & 0,001 & 0,001 & 0,001 & 0,001 & 0,001 & 0,001 & 0,001 \\
\hline 3,6 & 0,003 & 0,003 & 0,003 & 0,003 & 0,003 & 0,003 & 0,003 & 0,003 & 0,003 \\
\hline 4,5 & 0,006 & 0,005 & 0,005 & 0,005 & 0,005 & 0,005 & 0,005 & 0,005 & 0,005 \\
\hline 5,4 & 0,011 & 0,010 & 0,010 & 0,009 & 0,009 & 0,009 & 0,009 & 0,009 & 0,009 \\
\hline 6,3 & 0,020 & 0,018 & 0,017 & 0,017 & 0,016 & 0,016 & 0,016 & 0,016 & 0,016 \\
\hline 7,2 & 0,033 & 0,030 & 0,029 & 0,028 & 0,027 & 0,027 & 0,027 & 0,027 & 0,027 \\
\hline 8,2 & 0,053 & 0,048 & 0,045 & 0,044 & 0,044 & 0,043 & 0,043 & 0,043 & 0,043 \\
\hline 9,1 & 0,080 & 0,073 & 0,069 & 0,067 & 0,066 & 0,066 & 0,066 & 0,066 & 0,066 \\
\hline 10,0 & 0,116 & 0,107 & 0,101 & 0,099 & 0,098 & 0,097 & 0,097 & 0,097 &, 097 \\
\hline 10,9 & 0,163 & 0,151 & 0,144 & 0,141 & 0,139 & 0,139 & 0,138 & 0,138 & ,138 \\
\hline 11,8 & 0,222 & 0,209 & 0,200 & 0,195 & 0,194 & 0,193 & 0,192 & 0,192 & 0,192 \\
\hline 12,7 & 0,295 & 0,281 & 0,271 & 0,265 & 0,263 & 0,262 & 0,262 & 0,262 & ,262 \\
\hline 13,6 & 0,384 & 0,371 & 0,359 & 0,354 & 0,351 & 0,350 & 0,349 & 0,349 & 349 \\
\hline 14,5 & 0,490 & 0,480 & 0,468 & 0,463 & 0,460 & 0,459 & 0,458 & 0,458 & 0,458 \\
\hline 15,4 & 0,616 & 0,609 & 0,601 & 0,596 & 0,594 & 0,593 & 0,592 & 0,592 & 0,592 \\
\hline 16,3 & 0,765 & 0,762 & 0,759 & 0,757 & 0,756 & 0,755 & 0,755 & 0,755 & 0,755 \\
\hline 17,2 & 0,939 & 0,941 & 0,946 & 0,948 & 0,950 & 0,951 & 0,951 & 0,951 & 0,951 \\
\hline 18,1 & & & & & 1,18 & 8 & 1,18 & 8 & 1,18 \\
\hline 19,0 & 38 & & 41 & 1,44 & 45 & 46 & ,46 & 46 & 1,46 \\
\hline 20,0 & 1,65 & 1,65 & 70 & 1,74 & 77 & 78 & 1,78 & 78 & 1,78 \\
\hline 20,9 & 97 & & 2,03 & 2,09 & 13 & 2,15 & 16 & 16 & 2,16 \\
\hline 21,8 & 2,34 & 2,31 & 2,40 & 2,49 &, 55 & 58 & 2,59 & 60 & 2,60 \\
\hline 22,7 & 76 & & 2,81 & 4 & 02 & 07 & 09 & 10 & 3,11 \\
\hline 23 , & 3,24 & & 3,27 & & 3,56 & 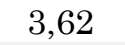 & 3,66 & 8 & 3,68 \\
\hline 24,5 & 3,79 & 6 & 3,79 & 4,00 & 4,16 & 4,26 & 4,30 & 3 & 4,34 \\
\hline 25,4 & 4,41 & 23 & 4,37 & 4,63 & 4,84 & 4,97 & 5,03 & 07 & 5,09 \\
\hline 26,3 & 12 & & 5,00 & 5,32 & 5,59 & 5,76 & 5,85 & 90 & 5,93 \\
\hline 27,2 & 5,91 & & 5,71 & 6,08 & 6,42 & 6,64 & 6,77 & 6,84 & 6,87 \\
\hline 28,1 & 6,80 & & 6,50 & & 7,33 & 7,62 & 7,79 & ,88 & 7,93 \\
\hline 2 & & & 7,37 & & 8,33 & & 8,92 & & 9,11 \\
\hline 30 & 0 & 8 & 8,33 & 8,8 & 9,42 & 8 & 10,17 & 10,33 & 10,42 \\
\hline 30,8 &, 1 & & & & 10,6 & 11,2 & 11,5 & 11,7 & 11,9 \\
\hline 31,7 &, 5 & & , & 1 & 11,9 & 12,6 & 13,0 & 3,3 & 13,5 \\
\hline 32,6 & 13,0 & 12,0 & 11,8 & 12,4 & 13,3 & 14,1 & 14,7 & 15,0 & 15,2 \\
\hline 33,6 & 14,6 & & 13,2 & 13,8 & 14,8 & 5,8 & 16,5 & 6,9 & 17,1 \\
\hline 34,5 & 16,5 & & & & 16,5 & & 18,4 & 9 & 19,2 \\
\hline 35, & (כ) & & & & 18,2 &, 5 & 20,5 & 1,1 & 21,5 \\
\hline & & & & & 20,2 & 6 & 22,7 & 3,5 & 24,0 \\
\hline 37,2 & 23,0 & & ת & & 22,2 & 23,8 & 25,2 & 6,1 & 26,7 \\
\hline 38,1 & 25,6 & 23,3 & 22,5 & 23,1 & 24,5 & 26,2 & 27,8 & 28,9 & 29,6 \\
\hline 39,0 & 28,4 & 25,8 & 24,9 & 25,4 & 26,9 & 28,8 & 30,5 & 31,9 & 32,8 \\
\hline 39,9 & 31,5 & 28,6 & 27,5 & 27,9 & 29,4 & 31,5 & 33,5 & 35,1 & 36,1 \\
\hline 40,8 & 34,8 & 31,5 & 30,3 & 30,7 & 32,2 & 34,4 & 36,7 & 38,5 & 39,8 \\
\hline
\end{tabular}


Tabela A.8 - Fatores de equivalência de carga por eixo simples, para índice de serventia final igual a 3,0

\begin{tabular}{|c|c|c|c|c|c|c|c|c|c|}
\hline Carga por & \multicolumn{10}{|c|}{ Espessura de placa $(\mathrm{cm})$} \\
\cline { 2 - 10 } eixo (tf) & 15 & 17,5 & 20 & 22,5 & 25 & 27,5 & 30 & 32,5 & 35 \\
\hline 0,9 & 0,0003 & 0,0002 & 0,0002 & 0,0002 & 0,0002 & 0,0002 & 0,0002 & 0,0002 & 0,0002 \\
1,8 & 0,003 & 0,003 & 0,002 & 0,002 & 0,002 & 0,002 & 0,002 & 0,002 & 0,002 \\
2,7 & 0,014 & 0,012 & 0,011 & 0,010 & 0,010 & 0,010 & 0,010 & 0,010 & 0,010 \\
3,6 & 0,045 & 0,038 & 0,034 & 0,033 & 0,032 & 0,032 & 0,032 & 0,032 & 0,032 \\
4,5 & 0,111 & 0,095 & 0,087 & 0,083 & 0,081 & 0,081 & 0,080 & 0,080 & 0,080 \\
5,4 & 0,228 & 0,202 & 0,186 & 0,179 & 0,176 & 0,174 & 0,174 & 0,174 & 0,173 \\
6,3 & 0,408 & 0,378 & 0,355 & 0,344 & 0,340 & 0,337 & 0,337 & 0,336 & 0,336 \\
7,2 & 0,660 & 0,640 & 0,619 & 0,608 & 0,603 & 0,600 & 0,599 & 0,599 & 0,599 \\
8,2 & 1,00 & 1,00 & 1,00 & 1,00 & 1,00 & 1,00 & 1,00 & 1,00 & 1,00 \\
9,1 & 1,46 & 1,47 & 1,52 & 1,55 & 1,57 & 1,58 & 1,58 & 1,59 & 1,59 \\
10,0 & 2,07 & 2,06 & 2,18 & 2,29 & 2,35 & 2,38 & 2,40 & 2,41 & 2,41 \\
10,9 & 2,90 & 2,81 & 3,00 & 3,23 & 3,38 & 3,47 & 3,51 & 3,53 & 3,54 \\
11,8 & 4,00 & 3,77 & 4,01 & 4,40 & 4,70 & 4,87 & 4,96 & 5,01 & 5,04 \\
12,7 & 5,43 & 4,99 & 5,23 & 5,80 & 6,31 & 6,65 & 6,83 & 6,93 & 6,98 \\
13,6 & 7,27 & 6,53 & 6,72 & 7,46 & 8,25 & 8,83 & 9,17 & 9,36 & 9,46 \\
14,5 & 9,59 & 8,47 & 8,53 & 9,42 & 10,54 & 11,44 & 12,03 & 12,37 & 12,56 \\
15,4 & 12,5 & 10,9 & 10,7 & 11,7 & 13,2 & 14,5 & 15,5 & 16,0 & 16,4 \\
16,3 & 16,0 & 13,8 & 13,4 & 14,4 & 16,2 & 18,1 & 19,5 & 20,4 & 21,0 \\
17,2 & 20,4 & 17,4 & 16,7 & 17,7 & 19,8 & 22,2 & 24,2 & 25,6 & 26,4 \\
18,1 & 25,6 & 21,8 & 20,6 & 21,5 & 23,8 & 26,8 & 29,5 & 31,5 & 32,9 \\
19,0 & 31,8 & 26,9 & 25,3 & 26,0 & 28,5 & 32,0 & 35,5 & 38,4 & 40,3 \\
20,0 & 39,2 & 33,1 & 30,8 & 31,3 & 33,9 & 37,9 & 42,3 & 46,1 & 48,8 \\
20,9 & 47,8 & 40,3 & 37,2 & 37,5 & 40,1 & 44,5 & 49,8 & 54,7 & 58,5 \\
21,8 & 57,9 & 48,6 & 44,8 & 44,7 & 47,3 & 52,1 & 58,2 & 64,3 & 69,4 \\
22,7 & 69,6 & 58,4 & 53,6 & 53,1 & 55,6 & 60,6 & 67,6 & 75,0 & 81,4 \\
\hline
\end{tabular}


Tabela A.9 - Fatores de equivalência de carga por eixo tandem duplo, para índice de serventia final igual a 3,0

\begin{tabular}{|c|c|c|c|c|c|c|c|c|c|}
\hline \multirow{2}{*}{$\begin{array}{c}\text { Carga por } \\
\text { eixo (tf) }\end{array}$} & \multicolumn{9}{|c|}{ Espessura de placa $(\mathrm{cm})$} \\
\hline & 15 & 17,5 & 20 & 22,5 & 25 & 27,5 & 30 & 32,5 & 35 \\
\hline 0,9 & 0,0001 & 0,0001 & 0,0001 & 0,0001 & 0,0001 & 0,0001 & 0,0001 & 0,0001 & 0,0001 \\
\hline 1,8 & 0,0007 & 0,0006 & 0,0005 & 0,0005 & 0,0005 & 0,0005 & 0,0005 & 0,0005 & 0,0005 \\
\hline 2,7 & 0,003 & 0,002 & 0,002 & 0,002 & 0,002 & 0,002 & 0,002 & 0,002 & 0,002 \\
\hline 3,6 & 0,008 & 0,006 & 0,006 & 0,006 & 0,005 & 0,005 & 0,005 & 0,005 & 0,005 \\
\hline 4,5 & 0,018 & 0,015 & 0,013 & 0,013 & 0,013 & 0,012 & 0,012 & 0,012 & 0,012 \\
\hline 5,4 & 0,036 & 0,030 & 0,027 & 0,026 & 0,026 & 0,025 & 0,025 & 0,025 &, 025 \\
\hline 6,3 & 0,066 & 0,056 & 0,050 & 0,048 & 0,047 & 0,047 & 0,047 & 0,047 &, 047 \\
\hline 7,2 & 0,111 & 0,095 & 0,087 & 0,083 & 0,081 & 0,081 & 0,081 & 0,080 & ,080 \\
\hline 8,2 & 0,174 & 0,153 & 0,140 & 0,135 & 0,132 & 0,131 & 0,131 & 0,131 & 0,131 \\
\hline 9,1 & 0,260 & 0,234 & 0,217 & 0,209 & 0,205 & 0,204 & 0,203 & 0,203 & 0,203 \\
\hline 10,0 & 0,368 & 0,341 & 0,321 & 0,311 & 0,307 & 0,305 & 0,304 & 0,303 & 0,303 \\
\hline 10,9 & 0,502 & 0,479 & 0,458 & 0,447 & 0,443 & 0,440 & 0,440 & 0,439 & ,439 \\
\hline 11,8 & 0,664 & 0,651 & 0,634 & 0,625 & 0,621 & 0,619 & 0,618 & 0,618 & 0,618 \\
\hline 12,7 & 0,859 & 0,857 & 0,853 & 0,851 & 0,850 & 0,850 & 0,850 & 0,849 & 0,849 \\
\hline 13,6 & 1,09 & 1,10 & 1,12 & 1,13 & 1,14 & 1,14 & 1,14 & 1,14 & 1,14 \\
\hline 14,5 & 38 & 1,38 & 1,44 & 1,47 & 1,49 & 50 & 1,51 & 51 & 1,51 \\
\hline 15,4 & 1,72 & 1,71 & 1,80 & 1,88 & 1,93 & 1,95 & 1,96 & 97 & 1,97 \\
\hline 16,3 & 2,13 & 2,10 & 2,23 & & 2,45 & 2,49 & 2,51 & ,52 & 2,52 \\
\hline 17,2 & 2,62 & 54 & 2,71 & 2, & 3,06 & 13 & 3,17 & 19 & 3,20 \\
\hline 18,1 & 3,21 & 05 & 3,26 & 3,55 & 3,76 & 3,89 & 3,95 & 98 & 4,00 \\
\hline 19,0 & 3,90 & 65 & 3,87 & 4,26 & 4,58 & 4,77 & 4,87 & ,92 & 4,95 \\
\hline 20 , & 2 & 35 & 4,57 & & ,50 & 78 &, 94 & 2 & 6,06 \\
\hline 20,9 & 8 & & 5,36 & & 6,54 & 94 & 7,17 & 29 & 7,36 \\
\hline 2 & 0 & 0 & 6,25 & & 7,69 & 24 & 8,57 & 8,76 & 8,86 \\
\hline 22,7 & 8,09 & 17 & 7,26 & 8,03 & 8,96 & 9,70 & 10,17 & 10,43 & 10,58 \\
\hline 23,6 & 9,57 & 8,41 & 8,40 & 9,24 & 10,36 & 11,32 & 11,96 & 12,33 & 12,54 \\
\hline 24,5 & 11,3 & 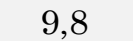 & 9,7 & 10,6 & 11,9 & 13,1 & 14,0 & 14,5 & 14,8 \\
\hline 25,4 & 3,2 & 4 & 11,2 & & 3,6 & 5,1 & 16,2 & 6,9 & 17,3 \\
\hline 26,3 & 15,4 & & 12,8 & & 5,4 &, 2 & 18,6 & 9,5 & 20,1 \\
\hline $2^{\prime}$ & & & & & 17,4 & & 21,3 & 5 & 23,2 \\
\hline 2 & 20,6 & & 8 & & 6 & 0 & 1 & 7 & 26,6 \\
\hline 29,0 &, 7 &, 2 & 19,1 & 19,9 & 22,0 & 4,7 & 27,3 & 29,2 & 30,4 \\
\hline 30,0 & 27,2 & 3,1 & 21,7 & 22,4 & 24,6 & 27,6 & 30,6 & 33,0 & 34,6 \\
\hline 30,8 & , 1 & & 24,6 & & 27,4 & 0,8 & 34,3 & 7,1 & 39,2 \\
\hline 31,7 & 35,4 & 29,8 & 27,8 & 28,2 & 30,6 & 34,2 & 38,2 & 1,6 & 44,1 \\
\hline 32,6 & 40,1 & & 31,3 & & 34,0 & & 42,3 & 6,4 & 49,4 \\
\hline 33, & & & & & 37,7 & & 46,8 & & 55,2 \\
\hline & & & 39 & & 41,8 & & 51,5 & 6,9 & 61,3 \\
\hline 35,4 & 57,4 & & 44,3 & 44 & 46,3 & 50,7 & 56,6 & 62,7 & 67,9 \\
\hline 36,3 & 3 & & 49,4 & & 51,1 & 8 & 62,1 & 8,9 & 74,9 \\
\hline 37,2 & 71,8 & 60,2 & 55,1 & 54,3 & 56,5 & 61,2 & 67,9 & 75,5 & 82,4 \\
\hline 38,1 & 80,0 & 67,0 & 61,2 & 60,2 & 62,2 & 67,0 & 74,2 & 82,4 & 90,3 \\
\hline 39,0 & 89,0 & 74,5 & 67,9 & 66,5 & 68,5 & 73,4 & 80,8 & 89,8 & 98,7 \\
\hline 39,9 & 98,7 & 82,5 & 75,2 & 73,5 & 75,3 & 80,2 & 88,0 & 97,7 & 107,5 \\
\hline 40,8 & 109 & 91 & 83 & 81 & 83 & 88 & 96 & 106 & 117 \\
\hline
\end{tabular}


Tabela A.10 - Fatores de equivalência de carga por eixo tandem triplo, para índice de serventia final igual a 3,0

\begin{tabular}{|c|c|c|c|c|c|c|c|c|c|}
\hline \multirow{2}{*}{$\begin{array}{c}\text { Carga por } \\
\text { eixo (tf) }\end{array}$} & \multicolumn{9}{|c|}{ Espessura de placa (cm) } \\
\hline & 15 & 17,5 & 20 & 22,5 & 25 & 27,5 & 30 & 32,5 & 35 \\
\hline 0,9 & 0,0001 & 0,0001 & 0,0001 & 0,0001 & 0,0001 & 0,0001 & 0,0001 & 0,0001 & 0,0001 \\
\hline 1,8 & 0,0004 & 0,0003 & 0,0003 & 0,0003 & 0,0003 & 0,0003 & 0,0003 & 0,0003 & 0,0003 \\
\hline 2,7 & 0,001 & 0,001 & 0,001 & 0,001 & 0,001 & 0,001 & 0,001 & 0,001 & 0,001 \\
\hline 3,6 & 0,003 & 0,003 & 0,002 & 0,002 & 0,002 & 0,002 & 0,002 & 0,002 & 0,002 \\
\hline 4,5 & 0,007 & 0,006 & 0,005 & 0,005 & 0,005 & 0,005 & 0,005 & 0,005 &, 005 \\
\hline 5,4 & 0,013 & 0,011 & 0,010 & 0,009 & 0,009 & 0,009 & 0,009 & 0,009 & ,009 \\
\hline 6,3 & 0,023 & 0,020 & 0,018 & 0,017 & 0,017 & 0,016 & 0,016 & 0,016 &, 016 \\
\hline 7,2 & 0,039 & 0,033 & 0,030 & 0,028 & 0,028 & 0,027 & 0,027 & 0,027 & 0,027 \\
\hline 8,2 & 0,061 & 0,052 & 0,047 & 0,045 & 0,044 & 0,044 & 0,043 & 0,043 & 0,043 \\
\hline 9,1 & 0,091 & 0,078 & 0,071 & 0,068 & 0,067 & 0,066 & 0,066 & 0,066 &, 066 \\
\hline 10,0 & 0,132 & 0,114 & 0,104 & 0,100 & 0,098 & 0,097 & 0,097 & 0,097 &, 097 \\
\hline 10,9 & 0,183 & 0,161 & 0,148 & 0,143 & 0,140 & & 0,139 & 0,138 & ,138 \\
\hline 11,8 & 0,246 & 0,221 & 0,205 & 0,198 & 0,195 & 93 & 0,193 & 0,193 &, 193 \\
\hline 12,7 & 0,322 & 0,296 & 0,277 & 0,268 & 0,265 & 0,263 & 0,262 & 0,262 &, 262 \\
\hline 13,6 & 0,411 & 0,387 & 0,367 & 0,357 & 0,353 & 0,351 & 0,350 & 0,349 & 0,349 \\
\hline 14,5 & 0,515 & 0,495 & 0,476 & 0,466 & 0,462 & 0,460 & 0,459 & 0,458 & 0,458 \\
\hline 15,4 & 0,634 & 0,622 & 0,607 & 0,599 & 0,595 & 0,594 & 0,593 & 0,592 & 0,592 \\
\hline 16,3 & 0,772 & 0,768 & 0,762 & 0,758 & 0,756 & & 0,755 & 0,755 & 0,755 \\
\hline 17,2 & 0,930 & 0,934 & 0,942 & 0,947 & 0,949 & 0,950 & 0,951 & 0,951 & 0,951 \\
\hline 18,1 & 1,11 & & 1,15 & 1,17 & 1,18 & 1 & 1,18 & 1,18 & 1,18 \\
\hline 19,0 & 32 & 33 & 1,38 & 1,42 & ,44 & 45 &, 46 & ,46 & 1,46 \\
\hline 20,0 & 56 & & 64 & 71 & ,75 & 77 & 1,78 &, 78 & 1,78 \\
\hline 20,9 & 84 & 1,83 & 1,94 & 2,04 & , 10 & 14 &, 15 & ,16 & 2,16 \\
\hline 21,8 & 16 & 2,12 & 2,26 & & ,51 & 56 & 2,58 & ,59 & 2,60 \\
\hline 22,7 & 2,53 & & 2,61 & & ,96 & 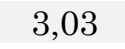 & 3,07 & ,09 & 3,10 \\
\hline 23,6 & 2,95 & 32 & 3,01 & 3,27 & 3,47 & 3,58 & 3,63 & 66 & 3,68 \\
\hline 24,5 & 3,43 & 23 & 3,43 & 3,77 & 4,03 & 4,18 & 4,27 & 4,31 & 4,33 \\
\hline 25,4 & 98 & & 3,90 & 4,3 & 4,65 & 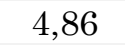 & 4,98 & ,04 & 5,07 \\
\hline 26,3 & 4,59 & 4,22 & 4,42 & 4,90 & 5,34 & 5,62 & 5,78 & 86 & 5,90 \\
\hline 27,2 & & & 400 & & 6,08 & & 6,66 & ,78 & 6,84 \\
\hline 28,1 & & & & & 9 & & 7,64 & ,80 & 7,88 \\
\hline 29 & & & $c$ & & 7,76 & U & 8,72 & 8,93 & 9,04 \\
\hline 30,0 & 39 & & 7,05 & 7,78 & 8,70 & 9,44 & 9,91 & 10,18 & 10,33 \\
\hline $30, \varepsilon$ & 8,96 & $7, \varepsilon$ & 7,87 & 8,6 & 9,71 & 10,61 & 11,20 & 11,55 & 11,75 \\
\hline 31,7 & 10,2 & & 8, & & 10,8 & 11,9 & 12,6 & 13,1 & 13,3 \\
\hline 32,6 & 11,5 & 10,0 & 9,8 & 10,6 & 12,0 & 3,2 & 14,1 & 4,7 & 15,0 \\
\hline 33,6 & 12,9 & & 10,9 & & 13,2 & & 15,8 & 6,5 & 16,9 \\
\hline 34 , & & & 12,1 & & 14,5 & & 17,5 & & 18,9 \\
\hline 3 & & & & & 15,9 & 17 , & 19,4 & 0,5 & 21,1 \\
\hline & & & & & 17,4 & U & 21,4 & 22,7 & 23,5 \\
\hline 37 , & 2 & & 16 & & 19,1 & 1,4 & 23,5 & 25,1 & 26,1 \\
\hline 38,1 & 22,5 & 19,1 & 18,1 & 18,8 & 20,8 & 23,4 & 25,8 & 27,6 & 28,8 \\
\hline 39,0 & 25,0 & 21,2 & 19,9 & 20,6 & 22,6 & 25,5 & 28,2 & 30,4 & 31,8 \\
\hline 39,9 & 27,6 & 23,4 & 21,9 & 22,5 & 24,6 & 27,7 & 30,7 & 33,2 & 35,0 \\
\hline 40,8 & 30,5 & 25,8 & 24,1 & 24,6 & 26,8 & 30,0 & 33,4 & 36,3 & 38,3 \\
\hline
\end{tabular}


Tabela A.11 - Nível de confiabilidade, R, DNER (1989)

\begin{tabular}{|c|c|}
\hline Tipo de estrada & $\mathrm{R}(\%)$ \\
\hline Local & 50 \\
Coletora & 60 \\
Primária & 75 \\
Auto-estrada & 80 \\
Pavimentos de difícil manutencão, túneis, etc. & 85 \\
\hline
\end{tabular}

Tabela A.12 - Coeficiente de Student e fator de segurança de carga, DNER (1989)

\begin{tabular}{|c|c|c|c|c|}
\hline $\mathrm{R}$ & $\mathrm{Z}_{\mathrm{r}}$ & \multicolumn{3}{|c|}{$\mathrm{F}$} \\
\cline { 3 - 5 }$(\%)$ & & $\mathrm{S}_{\mathrm{o}}=0,30$ & $\mathrm{~S}_{\mathrm{o}}=0,35$ & $\mathrm{~S}_{\mathrm{o}}=0,40$ \\
\hline 50 & 0,000 & 1,00 & 1,00 & 1,00 \\
60 & 0,253 & 1,19 & 1,23 & 1,26 \\
70 & 0,524 & 1,44 & 1,53 & 1,62 \\
75 & 0,674 & 1,59 & 1,72 & 1,86 \\
80 & 0,841 & 1,79 & 1,97 & 2,17 \\
85 & 1,037 & 2,05 & 2,31 & 2,60 \\
90 & 1,282 & 2,42 & 2,81 & 3,26 \\
92 & 1,405 & 2,64 & 3,10 & 3,65 \\
94 & 1,555 & 2,93 & 3,50 & 4,19 \\
95 & 1,645 & 3,12 & 3,76 & 4,55 \\
96 & 1,751 & 3,35 & 4,10 & 5,02 \\
98 & 2,054 & 4,13 & 5,23 & 6,63 \\
99 & 2,327 & 4,99 & 6,52 & 8,53 \\
99,99 & 3,750 & 13,34 & 20,54 & 31,63 \\
\hline
\end{tabular}

Tabela A.13 - Coeficiente de drenagem, $\mathrm{C}_{\mathrm{d}}$, DNER (1989)

\begin{tabular}{|c|c|c|c|c|c|}
\hline \multirow[t]{2}{*}{$\begin{array}{c}\text { Eficiência da } \\
\text { drenagem }\end{array}$} & \multirow{2}{*}{$\begin{array}{l}\text { Tempo de } \\
\text { remoção da } \\
\text { água }\end{array}$} & \multicolumn{4}{|c|}{$\begin{array}{c}\text { Porcentagem do tempo em que a estrutura estará exposta } \\
\text { a níveis de umidade próximos à saturação }\end{array}$} \\
\hline & & $<1 \%$ & $1 \%$ a $5 \%$ & $5 \%$ a $25 \%$ & $>25 \%$ \\
\hline Excelente & 2 horas & $1,20-1,25$ & $1,15-1,20$ & $1,10-1,15$ & 1,10 \\
\hline Boa & 24 horas & $1,15-1,20$ & $1,10-1,15$ & $1,00-1,10$ & 1,00 \\
\hline Regular & 1 semana & $1,10-1,15$ & $1,00-1,10$ & $0,90-1,00$ & 0,90 \\
\hline Má & 4 semanas & $1,00-1,10$ & $0,90-1,00$ & $0,80-0,90$ & 0,80 \\
\hline Muito má & não drena & $0,90-1,00$ & $0,80-0,90$ & $0,70-0,80$ & 0,70 \\
\hline
\end{tabular}

Tabela A.14a - Faixa de valores da perda de suporte para diferentes tipos de sub-bases, DNER (1989)

\begin{tabular}{|c|c|}
\hline Material & $\mathrm{p}_{\mathrm{s}}$ \\
\hline Sub-base tratada com cimento, estrutural & $0,00-0,50$ \\
Sub-base tratada com asfalto & $0,00-0,50$ \\
Brita tratada com cimento, não estrutural & $0,50-1,00$ \\
Brita tratada com asfalto, não estrutural & $0,50-1,00$ \\
Sub-base granular & $1,00-2,00$ \\
Materiais de graduação fina & $2,00-3,00$ \\
\hline
\end{tabular}


Tabela A.14b - Faixa de valores da perda de suporte para diferentes tipos de sub-bases, adaptado de AASHTO (1986)

\begin{tabular}{|c|c|}
\hline Material & $\mathrm{p}_{\mathrm{s}}$ \\
\hline $\begin{array}{l}\text { Sub-base granular tratada com cimento } \\
\quad(\mathrm{E}=1.000 .000 \text { a } 2.000 .000 \mathrm{psi})\end{array}$ & $0,0-1,0$ \\
\hline $\begin{array}{l}\text { Mistura de cimento e agregado } \\
(\mathrm{E}=500.000 \text { a } 1.000 .000 \mathrm{psi})\end{array}$ & $0,0-1,0$ \\
\hline $\begin{array}{l}\text { Sub-base tratada com asfalto } \\
(\mathrm{E}=350.000 \text { a } 1.000 .000 \mathrm{psi})\end{array}$ & $0,0-1,0$ \\
\hline $\begin{array}{l}\text { Mistura betuminosa estabilizada } \\
\qquad(\mathrm{E}=40.000 \text { a } 300.000 \mathrm{psi})\end{array}$ & $0,0-1,0$ \\
\hline $\begin{array}{c}\text { Sub-base granular } \\
(\mathrm{E}=15.000 \text { a } 45.000 \mathrm{psi})\end{array}$ & $1,0-3,0$ \\
\hline $\begin{array}{l}\text { Materiais de graduação fina } \\
\quad(\mathrm{E}=3.000 \mathrm{a} 40.000 \mathrm{psi})\end{array}$ & $2,00-3,00$ \\
\hline
\end{tabular}

Tabela A.15 - Coeficiente de transferência de carga, J, DNER (1989)

\begin{tabular}{|c|c|c|c|c|c|}
\hline \multirow{2}{*}{$\begin{array}{c}\text { Dispositivo de } \\
\text { transferência de } \\
\text { carga } \\
\end{array}$} & \multirow[t]{2}{*}{$\begin{array}{l}\text { Acostamento de } \\
\text { concreto }\end{array}$} & \multirow[t]{2}{*}{$\begin{array}{l}\text { Tipo de } \\
\text { sub-base }\end{array}$} & \multirow[t]{2}{*}{$\begin{array}{l}\text { Condição } \\
\text { climática }\end{array}$} & \multicolumn{2}{|c|}{$\mathrm{J}$} \\
\hline & & & & $4,5 \mathrm{~m}$ & 4,6 a $6,0 \mathrm{~m}$ \\
\hline \multirow[t]{8}{*}{ Não } & \multirow[t]{4}{*}{ não } & \multirow[t]{2}{*}{ gr } & rigorosa & 4,0 & 4,4 \\
\hline & & & leve & 3,8 & 4,2 \\
\hline & & \multirow[t]{2}{*}{ tcc } & rigorosa & 3,6 & 4,0 \\
\hline & & & leve & 3,4 & 3,8 \\
\hline & \multirow[t]{4}{*}{$\operatorname{sim}$} & \multirow[t]{2}{*}{ gr } & rigorosa & 3,4 & 3,8 \\
\hline & & & leve & 3,2 & 3,6 \\
\hline & & \multirow[t]{2}{*}{ tcc } & rigorosa & 3,0 & 3,4 \\
\hline & & & leve & 2,8 & 3,2 \\
\hline \multirow[t]{8}{*}{ Sim } & \multirow[t]{4}{*}{ não } & \multirow[t]{2}{*}{ gr } & rigorosa & 3,0 & 3,2 \\
\hline & & & leve & 2,9 & 3,0 \\
\hline & & \multirow[t]{2}{*}{ tcc } & rigorosa & 2,7 & 2,9 \\
\hline & & & leve & 2,6 & 2,7 \\
\hline & \multirow[t]{4}{*}{$\operatorname{sim}$} & \multirow[t]{2}{*}{ gr } & rigorosa & 2,9 & 3,1 \\
\hline & & & leve & 2,8 & 2,9 \\
\hline & & \multirow[t]{2}{*}{ tcc } & rigorosa & 2,6 & 2,8 \\
\hline & & & leve & 2,5 & 2,5 \\
\hline
\end{tabular}

Tabela A.16 - Coeficientes de segurança de carga, FSC, PCA (1966)

Auto-estradas, rodovias com mais de duas faixas por pista, ou qualquer projeto para tráfego ininterrupto ou de grande volume de caminhões pesados

Rodovias e vias urbanas submetidas a tráfego de caminhões pesados

Estradas rurais, ruas residenciais e vias em geral, $\mathrm{F}_{\mathrm{SC}}$
1,2 submetidas a tráfego de caminhões leves

\begin{tabular}{|c|}
\hline $\mathrm{F}_{\mathrm{SC}}$ \\
1,2 \\
1,1 \\
1,0 \\
\hline
\end{tabular}


Tabela A.17 - R $\mathrm{T}$ x N, PCA (1966)

\begin{tabular}{|c|c|c|c|}
\hline Relação de tensões & $\begin{array}{c}\mathrm{N}_{\text {adm }} \begin{array}{c}\text { de repetições de } \\
\text { carga }\end{array} \\
\text { Relação de tensões }\end{array}$ & $\begin{array}{c}\mathrm{N}_{\text {adm de repetições de }} \\
\text { carga }\end{array}$ \\
\hline 0.50 & ilimitado & 0,68 & 3.500 \\
0.51 & 400.000 & 0,69 & 2.500 \\
0.52 & 300.000 & 0,70 & 2.000 \\
0.53 & 240.000 & 0,71 & 1.500 \\
0.54 & 180.000 & 0,72 & 1.100 \\
0.55 & 130.000 & 0,73 & 850 \\
0.56 & 100.000 & 0,74 & 650 \\
0.57 & 75.000 & 0,75 & 490 \\
0.58 & 57.000 & 0,76 & 360 \\
0.59 & 42.000 & 0,77 & 270 \\
0.60 & 32.000 & 0,78 & 210 \\
0.61 & 24.000 & 0,79 & 160 \\
0.62 & 18.000 & 0,80 & 120 \\
0.63 & 14.000 & 0,81 & 90 \\
0.64 & 11.000 & 0,82 & 70 \\
0.65 & 8.000 & 0,83 & 50 \\
0.66 & 6.000 & 0,84 & 40 \\
0.67 & 4.500 & 0,85 & 30 \\
\hline
\end{tabular}

Tabela A.18 - Tensão equivalente - Sem acostamento de concreto, PITTA (1996)

\begin{tabular}{|c|c|c|c|c|c|c|c|c|c|c|c|c|c|c|c|c|c|c|}
\hline \multirow[t]{3}{*}{$\mathrm{h}$} & \multicolumn{18}{|c|}{$\mathrm{k}$ do sistema subleito - sub-base $(\mathrm{MPa} / \mathrm{m})$} \\
\hline & \multicolumn{3}{|c|}{20} & \multicolumn{3}{|c|}{40} & \multicolumn{3}{|c|}{60} & \multicolumn{3}{|c|}{80} & \multicolumn{3}{|c|}{140} & \multicolumn{3}{|c|}{180} \\
\hline & ES & $\mathrm{TD}$ & $\mathrm{TT}$ & ES & $\mathrm{TD}$ & $\mathrm{TT}$ & ES & TD & $\mathrm{TT}$ & ES & TD & $\mathrm{TT}$ & ES & TD & $\mathrm{TT}$ & ES & $\mathrm{TD}$ & $\mathrm{TT}$ \\
\hline 10 & 5,42 & 4,39 & 3,36 & 4,75 & 3,83 & 3,10 & 4,38 & 3,59 & 3,02 & 4,13 & 3,44 & 2,98 & 3,66 & 3,22 & 2,94 & 3,45 & 3,15 & 2,93 \\
\hline 11 & 4,47 & 3,88 & 2,92 & 4,16 & 3,35 & 2,64 & 3,85 & 3,12 & 2,55 & 3,63 & 2,97 & 2,50 & 3,23 & 2,76 & 2,45 & 3,06 & 2,68 & 2,44 \\
\hline 12 & 4,19 & 3,47 & 2,60 & 3,69 & 2,98 & 2,30 & 3,41 & 2,75 & 2,20 & 3,23 & 2,62 & 2,14 & 2,88 & 2,40 & 2,08 & 2,73 & 2,33 & 2,07 \\
\hline 13 & 3,75 & 3,14 & 2,35 & 3,30 & 2,68 & 2,04 & 3,06 & 2,46 & 1,93 & 2,89 & 2,33 & 1,87 & 2,59 & 2,13 & 1,80 & 2,46 & 2,05 & 1,78 \\
\hline 14 & 3,37 & 2,87 & 2,15 & 2,97 & 2,43 & \begin{tabular}{|l}
1,83 \\
\end{tabular} & 2,76 & 2,23 & 1,72 & 2,61 & 2,10 & 1,65 & 2,34 & 1,90 & 1,58 & 2,23 & 1,83 & 1,55 \\
\hline 15 & 3,06 & 2,64 & 1,99 & 2,70 & 2,23 & 1,67 & 2,51 & 2,04 & 1,55 & 2,37 & 1,92 & 1,48 & 2,13 & 1,72 & 1,40 & 2,03 & 1,65 & 1,37 \\
\hline 16 & 2,79 & 2,45 & 1,85 & 2,47 & 2,06 & 1,54 & 2,29 & 1,87 & 1,41 & 2,17 & 1,76 & 1,34 & 1,95 & 1,57 & 1,25 & 1,86 & 1,50 & 1,23 \\
\hline 17 & 2,56 & 2,28 & 1,73 & 2,26 & 1,91 & 1,43 & 2,10 & 1,74 & 1,30 & 1,99 & 1,63 & 1,23 & 1,80 & 1,45 & 1,14 & 1,71 & 1,38 & 1,11 \\
\hline 18 & 2,37 & 2,14 & 1,62 & 2,09 & 1,79 & 1,34 & 1,94 & 1,62 & 1,21 & 1,84 & 1,51 & 1,14 & 1,66 & 1,34 & 1,04 & 1,58 & 1,27 & 1,01 \\
\hline 19 & 2,19 & 2,01 & 1,53 & 1,94 & 1,67 & 1,26 & 1,80 & 1,51 & 1,13 & 1,71 & 1,41 & 1,06 & 1,54 & 1,25 & 0,96 & 1,47 & 1,18 & 0,92 \\
\hline 20 & 2,04 & 1,90 & 1,45 & 1,80 & 1,58 & \begin{tabular}{|l}
1,19 \\
\end{tabular} & 1,67 & 1,42 & 1,07 & 1,59 & 1,33 & 0,99 & 1,43 & 1,17 & 0,89 & 1,37 & 1,11 & 0,85 \\
\hline 21 & 1,91 & 1,79 & 1,37 & 1,68 & 1,49 & 1,13 & 1,56 & 1,34 & 1,01 & 1,48 & 1,25 & 0,93 & 1,34 & 1,10 & 0,83 & 1,28 & 1,04 & 0,79 \\
\hline 22 & 1,79 & 1,70 & 1,30 & 1,57 & 1,41 & 1,07 & 1,46 & 1,27 & 0,95 & 1,39 & 1,18 & 0,88 & 1,26 & 1,03 & 0,78 & 1,20 & 0,98 & 0,74 \\
\hline 23 & 1,68 & 1,62 & 1,24 & 1,48 & 1,34 & 1,02 & 1,38 & 1,21 & 0,91 & 1,31 & 1,12 & 0,84 & 1,18 & 0,98 & 0,73 & 1,13 & 0,92 & 0,70 \\
\hline 24 & 1,58 & 1,55 & 1,18 & 1,39 & 1,28 & $\mid 0,97$ & 1,30 & 1,15 & 0,87 & 1,23 & 1,06 & 0,80 & 1,11 & 0,93 & 0,69 & 1,06 & 0,87 & 0,66 \\
\hline 25 & 1,49 & 1,48 & 1,13 & 1,32 & 1,22 & 0,93 & 1,22 & 1,09 & 0,83 & 1,16 & 1,01 & 0,76 & 1,05 & 0,88 & 0,66 & 1,00 & 0,83 & 0,62 \\
\hline 26 & 1,41 & 1,41 & 1,07 & 1,25 & 1,17 & $\mid 0,89$ & 1,16 & 1,05 & 0,79 & 1,10 & 0,97 & 0,73 & 0,99 & 0,84 & 0,63 & 0,95 & 0,79 & 0,59 \\
\hline 27 & 1,34 & 1,36 & 1,02 & 1,18 & 1,12 & 0,86 & 1,10 & 1,00 & 0,76 & 1,04 & 0,93 & 0,70 & 0,94 & 0,80 & 0,60 & 0,90 & 0,75 & 0,57 \\
\hline 28 & 1,28 & 1,30 & 0,98 & 1,12 & 1,07 & |0,82 & 1,04 & 0,96 & 0,73 & 0,99 & 0,89 & 0,67 & 0,89 & 0,77 & 0,58 & 0,86 & 0,72 & 0,54 \\
\hline 29 & 1,22 & 1,25 & 0,93 & 1,07 & 1,03 & 0,79 & 0,99 & 0,92 & 0,71 & 0,94 & 0,85 & 0,65 & 0,85 & 0,74 & 0,55 & 0,81 & 0,69 & 0,52 \\
\hline 30 & 1,16 & 1,21 & 0,89 & 1,02 & 0,99 & $\mid 0,76$ & 0,95 & 0,89 & 0,68 & 0,90 & 0,82 & 0,63 & 0,81 & 0,71 & 0,53 & 0,78 & 0,66 & 0,50 \\
\hline 31 & 1,11 & 1,16 & 0,85 & 0,97 & 0,96 & 0,73 & 0,90 & 0,86 & 0,66 & 0,86 & 0,79 & 0,60 & 0,77 & 0,68 & 0,51 & 0,74 & 0,64 & 0,48 \\
\hline 32 & 1,06 & 1,12 & 0,81 & 0,93 & 0,92 & $\mid 0,70$ & 0,86 & 0,83 & 0,63 & 0,82 & 0,76 & 0,58 & 0,74 & 0,66 & 0,50 & 0,71 & 0,62 & 0,46 \\
\hline 33 & 1,02 & 1,09 & 0,77 & 0,89 & 0,89 & $\mid 0,68$ & 0,83 & 0,80 & 0,61 & 0,78 & 0,74 & 0,56 & 0,71 & 0,63 & 0,48 & 0,68 & 0,59 & 0,45 \\
\hline 34 & 0,98 & 1,05 & 0,73 & 0,85 & 0,86 & 0,65 & 0,79 & 0,77 & 0,59 & 0,75 & 0,71 & 0,55 & 0,68 & 0,61 & 0,46 & 0,65 & 0,57 & 0,43 \\
\hline 35 & 0,94 & 1,02 & 0,70 & 0,82 & 0,84 & 0,63 & 0,76 & 0,75 & 0,57 & 0,72 & 0,69 & 0,53 & 0,65 & 0,59 & 0,45 & 0,62 & 0,55 & 0,42 \\
\hline
\end{tabular}

ES - eixo simples; TD - eixo tandem duplo; TT - eixo tandem triplo 
Tabela A.19 - Tensão equivalente - Com acostamento de concreto, , PITTA (1996)

\begin{tabular}{|c|c|c|c|c|c|c|c|c|c|c|c|c|c|c|c|c|c|c|}
\hline \multirow[t]{3}{*}{$\mathrm{H}$} & \multicolumn{18}{|c|}{$\mathrm{k}$ do sistema subleito - sub-base $(\mathrm{MPa} / \mathrm{m})$} \\
\hline & \multicolumn{3}{|c|}{20} & \multicolumn{3}{|c|}{40} & \multicolumn{3}{|c|}{60} & \multicolumn{3}{|c|}{80} & \multicolumn{3}{|c|}{140} & \multicolumn{3}{|c|}{180} \\
\hline & $\mathrm{ES}$ & $\mathrm{TD}$ & $\mathrm{TT}$ & $\mathrm{ES}$ & $\mathrm{TD}$ & $\mathrm{TT}$ & $\mathrm{ES}$ & $\mathrm{TD}$ & $\mathrm{TT}$ & $\mathrm{ES}$ & $\mathrm{TD}$ & $\mathrm{TT}$ & $\mathrm{ES}$ & TD & $\mathrm{TT}$ & $\mathrm{ES}$ & TD & $\mathrm{TT}$ \\
\hline 10 & 4,18 & 3,48 & 2,87 & 3,65 & 3,10 & 2,67 & 3,37 & 2,94 & 2,60 & 3,19 & 2,85 & 2,57 & 2,85 & 2,74 & 2,56 & 2,72 & 2,72 & 2,57 \\
\hline 11 & 3,68 & 3,07 & 2,50 & 3,23 & 2,71 & 2,29 & 2,99 & 2,56 & 2,22 & 2,83 & 2,47 & 2,18 & 2,55 & 2,35 & 2,16 & 2,43 & 2,32 & 2,16 \\
\hline 12 & 3,28 & 2,75 & 2,20 & 2,88 & 2,41 & 2,00 & 2,67 & 2,26 & 1,93 & 2,54 & 2,17 & 1,89 & 2,29 & 2,05 & 1,85 & 2,19 & 2,02 & 1,85 \\
\hline 13 & 2,95 & 2,49 & 1,97 & 2,60 & 2,17 & 1,78 & 2,41 & 2,02 & 1,70 & 2,29 & 1,94 & 1,66 & 2,07 & 1,82 & 1,61 & 1,99 & 1,78 & 1,61 \\
\hline 14 & 2,68 & 2,27 & 1,78 & 2,36 & 1,97 & 1,59 & 2,19 & 1,83 & 1,52 & 2,08 & 1,75 & 1,48 & 1,89 & 1,63 & 1,43 & 1,81 & 1,59 & 1,42 \\
\hline 15 & 2,44 & 2,08 & 1,62 & 2,15 & 1,80 & 1,44 & 2,00 & 1,67 & 1,37 & 1,90 & 1,59 & 1,33 & 1,73 & 1,48 & 1,27 & 1,66 & 1,44 & 1,26 \\
\hline 16 & 2,24 & 1,93 & 1,49 & 1,97 & 1,66 & 1,32 & 1,84 & 1,53 & 1,24 & 1,75 & 1,46 & 1,20 & 1,59 & 1,35 & 1,15 & 1,53 & 1,31 & 1,13 \\
\hline 17 & 2,06 & 1,79 & 1,38 & 1,82 & 1,54 & 1,21 & 1,70 & 1,42 & 1,14 & 1,62 & 1,35 & 1,10 & 1,48 & 1,24 & 1,04 & 1,42 & 1,20 & 1,03 \\
\hline 18 & 1,91 & 1,67 & 1,28 & 1,69 & 1,43 & 1,12 & 1,57 & 1,32 & 1,05 & 1,50 & 1,25 & 1,01 & 1,37 & 1,15 & 0,96 & 1,32 & 1,11 & 0,94 \\
\hline 19 & 1,77 & 1,57 & 1,19 & 1,57 & 1,34 & 1,04 & 1,46 & 1,23 & 0,98 & 1,40 & 1,17 & 0,94 & 1,28 & 1,07 & 0,88 & 1,23 & 1,03 & 0,86 \\
\hline 20 & 1,65 & 1,48 & 1,12 & 1,46 & 1,26 & 0,98 & 1,37 & 1,16 & 0,91 & 1,30 & 1,10 & 0,87 & 1,19 & 1,00 & 0,82 & 1,15 & 0,96 & 0,80 \\
\hline 21 & 1,55 & 1,40 & 1,05 & 1,37 & 1,19 & 0,92 & 1,28 & 1,09 & 0,85 & 1,22 & 1,03 & 0,81 & 1,12 & 0,93 & 0,76 & 1,08 & 0,90 & 0,74 \\
\hline 22 & 1,45 & 1,32 & 0,99 & 1,29 & 1,12 & 0,86 & 1,20 & 1,03 & 0,80 & 1,15 & 0,97 & 0,76 & 1,05 & 0,88 & 0,71 & 1,01 & 0,85 & 0,69 \\
\hline 23 & 1,37 & 1,26 & 0,93 & 1,21 & 1,07 & 0,81 & 1,13 & 0,98 & 0,76 & 1,08 & 0,92 & 0,72 & 0,99 & 0,83 & 0,67 & 0,96 & 0,80 & 0,65 \\
\hline 24 & 1,29 & 1,20 & 0,88 & 1,15 & 1,01 & 0,77 & 1,07 & 0,93 & 0,71 & 1,02 & 0,87 & 0,68 & 0,94 & 0,79 & 0,63 & 0,90 & 0,76 & 0,61 \\
\hline 25 & 1,22 & 1,14 & 0,84 & 1,08 & 0,97 & 0,73 & 1,01 & 0,88 & 0,68 & 0,97 & 0,83 & 0,64 & 0,89 & 0,75 & 0,59 & 0,86 & 0,72 & 0,57 \\
\hline 26 & 1,16 & 1,09 & 0,79 & 1,03 & 0,92 & 0,70 & 0,96 & 0,84 & 0,64 & 0,92 & 0,79 & 0,61 & 0,84 & 0,71 & 0,56 & 0,81 & 0,68 & 0,54 \\
\hline 27 & 1,10 & 1,04 & 0,75 & 0,98 & 0,88 & 0,66 & 0,91 & 0,81 & 0,61 & 0,87 & 0,76 & 0,58 & 0,80 & 0,68 & 0,53 & 0,77 & 0,65 & 0,52 \\
\hline 28 & 1,05 & 1,00 & 0,72 & 0,93 & 0,85 & 0,63 & 0,87 & 0,77 & 0,59 & 0,83 & 0,73 & 0,56 & 0,76 & 0,65 & 0,51 & 0,74 & 0,62 & 0,49 \\
\hline 29 & 1,00 & 0,96 & 0,68 & 0,89 & 0,81 & 0,60 & 0,83 & 0,74 & 0,56 & 0,79 & 0,70 & 0,53 & 0,73 & 0,62 & 0,49 & 0,70 & 0,60 & 0,47 \\
\hline 30 & 0,95 & 0,93 & 0,65 & 0,85 & 0,78 & 0,58 & 0,79 & 0,71 & 0,54 & 0,76 & 0,67 & 0,51 & 0,70 & 0,60 & 0,46 & 0,67 & 0,57 & 0,45 \\
\hline 31 & 0,91 & 0,89 & 0,62 & 0,81 & 0,75 & 0,55 & 0,76 & 0,69 & 0,51 & 0,72 & 0,64 & 0,49 & 0,67 & 0,58 & 0,44 & 0,64 & 0,55 & 0,43 \\
\hline 32 & 0,87 & 0,86 & 0,59 & 0,78 & 0,73 & 0,53 & 0,73 & 0,66 & 0,49 & 0,69 & 0,62 & 0,47 & 0,64 & 0,55 & 0,43 & 0,62 & 0,53 & 0,41 \\
\hline 33 & 0,84 & 0,83 & 0,57 & 0,74 & 0,70 & 0,51 & 0,70 & 0,64 & 0,47 & 0,67 & 0,60 & 0,45 & 0,61 & 0,53 & 0,41 & 0,59 & 0,51 & 0,39 \\
\hline 34 & 0,80 & 0,80 & 0,54 & 0,71 & 0,68 & 0,49 & 0,67 & 0,62 & 0,46 & 0,64 & 0,58 & 0,43 & 0,59 & 0,52 & 0,39 & 0,57 & 0,49 & 0,38 \\
\hline 35 & 0,77 & 0,78 & 0,52 & 0,69 & 0,66 & 0,47 & 0,64 & 0,60 & 0,44 & 0,61 & 0,56 & 0,42 & 0,57 & 0,50 & 0,38 & 0,55 & 0,47 & 0,36 \\
\hline
\end{tabular}

ES - eixo simples; TD - eixo tandem duplo; TT - eixo tandem triplo

Tabela A.20 - Fatores de erosão - juntas transversais com transferência de carga por entrosagem de agregados - sem acostamento de concreto, PITTA (1996)

\begin{tabular}{|c|c|c|c|c|c|c|c|c|c|c|c|c|c|c|c|c|c|c|}
\hline \multirow[t]{3}{*}{$\mathrm{h}$} & \multicolumn{18}{|c|}{$\mathrm{k}$ do sistema subleito - sub-base $(\mathrm{MPa} / \mathrm{m})$} \\
\hline & \multicolumn{3}{|c|}{20} & \multicolumn{3}{|c|}{40} & \multicolumn{3}{|c|}{60} & \multicolumn{3}{|c|}{80} & \multicolumn{3}{|c|}{140} & \multicolumn{3}{|c|}{180} \\
\hline & ES & TD & TT & ES & TD & TT & ES & $\mathrm{TD}$ & TT & $\mathrm{ES}$ & $\mathrm{TD}$ & TT & $\mathrm{ES}$ & $\mathrm{TD}$ & $\mathrm{TT}$ & ES & TD & TT \\
\hline 10 & 3,94 & 4,00 & 4,03 & 3,92 & 3,93 & 3,93 & 3,90 & 3,90 & 3,88 & 3,88 & 3,88 & 3,84 & 3,84 & 3,84 & 3,75 & 3,80 & 3,82 & 3,70 \\
\hline 11 & 3,82 & 3,90 & 3,93 & 3,79 & 3,82 & 3,84 & 3,78 & 3,79 & 3,78 & 3,76 & 3,76 & 3,74 & 3,72 & 3,72 & 3,66 & 3,69 & 3,70 & 3,61 \\
\hline 12 & 3,71 & 3,81 & 3,85 & 3,68 & 3,73 & 3,75 & 3,67 & 3,69 & 3,70 & 3,65 & 3,66 & 3,66 & 3,62 & 3,62 & 3,57 & 3,59 & 3,59 & 3,53 \\
\hline 13 & 3,61 & 3,73 & 3,77 & 3,58 & 3,65 & 3,68 & 3,56 & 3,60 & 3,62 & 3,55 & 3,57 & 3,58 & 3,52 & 3,52 & 3,50 & 3,50 & 3,49 & 3,45 \\
\hline 14 & 3,52 & 3,66 & 3,70 & 3,49 & 3,57 & 3,60 & 3,47 & 3,52 & 3,55 & 3,46 & 3,49 & 3,51 & 3,43 & 3,43 & 3,42 & 3,41 & 3,41 & 3,38 \\
\hline 15 & 3,43 & 3,59 & 3,64 & 3,40 & 3,50 & 3,54 & 3,38 & 3,45 & 3,48 & 3,37 & 3,42 & 3,44 & 3,34 & 3,36 & 3,36 & 3,32 & 3,33 & 3,32 \\
\hline 16 & 3,35 & 3,53 & 3,58 & 3,32 & 3,43 & 3,47 & 3,30 & 3,38 & 3,42 & 3,29 & 3,35 & 3,38 & 3,26 & 3,28 & 3,29 & 3,24 & 3,26 & 3,25 \\
\hline 17 & 3,28 & 3,48 & 3,52 & 3,24 & 3,37 & 3,42 & 3,22 & 3,32 & 3,36 & 3,21 & 3,28 & 3,32 & 3,18 & 3,22 & 3,23 & 3,17 & 3,19 & 3,19 \\
\hline 18 & 3,21 & 3,42 & 3,47 & 3,17 & 3,32 & 3,36 & 3,15 & 3,26 & 3,30 & 3,14 & 3,23 & 3,26 & 3,11 & 3,16 & 3,18 & 3,10 & 3,13 & 3,14 \\
\hline 19 & 3,15 & 3,37 & 3,42 & 3,11 & 3,27 & 3,31 & 3,08 & 3,21 & 3,25 & 3,07 & 3,17 & 3,21 & 3,04 & 3,10 & 3,13 & 3,03 & 3,07 & 3,09 \\
\hline 20 & 3,09 & 3,33 & 3,37 & 3,04 & 3,22 & 3,26 & 3,02 & 3,16 & 3,20 & 3,01 & 3,12 & 3,16 & 2,98 & 3,05 & 3,08 & 2,96 & 3,01 & 3,04 \\
\hline 21 & 3,04 & 3,28 & 3,33 & 2,99 & 3,17 & 3,22 & 2,96 & 3,11 & 3,16 & 2,95 & 3,07 & 3,11 & 2,92 & 3,00 & 3,03 & 2,90 & 2,96 & 2,99 \\
\hline 22 & 2,98 & 3,24 & 3,29 & 2,93 & 3,13 & 3,18 & 2,90 & 3,07 & 3,11 & 2,89 & 3,03 & 3,07 & 2,86 & 2,95 & 2,99 & 2,85 & 2,92 & 2,95 \\
\hline 23 & 2,93 & 3,20 & 3,25 & 2,88 & 3,09 & 3,13 & 2,85 & 3,03 & 3,07 & 2,83 & 2,98 & 3,03 & 2,80 & 2,91 & 2,94 & 2,79 & 2,87 & 2,91 \\
\hline 24 & 2,89 & 3,16 & 3,21 & 2,83 & 3,05 & 3,10 & 2,80 & 2,99 & 3,03 & 2,78 & 2,94 & 2,99 & 2,75 & 2,86 & 2,90 & 2,74 & 2,83 & 2,86 \\
\hline 25 & 2,84 & 3,13 & 3,17 & 2,78 & 3,01 & 3,06 & 2,75 & 2,95 & 2,99 & 2,73 & 2,91 & 2,95 & 2,70 & 2,82 & 2,87 & 2,69 & 2,79 & 2,83 \\
\hline 26 & 2,80 & 3,09 & 3,14 & 2,73 & 2,98 & 3,02 & 2,70 & 2,91 & 2,96 & 2,69 & 2,87 & 2,91 & 2,65 & 2,79 & 2,83 & 2,64 & 2,75 & 2,79 \\
\hline 27 & 2,76 & 3,06 & 3,10 & 2,69 & 2,94 & 2,99 & 2,66 & 2,88 & 2,92 & 2,64 & 2,83 & 2,88 & 2,61 & 2,75 & 2,79 & 2,59 & 2,71 & 2,75 \\
\hline 28 & 2,72 & 3,03 & 3,07 & 2,65 & 2,91 & 2,96 & 2,62 & 2,84 & 2,89 & 2,60 & 2,80 & 2,85 & 2,56 & 2,71 & 2,76 & 2,55 & 2,68 & 2,72 \\
\hline 29 & 2,68 & 3,00 & 3,04 & 2,61 & 2,88 & 2,92 & 2,58 & 2,81 & 2,86 & 2,56 & 2,77 & 2,81 & 2,52 & 2,68 & 2,73 & 2,50 & 2,64 & 2,69 \\
\hline 30 & 2,65 & 2,97 & 3,01 & 2,57 & 2,85 & 2,89 & 2,54 & 2,78 & 2,83 & 2,52 & 2,74 & 2,78 & 2,48 & 2,65 & 2,69 & 2,46 & 2,61 & 2,65 \\
\hline 31 & 2,61 & 2,94 & 2,98 & 2,54 & 2,82 & 2,87 & 2,50 & 2,75 & 2,80 & 2,48 & 2,71 & 2,75 & 2,44 & 2,62 & 2,66 & 2,42 & 2,58 & 2,62 \\
\hline 32 & 2,58 & 2,91 & 2,96 & 2,50 & 2,79 & 2,84 & 2,47 & 2,72 & 2,77 & 2,44 & 2,68 & 2,72 & 2,40 & 2,59 & 2,63 & 2,38 & 2,55 & 2,59 \\
\hline 33 & 2,55 & 2,89 & 2,93 & 2,47 & 2,77 & 2,81 & 2,43 & 2,70 & 2,74 & 2,41 & 2,65 & 2,70 & 2,36 & 2,56 & 2,61 & 2,35 & 2,52 & 2,57 \\
\hline 34 & 2,52 & 2,86 & 2,91 & 2,44 & 2,74 & 2,78 & 2,40 & 2,67 & 2,72 & 2,37 & 2,62 & 2,67 & 2,33 & 2,53 & 2,58 & 2,31 & 2,49 & 2,54 \\
\hline 35 & 2,49 & 2,84 & 2,88 & 2,41 & 2,71 & 2,76 & 2,37 & 2,65 & 2,69 & 2,34 & 2,60 & 2,64 & 2,29 & 2,51 & 2,55 & 2,28 & 2,47 & 2,51 \\
\hline
\end{tabular}

ES - eixo simples; TD - eixo tandem duplo; TT - eixo tandem triplo 
Tabela A.21 - Fatores de erosão - juntas transversais com barras de transferência - sem acostamento de concreto, PITTA (1996)

\begin{tabular}{|c|c|c|c|c|c|c|c|c|c|c|c|c|c|c|c|c|c|c|}
\hline \multirow[t]{3}{*}{$\mathrm{h}$} & \multicolumn{18}{|c|}{$\mathrm{k}$ do sistema subleito - sub-base $(\mathrm{MPa} / \mathrm{m})$} \\
\hline & \multicolumn{3}{|c|}{20} & \multicolumn{3}{|c|}{40} & \multicolumn{3}{|c|}{60} & \multicolumn{3}{|c|}{80} & \multicolumn{3}{|c|}{140} & \multicolumn{3}{|c|}{180} \\
\hline & ES & $\mathrm{TD}$ & $\mathrm{TT}$ & $\mathrm{ES}$ & $\mathrm{TD}$ & TT & $\mathrm{ES}$ & $\mathrm{TD}$ & $\mathrm{TT}$ & $\mathrm{ES}$ & $\mathrm{TD}$ & TT & $\mathrm{ES}$ & $\mathrm{TD}$ & $\mathrm{TT}$ & $\mathrm{ES}$ & $\mathrm{TD}$ & TT \\
\hline 10 & 3,76 & 3,83 & 3,86 & 3,75 & 3,79 & 3,80 & 3,74 & 3,77 & 3,75 & 3,74 & 3,76 & 3,71 & 3,72 & 3,72 & 3,62 & 3,70 & 3,70 & 3,56 \\
\hline 11 & 3,63 & 3,71 & 3,76 & 3,62 & 3,67 & 3,69 & 3,61 & 3,65 & 3,65 & 3,61 & 3,63 & 3,62 & 3,59 & 3,60 & 3,53 & 3,58 & 3,58 & 3,48 \\
\hline 12 & 3,52 & 3,61 & 3,68 & 3,50 & 3,56 & 3,60 & 3,49 & 3,54 & 3,56 & 3,49 & 3,52 & 3,52 & 3,47 & 3,49 & 3,45 & 2,46 & 3,47 & 3,40 \\
\hline 13 & 3,41 & 3,52 & 3,60 & 3,39 & 3,47 & 3,51 & 3,39 & 3,44 & 3,47 & 3,38 & 3,43 & 3,44 & 3,37 & 3,39 & 3,37 & 3,35 & 3,37 & 3,33 \\
\hline 14 & 3,31 & 3,43 & 3,53 & 3,30 & 3,38 & 3,43 & 3,29 & 3,35 & 3,39 & 3,28 & 3,33 & 3,36 & 3,27 & 3,30 & 3,29 & 3,26 & 3,28 & 3,26 \\
\hline 15 & 3,22 & 3,36 & 3,47 & 3,21 & 3,30 & 3,36 & 3,20 & 3,27 & 3,31 & 3,19 & 3,25 & 3,28 & 3,17 & 3,21 & 3,22 & 3,16 & 3,19 & 3,19 \\
\hline 16 & 3,14 & 3,28 & 3,41 & 3,12 & 3,22 & 3,30 & 3,11 & 3,19 & 3,25 & 3,10 & 3,17 & 3,21 & 3,09 & 3,13 & 3,15 & 3,08 & 3,12 & 3,12 \\
\hline 17 & 3,06 & 3,22 & 3,35 & 3,04 & 3,15 & 3,24 & 3,03 & 3,12 & 3,19 & 3,02 & 3,10 & 3,15 & 3,01 & 3,06 & 3,08 & 3,00 & 3,04 & 3,05 \\
\hline 18 & 2,99 & 3,16 & 3,30 & 2,97 & 3,09 & 3,19 & 2,96 & 3,06 & 3,13 & 2,95 & 3,03 & 3,09 & 2,93 & 2,99 & 3,02 & 2,92 & 2,97 & 2,99 \\
\hline 19 & 2,92 & 3,10 & 3,25 & 2,90 & 3,03 & 3,14 & 2,88 & 2,99 & 3,08 & 2,88 & 2,97 & 3,04 & 2,86 & 2,93 & 2,96 & 2,85 & 2,91 & 2,93 \\
\hline 20 & 2,85 & 3,05 & 3,21 & 2,83 & 2,97 & 3,09 & 2,82 & 2,94 & 3,03 & 2,81 & 2,91 & 2,99 & 2,79 & 2,87 & 2,91 & 2,78 & 2,85 & 2,88 \\
\hline 21 & 2,79 & 2,99 & 3,16 & 2,77 & 2,92 & 3,05 & 2,75 & 2,88 & 2,99 & 2,75 & 2,86 & 2,94 & 2,73 & 2,81 & 2,86 & 2,72 & 2,79 & 2,83 \\
\hline 22 & 2,73 & 2,95 & 3,12 & 2,71 & 2,87 & 3,01 & 2,69 & 2,83 & 2,94 & 2,69 & 2,80 & 2,90 & 2,67 & 2,76 & 2,82 & 2,66 & 2,73 & 2,78 \\
\hline 23 & 2,67 & 2,90 & 3,08 & 2,65 & 2,82 & 2,97 & 2,64 & 2,78 & 2,90 & 2,63 & 2,75 & 2,86 & 2,61 & 2,70 & 2,77 & 2,60 & 2,68 & 2,74 \\
\hline 24 & 2,62 & 2,86 & 3,05 & 2,60 & 2,78 & 2,93 & 2,58 & 2,73 & 2,86 & 2,57 & 2,71 & 2,82 & 2,55 & 2,66 & 2,73 & 2,54 & 2,63 & 2,69 \\
\hline 25 & 2,57 & 2,82 & 3,01 & 2,54 & 2,73 & 2,89 & 2,53 & 2,69 & 2,83 & 2,52 & 2,66 & 2,78 & 2,50 & 2,61 & 2,69 & 2,49 & 2,59 & 2,65 \\
\hline 26 & 2,52 & 2,78 & 2,98 & 2,49 & 2,69 & 2,86 & 2,48 & 2,65 & 2,79 & 2,47 & 2,62 & 2,74 & 2,45 & 2,56 & 2,66 & 2,44 & 2,54 & 2,62 \\
\hline 27 & 2,47 & 2,74 & 2,94 & 2,44 & 2,65 & 2,82 & 2,43 & 2,61 & 2,76 & 2,42 & 2,58 & 2,71 & 2,40 & 2,52 & 2,62 & 2,39 & 2,50 & 2,58 \\
\hline 28 & 2,42 & 2,71 & 2,91 & 2,40 & 2,62 & 2,79 & 2,38 & 2,57 & 2,72 & 2,37 & 2,54 & 2,68 & 2,35 & 2,48 & 2,59 & 2,34 & 2,46 & 2,55 \\
\hline 29 & 2,38 & 2,67 & 2,88 & 2,35 & 2,58 & 2,76 & 2,34 & 2,53 & 2,69 & 2,33 & 2,50 & 2,65 & 2,31 & 2,44 & 2,55 & 2,30 & 2,42 & 2,51 \\
\hline 30 & 2,34 & 2,64 & 2,85 & 2,31 & 2,55 & 2,73 & 2,30 & 2,50 & 2,66 & 2,29 & 2,46 & 2,62 & 2,26 & 2,41 & 2,52 & 2,26 & 2,38 & 2,48 \\
\hline 31 & 2,29 & 2,61 & 2,82 & 2,27 & 2,51 & 2,70 & 2,25 & 2,46 & 2,63 & 2,24 & 2,43 & 2,59 & 2,22 & 2,37 & 2,49 & 2,21 & 2,34 & 2,45 \\
\hline 32 & 2,25 & 2,58 & 2,80 & 2,23 & 2,48 & 2,68 & 2,21 & 2,43 & 2,61 & 2,20 & 2,40 & 2,56 & 2,18 & 2,33 & 2,46 & 2,17 & 2,31 & 2,42 \\
\hline 33 & 2,21 & 2,55 & 2,77 & 2,19 & 2,45 & 2,65 & 2,17 & 2,40 & 2,58 & 2,16 & 2,36 & 2,53 & 2,14 & 2,30 & 2,44 & 2,13 & 2,28 & 2,40 \\
\hline 34 & 2,18 & 2,52 & 2,74 & 2,15 & 2,42 & 2,62 & 2,14 & 2,37 & 2,55 & 2,12 & 2,33 & 2,50 & 2,10 & 2,27 & 2,41 & 2,09 & 2,24 & 2,37 \\
\hline 35 & 2,14 & 2,49 & 2,72 & 2,11 & 2,39 & 2,60 & 2,10 & 2,34 & 2,53 & 2,09 & 2,30 & 2,48 & 2,07 & 2,24 & 2,38 & 2,06 & 2,21 & 2,34 \\
\hline
\end{tabular}

ES - eixo simples; TD - eixo tandem duplo; TT - eixo tandem triplo

Tabela A.22 - Fatores de erosão - juntas transversais com entrosagem de agregados com acostamento de concreto, PITTA (1996)

\begin{tabular}{|c|c|c|c|c|c|c|c|c|c|c|c|c|c|c|c|c|c|c|}
\hline \multirow[t]{3}{*}{$\mathrm{h}$} & \multicolumn{18}{|c|}{$\mathrm{k}$ do sistema subleito - sub-base $(\mathrm{MPa} / \mathrm{m})$} \\
\hline & \multicolumn{3}{|c|}{20} & \multicolumn{3}{|c|}{40} & \multicolumn{3}{|c|}{60} & \multicolumn{3}{|c|}{80} & \multicolumn{3}{|c|}{140} & \multicolumn{3}{|c|}{180} \\
\hline & $\mathrm{ES}$ & TD & TT & ES & TD & TT & $\mathrm{ES}$ & $\mathrm{TD}$ & TT & $\mathrm{ES}$ & $\mathrm{TD}$ & TT & $\mathrm{ES}$ & $\mathrm{TD}$ & $\mathrm{TT}$ & ES & $\mathrm{TD}$ & TT \\
\hline 10 & 45 & 3,45 & 3,44 & 41 & 3,36 & 3,35 & 3,39 & 3,33 & 3,30 & 3,38 & 3,31 & 3,27 & 3,34 & 3,28 & 3,22 & 3,31 & 3,27 & 3,19 \\
\hline 11 & 34 & 3,36 & 3,36 & 3,30 & 3,27 & 3,26 & 3,28 & 3,22 & 3,20 & 3,27 & 3,20 & 3,17 & 3,23 & 3,16 & 3,12 & 3,20 & 3,15 & 3,09 \\
\hline 12 &, 24 & 3,28 & 3,29 & 3,20 & 3,18 & 3,18 & 3,18 & 3,13 & 3,12 & 3,16 & 3,11 & 3,09 & 3,13 & 3,06 & 3,02 & 3,11 & 3,04 & 2,99 \\
\hline 13 & 15 & 3,21 & 3,23 & 3,11 & 3,11 & 3,11 & 3,08 & 3,05 & 3,05 & 3,07 & 3,02 & 3,01 & 3,04 & 2,97 & 2,94 & 3,02 & 2,95 & 2,91 \\
\hline 14 & 3,07 & 3,15 & 3,17 & 3,02 & 3,04 & 3,04 & 3,00 & 2,98 & 2,98 & 2,98 & 2,95 & 2,94 & 2,95 & 2,89 & 2,87 & 2,93 & 2,86 & 2,83 \\
\hline 15 & 2,99 & 3,09 & 3,12 & 2,94 & 2,98 & 2,99 & 2,92 & 2,91 & 2,92 & 2,90 & 2,88 & 2,88 & 2,87 & 2,82 & 2,80 & 2,85 & 2,79 & 2,77 \\
\hline 16 & 2,91 & 3,04 & 3,08 & 2,87 & 2,92 & 2,94 & 2,84 & 2,86 & 2,87 & 2,83 & 2,82 & 2,82 & 2,80 & 2,75 & 2,74 & 2,78 & 2,72 & 2,70 \\
\hline 17 & 2,85 & 2,99 & 3,03 & 2,80 & 2,87 & 2,89 & 2,77 & 2,81 & 2,82 & 2,76 & 2,77 & 2,77 & 2,73 & 2,69 & 2,69 & 2,71 & 2,66 & 2,65 \\
\hline 18 & 2,78 & 2,94 & 2,99 & 2,73 & 2,82 & 2,85 & 2,71 & 2,76 & 2,77 & 2,69 & 2,71 & 2,72 & 2,66 & 2,64 & 2,63 & 2,64 & 2,61 & 2,60 \\
\hline 19 & 2,73 & 2,90 & 2,96 & 2,67 & 2,77 & 2,81 & 2,64 & 2,71 & 2,73 & 2,63 & 2,67 & 2,68 & 2,60 & 2,59 & 2,59 & 2,58 & 2,55 & 2,55 \\
\hline 20 & 2,67 & 2,86 & 2,93 & 2,61 & 2,73 & 2,77 & 2,59 & 2,67 & 2,69 & 2,57 & 2,62 & 2,64 & 2,54 & 2,54 & 2,54 & 2,52 & 2,51 & 2,50 \\
\hline 21 & 2,62 & 2,82 & 2,89 & 2,56 & 2,69 & 2,74 & 2,53 & 2,63 & 2,65 & 2,51 & 2,58 & 2,60 & 2,48 & 2,50 & 2,50 & 2,47 & 2,46 & 2,46 \\
\hline 22 & 2,57 & 2,78 & 2,87 & 2,51 & 2,66 & 2,71 & 2,48 & 2,59 & 2,62 & 2,46 & 2,54 & 2,56 & 2,43 & 2,46 & 2,4 & 2,41 & 2,42 & 2,42 \\
\hline 23 & 2,52 & 2,75 & 2,84 & 2,46 & 2,62 & 2,68 & 2,43 & 2,55 & 2,59 & 2,41 & 2,50 & 2,53 & 2,38 & 2,42 & 2,43 & 2,36 & 2,38 & 2,38 \\
\hline 24 & 2,47 & 2,72 & 2,81 & 2,41 & 2,59 & 2,65 & 2,38 & 2,52 & 2,56 & 2,36 & 2,47 & 2,50 & 2,33 & 2,38 & 2,4 & 2,31 & 2,34 & 2,35 \\
\hline 25 & 2,43 & 2,69 & 2,79 & 2,37 & 2,55 & 2,62 & 2,34 & 2,48 & 2,53 & 2,32 & 2,43 & 2,47 & 2,28 & 2,35 & 2,37 & 2,27 & 2,31 & 2,32 \\
\hline 26 & 2,39 & 2,66 & 2,77 & 2,33 & 2,52 & 2,60 & 2,29 & 2,45 & 2,50 & 2,27 & 2,40 & 2,44 & 2,24 & 2,31 & 2,34 & 2,22 & 2,27 & 2,29 \\
\hline 27 & 2,35 & 2,63 & 2,74 & 2,28 & 2,49 & 2,57 & 2,25 & 2,42 & 2,48 & 2,23 & 2,37 & 2,42 & 2,20 & 2,28 & 2,31 & 2,18 & 2,24 & 2,26 \\
\hline 28 & 2,31 & 2,60 & 2,72 & 2,25 & 2,47 & 2,55 & 2,21 & 2,39 & 2,46 & 2,19 & 2,34 & 2,39 & 2,16 & 2,25 & 2,28 & 2,14 & 2,21 & 2,23 \\
\hline 29 & 2,28 & 2,58 & 2,70 & 2,21 & 2,44 & 2,53 & 2,17 & 2,37 & 2,43 & 2,15 & 2,32 & 2,37 & 2,12 & 2,22 & 2,26 & 2,10 & 2,18 & 2,20 \\
\hline 30 & 2,24 & 2,55 & 2,68 & 2,17 & 2,41 & 2,51 & 2,14 & 2,34 & 2,41 & 2,12 & 2,29 & 2,35 & 2,08 & 2,19 & 2,23 & 2,06 & 2,15 & 2,18 \\
\hline 31 & 2,21 & 2,53 & 2,67 & 2,14 & 2,39 & 2,49 & 2,10 & 2,31 & 2,39 & 2,08 & 2,26 & 2,33 & 2,04 & 2,17 & 2,21 & 2,02 & 2,13 & 2,16 \\
\hline 32 & 2,18 & 2,50 & 2,65 & 2,11 & 2,36 & 2,47 & 2,07 & 2,29 & 2,37 & 2,05 & 2,24 & 2,31 & 2,01 & 2,14 & 2,19 & 1,99 & 2,10 & 2,13 \\
\hline 33 & 2,15 & 2,48 & 2,63 & 2,07 & 2,34 & 2,45 & 2,04 & 2,27 & 2,35 & 2,01 & 2,21 & 2,29 & 1,97 & 2,12 & 2,17 & 1,95 & 2,07 & 2,11 \\
\hline 34 & 2,12 & 2,46 & 2,61 & 2,04 & 2,32 & 2,43 & 2,01 & 2,24 & 2,33 & 1,98 & 2,19 & 2,27 & 1,94 & 2,09 & 2,15 & 1,92 & 2,05 & 2,09 \\
\hline 35 & 2,09 & 2,44 & 2,60 & 2,01 & 2,30 & 2,42 & 1,97 & 2,22 & 2,32 & 1,95 & 2,17 & 2,25 & 1,91 & 2,07 & 2,13 & 1,89 & 2,03 & 2,07 \\
\hline
\end{tabular}

ES - eixo simples; TD - eixo tandem duplo; TT - eixo tandem triplo 
Tabela A.23 - Fatores de erosão - juntas transversais com barras de tranferência - com acostamento de concreto, PITTA (1996)

\begin{tabular}{|c|c|c|c|c|c|c|c|c|c|c|c|c|c|c|c|c|c|c|}
\hline \multirow[t]{3}{*}{$\mathrm{h}$} & \multicolumn{18}{|c|}{$\mathrm{k}$ do sistema subleito - sub-base $(\mathrm{MPa} / \mathrm{m})$} \\
\hline & \multicolumn{3}{|c|}{20} & \multicolumn{3}{|c|}{40} & \multicolumn{3}{|c|}{60} & \multicolumn{3}{|c|}{80} & \multicolumn{3}{|c|}{140} & \multicolumn{3}{|c|}{180} \\
\hline & $\mathrm{ES}$ & TD & TT & $\mathrm{ES}$ & TD & TT & $\mathrm{ES}$ & $\mathrm{TD}$ & $\mathrm{TT}$ & ES & TD & TT & $\mathrm{ES}$ & TD & TT & $\mathrm{ES}$ & $\mathrm{TD}$ & TT \\
\hline 10 & 3,27 & 3,25 & 3,27 & 3,24 & 3,17 & 3,17 & 3,22 & 3,14 & 3,13 & 3,21 & 3,12 & 3,12 & 3,17 & 3,11 & 3,07 & 3,15 & 3,11 & 3,03 \\
\hline 11 & 3,16 & 3,16 & 3,19 & 3,12 & 3,07 & 3,07 & 3,10 & 3,03 & 3,02 & 3,09 & 3,00 & 3,00 & 3,05 & 2,98 & 2,95 & 3,03 & 2,97 & 2,92 \\
\hline 12 & 3,05 & 3,08 & 3,12 & 3,01 & 2,98 & 2,99 & 2,99 & 2,93 & 2,93 & 2,98 & 2,90 & 2,90 & 2,94 & 2,86 & 2,85 & 2,92 & 2,84 & 2,82 \\
\hline 13 & 2,96 & 3,01 & 3,06 & 2,92 & 2,90 & 2,92 & 2,89 & 2,85 & 2,85 & 2,88 & 2,81 & 2,81 & 2,84 & 2,76 & 2,76 & 2,82 & 2,74 & 2,73 \\
\hline 14 & 2,87 & 2,94 & 3,00 & 2,82 & 2,83 & 2,86 & 2,80 & 2,77 & 2,78 & 2,78 & 2,74 & 2,74 & 2,75 & 2,67 & 2,67 & 2,73 & 2,65 & 2,64 \\
\hline 15 & 2,79 & 2,88 & 2,95 & 2,74 & 2,77 & 2,80 & 2,72 & 2,71 & 2,73 & 2,70 & 2,67 & 2,67 & 2,67 & 2,60 & 2,59 & 2,65 & 2,57 & 2,56 \\
\hline 16 & 2,71 & 2,82 & 2,91 & 2,66 & 2,71 & 2,76 & 2,64 & 2,65 & 2,67 & 2,62 & 2,60 & 2,62 & 2,59 & 2,53 & 2,52 & 2,57 & 2,50 & 2,49 \\
\hline 17 & 2,64 & 2,77 & 2,86 & 2,59 & 2,65 & 2,71 & 2,57 & 2,59 & 2,62 & 2,55 & 2,55 & 2,57 & 2,51 & 2,46 & 2,47 & 2,49 & 2,43 & 2,43 \\
\hline 18 & 2,57 & 2,72 & 2,82 & 2,52 & 2,60 & 2,67 & 2,50 & 2,54 & 2,58 & 2,48 & 2,49 & 2,52 & 2,44 & 2,41 & 2,41 & 2,42 & 2,37 & 2,37 \\
\hline 19 & 2,51 & 2,67 & 2,79 & 2,46 & 2,56 & 2,63 & 2,43 & 2,49 & 2,54 & 2,41 & 2,44 & 2,48 & 2,38 & 2,35 & 2,37 & 2,36 & 2,32 & 2,32 \\
\hline 20 & 2,45 & 2,63 & 2,75 & 2,40 & 2,51 & 2,59 & 2,37 & 2,44 & 2,50 & 2,35 & 2,40 & 2,44 & 2,31 & 2,31 & 2,32 & 2,30 & 2,27 & 2,28 \\
\hline 21 & 2,39 & 2,58 & 2,72 & 2,34 & 2,47 & 2,56 & 2,31 & 2,40 & 2,47 & 2,29 & 2,35 & 2,40 & 2,26 & 2,26 & 2,28 & 2,24 & 2,22 & 2,23 \\
\hline 22 & 2,34 & 2,54 & 2,68 & 2,29 & 2,43 & 2,53 & 2,26 & 2,36 & 2,43 & 2,24 & 2,31 & 2,37 & 2,20 & 2,22 & 2,25 & 2,18 & 2,18 & 2,20 \\
\hline 23 & 2,29 & 2,50 & 2,65 & 2,23 & 2,39 & 2,49 & 2,21 & 2,32 & 2,40 & 2,19 & 2,27 & 2,34 & 2,15 & 2,18 & 2,21 & 2,13 & 2,13 & 2,16 \\
\hline 24 & 2,24 & 2,46 & 2,62 & 2,18 & 2,35 & 2,46 & 2,16 & 2,28 & 2,37 & 2,13 & 2,23 & 2,31 & 2,10 & 2,14 & 2,18 & 2,08 & 2,10 & 2,13 \\
\hline 25 & 2,19 & 2,43 & 2,59 & 2,14 & 2,31 & 2,44 & 2,11 & 2,24 & 2,34 & 2,09 & 2,20 & 2,28 & 2,05 & 2,10 & 2,15 & 2,03 & 2,06 & 2,10 \\
\hline 26 & 2,15 & 2,39 & 2,57 & 2,09 & 2,28 & 2,41 & 2,06 & 2,21 & 2,32 & 2,04 & 2,16 & 2,25 & 2,00 & 2,07 & 2,12 & 1,98 & 2,02 & 2,07 \\
\hline 27 & 2,10 & 2,36 & 2,54 & 2,05 & 2,24 & 2,38 & 2,02 & 2,18 & 2,29 & 2,00 & 2,13 & 2,22 & 1,96 & 2,03 & 2,10 & 1,94 & 1,99 & 2,04 \\
\hline 28 & 2,06 & 2,32 & 2,51 & 2,01 & 2,21 & 2,36 & 1,98 & 2,14 & 2,26 & 1,95 & 2,10 & 2,20 & 1,91 & 2,00 & 2,07 & 1,89 & 1,96 & 2,01 \\
\hline 29 & 2,20 & 2,29 & 2,49 & 1,97 & 2,18 & 2,33 & 1,93 & 2,11 & 2,24 & 1,91 & 2,06 & 2,17 & 1,87 & 1,97 & 2,04 & 1,85 & 1,93 & 1,99 \\
\hline 30 & 1,98 & 2,26 & 2,47 & 1,93 & 2,15 & 2,31 & 1,90 & 2,08 & 2,22 & 1,87 & 2,03 & 2,15 & 1,83 & 1,94 & 2,02 & 1,81 & 1,90 & 1,96 \\
\hline 31 & 1,95 & 2,23 & 2,44 & 1,89 & 2,12 & 2,29 & 1,86 & 2,05 & 2,19 & 1,84 & 2,01 & 2,13 & 1,79 & 1,91 & 2,00 & 1,77 & 1,87 & 1,94 \\
\hline 32 & 1,91 & 2,20 & 2,42 & 1,85 & 2,09 & 2,26 & 1,82 & 2,03 & 2,17 & 1,80 & 1,98 & 2,10 & 1,76 & 1,88 & 1,97 & 1,74 & 1,84 & 1,92 \\
\hline 33 & 1,87 & 2,17 & 2,40 & 1,82 & 2,06 & 2,24 & 1,78 & 2,00 & 2,15 & 1,76 & 1,95 & 2,08 & 1,72 & 1,86 & 1,95 & 1,70 & 1,81 & 1,89 \\
\hline 34 & 1,84 & 2,15 & 2,38 & 1,78 & 2,04 & 2,22 & 1,75 & 1,97 & 2,13 & 1,73 & 1,92 & 2,06 & 1,69 & 1,83 & 1,93 & 1,67 & 1,79 & 1,87 \\
\hline 35 & 1,81 & 2,12 & 2,36 & 1,75 & 2,01 & 2,20 & 1,72 & 1,95 & 2,11 & 1,69 & 1,90 & 2,04 & 1,65 & 1,80 & 1,91 & 1,63 & 1,76 & 1,85 \\
\hline
\end{tabular}

ES - eixo simples; TD - eixo tandem duplo; TT - eixo tandem triplo

Tabela A.24 - Coeficientes de segurança devido à fadiga, PACKARD (1976)

\begin{tabular}{|c|c|c|c|}
\hline $\begin{array}{c}\text { Número de } \\
\text { repetições }\end{array}$ & $\begin{array}{c}\text { Fator de } \\
\text { segurança } \gamma_{\text {fad }}\end{array}$ & $\begin{array}{c}\text { Número de } \\
\text { repetições }\end{array}$ & $\begin{array}{c}\text { Fator de } \\
\text { segurança } \gamma_{\text {fad }}\end{array}$ \\
\hline ilimitado & 2,00 & 90.000 & 1,78 \\
\hline 500.000 & 2.00 & 80.000 & 1,77 \\
\hline 400.000 & 1,97 & 70.000 & 1,75 \\
\hline 300.000 & 1,93 & 60.000 & 1,74 \\
\hline 200.000 & 1.88 & 50.000 & 1.72 \\
\hline 100.000 & 1,79 & 42.000 ou menos & 1,70 \\
\hline
\end{tabular}


Tabela A.25 - Valores de $\mathrm{k}_{\mathrm{c}}$ e $\mathrm{k}_{\mathrm{s}}$, adaptado de PINHEIRO (1993)

\begin{tabular}{|c|c|c|c|c|c|c|c|c|c|}
\hline \multicolumn{10}{|c|}{ Flexão simples em seção retangular - Armadura simples } \\
\hline \multirow[t]{2}{*}{$\beta_{x}=\frac{x}{d}$} & \multicolumn{6}{|c|}{$\mathrm{k}_{\mathrm{c}}=\frac{\mathrm{b} \cdot \mathrm{d}^{2}}{\mathrm{M}_{\mathrm{d}}}\left(\mathrm{cm}^{2} / \mathrm{kN}\right)$} & \multicolumn{2}{|c|}{$\begin{array}{c}\mathrm{k}_{\mathrm{s}}=\frac{\mathrm{A}_{\mathrm{s}} \cdot \mathrm{d}}{\mathrm{M}_{\mathrm{d}}}\left(\mathrm{cm}^{2} /\right. \\
\mathrm{kN})\end{array}$} & \multirow[t]{2}{*}{ 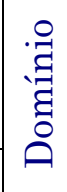 } \\
\hline & C-25 & C-30 & C-35 & C-40 & C-45 & C-50 & CA50A & CA60B & \\
\hline 0,02 & 41,5 & 34,6 & 29,6 & 25,9 & 23,1 & 20,8 & 0,023 & 0,019 & \\
\hline 0,04 & 20,9 & 17,4 & 14,9 & 13,1 & 11,6 & 10,5 & 0,023 & 0,019 & \\
\hline 0,06 & 14,1 & 11,7 & 10,0 & 8,8 & 7,8 & 7,0 & 0,024 & 0,020 & \\
\hline 0,08 & 10,6 & 8,9 & 7,6 & 6,6 & 5,9 & 5,3 & 0,024 & 0,020 & \\
\hline 0,10 & 8,6 & 7,1 & 6,1 & 5,4 & 4,8 & 4,3 & 0,024 & 0,020 & \\
\hline 0,12 & 7,2 & 6,0 & 5,1 & 4,5 & 4,0 & 3,6 & 0,024 & 0,020 & \\
\hline 0,14 & 6,2 & 5,2 & 4,5 & 3,9 & 3,5 & 3,1 & 0,024 & 0,020 & 2 \\
\hline 0,16 & 5,5 & 4,6 & 3,9 & 3,4 & 3,1 & 2,7 & 0,025 & 0,020 & \\
\hline 0,18 & 4,9 & 4,1 & 3,5 & 3,1 & 2,7 & 2,5 & 0,025 & 0,021 & \\
\hline 0,20 & 4,5 & 3,7 & 3,2 & 2,8 & 2,5 & 2,2 & 0,025 & 0,021 & \\
\hline 0,22 & 4,1 & 3,4 & 2,9 & 2,6 & 2,3 & 2,1 & 0,025 & 0,021 & \\
\hline 0,24 & 3,8 & 3,2 & 2,7 & 2,4 & 2,1 & 1,9 & 0,025 & 0,021 & \\
\hline 0,26 & 3,5 & 2,9 & 2,5 & 2,2 & 2,0 & 1,8 & 0,026 & 0,021 & \\
\hline 0,28 & 3,3 & 2,8 & 2,4 & 2,1 & 1,8 & 1,7 & 0,026 & 0,022 & \\
\hline 0,30 & 3,1 & 2,6 & 2,2 & 1,9 & 1,7 & 1,6 & 0,026 & 0,022 & \\
\hline 0,32 & 3,0 & 2,5 & 2,1 & 1,8 & 1,6 & 1,5 & 0,026 & 0,022 & \\
\hline 0,34 & 2,8 & 2,3 & 2,0 & 1,8 & 1,6 & 1,4 & 0,027 & 0,022 & 3 \\
\hline 0,36 & 2,7 & 2,2 & 1,9 & 1,7 & 1,5 & 1,3 & 0,027 & 0,022 & \\
\hline 0,38 & 2,6 & 2,1 & 1,8 & 1,6 & 1,4 & 1,3 & 0,027 & 0,023 & \\
\hline 0,40 & 2,5 & 2,0 & 1,8 & 1,5 & 1,4 & 1,2 & 0,027 & 0,023 & \\
\hline 0,438 & 2,3 & 1,9 & 1,6 & 1,4 & 1,3 & 1,1 & 0,028 & 0,023 & \\
\hline 0,44 & 2,3 & 1,9 & 1,6 & 1,4 & 1,3 & 1,1 & 0,028 & 0,023 & \\
\hline 0,462 & 2,2 & 1,8 & 1,6 & 1,4 & 1,2 & 1,1 & 0,028 & 0,024 & \\
\hline 0,48 & 2,1 & 1,8 & 1,5 & 1,3 & 1,2 & 1,1 & 0,028 & 0,025 & \\
\hline 0,52 & 2,0 & 1,7 & 1,4 & 1,2 & 1,1 & 1,0 & 0,029 & 0,027 & 4 \\
\hline 0,56 & 1,9 & 1,6 & 1,4 & 1,2 & 1,1 & 1,0 & 0,030 & 0,029 & \\
\hline 0,60 & 1,8 & 1,5 & 1,3 & 1,1 & 1,0 & 0,9 & 0,030 & - & \\
\hline 0,628 & 1,8 & 1,5 & 1,3 & 1,1 & 1,0 & 0,9 & 0,031 & - & \\
\hline
\end{tabular}

Tabela A.26 - Barras de transferência, adaptado de: RODRIGUES e CASSARO (1998) e PITTA (1987)

\begin{tabular}{|c|c|c|c|}
\hline $\begin{array}{c}\text { Espessura de placa } \\
(\mathrm{mm})\end{array}$ & $\begin{array}{c}\text { Diâmetro da barra } \\
(\mathrm{mm})\end{array}$ & $\begin{array}{c}\text { Comprimento da } \\
\text { barra }(\mathrm{mm})\end{array}$ & Espaçamento $(\mathrm{mm})$ \\
\hline 125 & 16 & 400 & 300 \\
150 & 20 & 400 & 300 \\
200 & 25 & 460 & 300 \\
225 & 25 & 460 & 300 \\
250 & 32 & 460 & 300 \\
275 & 32 & 460 & 300 \\
300 & 32 & 460 & 300 \\
$>300$ & 40 & 460 & 300 \\
\hline
\end{tabular}




\section{Anexo}

\section{ANÁLISES NUMÉRICAS}

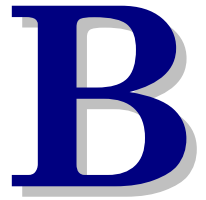

\section{B.1 ANÁlise DE PlaCAS ISOLADAS SOB CARREGAMENTO DE EIXOS RODOVIÁRIOS COM CARGA MÁXIMA PERMITIDA PELO DNER}

A seguir serão apresentados os resultados das análises de placas isoladas, submetidas a carregamentos de eixos simples de rodagem simples, tandem duplo e tandem triplo. As condições do problema e os resultados para eixos simples de rodagem dupla já foram mostrados no capítulo 5. Os resultados numéricos dependem dos valores adotados, mas um comportamento semelhante ao apresentado a seguir foi observado em análises com diferentes valores de $\mathrm{k} e$ diferentes espessuras do pavimento.

B.1.1 Eixo simples de rodagem simples

Nas figuras B.1 e B.2 estão apresentados os resultados obtidos para eixo tangente à borda.

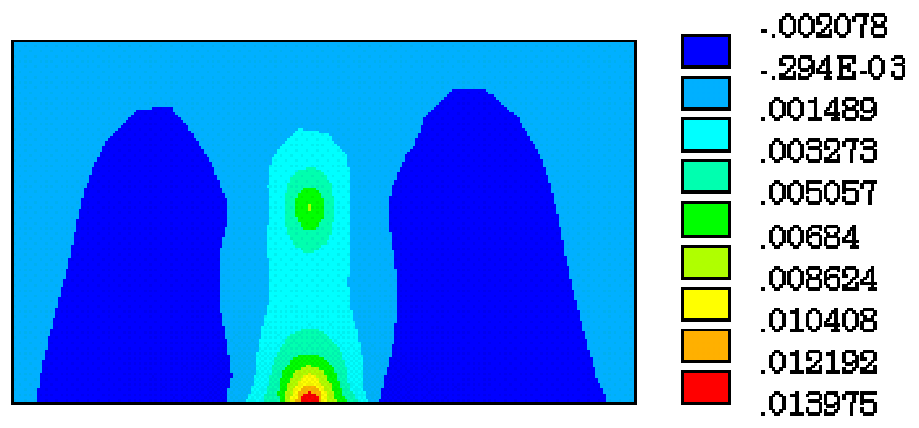

Figura B.1 - Distribuição dos momentos fletores (MN.m), na direção x, para eixo tangente à borda da placa - eixo simples de rodagem simples 

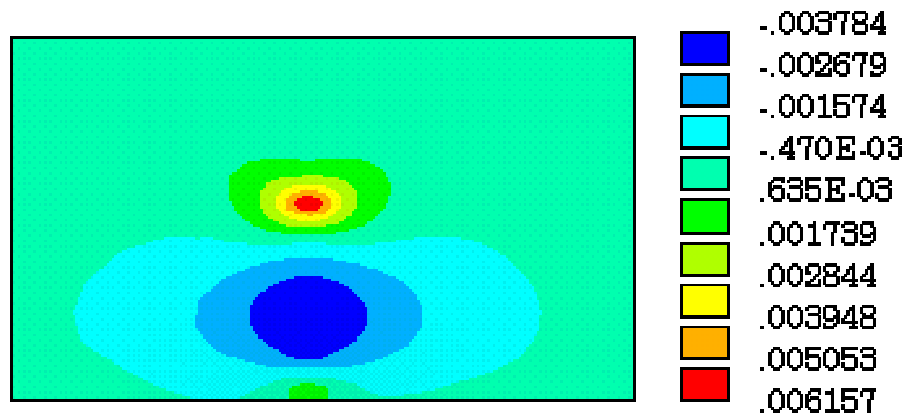

Figura B.2 - Distribuição dos momentos fletores (MN.m), na direção y, para eixo tangente à borda da placa - eixo simples de rodagem simples

O momento fletor máximo ocorre na direção x, na borda da placa. No interior, os momentos em $\mathrm{x}$ e y assumem valores próximos a $50 \%$ do valor máximo. Os momentos fletores negativos são pequenos, atingindo $25 \%$ do valor máximo.

Nas figuras B.3 e B.4 estão apresentados os resultados obtidos para eixo no canto da placa.
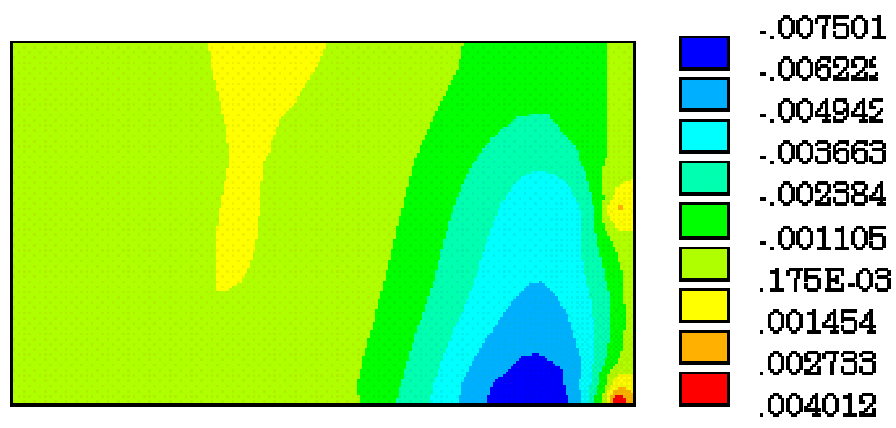

Figura B.3 - Distribuição dos momentos fletores (MN.m), na direção x, para eixo no canto da placa - eixo simples de rodagem simples
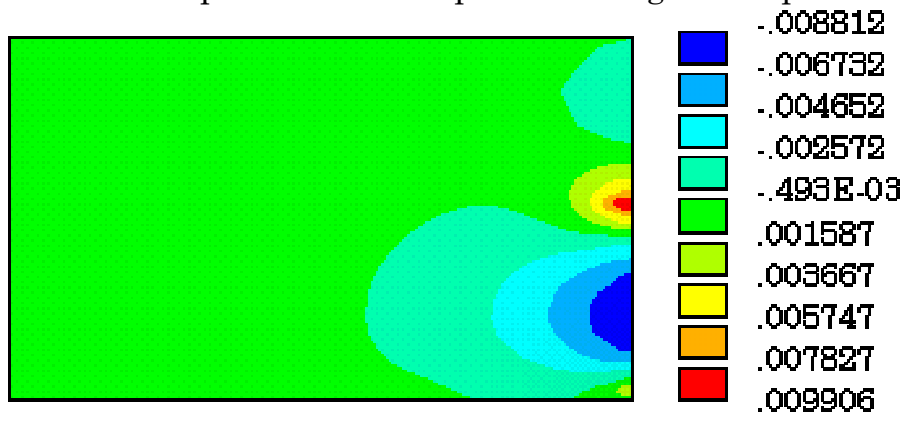

Figura B.4 - Distribuição dos momentos fletores (MN.m), na direção y, para eixo no canto da placa - eixo simples de rodagem simples

Assim como no caso de eixo simples de rodagem dupla, os momentos fletores positivos na direção $\mathrm{x}$ são pequenos, sendo mais significativos os 
momentos positivos em y e negativos nas duas direções, que atingem $70 \%$ do esforço máximo.

\section{B.1.2 Eixo tandem duplo}

Nas figuras B.5 e B.6 estão apresentados os resultados obtidos para eixo tandem duplo tangente à borda.
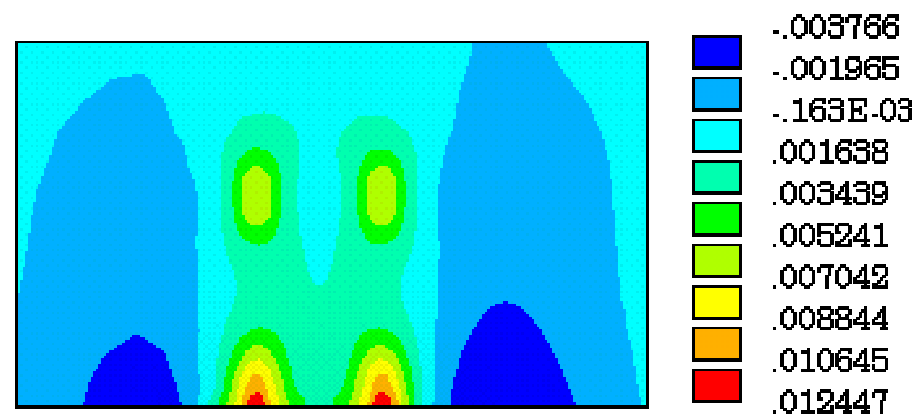

Figura B.5 - Distribuição dos momentos fletores (MN.m), na direção x, para eixo tangente à borda da placa - eixo tandem duplo
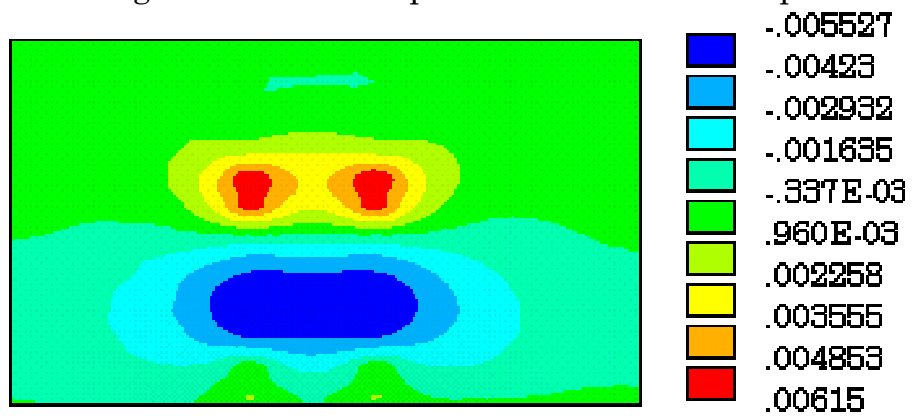

Figura B.6 - Distribuição dos momentos fletores (MN.m), na direção y, para eixo tangente à borda da placa - eixo tandem duplo

Assim como nos casos anteriores, no interior o esforço é de aproximadamente $50 \%$ do esforço na borda.

Nas figuras B.7 e B.8 estão apresentados os resultados obtidos para eixo tandem duplo, no canto da placa. 


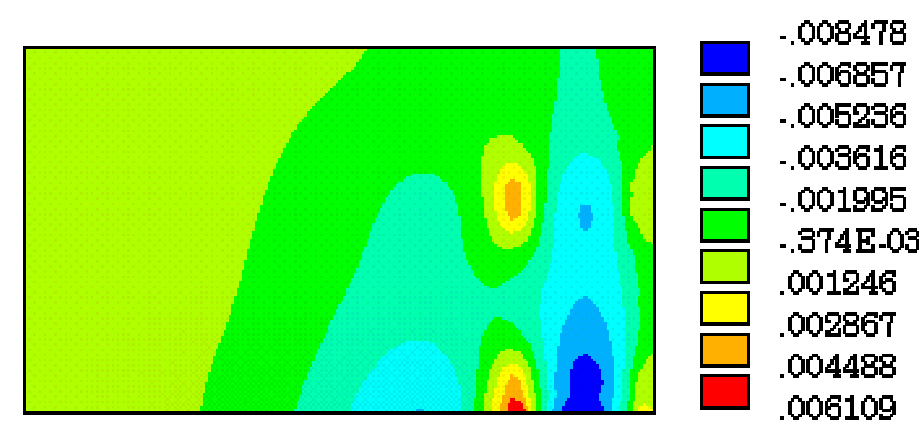

Figura B.7 - Distribuição dos momentos fletores (MN.m), na direção x, para eixo no canto da placa - eixo tandem duplo
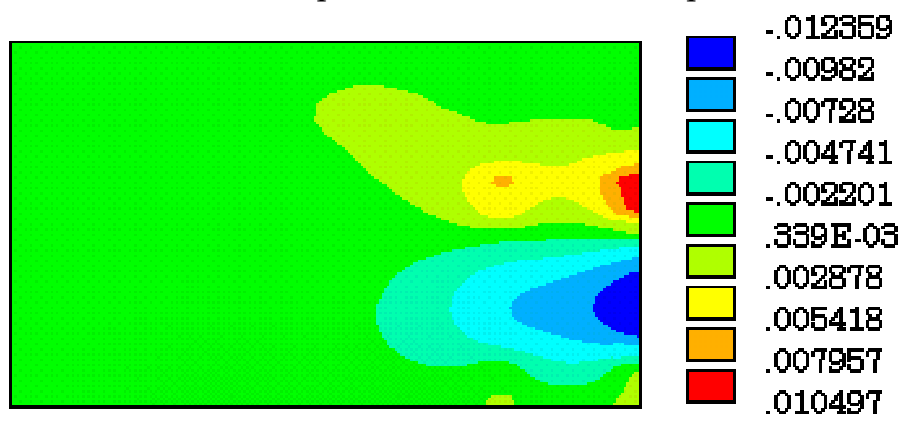

Figura B.8 - Distribuição dos momentos fletores (MN.m), na direção y, para eixo no canto da placa - eixo tandem duplo

No caso de eixos tandem duplos, o momento negativo devido à carga no canto da placa chega a atingir valores próximos ao momento fletor negativo na borda da placa. O momento fletor, na direção y, no meio da junta, atingiu 85\% do valor máximo, na borda.

\section{B.1.3 Eixo tandem triplo}

Nas figuras B.9 e B.10 estão apresentados os resultados obtidos para eixo tandem triplo tangente à borda.
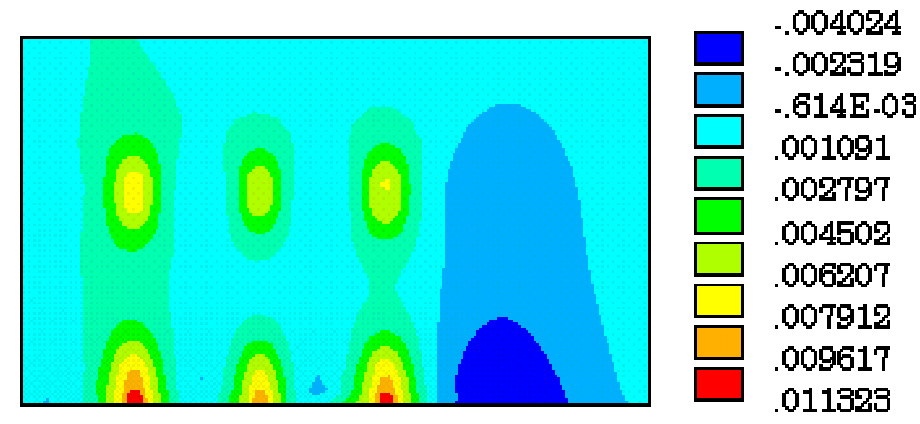

Figura B.9 - Distribuição dos momentos fletores (MN.m), na direção x, para eixo tangente à borda da placa - eixo tandem triplo 


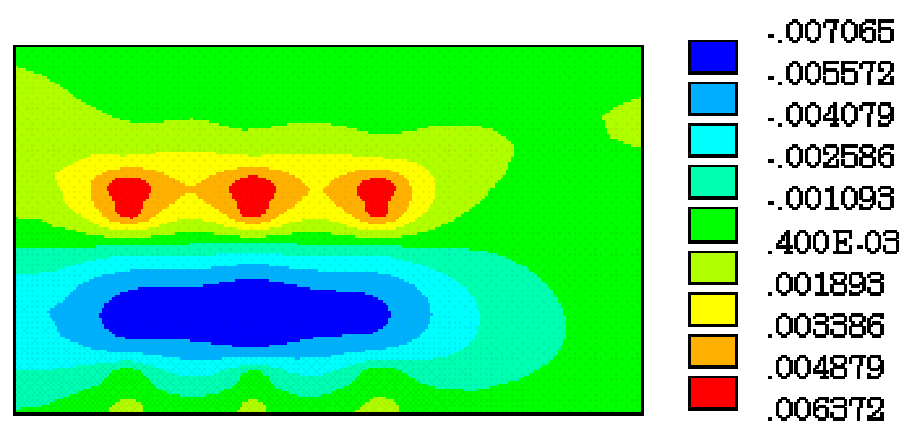

Figura B.10 - Distribuição dos momentos fletores (MN.m), na direção y, para eixo tangente à borda da placa - eixo tandem triplo

No interior o esforço é de aproximadamente $60 \%$ do esforço na borda.

Os momentos negativos chegam a $60 \%$ do máximo momento fletor positivo.

Nas figuras B.11 e B.12 estão apresentados os resultados obtidos para eixo tandem triplo, no canto da placa.

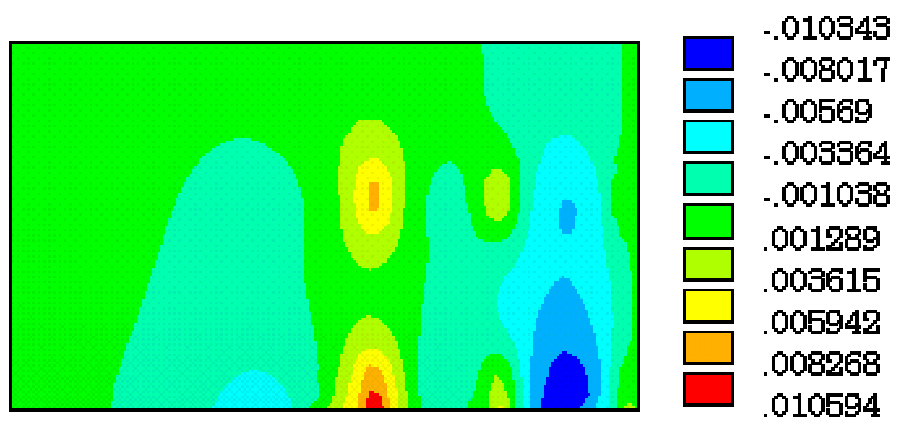

Figura B.11 - Distribuição dos momentos fletores (MN.m), na direção x, para eixo no canto da placa - eixo tandem triplo

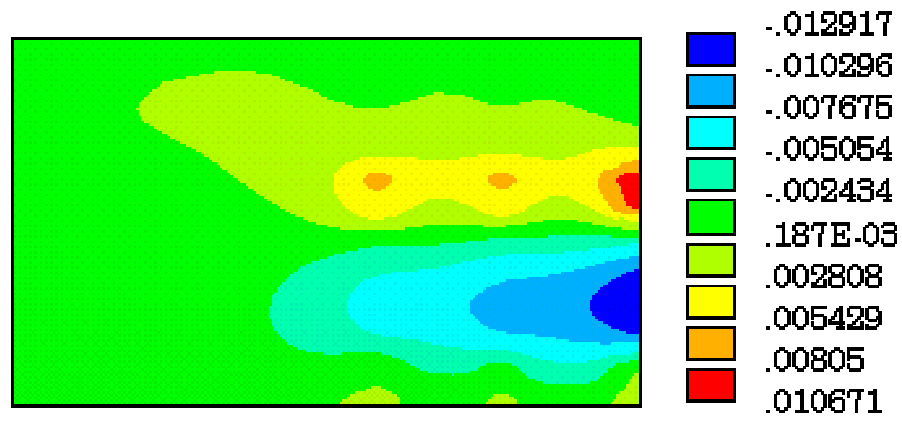

Figura B.12 - Distribuição dos momentos fletores (MN.m), na direção y, para eixo no canto da placa - eixo tandem triplo

No caso de eixos tandem triplos, o momento negativo devido à carga no canto da placa ultrapassou o máximo momento positivo, com eixo tangente à borda. 


\section{B.2 ANÁLISE DA VARIAÇÃO DOS ESFORÇOS MÁXIMOS DE ACORDO COM A POSIÇÃO DO CARREGAMENTO EM PLACAS ISOLADAS}

No capítulo 4 foram mostrados os gráficos dos valores de momentos fletores máximos em função da posição da carga de semi-eixos simples de rodagem dupla, rodoviários. A seguir serão apresentados os resultados obtidos para eixos simples de rodagem simples, tandem duplo e tandem triplo, cujas características físicas e geométricas foram definidas no capítulo 4.

No gráfico da figura B.13 é mostrada a variação dos máximos momentos positivos, quando um semi-eixo rodoviário simples de rodagem simples caminha da borda em direção ao centro da placa.

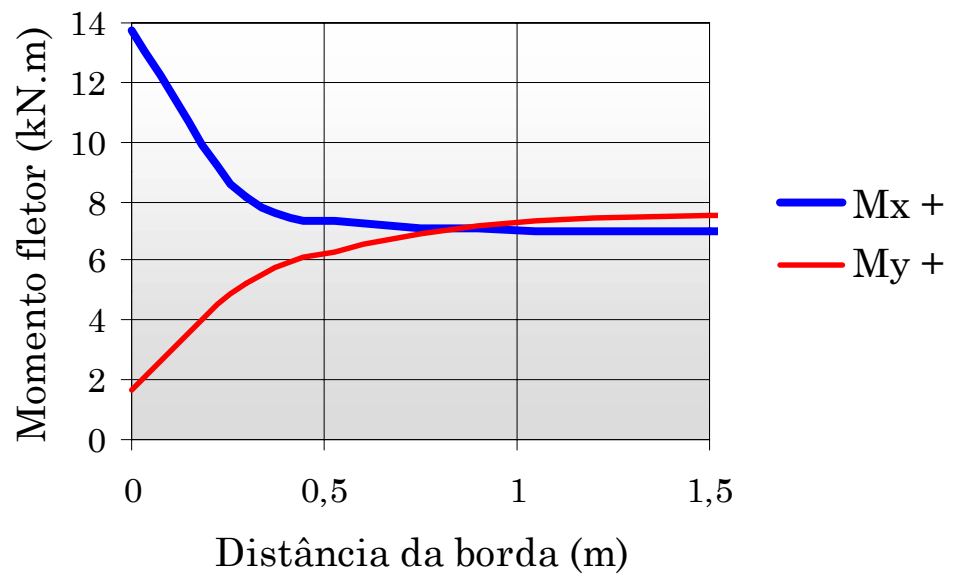

Figura B.13 - Variação do momento fletor máximo, em função da posição da carga, borda - interior, semi-eixo simples de rodagem simples

Assim como no caso de eixos simples de rodagem dupla, o momento fletor, na direção $\mathrm{x}$, decresce rapidamente nos 50 centímetros mais próximos à borda, sendo praticamente constante deste ponto até o interior da placa. O momento fletor na direção y, que é muito pequeno na borda, atinge um valor pouco maior que na direção $\mathrm{x}$, no interior da placa.

Variando o carregamento desde o canto da placa, até o centro da junta transversal, obtém-se a variação de momentos fletores máximos positivos e negativos apresentados nas figuras B.14 e B.15. 


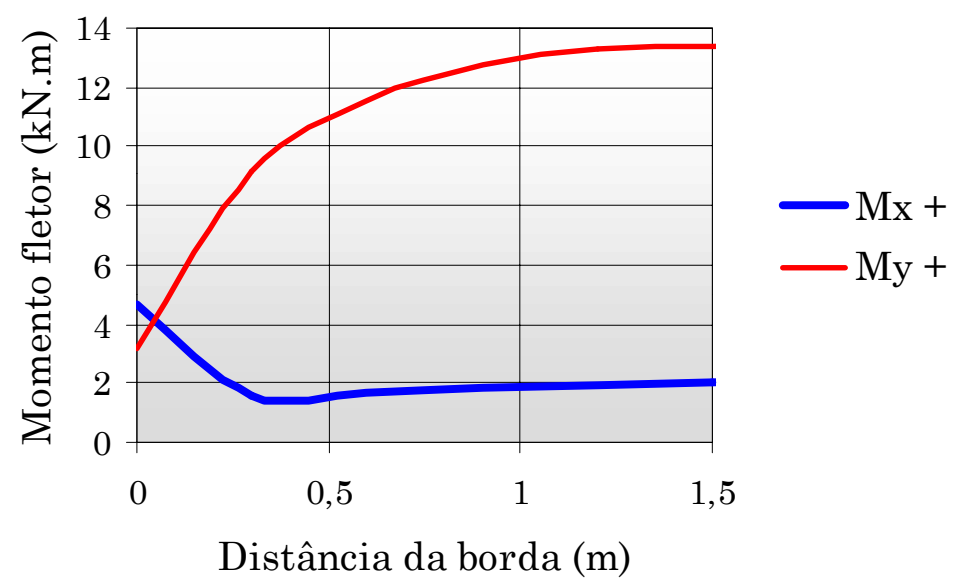

Figura B.14 - Variação do momento fletor máximo positivo, em função da posição da carga, canto - centro da junta transversal, semi-eixo simples de rodagem simples

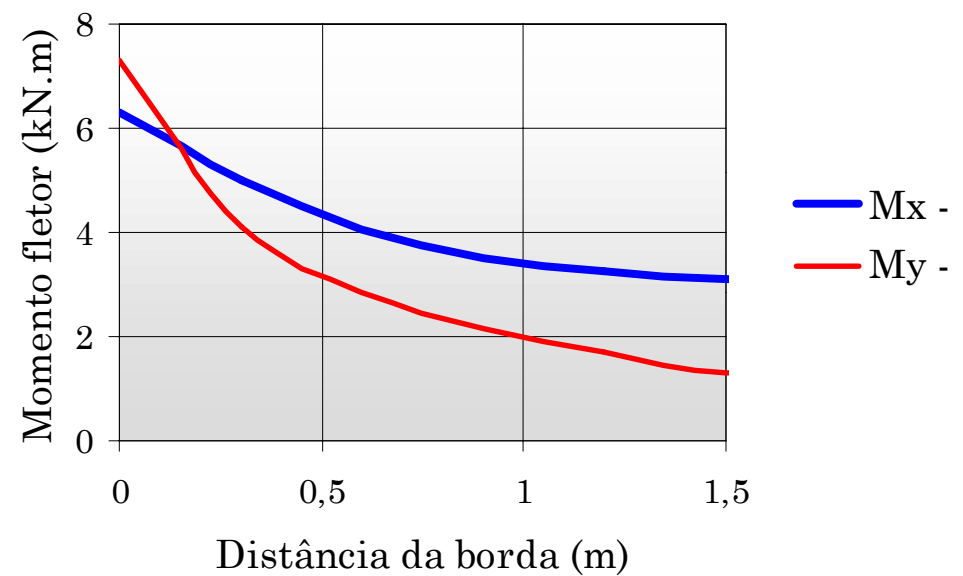

Figura B.15 - Variação do momento fletor máximo negativo, em função da posição da carga, canto - centro da junta transversal, semi-eixo simples de rodagem simples

Os gráficos para eixo simples de rodagem simples são muito semelhante aos de eixo simples de rodagem dupla, sendo que, ao contrário do que ocorre no primeiro, no caso de eixos de rodagem dupla, os esforços na direção x são sempre maiores que em y.

Para eixos tandem duplo e tandem triplo os gráficos assumem configurações semelhantes às das figuras B.13 a B.15, variando apenas os valores dos esforços devidos à carga aplicada e à configuração do eixo. 


\section{B.3 ANÁLISE DA INFLUÊNCIA ENTRE AS RODAS DE EIXOS RODOVIÁRIOS}

A seguir será analisada a diferença dos esforços obtidos com a aplicação da carga em apenas um semi-eixo e no eixo todo. Serão utilizados os mesmos modelos do capítulo 4 .

\section{B.3.1 Eixo simples de rodagem simples}

Quando é aplicado o carregamento em apenas uma roda tangente à borda, obtém-se a distribuição de esforços da figura B.16. Se a roda estiver posicionada no interior da placa, o resultado é o apresentado na figura B.17. Os principais esforços para carga no canto da placa e tangente à junta estão apresentados nas figuras B.18 e B.19.
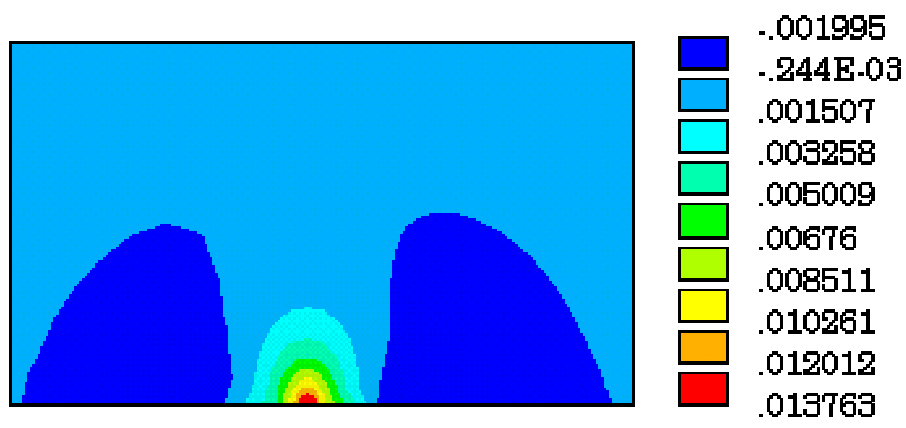

Figura B.16 - Distribuição dos momentos fletores (MN.m), na direção x, para semi-eixo tangente à borda da placa - eixo simples de rodagem simples
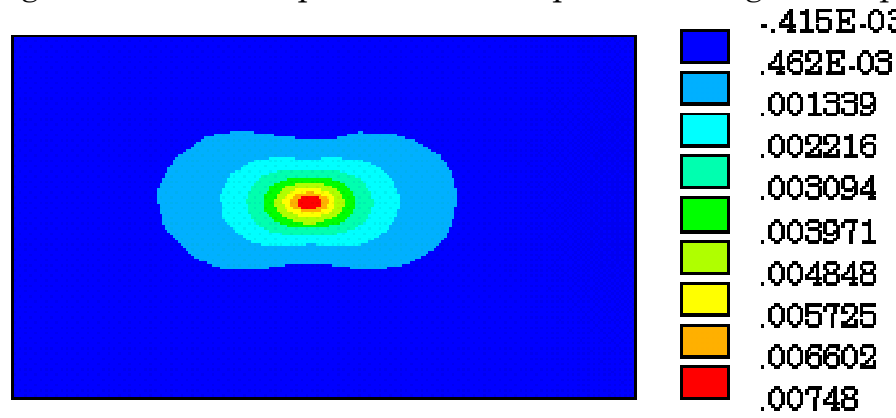

Figura B.17 - Distribuição dos momentos fletores (MN.m), na direção y, para semi-eixo no interior da placa - eixo simples de rodagem simples 


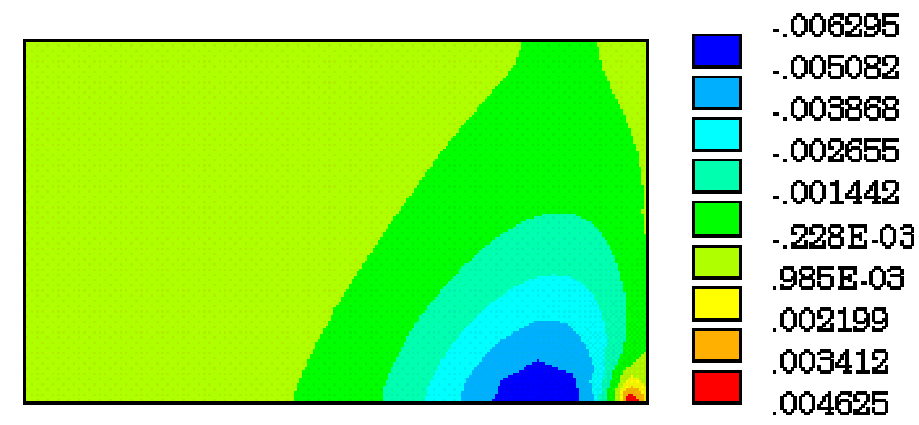

Figura B.18 - Distribuição dos momentos fletores (MN.m), na direção x, para semi-eixo no canto da placa - eixo simples de rodagem simples

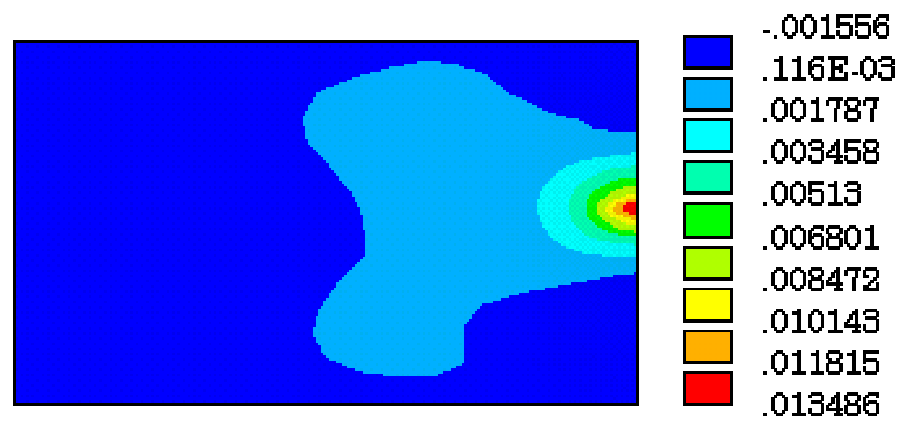

Figura B.19 - Distribuição dos momentos fletores (MN.m), na direção y, para semi-eixo tangente à junta transversal- eixo simples de rodagem simples

Aplicando a carga em apenas uma roda tangente à borda ocorreu a redução de 1,5\% no momento fletor máximo, em relação à aplicação do carregamento nas duas rodas do eixo simples de rodagem simples. O esforço no interior da placa aumentou $20 \%$.

O máximo momento fletor negativo decresceu em $17 \%$ devido ao desprezo da outra roda. O momento fletor na direção y aumentou $36 \%$ devido à ausência da outra metade do eixo.

Dessa forma, conclui-se que essa simplificação não incorreu em erros consideráveis na determinação de esforços em placas apoiadas em líquido denso, para carregamento na borda da placa, e está a favor da segurança para carga no interior; mas para cargas no canto da placa o esforço foi subestimado.

\section{B.3.2 Eixo simples de rodagem dupla}

Quando é aplicado o carregamento das duas rodas do semi-eixo tangente à borda, obtém-se a distribuição de esforços da figura B.20. Se as rodas 
estiverem no interior da placa, o resultado é o da figura B.21. Os principais esforços para carga no canto da placa e tangente à junta estão apresentados nas figuras B.22 e B.23.

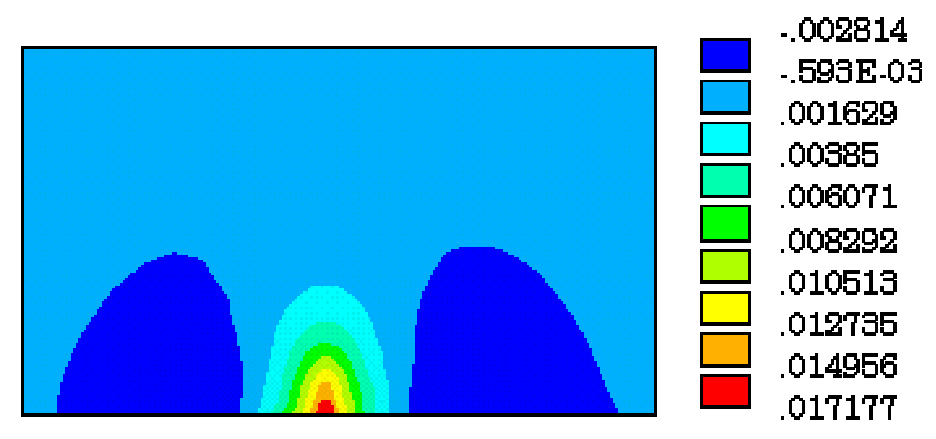

Figura B.20 - Distribuição dos momentos fletores (MN.m), na direção x, para semi-eixo tangente à borda da placa - eixo simples de rodagem dupla

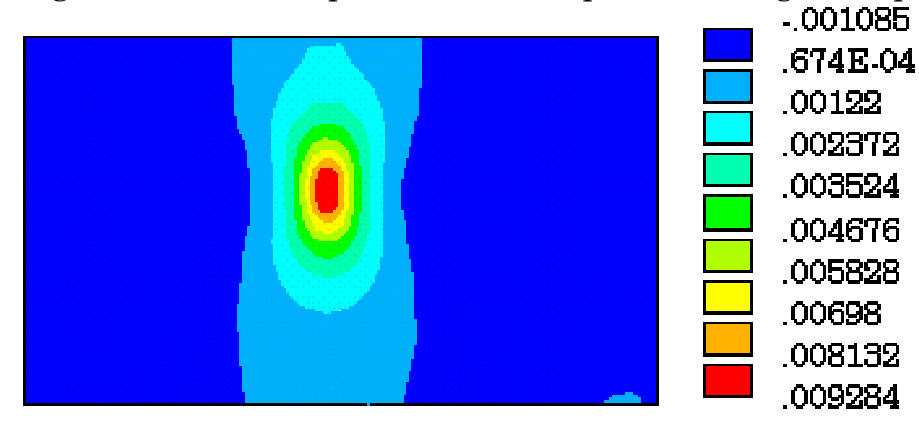

Figura B.21 - Distribuição dos momentos fletores (MN.m), na direção x, para semi-eixo no interior da placa - eixo simples de rodagem dupla

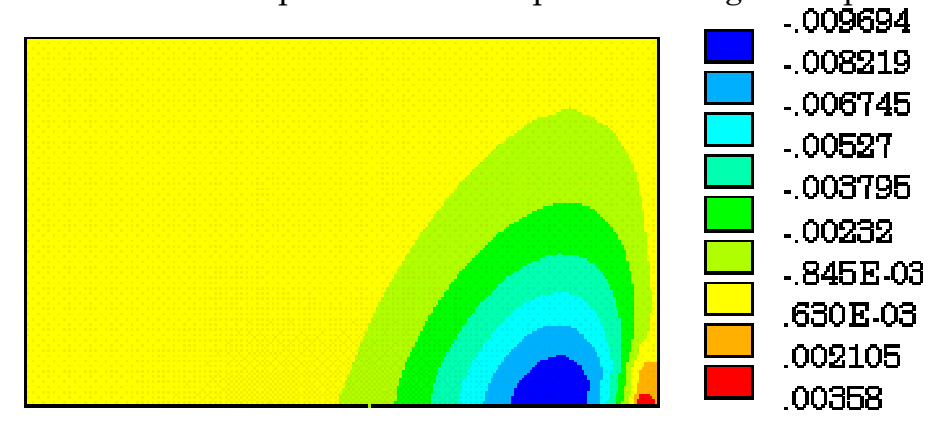

Figura B.22 - Distribuição dos momentos fletores (MN.m), na direção x, para semi-eixo no canto da placa - eixo simples de rodagem dupla

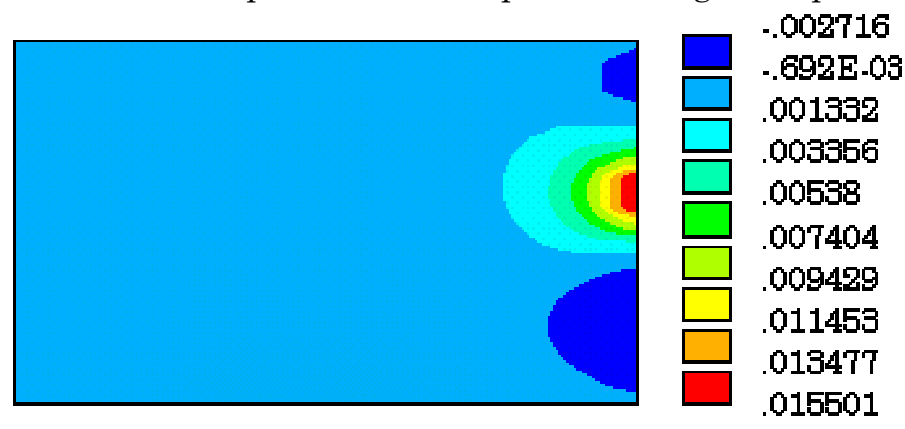

Figura B.23 - Distribuição dos momentos fletores (MN.m), na direção y, para semi-eixo tangente à junta transversal- eixo simples de rodagem dupla 
Aplicando a carga em apenas um semi-eixo tangente à borda ocorreu a redução de 1,33\% no momento fletor máximo, em relação à aplicação do carregamento nas quatro rodas do eixo simples de rodagem dupla. O esforço no interior da placa diminuiu em aproximadamente $2 \%$.

O máximo momento fletor negativo decresceu em 16\%. O momento fletor na direção y aumentou $38 \%$.

No caso de eixo simples de rodagem dupla também pode ser adotada a simplificação, para cargas de borda e de interior. No caso de cargas de canto ou próximas à junta, a simplificação conduz a erros consideráveis.

\section{B.3.3 Eixo tandem duplo}

A aplicação da carga nas 4 rodas do semi-eixo tangente à borda produz os resultados da figura B.24. Se for considerado o carregamento no interior da placa, o resultado é o da figura B.25. Os principais esforços para carga no canto da placa e tangente à junta estão apresentados nas figuras B.26 e B.27.
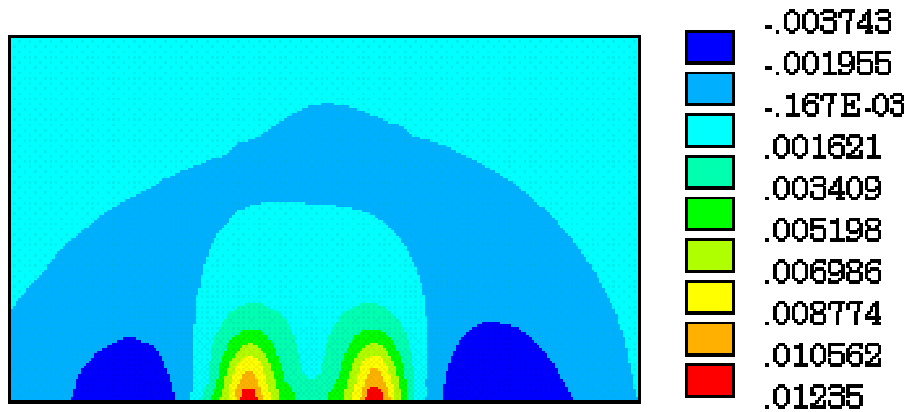

Figura B.24 - Distribuição dos momentos fletores (MN.m), na direção x, para semi-eixo tangente à borda da placa - eixo tandem duplo
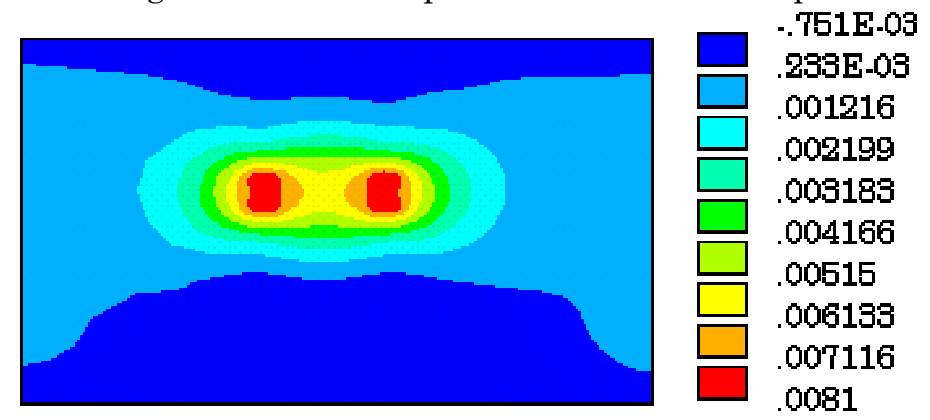

Figura B.25 - Distribuição dos momentos fletores (MN.m), na direção y, para semi-eixo no interior da placa - eixo tandem duplo 


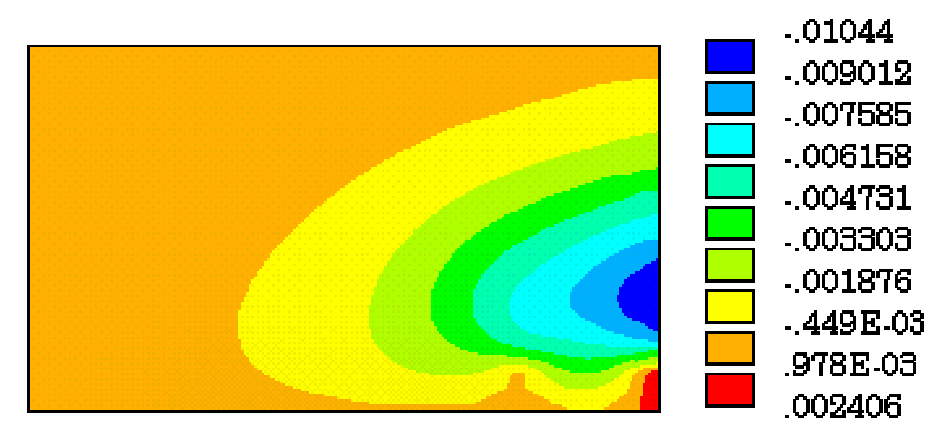

Figura B.26 - Distribuição dos momentos fletores (MN.m), na direção y, para semi-eixo no canto da placa - eixo tandem duplo

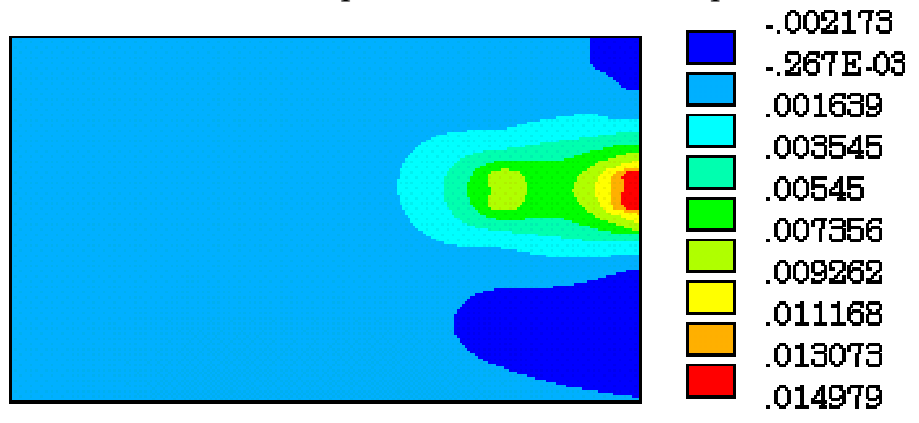

Figura B.27 - Distribuição dos momentos fletores (MN.m), na direção y, para semi-eixo tangente à junta transversal- eixo tandem duplo

Aplicando a carga em apenas um semi-eixo tangente à borda ocorreu a redução de $0,77 \%$ no momento fletor máximo, em relação à aplicação do carregamento nas oito rodas do eixo tandem duplo. $\mathrm{O}$ esforço no interior da placa aumentou em aproximadamente $15 \%$.

O máximo momento fletor negativo decresceu em 16\%. O momento fletor na direção y aumentou $43 \%$.

Para eixo tandem duplo, a simplificação não incorreu em erro considerável na determinação do esforço para carregamento na borda da placa e está a favor da segurança para carga no interior; para cargas no canto o esforço foi subestimado e para carga tangente à junta a simplificação é muito conservadora.

\section{B.3.4 Eixo tandem triplo}

A aplicação da carga nas 6 rodas próximas à borda produz os resultados da figura B.28. Para carregamento no interior da placa o resultado é 
o da figura B.29. Os principais esforços para carga no canto da placa e tangente à junta estão apresentados nas figuras B.30 e B.31.

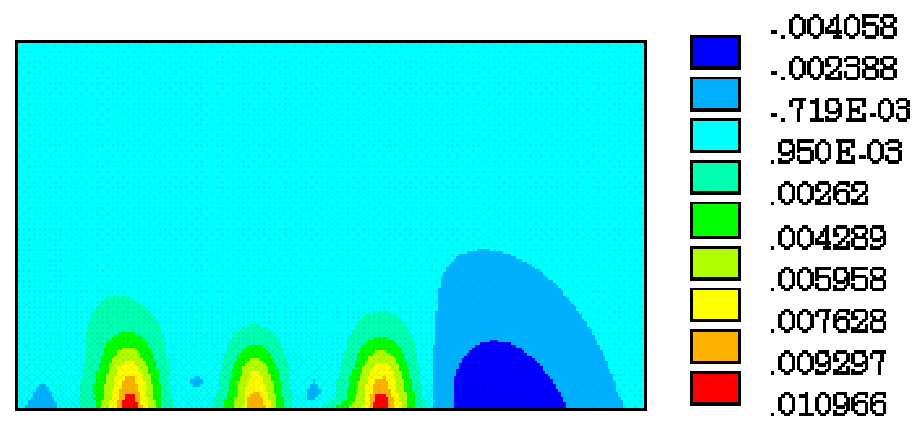

Figura B.28 - Distribuição dos momentos fletores (MN.m), na direção x, para semi-eixo tangente à borda da placa - eixo tandem duplo
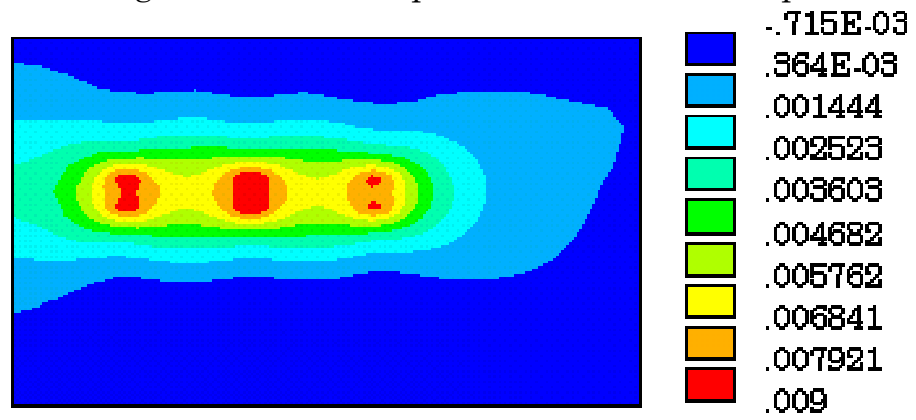

Figura B.29 - Distribuição dos momentos fletores (MN.m), na direção y, para semi-eixo no interior da placa - eixo tandem duplo
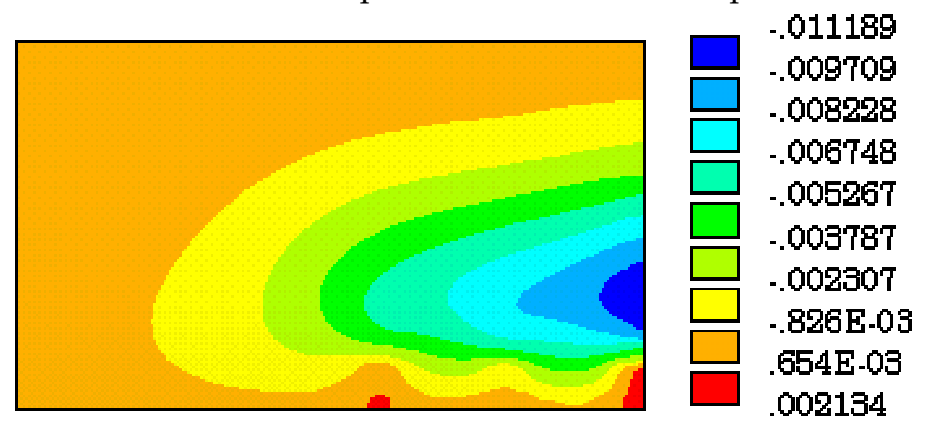

Figura B.30 - Distribuição dos momentos fletores (MN.m), na direção y, para semi-eixo no canto da placa - eixo tandem duplo

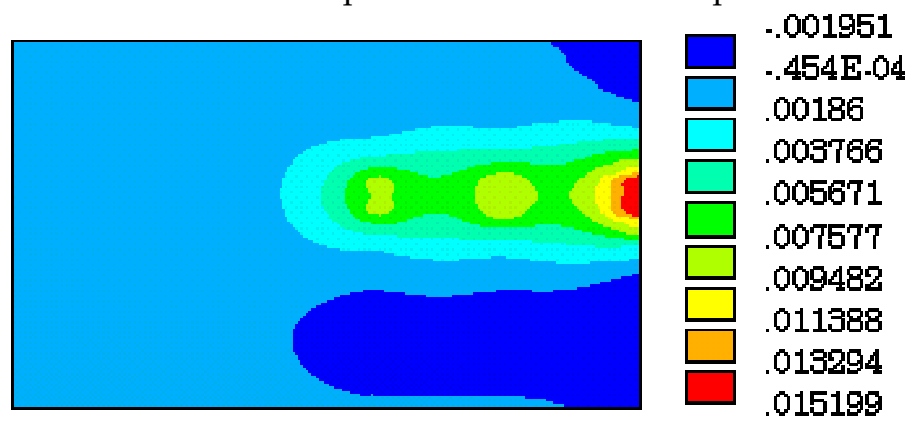

Figura B.31 - Distribuição dos momentos fletores (MN.m), na direção y, para semi-eixo tangente à junta transversal- eixo tandem duplo 
Aplicando a carga no semi-eixo tangente à borda ocorreu a redução de $3,15 \%$ no momento fletor máximo, em relação à aplicação do carregamento em todas as rodas do eixo tandem triplo. O esforço no interior da placa aumentou em aproximadamente $14 \%$.

O máximo momento fletor negativo decresceu em 13\%. O momento fletor na direção y aumentou $42 \%$.

Para eixo tandem triplo, a simplificação também não provocou erro considerável na determinação do esforço para carregamento na borda da placa e está a favor da segurança para carga no interior; para cargas no canto o esforço foi subestimado e para carga tangente à junta a simplificação é conservadora.

\section{B.4 ANÁlise DA INFLUÊNCIA ENTRE AS RODAS DE EIXO DE EMPILHADEIRA}

A seguir serão apresentados os resultados obtidos com a análise de uma placa sob carregamento de eixo de empilhadeira, de rodagem simples, com 1 metro de comprimento, peso de $10 \mathrm{tf}$ e pressão nos pneus de 1,75MPa. Foram aplicadas forças em uma roda tangente à borda, uma roda no interior da placa e nas duas rodas. As características do problema estão apresentadas na tabela B.1.

Tabela B.1 - Dados do problema

\begin{tabular}{|c|c|}
\hline Variável & Valor adotado \\
\hline Coeficiente de recalque $-\mathrm{k}$ & $50 \mathrm{MPa} / \mathrm{m}$ \\
Módulo de elasticidade do concreto $-\mathrm{E}$ & $33660 \mathrm{MPa}$ \\
Coeficiente de Poisson do concreto - $v$ & 0,2 \\
Pressão nos pneus - $\mathrm{q}$ & $1,75 \mathrm{MPa}$ \\
Dimensões da placa - comprimento x largura x espessura & $6,0 \times 3,5 \times 0,15 \mathrm{~m}$ \\
\hline
\end{tabular}

Foi adotada área retangular com as dimensões: 0,208 x 0,135 m.

Nas figuras B.32 a B.34 são mostradas as distribuições dos momentos fletores, para roda tangente à borda e no interior da placa. 

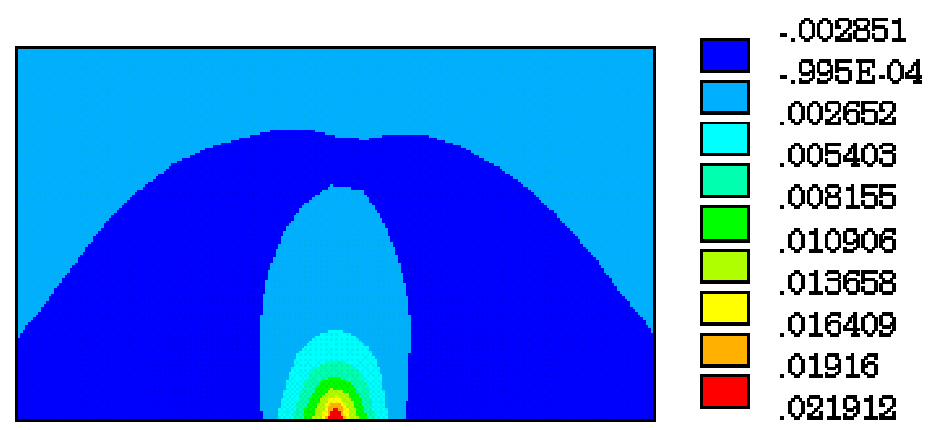

Figura B.32 - Distribuição dos momentos fletores (MN.m), na direção x, para semi-eixo tangente à borda- empilhadeira de rodagem simples
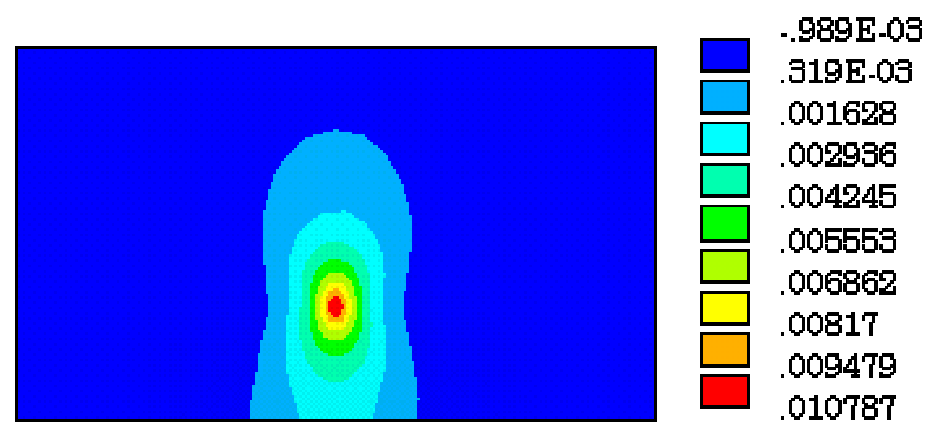

Figura B.33 - Distribuição dos momentos fletores (MN.m), na direção x, para semi-eixo no interior da placa - empilhadeira de rodagem simples
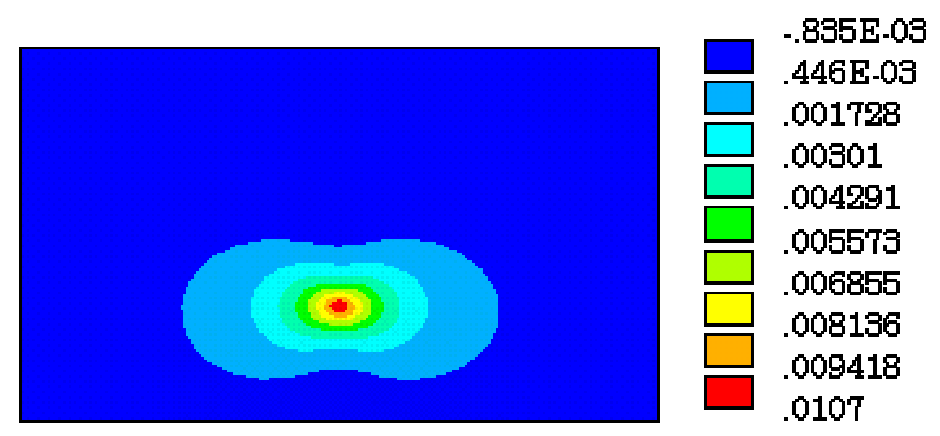

Figura B.34 - Distribuição dos momentos fletores (MN.m), na direção y, para semi-eixo no interior da placa - empilhadeira de rodagem simples

Nas figuras B.35 e B.36 são mostradas as distribuições dos momentos fletores para aplicação do carregamento nas duas rodas do eixo de rodagem simples, com uma das rodas tangente à borda. 


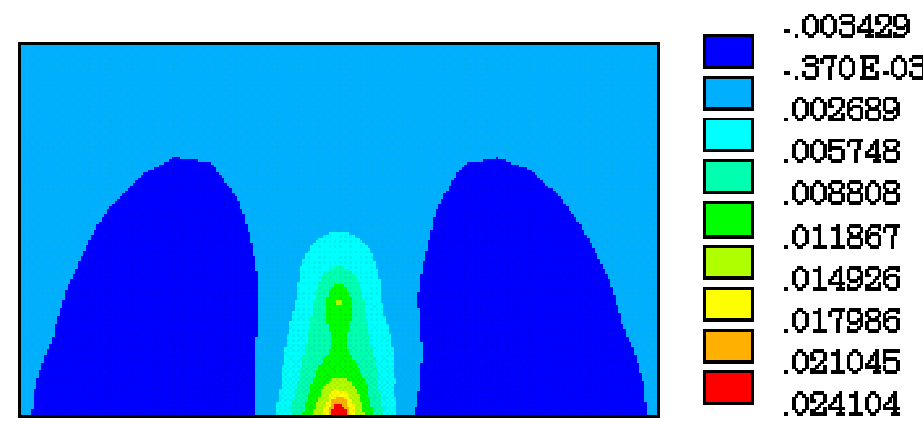

Figura B.35 - Distribuição dos momentos fletores (MN.m), na direção x, para eixo de empilhadeira de rodagem simples, com uma das rodas tangente à borda

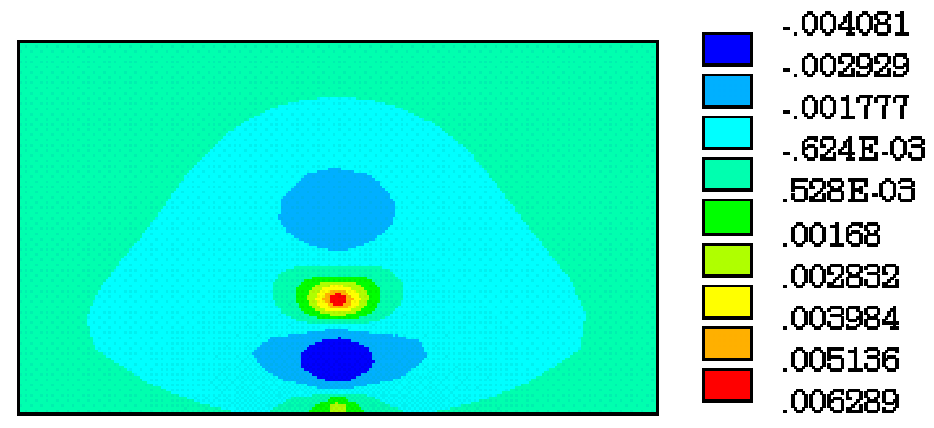

Figura B.36 - Distribuição dos momentos fletores (MN.m), na direção y, para eixo de empilhadeira de rodagem simples, com uma das rodas tangente à borda

O máximo momento fletor, para força na borda da placa, diminuiu em cerca de 10\%, quando se desconsiderou a outra roda do eixo. O esforço, no interior da placa, foi superestimado em $70 \%$, quando se desprezou o semi-eixo tangente à borda. Quando não existirem mecanismos eficientes de transferência de carga e houver a possibilidade de cada roda solicitar uma placa diferente do piso, a análise das rodas isoladas passa a ser importante.

Portanto, pode-se concluir que, no caso de eixos de empilhadeiras, não se deve determinar os esforços simplificando o carregamento para apenas metade do eixo. 


\section{REFERÊNCIAS BIBLIOGRÁFICAS}

AMERICAN ASSOCIATION OF STATE HIGHWAY AND TRANSPORTATION OFFICIALS (1986). Guide for design of pavements structures. Washington. AMERICAN ASSOCIATION OF STATE HIGHWAY AND TRANSPORTATION OFFICIALS (1993). Guide for design of pavements structures. Washington. AMERICAN CONCRETE INSTITUTE (1992). ACI 215R-74 (revised 1992) Considerations for design of concrete structures subjected to fatigue loading. Detroit, ACI.

AMERICAN CONCRETE INSTITUTE (1995). ACI 318-95 - Building code requirements for reinforced concrete. Detroit, ACI.

ASSOCIAÇÃO BRASILEIRA DE CIMENTO PORTLAND (1998). 25 anos de Imigrantes. Cimento Hoje - Informativo da $A B C P$, v. 3, n. 17, ago.

ASSOCIAÇÃO BRASILEIRA DE NORMAS TÉCNICAS (1984). NBR-7583 Execução de pavimentos de concreto simples por meio mecânico. Rio de Janeiro.

ASSOCIAÇÃO BRASILEIRA DE NORMAS TÉCNICAS (1999). Revisão da NB1 - Projeto e execução de obras de concreto armado. Rio de Janeiro.

BALBO, José Tadeu (1989). Aplicação do método dos elementos finitos na avaliação estrutural de pavimentos rígidos rodoviários. São Paulo. 156 p. Dissertação (Mestrado) - Escola Politécnica, Universidade de São Paulo.

BALBO, José Tadeu (1999). Contribuição à análise estrutural de reforços com camadas ultradelgadas de concreto de cimento Portland sobre pavimentos asfálticos (whitetopping ultradelgado). São Paulo. 195p. Tese (LivreDocência) - Escola Politécnica, Universidade de São Paulo. 
BRADBURY, R. D. (1938). Reinforced concrete pavements. Washington, Wire Reinforced Institute.

CARNIO, Marco Antônio (1998). Análise em regime plástico de placas de concreto reforçado com fibras de aço sobre base elástica. Campinas. 104p. Dissertação (Mestrado) - Universidade Estadual de Campinas.

COMITE EURO-INTERNATIONAL DU BETON (1988). Fatigue of concrete structures. state of art report. Bulletin d'Information, n. 188.

COMITE EURO-INTERNATIONAL DU BETON (1991). CEB-FIP Model Code 1990. Bulletin d'Information, n. 203-205.

DARTER, Michael I. (1999). Design \& construction of Portland cement concrete pavements. Section 1-4. São Paulo, ABCP.

DEPARTAMENTO NACIONAL DE ESTRADAS DE RODAGEM (1989). Manual de pavimentos rígidos. Rio de Janeiro. v. 2.

DEPARTAMENTO NACIONAL DE ESTRADAS DE RODAGEM (1992). Manual de pavimentos de concreto rolado: histórico, características tecnológicas, estado-da-arte, materiais, dosagem e normas pertinentes. Rio de Janeiro. v. 1.

DRIEMEIER, Larissa (1995). Considerações sobre a fadiga em metais e o comportamento do concreto sob solicitação cíclica. São Carlos. 120p. Dissertação (Mestrado) - Escola de Engenharia de São Carlos, Universidade de São Paulo.

FEDERAL AVIATION ADMINISTRATION (1995). Airport pavement design and evaluation. U.S. Department of Transportation.

FRIBERG, B. F. (1940). Design of dowels in transverse joints of concrete pavements. Transactions, ASCE, v. 105.

HUANG, Y. H. (1993). Pavement analysis and design. New Jersey, Prentice Hall.

LARANJEIRAS, Antônio Carlos Reis (1990). Fadiga das estruturas de concreto. In: SIMPÓSIO EPUSP SOBRE ESTRUTURAS DE CONCRETO, 2., São Paulo, 1990. Anais. São Paulo, EPUSP. v.1, p. 187-232.

MELGES, José Luiz Pinheiro (1995). Punção em lajes: exemplos de cálculo e análise teórico-experimental. São Carlos. 217p. Dissertação (Mestrado) Escola de Engenharia de São Carlos, Universidade de São Paulo. 
MELGES, José Luiz Pinheiro; PINHEIRO, Libânio Miranda (1999). Punção em lajes conforme a revisão da NB-1/97. In: SÁNCHES, Emil. Nova normalização brasileira para o concreto estrutural. Juiz de Fora, UFJF/Interciência. Cap. 12, p. 33-79.

MOURA, José Cavalcanti (1999). Análise comparativa do desempenho dos métodos de dimensionamento de pavimentos rígidos. Campinas. 165p. Dissertação (Mestrado) - Universidade de Campinas.

PACKARD, Robert G. (1973). Design of concrete airport pavement. Skokie, Portland Cement Association.

PACKARD, Robert (1976). Slab thickness design for industrial concrete floors on grade. Skokie, Portland Cement Association.

PICKETT, Gerald; RAY, G. K. (1951). Influence charts for concrete pavements. American Society of Civil Engineers, p. 49-73.

PFEIL, Walter (1979). Pontes em concreto armado. Rio de Janeiro, Livros Técnicos e Científicos.

PINHEIRO, Libânio Miranda (1993). Concreto armado: tabelas e ábacos. 2.ed. São Carlos, Escola de Engenharia de São Carlos - Universidade de São Paulo.

PITTA, Márcio Rocha (1978). Dimensionamento de pavimentos rodoviários de concreto para o caso de eixos tandem triplos. In: REUNIÃO ANUAL DA ABPav, 14., João Pessoa, 1978. Anais, Rio de Janeiro, Associação Brasileira de Pavimentação. v. 2., p. 329 - 350.

PITTA, Márcio Rocha (1987). Projeto de juntas em pavimentos rodoviários de concreto. São Paulo, ABCP.

PITTA, Márcio Rocha (1989). Construção de pavimentos de concreto simples. São Paulo, ABCP.

PITTA, Márcio Rocha (1990). Projeto de sub-bases para pavimentos de concreto. 5. ed. São Paulo, ABCP.

PITTA, Márcio Rocha (1996). Dimensionamento de pavimentos rodoviários e urbanos de concreto pelo Método da PCA/1984. 2. ed., São Paulo, ABCP.

PORTLAND CEMENT ASSOCIATION (1966). Thickness design for concrete pavements. Chicago. 
PORTLAND CEMENT ASSOCIATION (1984). Thickness design for concrete hightway and street pavements. Chicago.

RODRIGUES, Públio Penna Firme; CASSARO, Caio Franscino (1998). Pisos industriais de concreto armado. São Paulo, IBTS.

RODRIGUES, Públio Penna Firme; PITTA, Márcio Rocha (1997). Pavimento de concreto estruturalmente armado. Revista do IBRACON, n. 19, p. 15-25, set/dez.

RODRIGUES, Públio Penna Firme; PITTA, Márcio Rocha (1998). Dimensionamento de pavimentos de concreto estruturalmente armados. São Paulo, ABCP.

RUFINO, Dulce Maria Saraiva (1997). Estudos dos procedimentos de dimensionamento e dos novos programas de análise de tensões em pavimentos de concreto. Rio de Janeiro. 436p. Dissertação (Mestrado) - Universidade Federal do Rio de Janeiro.

SENÇO, Wlatermiler (1997). Manual de técnicas de pavimentação. São Paulo, PINI.

SCHMID, Manfred Theodor (1996). O pavimento rígido em concreto protendido. In: REIBRAC, 38., Ribeirão Preto, 1996. Anais, Ribeirão Preto, IBRACON. v. 1, p. 79-91.

SOUZA, Murilo Lopes de (1980). Pavimentação Rodoviária. 2.ed. Rio de Janeiro, Livros Técnicos e Científicos.

WESTERGAARD, H. M. (1926). Stress in concrete pavements computed by theorical analysis. Public Roads, v. 7, p. 25-35, Apr.

WESTERGAARD, H. M. (1948). New formulas for stresses in concrete pavements of airfields. Transactions, ASCE, v. 113, p. 425-444, Nov.

WU, Chung-Lung; TIA, Mang (1989). Development of a rational thickness design method for rigid pavements. Transportation Research Record 1227. Washington, Transportation Research Board.

YODER, E. J.; WITCZAK, M. W. (1975) Principles of pavement design. 2. ed., New York, John Wiley \& Sons.

ZHANG, J.; STANG, Henrik (1998). Fatigue performance in flexural of fiber reinforced concrete. ACI Materials Journal, v. 95, n.1, p. 58-67, Jan-Fev. 


\section{BIBLIOGRAFIA COMPLEMENTAR}

AMERICAN CONCRETE PAVEMENT ASSOCIATION (1999). Ultrathin whitetopping: a brief introduction. http://www.moksacpa.com/concrete.html (19 de fevereiro)

ASSOCIAÇÃO BRASILEIRA DE NORMAS TÉCNICAS (1978). NBR-6118 Projeto e execução de obras de concreto armado, Rio de Janeiro.

ASSOCIAÇÃO BRASILEIRA DE NORMAS TÉCNICAS (1989). NBR-7197 Projeto de estruturas de concreto protendido, Rio de Janeiro.

AUSTROADS (1987). A guide to the visual assessment of pavement condition. Sydney, AUSTROADS.

BALÁZS, György L. (1991). Fatigue of bond. ACI Material Journal, v. 88, n. 6, p. 620-629, Nov-Dec.

BAPTISTA, Cyro Nogueira (1976). Pavimentação. 2.ed. Globo.

KISS, Paulo (1999). Combate às juntas. Téchne, São Paulo. n. 39, p. 26-28, marabr.

CHATTIN, Bruce (1999). Building with concrete. 'Ultrathin' becoming popular. http://www.djc.com/special/concrete/10003370.htm (19 de fevereiro).

DEPARTAMENTO NACIONAL DE ESTRADAS DE RODAGEM (1992). Manual de pavimentos de concreto rolado: projeto, dimensionamento, construção e normas pertinentes, relatório parcial da pesquisa sobre concreto rolado na pista circular experimental. Rio de Janeiro, DNER. v. 2.

DEPARTAMENTO NACIONAL DE ESTRADAS DE RODAGEM (1993). Manual de pavimentos de concreto rolado: relatório da pesquisa sobre concreto rolado na pista circular experimental, tráfego pesado. Rio de Janeiro, DNER. v. 3. 
GAPOZZI, Simone (1999). O especialista. Construção São Paulo, n. 2670, p. 1011, abr.

GEIGER, Lynn (1999). Ultra-thin Whitetopping: a pavement rehabilitation option. http://www.irmca.com (19 de fevereiro).

GERDAU (1999). Superestrada: a estrada de aço e concreto. http://www.superestrada.com.br (19 de fevereiro)

IOANNIDES, A. M.; DAVIS, C. M.; WEBER, C. M. (s.d.). Curling analysis: change and continuity. Cincinnati, University of Cincinnati.

LEONHARD, F.; MÖNNIG, E. (1977). Construções de concreto. Rio de Janeiro, Interciência. v. 1.

MARTINELLI, D. A. O.; MONTANARI, I.; SAVASSI, W. (1986). Placas elásticas - equações gerais e placas retangulares - conceituação teórica, métodos das diferenças finitas e elementos finitos. São Carlos, Escola de Engenharia de São Carlos - Universidade de São Paulo.

PASKO Jr., Thomas J. (1998). Concrete pavements - Past, Present, and Future. Public Roads, v. 62, n. 1, p. 7-15, Jul-Aug.

PITTA, Márcio Rocha (1989). Concreto Rolado: Aplicações em Pavimentação. 6. ed, São Paulo, ABCP.

PITTA, Márcio Rocha (1998). Selagem de juntas em pavimentos de concreto. São Paulo, ABCP.

RÊGO, L. R. A. M.; GASPARETTO, W. E. (1984). Pavimentos rígidos de concreto armado com telas soldadas. São Paulo, IBTS.

RODOLFO, Marcos P.; BALBO, José T. (1998). Stresses analysis of bases on concrete pavement. In: INTERNATIONAL SYMPOSIUM ON CONCRETE ROADS, 8., Lisbon, 1998. Proceedings, Lisbon. p. 21-25.

SEVERI, Andréa Arantes (1997). Considerações sobre os custos de pavimentos rígidos com base em conceitos de gerência de pavimentos. São Carlos. 137p. Dissertação (Mestrado) - Escola de Engenharia de São Carlos - Universidade de São Paulo.

SCHROEDER, Renato (1998). Show de rigidez. Construção São Paulo, n. 2619, p. $25-27$, abr.

TIMOSHENKO, S; LESSELS, J. M. (1925). Applied elasticity. Pittsburg, Westinghouse Technical Night School Press. 
WESTERGAARD, H. M. (1933). Analytical tools for judging results of structural tests of concrete pavements. Public Roads, v. 14, p. 185-188, Dec.

WESTERGAARD, H. M. (1939). Stresses in concrete runways of airports. In: ANNUAL MEETING OF HIGHTWAY RESEARCH BOARD, 9., Washington, 1939. Proceedings, Washington, Hightway Research Board. p. 197-205. 